NATIONAL LABORATORY

MANAGED BY UT-BATTELLE

FOR THE DEPARTMENT OF ENERGY
CRADA Final Report

for

CRADA Number ORNL 04-0691

\section{APPLICATION OF DUAL-MODE INVERTER CONTROL TO COMMERCIALLY AVAILABLE RADIAL-GAP PERMANENT MAGNET MOTORS - VOL. I}

\author{
J. S. Lawler \\ J. W. McKeever \\ M. E. Downing \\ Oak Ridge National Laboratory \\ R. D. Stahlhut \\ R. Bremmer \\ J. M. Shoemaker \\ A. K. Seksarian \\ B. Poore \\ John Deere - Moline Tech Center \\ J. Lutz \\ UQM Technologies, Inc.
}

Publication Date: May 2006

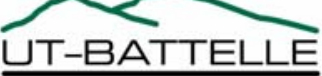

APPROVED FOR PUBLIC RELEASE 
Reports produced after January 1, 1996, are generally available free via the U.S. Department of Energy (DOE) Information Bridge.

Web site http://www.osti.gov/bridge

Reports produced before January 1, 1996, may be purchased by members of the public from the following source.

National Technical Information Service 5285 Port Royal Road

Springfield, VA 22161 Telephone 703-605-6000 (1-800-553-6847)

TDD 703-487-4639 Fax 703-605-6900 E-mail

info@ntis.fedworld.gov Web site

http://www.ntis.gov/support/ordernowabout.htm

Reports are available to DOE employees, DOE contractors, Energy

Technology Data Exchange (ETDE) representatives, and International

Nuclear Information System (INIS) representatives from the

following source.

Office of Scientific and Technical Information

P.O. Box 62Oak Ridge, TN 37831

Telephone 865-576-8401

Fax 865-576-5728

E-mail reports@osti.gov

Web site http://www.osti.gov/contact.html

This report was prepared as an account of work sponsored by an agency of the United States Government. Neither the United States Government nor any agency thereof, nor any of their employees, makes any warranty, express or implied, or assumes any legal liability or responsibility for the accuracy, completeness, or usefulness of any information, apparatus, product, or process disclosed, or represents that its use would not infringe privately owned rights. Reference herein to any specific commercial product, process, or service by trade name, trademark, manufacturer, or otherwise, does not necessarily constitute or imply its endorsement, recommendation, or favoring by the United States Government or any agency thereof. The views and opinions of authors expressed herein do not necessarily state or reflect those of the United States Government or any agency thereof. 
Engineering Science and Technology Division

Final Report for CRADA ORNL04-0691

\title{
APPLICATION OF DUAL-MODE INVERTER CONTROL TO COMMERCIALLY AVAILABLE RADIAL-GAP PERMANENT MAGNET MOTORS - VOL. I
}

\author{
J. S. Lawler (PI) \\ J. W. McKeever (Task Administrator) \\ M. E. Downing (CRADA Administrator) \\ Oak Ridge National Laboratory \\ R. D. Stahlhut (PI) \\ R. Bremmer \\ J. M. Shoemaker \\ A. K. Seksarian \\ B. Poore \\ John Deere and Company \\ Moline Tech Center \\ J. Lutz \\ UQM Technologies, Inc.
}

May 2006

Prepared by the

OAK RIDGE NATIONAL LABORATORY

Oak Ridge, Tennessee 37831

managed by

UT-BATTELLE, LLC

for the

U.S. DEPARTMENT OF ENERGY

Under contract DE-AC05-00OR2272 


\section{CONTENTS}

Page

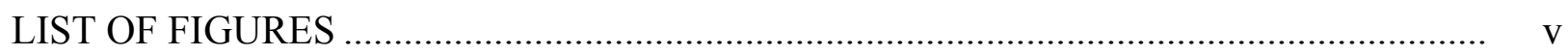

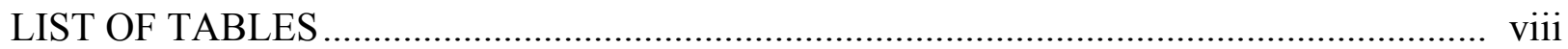

ACRONYMS, ABBREVIATIONS, AND INITIALISM ........................................... ix

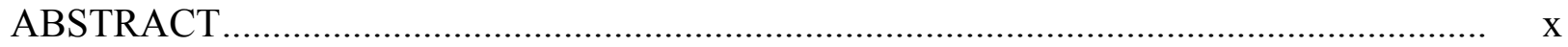

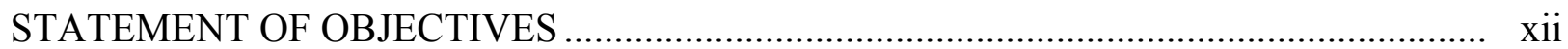

BENEFITS TO THE OFFICE OF FREEDOMCAR AND VEHICLE TECHNOLGIES ....... xiii

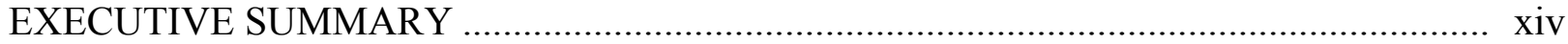

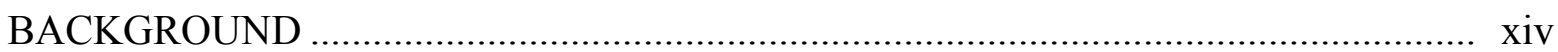

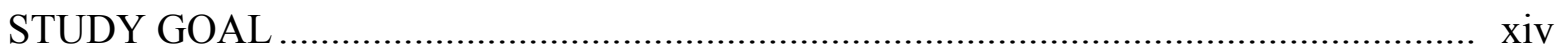

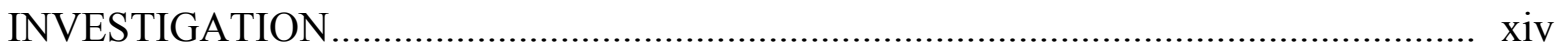

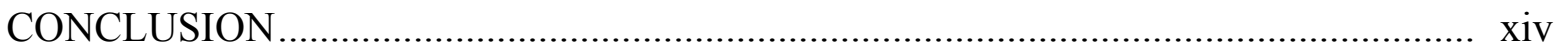

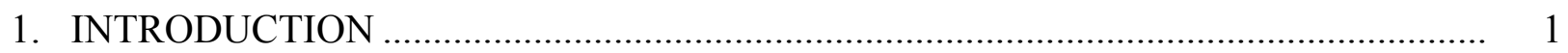

1.1 BACKGROUND ..................................................................................... 1

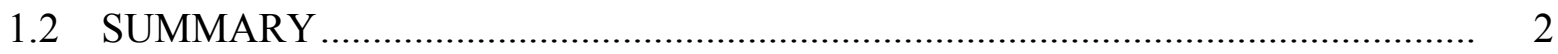

2. ANALYSIS OF THE PMSM WHEN DRIVEN BY CPA ........................................ 4

3. ANALYSIS OF THE PMSM WHEN DRIVEN BY DMIC .................................... 12

3.1 HIGH-INDUCTANCE PMSM DRIVEN BY CPA ........................................ 14

3.2 PMSM CURRENT-MAGNITUDE MINIMIZATION WHEN DRIVEN

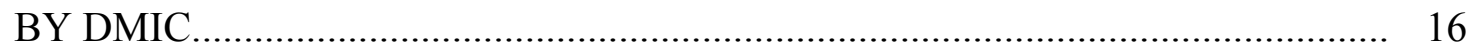

3.3 COMPARISON OF DEERE 1 MOTOR-CURRENT MAGNITUDE WITH CPA AND DMIC ................................................................................... 20

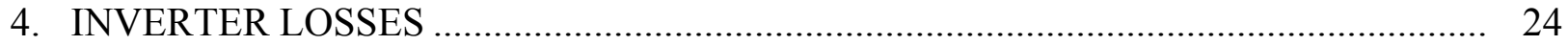

4.1 CONDUCTION LOSSES ......................................................................... 24

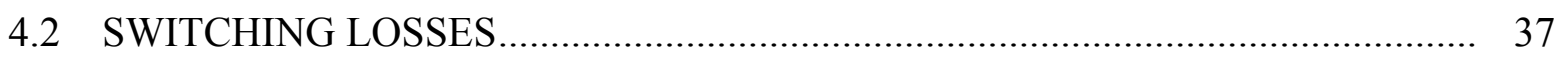

4.3 REVERSE-RECOVERY LOSSES .............................................................. 38

4.4 INVERTER SEMICONDUCTOR SELECTIONS FOR THE DEERE 1 AND
DEERE 2 DESIGNS AND LOSS-MODEL PARAMETERS $. \ldots \ldots \ldots \ldots \ldots \ldots . . .40$

4.5 MODEL VALIDATION USING EXPERIMENTAL DATA FOR THE CPA DRIVEN DEERE 1 DESIGN ..................................................................... 43 


\section{CONTENTS (cont'd)}

Page

5. MODELED PERFORMANCE OF CPA AND DMIC DRIVING THE DEERE 1

AND DEERE 2 DESIGNS ……….................................................................. 45

5.1 DEERE 1 DRIVEN BY CPA ………………….......................................... 45

5.1.1 Deere 1 Driven by CPA with Rotational Losses ........................................ 45

5.1.2 Comparison of Deere 1 Driven by CPA With and Without

Rotational Losses .......................................................................... 49

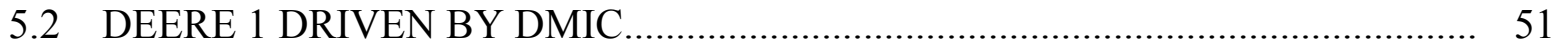

5.2.1 Deere 1 Driven by DMIC with Rotational Losses........................................ 51

5.2.2 Deere 1 Driven by DMIC Neglecting Rotational Losses ............................ 54

5.3 COMPARISON OF THE MODELED PERFORMANCE OF DEERE 1

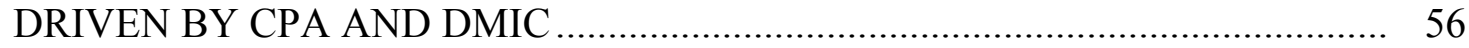

5.4 DEERE 2 DRIVEN BY DMIC................................................................... 57

5.5 COMPARISON OF THE DMIC DRIVEN DEERE 1 AND DEERE 2 ……........... 60

5.6 COMPARISON OF THE CPA DRIVEN DEERE 1 AND

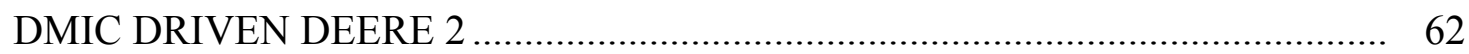

5.7 DEERE 1 DRIVEN BY THE MODIFIED DMIC ................................................. 63

6. COST STUDY

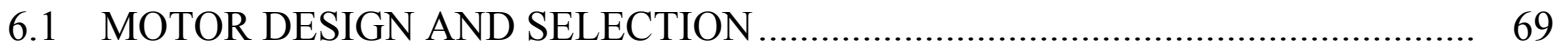

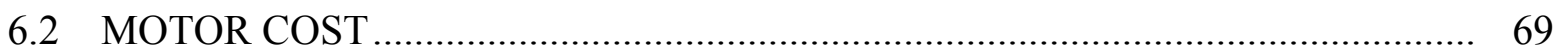

6.3 INVERTER SEMICONDUCTOR COST …….............................................. 70

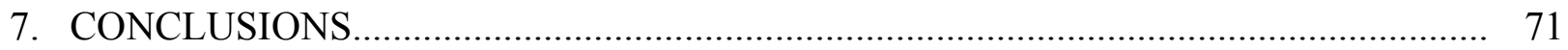

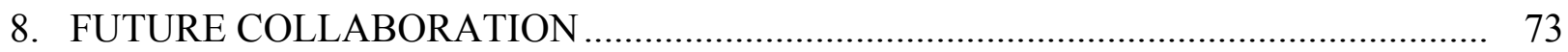

8.1 MAXIMUM COMMUTATION SPEED OF THYRISTORS AND

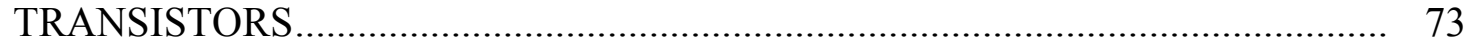

8.2 SEARCH FOR DEERE DMIC-USEFUL LIFETIME DUTY CYCLE

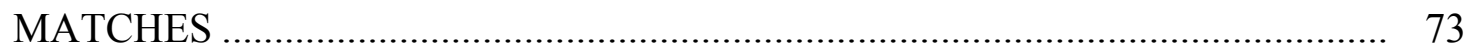

8.3 TRACTION DRIVES FOR HEAVY ON-ROAD VEHICLES ................................. 74

8.4 HIGH CPSR SRMS OPERATING IN THE CONTINUOUS CONDUCTION

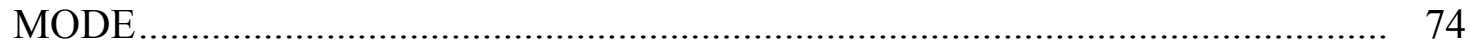

8.5 THE HSUB DC MOTOR AS A TRACTION DRIVE FOR DEERE

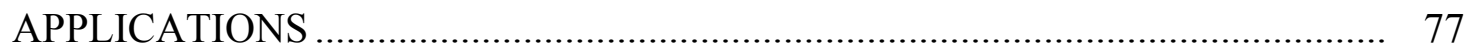

8.6 IDENTIFICATION, QUANTIFICATION, AND REDUCTION OF DEERE 1 MOTOR LOSSES............................................................................... 78

8.7 PACKAGING VSI/SCR COMPONENTS TO REDUCE COSTS ........................... 78

APPENDIX A. SEMICONDUCTOR DATA SHEETS

A.1. IGBTS FOR DEERE 1

A.2. SCRS FOR DEERE 1

A.3. IGBTS FOR DEERE 2 


\section{CONTENTS (cont'd)}

Page

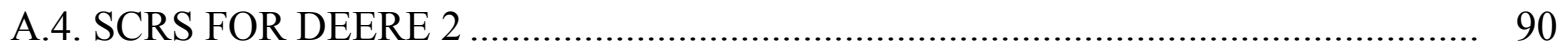

APPENDIX B. DEERE 1 TEST DATA _....................................................................... 92

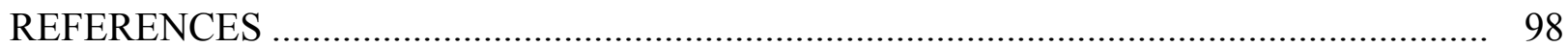




\section{LIST OF FIGURES}

Figure

Page

$1 \quad$ Motor/inverter schematic for PMSM driven by CPA ......................................... 4

$2 \quad$ Fundamental-frequency model of one phase of a PMSM ..................................... 5

3 Constant power performance of the PMSM driven by sinusoidal PWM ............... 10

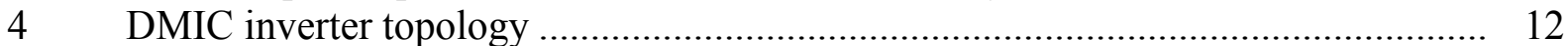

5 Per-phase fundamental-frequency phasor model for constant power mode............. 13

6 Constant-power operation of a PMSM motor comparing CPA control with DMIC

7 RMS motor current vs. power output during high-speed operation of the Deere 1 motor with $215.3 \mathrm{~V}$ and $350 \mathrm{Vdc}$ supplies

8 RMS motor current vs. power output during high-speed operation of the Deere 2 motor with $252.7 \mathrm{~V}$ and $350 \mathrm{Vdc}$ supplies

9 Transistor with bypass diode and thyristor equivalents for determining conduction losses

10 Per-phase model used to calculate average and rms device currents...................... 26

11 Time domain simulation at $300 \mathrm{rpm}, 60 \%$ rated torque with $340 \mathrm{Vdc}$ supply, and a carrier frequency of $5940 \mathrm{~Hz}$.

12 Time domain simulation at $300 \mathrm{rpm}, 60 \%$ rated torque with $340 \mathrm{Vdc}$ supply and a carrier frequency of $900 \mathrm{~Hz}$

13 Per-phase fundamental-frequency model of the Deere 1 design driven by CPA at $4200 \mathrm{rpm}$ and $42 \mathrm{~kW}$ useful output power with rotational losses included.......... 32

14 Time-domain simulation results of the CPA simulator driving the Deere 1 design at $4200 \mathrm{rpm}$ and $42 \mathrm{~kW}$ output with rotational losses included

15 Per-phase fundamental-frequency model of the Deere 1 design driven by DMIC at $4200 \mathrm{rpm}$ and $42 \mathrm{~kW}$ useful output power with rotational losses included

16 Time domain simulation results of the DMIC simulator driving the Deere 1 design at $4200 \mathrm{rpm}$ and $42 \mathrm{~kW}$ output with rotational losses included

17 Simplified description of switching dynamics during turn-on and turn-off......

18 Reverse-recovery current and voltage

19 Comparison of modeled and measured losses for Deere 1 when driven by CPA at $600 \mathrm{rpm}$

20 Performance of Deere 1 driven at maximum torque driven by CPA from 0-6000 rpm with rotational losses

21 Motor, inverter, and total losses of Deere 1 driven by CPA vs. torque and speed with rotational losses included

22 Motor, inverter, and total drive-efficiency contours overlayed on the torque-speed envelope of the Deere application for Deere 1 driven by CPA with the effects of rotational losses.

23 Comparison of the motor, inverter, and total losses of Deere 1 driven by CPA with and without rotational losses.

24 Comparison of motor, inverter, and total drive-efficiency contours of Deere 1 driven by CPA with and without rotational losses. 


\section{LIST OF FIGURES (cont'd)}

Figure

Page

25 Performance of Deere 1 driven at maximum torque by DMIC from 0-6000 rpm, with rotational losses.

26 Motor, inverter, and total losses of Deere 1 driven by DMIC vs. torque and speed with rotational losses

27 Motor, inverter, and total drive-efficiency contours overlayed on the torque-speed envelope of the Deere application for Deere 1 driven by DMIC with the effects of rotational losses.

28 Comparison of the motor, inverter, and total losses of Deere 1 driven by DMIC with and without rotational losses

29 Comparison of motor, inverter, and total drive-efficiency contours of Deere 1 driven by DMIC with and without rotational losses

30 Comparison of the motor, inverter, and total losses of Deere 1 driven by CPA and DMIC with rotational losses neglected

31 Comparison of motor, inverter, and total drive-efficiency contours of Deere 1 driven by CPA and DMIC with rotational losses neglected

32 Comparison of the motor, inverter, and total losses of Deere 2 driven by DMIC with "typical" and "maximum" VSI loss parameters

33 Comparison of motor, inverter, and total drive-efficiency contours of Deere 2 driven by DMIC with "typical" and "maximum" VSI loss parameters.

34 Comparison of the motor, inverter, and total losses of Deere 1 and Deere 2 driven by DMIC with "maximum" VSI loss parameters and with rotational losses.

35 Comparison of motor, inverter, and total drive-efficiency contours of Deere 1 and Deere 2 driven by DMIC with "maximum" VSI loss parameters and with rotational losses.....

36 Comparison of the motor, inverter, and total losses of Deere 1 driven by CPA and Deere 2 driven by DMIC with "typical" VSI loss parameters and rotational losses neglected

37 Comparison of the motor, inverter, and total efficiency contours of Deere 1 driven by CPA and Deere 2 driven by DMIC with "typical VSI loss parameters with rotational losses neglected

38 Modified DMIC Inverter

39 Performance of Deere 1 driven at maximum torque by Modified DMIC from 0-6000 rpm with rotational losses

40 Comparison of the motor, inverter, and total losses of Deere 1 driven by Deere 1 with CPA and Deere 1 with Modified DMIC and without rotational losses

41 Comparison of motor, inverter, and total drive-efficiency contours of Deere 1 driven by CPA and by Modified DMIC without rotational losses. 


\section{LIST OF FIGURES (cont'd)}

Figure

Page

42 Phase A current, co-energy, and useful power for a hypothetical $320 \mathrm{hp}$ 8/6 SRM at half-base speed and base speed with supply voltage, $\mathrm{V}_{\mathrm{dc}}=700 \mathrm{~V}$, and current limit, $\mathrm{I}_{\text {set }}=600 \mathrm{~A}$

75

43 Phase A current, voltage, co-energy, and useful power for a hypothetical $320 \mathrm{hp} \mathrm{8/6} \mathrm{SRM} \mathrm{at} 6500 \mathrm{rpm}(\mathrm{n}=26)$ with supply voltage, $\mathrm{V}_{\mathrm{dc}}=700 \mathrm{~V}$, and current limit $\mathrm{I}_{\text {set }}=600 \mathrm{~A}$ 


\section{LIST OF TABLES}

Table

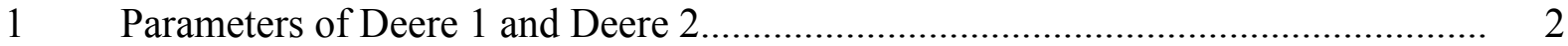

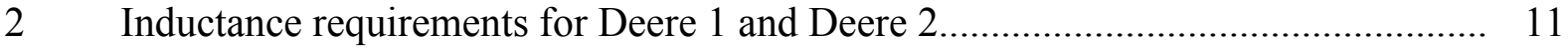

3 Comparison of theoretical and simulated motor and inverter-current Magnitudes at $300 \mathrm{rpm}, 60 \%$ rated torque, and dc supply of $340 \mathrm{~V} \mathrm{\ldots ....................} 32$

4 Typical semiconductor parameters for the Deere 1 drive..................................... 41

$5 \quad$ Typical semiconductor parameters for the Deere 2 drive .................................... 42

$6 \quad$ Maximum semiconductor parameters for the Deere 1 drive ............................... 43

$7 \quad$ Maximum semiconductor parameters for the Deere 2 drive .............................. 58

8 Weight and cost comparison of three permanent magnet (PM) motor designs........ 69 


\section{ACRONYMS, ABBREVIATIONS, AND INITIALISMS}

ac

amp

emf

CPA

CPSR

CRADA

DBC

dc

Deere

DMIC

DOE

HSUB

IGBT

$\mathrm{Nm}$ alternating current

ampere

electromotive force conventional phase advance constant power speed ratio cooperative research and development agreement direct bonded cooper direct current

John Deere and Company dual-mode inverter control

Department of Energy high-strength undiffused brushless insulated gate bipolar transistor Newton-meters
OFCVT

ORNL PEEMRC

PM

PMSM

PWM

rms

rpm

SCR

SRM

UQM

VSI
Office of FreedomCAR and

Vehicle Technologies

Oak Ridge National Laboratory Power Electronics and Electric Machinery Research Center permanent magnet permanent magnet synchronous motor pulse-width modulation root-mean-square revolutions per minute silicon-controlled rectifier switched reluctance motor UQM Technologies, Inc. voltage-source inverter 


\begin{abstract}
John Deere and Company (Deere), their partner, UQM Technologies, Inc. (UQM), and the Oak Ridge National Laboratory's (ORNL's) Power Electronics and Electric Machinery Research Center (PEEMRC) recently completed work on the cooperative research and development agreement (CRADA) Number ORNL 04-0691 outlined in this report. CRADA 04-0691 addresses two topical issues of interest to Deere:
\end{abstract}

1. Improved characterization of hydrogen storage and heat-transfer management; and

2. Potential benefits from advanced electric motor traction-drive technologies.

This report presents the findings of the collaborative examination of potential operational and cost benefits from using ORNL/PEEMRC dual-mode inverter control (DMIC) to drive permanent magnet (PM) motors in applications of interest to Deere.

DMIC was initially developed and patented by ORNL to enable PM motors to be driven to speeds far above base speed where the back-electromotive force (emf) equals the source voltage where it is increasingly difficult to inject current into the motor. DMIC is a modification of conventional phase advance (CPA). DMIC's dual-speed modes are below base speed, where traditional pulse-width modulation (PWM) achieves maximum torque per ampere (amp), and above base speed, where six-step operation achieves maximum power per amp. The modification that enables DMIC adds two anti-parallel thyristors in each of the three motor phases, which consequently adds the cost of six thyristors. Two features evaluated in this collaboration with potential to justify the additional thyristor cost were a possible reduction in motor cost and savings during operation because of higher efficiency, both permitted because of lower current.

The collaborative analysis showed that the reduction of motor cost and base cost of the inverter was small, while the cost of adding six thyristors was greater than anticipated. Modeling the DMIC control displayed inverter efficiency gains due to reduced current, especially under light load and higher speed. This current reduction, which is the salient feature of DMIC, may be significant when operating duty cycles have low loads at high frequencies. Reduced copper losses make operation more efficient thereby reducing operating costs. In the Deere applications selected for this study, the operating benefit was overshadowed by the motor's rotational losses.

Rotational losses of Deere 1 and Deere 2 dominate the overall drive efficiency so that their reduction has the greatest potential to improve performance. A good follow-up project would be to explore cost erective ways to reduce the rotational losses buy $66 \%$.

During this analysis it has been shown that, for a PM synchronous motor (PMSM), the DMIC's salient feature is its ability to minimize the current required to deliver a given power. The rootmean-square (rms) current of a motor is determined by the speed, power, motor drive parameters, and controls as

$$
\mathrm{I}_{\mathrm{rms}}=(\mathrm{n}, \mathrm{P}, \text { motor drive parameters, controls }) \text {, }
$$


where $\mathrm{n}$ is the relative speed, $\omega / \omega_{\text {base }}=\Omega / \Omega_{\text {base }}, \omega$ is the mechanical frequency, $\Omega$ is the electrical frequency, and $\mathrm{P}$ is the power. The characteristic current is the rms current at infinite speed, when all resistance and rotational losses are neglected. Expressions have been derived for the characteristic currents of PMSMs when the motor is controlled by CPA and by DMIC. The expression for CPA characteristic current is

$$
\mathrm{I}_{\mathrm{n} \rightarrow \infty}^{\mathrm{CPA}}=\frac{\mathrm{nE}_{\text {base }}}{\mathrm{X}}=\frac{n E_{\text {base }}}{\mathrm{n} \Omega_{\mathrm{b}} \mathrm{L}}=\frac{\mathrm{E}_{\text {base }}}{\Omega_{\mathrm{b}} \mathrm{L}},
$$

which is strictly a function of the machine parameters, back-emf at base speed, base speed electrical frequency, and inductance. At high speeds, the rms current tends to remain constant even when the load-power requirements are reduced. The expression for DMIC characteristic current is

$$
\mathrm{I}_{\mathrm{n} \rightarrow \infty}^{\mathrm{DMIC}}=\frac{\mathrm{P}}{3 \mathrm{~V}_{\max }}=\frac{\mathrm{P} \pi}{3 \sqrt{2} \mathrm{~V}_{\mathrm{dc}}},
$$

which has nothing to do with machine parameters. This interesting result shows that at high speeds under DMIC control, the rms current diminishes as the load-power requirements are reduced. It also shows that the DMIC characteristic current can be further reduced by increasing the dc supply voltage. This explains the main benefit of DMIC; its ability to minimize the current required to meet a required load. 


\section{STATEMENT OF OBJECTIVES}

Deere, founded in 1837, is a world leader in off-road technologies that combine state-of-the-art drive systems with alternative power and fueling systems to meet the demands of agricultural, construction, and other consumer sectors. At ORNL, PEEMRC is a world leader in research on power electronics and electric machinery and associated technologies such as fuel cells. Researchers develop and prototype the next generation of cost-effective converters, adjustablespeed drives, electric utility and distributed-generation applications, motor controls, and efficient, compact electric machines. ORNL and Deere would use their respective expertise in this highly integrated collaborative effort. ORNL would contribute expertise in thermal dynamics and power electronics, and Deere would contribute its experience and expertise with motors, inverters, and generators for off-road equipment. The Parties would collaborate to solve problems with hydrogen storage, heat-transfer management, and traction-drive torque. This part of the collaboration deals with advance traction-drive technology.

Task 2.A.1 was to determine if Deere can benefit from using DMIC technology to drive a traction motor. The objective of this task was to determine whether or not the DMIC technology has value in Deere applications that require a wide constant power speed ratio (CPSR). The study involved a technical evaluation, including torque-speed performance and efficiency as a function of speed, as well as an economic evaluation including cost of materials, fabrication, and total drive cost.

Task 2.B was to collaborate with the Deere team to determine the values of power, torque, or efficiency for which it is cost effective to apply ORNL's DMIC, switched reluctance motor (SRM), and High-Strength Undiffused Brushless (HSUB) technologies. The objective of this task was to summarize for Deere the key analytical techniques for assessing the performance of PMSMs driven by either DMIC or CPA. Sections 2 and 3 contain synopses of the relevant theory for the evaluation of PMSM performance when driven by CPA and DMIC respectively. These sections employ the parameters of the Deere 1 and Deere 2 designs for demonstration. Since overall drive efficiency is a concern, methods for estimating inverter losses are summarized in Section 4. 


\section{BENEFITS TO THE OFFICE OF FREEDOMCAR AND VEHICLE TECHNOLOGIES}

An objective of the Department of Energy's (DOE's) Office of FreedomCAR and Vehicle Technologies (OFCVT) is to move technology from invention to commercial application. This CRADA between Deere and ORNL had as its objective an investigation of potential cost benefits related to commercial application of inverter control technology developed at ORNL's PEEMRC. The technology was ORNL's DMIC, which has the unique capability to control PM motors for maximum torque per amp below base speed and for maximum power per amp above base speed, and which has desirable inherent safety features. The goal was to quantify a cost benefit for Deere to apply DMIC to one of its commercial products. 


\section{EXECUTIVE SUMMARY}

\section{BACKGROUND}

Many production traction-drive systems must provide sufficient torque for vehicles to climb a hill with a large load at low speed and yet have modest highway speed. This requires their system to deliver design torque from rest to base speed and to deliver constant power over a wide range of speed, meaning it must have a high CPSR. The DMIC has potential to deliver constant power with minimum current, which may enable a low cost traction-drive system to be designed for low-inductance traction motors.

\section{STUDY GOAL}

For PM motor technology, two basic options exist to develop an electric-drive system with high CPSR. One option is to add inductance to allow CPA control of the machine. The other option is to use DMIC control. With CPA control additional current, which must be accommodated by the motor windings and the inverter circuit and which reduces efficiency, is regenerated by the motor rotor at high speed flowing back through the semiconductors' bypass diodes. With DMIC control, the effects of motor rotor at high speed are blocked by additional thyristors, which are silicon-controlled rectifier (SCR) semi-conductors, whose control leads to the minimum current necessary to deliver rated torque. The goal of this collaboration was to obtain a deeper understanding of how the resulting system and operational costs are impacted by the use of DMIC.

\section{INVESTIGATION}

Given a proposed traction application and design using a PM motor and CPA control as a baseline, the cost impacts of using DMIC were investigated. The DMIC design leads to a substantial reduction of peak-continuous current, which has potential to reduce motor and inverter costs thereby offsetting additional SCR semi-conductor costs. Analysis showed that reduction of motor and inverter costs was small, while the cost of adding separate SCRs was greater than expected. Modeling of the DMIC control did display inverter efficiency gains due to reduced current, especially under light load and higher speed. Reduction of these losses would effect low-load high-speed duty cycle applications and make operation more efficient saving operation costs due to reduced energy input.

\section{CONCLUSION}

DMIC control does offer a solid technical basis for extension of an electric-drive system with high CPSR. The potential cost benefit of this configuration is limited due to the additional cost of the SCR components, since offsetting savings from a reduction of peak-continuous current during operation is limited. A high level of insulated gate bipolar transistor (IGBT) and SCR integration within the semiconductor packaging has potential to reduce this cost trade-off, thus increasing the favorability of DMIC. DMIC did provide higher efficiency under light load and higher speed, being favorable for applications where operational energy savings is important. In this example of a high-duty load, the value of the operating benefit was less. 


\section{INTRODUCTION}

The main objective of this study was to determine whether or not the dual-mode inverter control (DMIC) technology has value for the John Deere and Company (Deere) applications that require

a wide constant power speed ratio (CPSR). The study involved a technical evaluation of torque-speed performance and efficiency as well as an economic evaluation of material, fabrication, and total drive cost costs.

A secondary objective of the study was to summarize for Deere the key analytical techniques for assessing the performance of permanent magnet synchronous motors (PMSMs) driven by either DMIC or conventional phase advance (CPA). Sections 2 and 3 contain synopses of the relevant theory for the evaluation of PMSM performance when driven by CPA and DMIC respectively. These sections use the parameters of the Deere 1 and Deere 2 designs for demonstration. Since overall drive efficiency is a concern, the methods for estimating inverter losses are summarized in Section 4.

\subsection{BACKGROUND}

The DMIC was developed at the Oak Ridge National Laboratory (ORNL) for extending the CPSR of surface mounted PMSM that have low inductance. If one neglects resistance and rotational losses, the DMIC allows low-inductance machines to be driven to an infinite CPSR. However, recent research has shown that the DMIC may also have value in enhancing the efficiency of high-inductance PMSMs. Competing PMSM drive configurations, which employ CPA, work well if the machine inductance is sufficiently high. The study comprised evaluations of two PMSMs, referred to as "Deere 1" and "Deere 2." Both designs have a base speed of 600 revolutions per minute $(\mathrm{rpm})$, a power rating of $60 \mathrm{~kW}$, and a top speed of $6000 \mathrm{rpm}$. Their rated torque was 955 Newton-meters $(\mathrm{Nm})$ and their CPSR capability was 10:1. Deere 1 is a high-inductance motor that can be driven over a wide CPSR by CPA or by DMIC. Deere 2 is a low-inductance motor that requires DMIC to meet the CPSR requirement. Key parameters of these two motors are summarized in Table 1. 
Table 1. Parameters of Deere 1 and Deere 2

\begin{tabular}{|l|c|c|}
\hline \multicolumn{1}{|c|}{ Parameter } & Deere 1 & Deere 2 \\
\hline Stator outer diameter & $341 \mathrm{~mm}$ & $341 \mathrm{~mm}$ \\
\hline Stack length & $216 \mathrm{~mm}$ & $188 \mathrm{~mm}$ \\
\hline Length over end turns & $267 \mathrm{~mm}$ & $243 \mathrm{~mm}$ \\
\hline Lamination weight & $56 \mathrm{~kg}$ & $49 \mathrm{~kg}$ \\
\hline Copper weight & $14 \mathrm{~kg}$ & $13 \mathrm{~kg}$ \\
\hline Magnet weight & $3.2 \mathrm{~kg}$ & $3.5 \mathrm{~kg}$ \\
\hline Number of poles & 24 & 20 \\
\hline Base speed & $600 \mathrm{rpm}$ & $600 \mathrm{rpm}$ \\
\hline Top speed & $6000 \mathrm{rpm}$ & $6000 \mathrm{rpm}$ \\
\hline CPSR requirement & $10: 1$ & $10: 1$ \\
\hline $\begin{array}{l}\text { Back-emf magnitude at base speed, Eb } \\
\text { (root-mean-square }(\mathrm{rms}) \text { volts per phase) }\end{array}$ & $63.63 @ 600 \mathrm{rpm}$ & $94 @ 600 \mathrm{rpm}$ \\
\hline $\begin{array}{l}\text { Voltage constant, Kv } \\
\text { (rms volts per elec. rad/sec) }\end{array}$ & 0.0844 & 0.1496 \\
\hline Rated power & $60 \mathrm{~kW}$ & $60 \mathrm{~kW}$ \\
\hline Rated rms current & $314 \mathrm{~A}$ & $213 \mathrm{~A}$ \\
\hline Resistance per phase & $15 \mathrm{~m} \Omega$ & $30 \mathrm{~m} \Omega$ \\
\hline Inductance per phase & $290 \mu \mathrm{H}$ & $400 \mu \mathrm{H}$ \\
\hline Rotational losses $P_{\text {rot }}(n) @ \mathrm{n}=\mathrm{rpm} / 600$ & & $752 \mathrm{~W}$ \\
\hline $1000 \mathrm{rpm}(\mathrm{n}=1.67)$ & $700 \mathrm{~W}$ & $1935 \mathrm{~W}$ \\
\hline $2000 \mathrm{rpm}(\mathrm{n}=3.33)$ & $1800 \mathrm{~W}$ & $3548 \mathrm{~W}$ \\
\hline $3000 \mathrm{rpm}(\mathrm{n}=5.00)$ & $3300 \mathrm{~W}$ & $5590 \mathrm{~W}$ \\
\hline $4000 \mathrm{rpm}(\mathrm{n}=6.67)$ & $5200 \mathrm{~W}$ & $8170 \mathrm{~W}$ \\
\hline $5000 \mathrm{rpm}(\mathrm{n}=8.33)$ & $7600 \mathrm{~W}$ & $11290 \mathrm{~W}$ \\
\hline $6000 \mathrm{rpm}(\mathrm{n}=10.0)$ & $10500 \mathrm{~W}$ & \\
\hline
\end{tabular}

\subsection{SUMMARY}

Technical evaluation of the Deere 1 and Deere 2 designs was performed by ORNL. Key findings of the evaluation are given in Section 5. Main results may be summarized as follows:

- Both Deere 1 and Deere 2 can meet a 10:1 CPSR requirement.

- The efficiency of the CPA driven Deere 1 is higher than that of the DMIC driven Deere 1 at speeds up to and slightly beyond base speed. The reason for this lies in the added losses resulting from the additional inverter components (thyristors) in the DMIC inverter. An application whose load involves a high percentage of operation in the vicinity of base speed will not likely benefit from DMIC.

- The use of the thyristors in the DMIC design allows the motor to be designed for high motor back-electromotive force (emf) and lower motor current. The lower current handling requirement may allow the DMIC inverter to be lower in cost than the CPA inverter especially if the difference in current is at a "technology" breakpoint; e.g. if the use of DMIC were to allow 300A transistors to be used when 600A transistors would otherwise be required.

- The rotational losses of both motor designs are large at high speed and totaling approximately $10 \mathrm{~kW}$ at the top speed of $6000 \mathrm{rpm}$. The cause of the rotational losses and means for substantially reducing them warrants further study. Reducing these losses 
would greatly enhance the overall efficiency of both the CPA and DMIC driven machines.

- The rotational losses at high speed dominate other loss mechanisms such as motor-copper losses and inverter losses. To sharpen the distinction between the DMIC and CPA driven cases relative to motor and inverter losses, the efficiency studies were performed twice. In the first analysis the rotational losses of Deere 1 and Deere 2, displayed in Table 1, were included while in the second analysis the rotational losses were neglected. Efficiency maps, with and without rotational losses, were constructed showing regions of similar efficiency plotted on the torque speed envelope of the drives.

- Above base speed, the efficiency of the DMIC driven Deere 2 configuration is superior to that of the CPA driven Deere 1. This is due to DMIC's current minimizing feature, which achieves optimal watt per ampere (amp) control in the constant power mode. The efficiency enhancement of DMIC is most pronounced for load conditions less than full power when operating at high speed. The value of DMIC for Deere applications will depend strongly on the load-duty cycle. Applications with varying duty cycle that involve considerable operating time above base speed will have the greatest gain in energy efficiency from the application of DMIC.

Cost analysis of Deere 1 and Deere 2 cases was conducted by Deere personnel. The findings are contained in Section 6. The main points of the cost evaluation are summarized as follows:

- UQM Technologies, Inc. (UQM's) Deere 2 design did lead to a slight cost reduction while ORNL's Deere 3 design actually leads to a small cost increase.

- For the examples under study, no significant benefit in motor cost reduction was found.

- The redesign did lead to some slight but insignificant package size reduction.

Overall conclusions of the study are contained in Section 7. The main conclusions are:

- Drive efficiency can be improved, at high speed, using the DMIC even when the motor inductance is high. Providing additional direct current (dc) supply voltage can further improve the advantage of DMIC relative to CPSR.

- The main consideration in whether or not the DMIC has value in a given application depends greatly on load-duty cycle at high speed.

- In this study, there is little difference in performance between the Deere 1 and Deere 2 drives with respect to losses and efficiency so that selection decisions would necessarily be based on motor cost, which was not sufficient to pay for the DMIC's thyristors.

- For the examples under study, no significant benefit in motor cost reduction was found.

- Use of DMIC is a mismatch for the cases examined because motor redesign doesn't lead to motor cost reduction and the Deere application spends most of its duty cycle at or below base speed where the efficiency gains do not pay for the additional siliconcontrolled rectifiers (SCRs) required by DMIC.

The next section contains a discussion of the means for theoretical analysis of the performance of the PMSM driven by CPA. 


\section{ANALYSIS OF THE PMSM WHEN DRIVEN BY CPA}

Figure 1 shows a schematic of the three-phase PMSM driven by a voltage-source inverter (VSI) as used in CPA. The figure also defines some of the parameters and notation used in this discussion. The resistors $R$ and $R_{\text {rot }}$ represent the copper losses and the speed sensitive rotational losses respectively. The value of $R_{\text {rot }}$ can be calculated for any given speed using knowledge of the back-emf rms magnitude and the watt value of rotational losses as contained in Table 1. At relative speed $n$, the value of $R_{r o t}(n)$ is calculated as

$$
R_{\text {rot }}(n)=\frac{3\left(n E_{b}\right)}{P_{\text {rot }}(n)}
$$

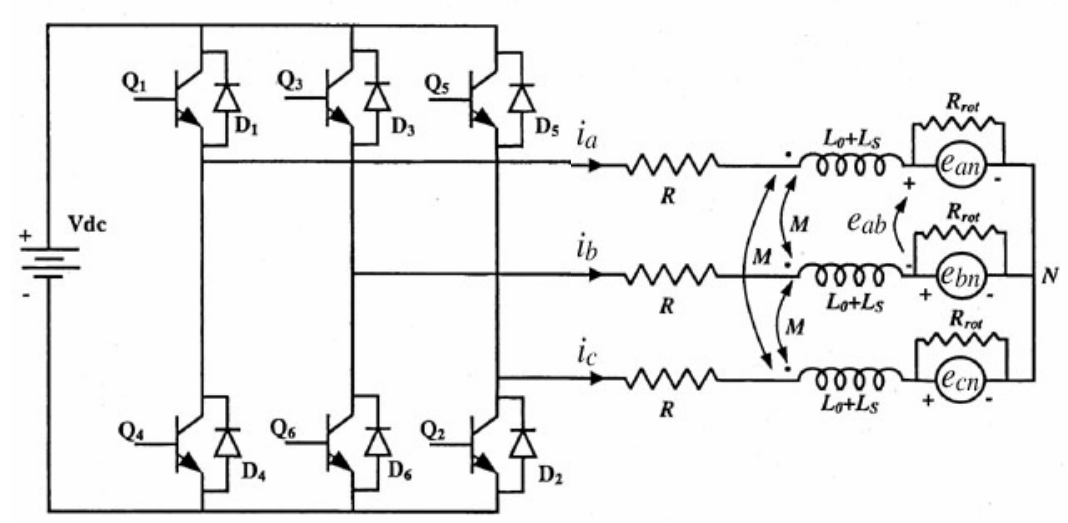

Fig. 1. Motor/inverter schematic for PMSM driven by CPA.

$$
\begin{aligned}
p & =\text { number of poles } \\
N & =\text { actual rotor speed in rpm } \\
N_{b} & =\text { base speed in rpm } \\
n & =\text { relative speed }=\frac{\mathrm{N}}{\mathrm{N}_{\mathrm{b}}} \\
\Omega_{b} & =\text { base speed in electrical radians } / \mathrm{sec} \\
& =\frac{\mathrm{p}}{2} \cdot \frac{2 \pi \mathrm{N}_{\mathrm{b}}}{60} \\
\Omega & =\text { actual rotor speed in electrical radians } / \mathrm{sec} \\
& =n \Omega_{b} \\
E_{b} & =\text { rms magnitude of the phase-to-neutral emf at base speed } \\
I_{R} & =\text { rated rms motor current } \\
P_{R} & =\text { rated output power }=3 E_{b} I_{R} \\
L_{s} & =\text { self inductance per phase } \\
L_{o} & =\text { leakage inductance per phase } \\
M & =\text { mutual inductance } \\
L & =\text { equivalent inductance per phase }=L_{o}+L_{s}+M \\
R & =\text { winding resistance per phase }
\end{aligned}
$$




$$
\begin{aligned}
& v_{a n}=\text { applied phase } \mathrm{A} \text { to neutral voltage } \\
& e_{a n}=\text { phase } \mathrm{A} \text { to neutral back-emf } \\
& e_{a b}=\text { phase } \mathrm{A} \text { to phase } \mathrm{B} \text { back-emf }
\end{aligned}
$$

The detailed technical assessment of Deere 1 and Deere 2 presented in Section 5 includes the evaluation of losses, not only in the motor but also in the inverter. The main focus in Sections 2 and 3 is on CPSR performance and current-magnitude control and the discussion is greatly simplified by neglecting the losses. Unless otherwise specified, the discussion in the remainder of this section and the next assumes that the winding resistance, $R$, is zero and the rotational-loss resistance, $R_{\text {rot }}$, is infinite.

The transistors in the inverter of Fig. 1 are typically controlled by sinusoidal pulse-width modulation (PWM) which uses a triangular carrier wave and three sinusoidal reference waves to decide the switching pattern. A detailed PSPICE simulator is available to analyze the performance of the PMSM as displayed in Fig. 1 and controlled by PWM when operating at constant speed. Since the objective here is to focus on CPSR and efficiency calculations, the details of control are intentionally omitted and a simplified per-phase fundamental-frequency model is developed. Such a model is shown in Fig. 2 which is a phasor model of the motor drive at a selectable but constant speed.

ORNL 2002-03422/jcn

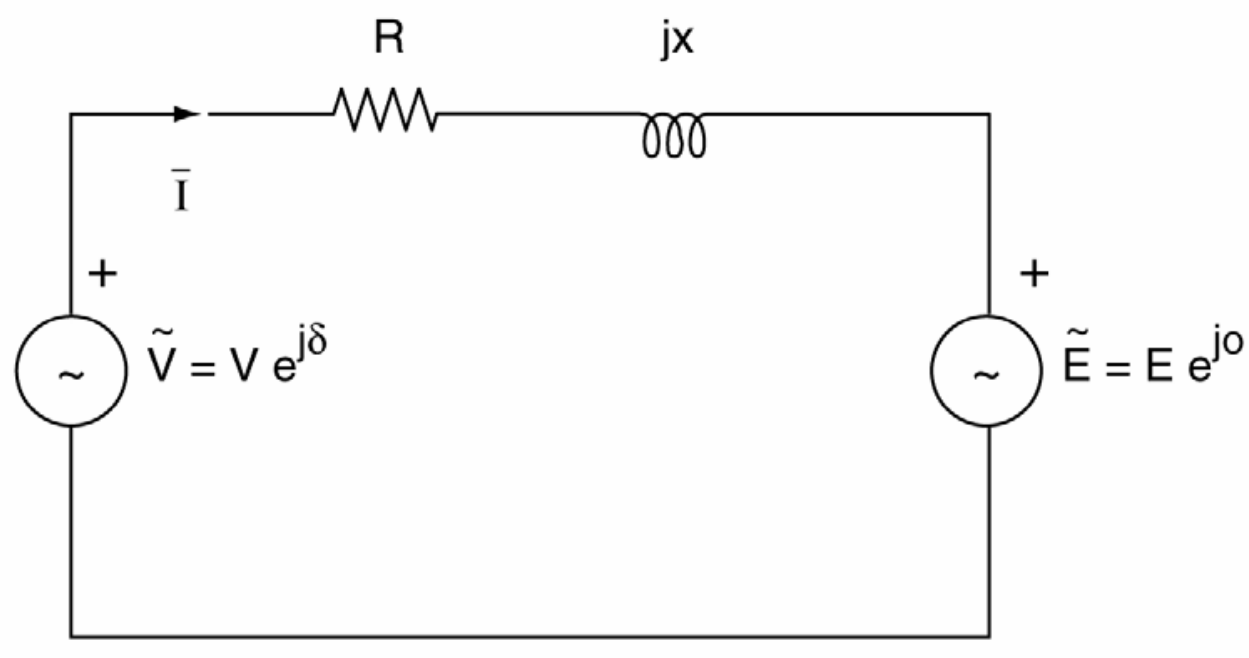

Fig. 2. Fundamental-frequency model of one phase of a PMSM.

In the per-phase model of Fig. 2, the phasor $\bar{V}$ represents the fundamental frequency line-toneutral voltage applied to the motor by the inverter. $\mathrm{V}$ is the rms magnitude and $\delta$ is the inverter-lead angle. Phasor $\bar{E}$ represents the phase-to-neutral motor back-emf and is chosen as the reference phasor, such that the angle of $\overline{\mathrm{E}}$ is zero. The magnitude of the emf is linear in motor speed and the voltage constant, $K_{v}$, with units of rms volts per electrical radian per second. Thus, the rms value of the back-emf at any speed is given by 


$$
\begin{aligned}
E & =K_{v} \Omega \\
& =\frac{\Omega}{\Omega_{b}} K_{v} \Omega_{b}, \\
& =n E_{b}
\end{aligned}
$$

where $E_{b}$ is the rms magnitude of the line-to-neutral back-emf at base speed and $\mathrm{n}$ is relative speed. Similarly, the motor reactance can be expressed as

$$
\begin{aligned}
X & =\Omega L \\
& =\frac{\Omega}{\Omega_{b}} \Omega_{b} L, \\
& =n X_{b}
\end{aligned}
$$

where $X_{b}$ is the reactance at base speed.

We should distinguish between "base speed" and "true base speed." Base speed is the highest speed at which rated torque is required and the power developed at this speed is the rated power of the motor drive. True base speed is the highest speed at which rated torque can be developed. The true base speed is exactly the same as base speed when the dc supply voltage is selected as the minimum value that permits rated torque to be developed at the base speed and is given by

$$
V_{d c-\min }=\frac{\pi}{\sqrt{2}} \sqrt{E_{b}^{2}+\left(X_{b} I_{R}\right)^{2}}
$$

This expression assumes that the PWM control will be in full over-modulation when developing rated torque at base speed. If the dc supply voltage is less than $V_{d c-m i n}$, it will not be possible to develop rated torque at the specified base speed; i.e., the true base speed will be less than the specified value. If the dc supply voltage is larger than $V_{d c-\min }$, then the true base speed is larger than the specified value. Letting the true base speed be denoted as $n_{b t}$ we have

$$
n_{b t}=\frac{V_{d c}}{V_{d c-\min }} \cdot n_{b}
$$

When a dc supply larger than the minimum is used, the rated torque can be developed at a higher speed resulting in greater power-conversation capability; however, the drive control can be configured to preclude using this extra capability; i.e., the control can restrict the maximum torque above the base speed. Even though control may be used to constrain the torque speed envelope, the addition of surplus de supply voltage may allow reduced current magnitude at high speed, thereby reducing inverter and motor-copper losses and improving efficiency. This possibility is discussed further in Section 3. 
Up to base speed the magnitude of the applied voltage, $V$, and the lead angle, $\delta$, can be adjusted allowing the motor-current phasor to be put in phase with the back-emf. This maximizes the torque produced per amp. Voltage magnitude $V$ and lead angle $\delta$, required to support any relative speed below base speed, $\mathrm{n} \leq 1$, and rms current, $I$, is found from

$$
\begin{aligned}
\bar{V} & =n E_{b}+j n I X_{b} \\
& =\sqrt{\left(n E_{b}\right)^{2}+\left(n I X_{b}\right)^{2}} e^{j \tan ^{-1}\left[\frac{n I X_{b}}{n E_{b}}\right]} \\
& =n \sqrt{E_{b}^{2}+\left(X_{b} I\right)^{2}} e^{j \tan ^{-1}\left[\frac{n I X_{b}}{n E_{b}}\right]} . \\
& =V e^{j \delta}
\end{aligned}
$$

The rms magnitude of $\bar{V}$ increases with speed and is limited by the available dc supply voltage. Assuming that the de supply voltage is the minimum value and that full over-modulation is allowed, the maximum magnitude is obtained at base speed where $n=1$ and rated rms motor current is $I=I_{R}$, then

$$
V_{\text {max }}=\sqrt{\left(E_{b}\right)^{2}+\left(I_{R} X_{b}\right)^{2}}=\sqrt{\left(E_{b}\right)^{2}+\left(I_{R} \Omega_{b} L\right)^{2}} .
$$

Similarly, the lead angle $\delta$ at base speed and rated current is given by

$$
\delta=\tan ^{-1}\left(\frac{I_{R} X_{b}}{E_{b}}\right) .
$$

The power developed at base speed and rated current is the rated power of the motor and since the current is in phase with the back-emf we have

$$
P_{R}=3 E_{b} I_{R}
$$

Let us now restrict our attention to operation above base speed such that $n>1$ and $V=V_{\text {max }}$. Neglecting the armature resistance, the phasor current of the motor is

$$
\bar{I}=\frac{V_{\max }}{n X_{b}} \sin \delta+j\left[\frac{E_{b}}{X_{b}}-\frac{V_{\max }}{n X_{b}} \cos \delta\right],
$$

which has rms magnitude

$$
I=\frac{\sqrt{V_{\max }^{2}-n 2 V_{\max } E_{b} \cos \delta+n^{2} E_{b}^{2}}}{n X_{b}} .
$$


The total power injected into the motor by the inverter is

$$
P_{i n}=3 \operatorname{Re}\left(\bar{V} \bar{I}^{*}\right)=\frac{3 V_{\max } E_{b}}{X_{b}} \sin \delta,
$$

while the total power converted by the motor is

$$
\begin{aligned}
P_{m} & =3 \operatorname{Re}\left(\bar{E} \bar{I}^{*}\right)=\frac{3 V_{\max } E_{b}}{X_{b}} \sin \delta \\
& =P_{\max } \sin \delta
\end{aligned}
$$

where

$$
P_{\max }=3 \frac{V_{\max } E_{b}}{X_{b}}
$$

is the maximum power that can possibly be converted, which corresponds to the lead angle being $90^{\circ}$. Since we have neglected the winding resistance, $P_{i n}$ equals $P_{m}$ and the common value is

$$
\begin{aligned}
P_{m} & =P_{i n}=\frac{3 V_{\max } E_{b}}{X_{b}} \sin \delta \\
& =P_{\max } \sin \delta
\end{aligned} .
$$

This expression shows that it is easy to control the motor to deliver rated power above base speed. All that is necessary is that the inverter-lead angle, $\delta$, be held fixed at that value which causes $P_{m}$ in Eq. (15) to be equal to the rated value, $P_{R}$, given in Eq. (9), that is

$$
\begin{aligned}
\delta & =\sin ^{-1}\left(\frac{X_{b} P_{R}}{3 V_{\max } E_{b}}\right) . \\
& =\cos ^{-1}\left(\frac{E_{b}}{V_{\max }}\right)
\end{aligned}
$$

While constant lead-angle control allows the PMSM to operate at constant power above base speed, it is not a certainty that doing so results in operating within the rated current. The critical factor is the motor inductance as shown below.

Equation (11) gives the rms motor current, $I$, when operating at any speed above base speed. Using lead angle, $\delta$, from Eq. (16) so that rated power is produced, we require that the rms current in Eq. (11) be no greater than the rated value $I_{R}$, that is 


$$
\begin{aligned}
I & =\frac{\sqrt{V_{\max }^{2}-n 2 V_{\max } E_{b} \cos \delta+n^{2} E_{b}^{2}}}{n X_{b}} \leq I_{R} \\
& =\frac{\sqrt{V_{\max }^{2}+n(n-2) E_{b}^{2}}}{n X_{b}} \leq I_{R} \\
& =\frac{\sqrt{V_{\max }^{2}+n(n-2) E}}{n \Omega_{b} L} \leq I_{R}
\end{aligned}
$$

Observe from Eq. (17) that, as the speed becomes unbounded

$$
\begin{aligned}
\lim _{n \rightarrow \infty} I & =\lim _{n \rightarrow \infty} \frac{\sqrt{V_{\max }^{2}+n(n-2) E_{b}^{2}}}{n X_{b}}=\frac{E_{b}}{X_{b}} . \\
& =\frac{E_{b}}{\Omega_{b} L}
\end{aligned}
$$

The limiting rms current magnitude in Eq. (18) is called the "characteristic current" [1]. Note that the characteristic current depends only on motor parameters $\left(E_{b}, \Omega_{b}, L\right)$ and is independent of motor load and dc supply voltage. If we require that the limit in Eq. (18) be less than, or equal to, the rated current, $I_{R}$, then we have an inductance requirement that yields an infinite CPSR, which is

$$
L_{\infty}=\frac{E_{b}}{\Omega_{b} I_{R}} .
$$

Any PMSM having an inductance with the value in Eq. (19) or higher will have an unlimited CPSR. Be reminded that winding resistance and rotational losses have been neglected in this development.

For a finite CPSR requirement, the inequality in Eq. (17) at relative speed $n$ equal to the CPSR yields a minimum requirement on the motor inductance,

$$
L_{\min }=\frac{\sqrt{V_{\max }^{2}+C P S R(C P S R-2) E_{b}^{2}}}{C P S R \Omega_{b} I_{R}} .
$$

And when $V_{\max }$ is determined from Eq. (7) and substituted into Eq. (17) the equivalent requirement is

$$
L_{\text {min }}=\sqrt{\frac{C P S R-1}{C P S R+1}} * \frac{E_{b}}{\Omega_{b} I_{R}}=\sqrt{\frac{C P S R-1}{C P S R+1}} * L_{\infty} .
$$


This expression shows that even for a modest finite CPSR, such as 4:1, the minimum inductance is $0.77 L_{\infty}$, which is a significant fraction of inductance for infinite CPSR.

The CPSR performance of a PMSM with a finite CPSR is shown conceptually in Fig. 3. In summary, the key parameter in determining the CPSR capability of the sinusoidal back-emf PMSM when driven by CPA is the motor inductance.

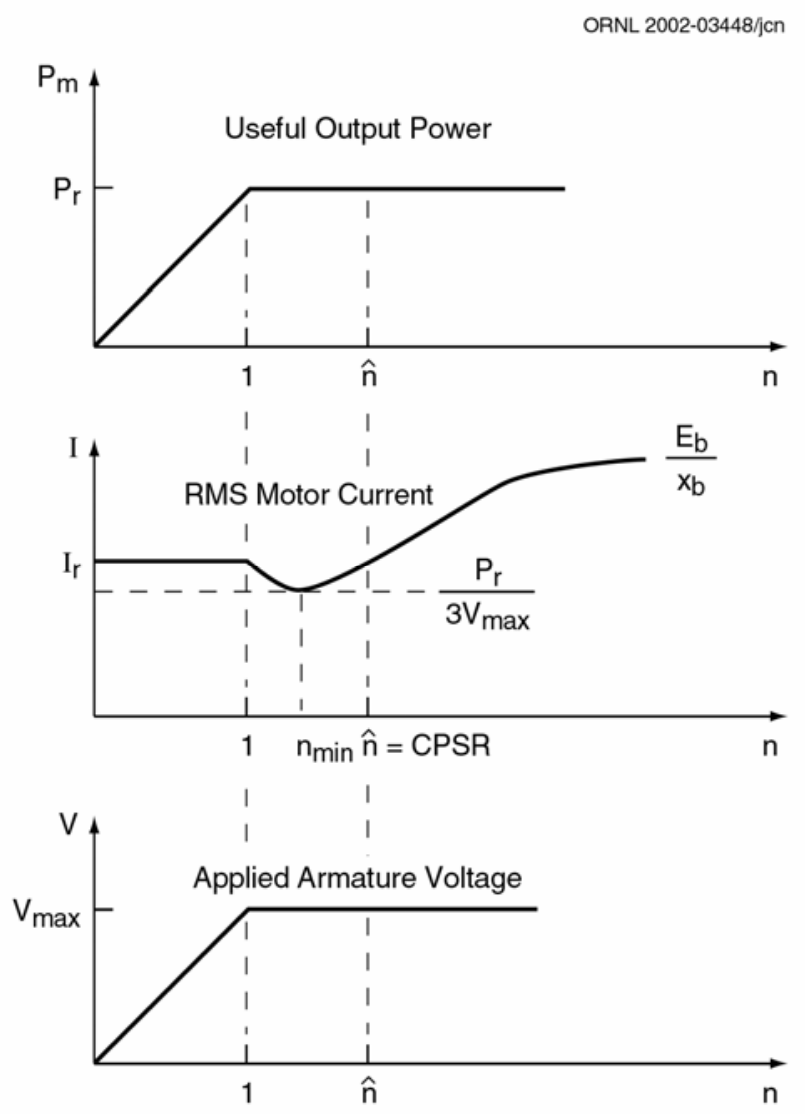

Fig. 3. Constant power performance of the PMSM driven by sinusoidal PWM.

To illustrate the use of the various formulas, the design parameters of the Deere 1 and Deere 2 motors from Table 1 are applied to Eqs. (4), (7), (14), (19), and (21) and presented in Table 2. 
Table 2. Inductance requirements for Deere 1 and Deere 2

\begin{tabular}{|l|l|l|}
\hline \multicolumn{1}{|c|}{ Parameter } & \multicolumn{1}{|c|}{ Deere 1 } & \multicolumn{1}{c|}{ Deere 2 } \\
\hline $\operatorname{Pr}$ & $60 \mathrm{~kW}$ & $60 \mathrm{~kW}$ \\
\hline$\Omega_{b}$ & $754 \mathrm{elec} \mathrm{rad} / \mathrm{sec}$ & $628.3 \mathrm{elec} \mathrm{rad} / \mathrm{sec}$ \\
\hline $\mathrm{Eb}$ & $63.63 \mathrm{Vrms}$ & $94 \mathrm{Vrms}$ \\
\hline $\mathrm{Ir}$ & $314.3 \mathrm{Arms}$ & $212.8 \mathrm{Arms}$ \\
\hline & & $703 \mu \mathrm{H}$ \\
\hline$L_{\infty}$ & $269 \mu \mathrm{H}$ & $636 \mu \mathrm{H}$ \\
\hline$L_{\min }($ for CPSR $=10)$ & $243 \mu \mathrm{H}$ & \\
\hline & & $400 \mu \mathrm{H} / 0.2513 \Omega$ \\
\hline Actual L/ $X_{b}$ & $290 \mu \mathrm{H} / 0.2187 \Omega$ & $374 \mathrm{~A}$ \\
\hline Characteristic current $\left(E_{b} / X_{b}\right)$ & $291 \mathrm{~A}$ & \\
\hline & & $108.1 \mathrm{Vrms} / 113.7 \mathrm{Vrms}{ }^{*}$ \\
\hline$V_{\max }$ & $93.66 \mathrm{Vrms} / 96.92 \mathrm{Vrms}{ }^{*}$ & $240.2 \mathrm{~V} / 252.7 \mathrm{~V}$ \\
\hline$V_{d c}$ & $208 \mathrm{~V} / 215.3 \mathrm{~V}$ & $121.3 \mathrm{~kW} / 114.3 \mathrm{~kW}^{* *}$ \\
\hline$P_{\max }$ & $81.7 \mathrm{~kW} / 80.6 \mathrm{~kW}^{* *}$ & \\
\hline & & $1.96{ }^{* * *}$ \\
\hline $\begin{array}{l}\text { CPSR } \\
(\text { when driven by CPA) }\end{array}$ & $\infty$ & \\
\hline
\end{tabular}

*The second value of $V_{\max }$ corrects for the winding resistance, i.e. $V_{\max }$ is computed as

$$
V_{\max }=\sqrt{\left(E_{b}+I_{R} R\right)^{2}+\left(\Omega_{b} L I_{R}\right)^{2}} .
$$

${ }^{* *}$ With winding resistance included,

$$
P_{\max }=\frac{3\left[V_{\max } E_{b}-E_{b}^{2} \cos \left(\tan ^{-1}\left(\frac{X_{b}}{R}\right)\right)\right]}{\sqrt{R^{2}+X_{b}^{2}}} .
$$

${ }^{* * *}$ When the actual inductance $L$ is less than $L_{\text {min }}$, the CPSR can be computed from Eq. (21) as

$$
C P S R=\frac{1+\left(\frac{L}{L_{\infty}}\right)^{2}}{1-\left(\frac{L}{L_{\infty}}\right)^{2}} .
$$

The results in Table 2 show that Deere 1 has sufficient inductance to meet the 10:1 CPSR requirement using CPA. Deere 2, however, cannot meet the 10:1 using CPA. DMIC will be required if Deere 2 is to be driven over a 10:1 CPSR.

In the next section, the analysis of the PMSM driven by DMIC is discussed. 


\section{ANALYSIS OF THE PMSM WHEN DRIVEN BY DMIC}

The previous section contained a discussion of the PMSM when driven by CPA. The focus in that section was on the relationship between CPSR and motor inductance. Although the DMIC was originally intended for motors with low inductance, it has recently been shown to have the potential for significant loss reduction for PMSMs with large inductance. To make this latter point, an abbreviated treatment of the PMSM is given below that slightly overlaps the previous discussion in Section 2. The mechanism through which the DMIC is able to achieve an infinite CPSR, even though the motor inductance may be small, will be made clear within the discussion.

A recent paper [2] used a fundamental-frequency model to analyze the performance of the sinusoidal back-emf PMSM driven in constant power mode by DMIC. The inverter includes a common three-phase VSI supplemented with an alternating current (ac) voltage controller between the inverter output and the motor. The ac voltage controller consists of three pairs of anti-parallel SCRs as shown in Fig. 4.

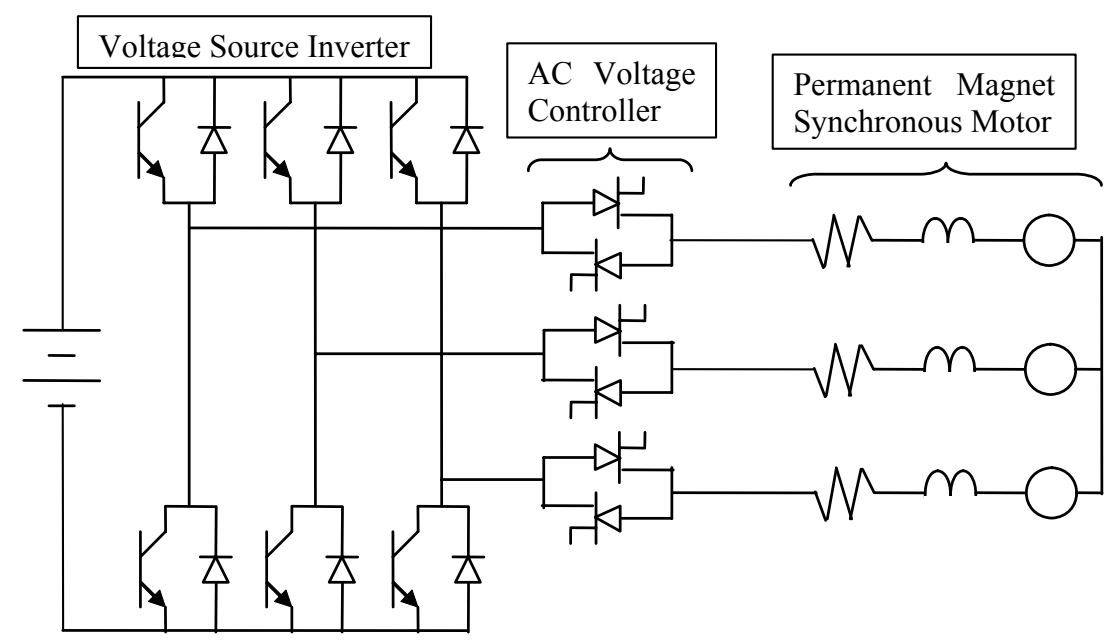

Fig. 4. DMIC inverter topology.

Each SCR pair is a full ac switch. In steady state, the fundamental-frequency components of the voltage across and current through the switch are $90^{\circ}$ out of phase reflecting the lossless behavior of the switch and giving rise to an "equivalent-reactance" interpretation of the SCRs. On a per-phase basis, a fundamental-frequency phasor model has the form shown in Fig. 5 with winding resistance and rotational losses neglected. In the figure, the parameter $X_{\text {thy }}$ is the equivalent reactance of an SCR pair. 


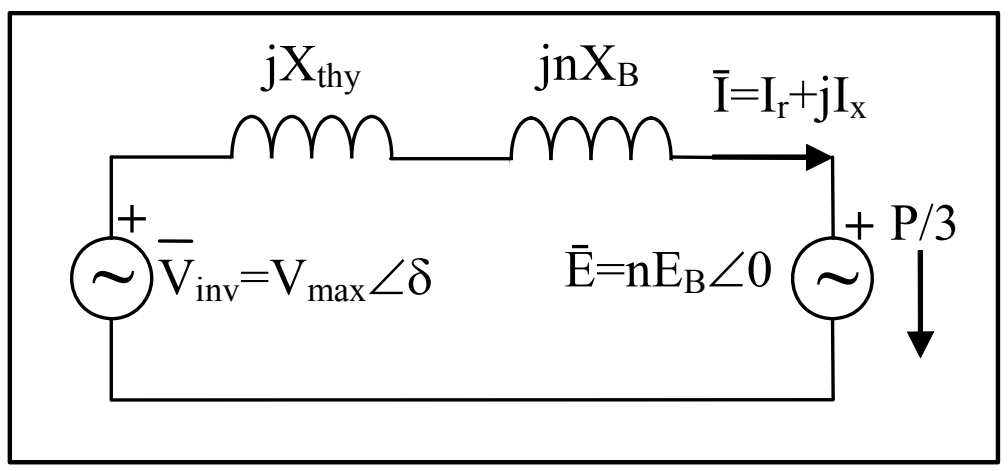

Fig. 5. Per-phase fundamental-frequency phasor model for constant power mode.

As noted in Ref. [2], the equivalent reactance of the ac switch is not constant but varies with the firing angle of the SCRs. The firing angle of the SCRs also controls the developed power of the motor. Since the equivalent reactance of the switch varies with the developed power, one cannot infer that the equivalent-reactance interpretation can be extended to a fixed equivalent inductance that is in series with the motor winding. Note that the total reactance presented to the inverter is the sum of the thyristor reactance and the motor reactance, $X_{\text {thy }}+n X_{b}$. Thus, no matter how small the machine reactance may happen to be, the thyristor reactance can be adjusted through firing angle control to make the motor behave as though it were a high-reactance machine. This is why the DMIC achieves an infinite CPSR even when the motor inductance is less, even substantially less, than the minimum required to be driven by CPA.

The discussion in this section is based on Ref. [2] and has two main objectives. The first is to show that the SCRs in the DMIC have greater value than simply extending the CPSR. Specifically it is shown that during constant-power operation they allow the rms motor-current magnitude to be minimized for any given power level. Thus, the DMIC enables "dual modes" of optimal control. Above base speed, the DMIC allows "maximum watts per rms amp" control during constant-power operation. Below base speed, the SCRs do not interfere in the inverter voltage magnitude control that allows "maximum $\mathrm{Nm}$ per rms amp" during constant torque operation. The second objective is to show that the current minimization capability enabled by the SCRs in the DMIC inverter can result in substantially lower motor current than a common VSI drive employing CPA even when the motor inductance is high. It is shown that the minimum current magnitude achieved with the DMIC is independent of speed and proportional to developed power. For a high-inductance motor driven by a VSI using CPA, the current magnitude is shown to be speed dependent but virtually independent of developed power level. At high speed, the reduction in motor-current magnitude is at least 0.7071 with the DMIC relative to the same motor driven by a VSI. Significant reduction in motor current reduces not only copper losses but also losses in the VSI. An economic evaluation of the DMIC must look past the added first cost and additional losses due to the SCRs and consider the total value of loss reduction in the motor and the inverter over the life of the drive.

The fact that high-machine inductance, or the addition of supplemental-series inductance, can increase CPSR is not new as noted in previous works [3,4,5]. Removing the SCRs from Fig. 4 results in CPA. To contrast the performance of CPA and DMIC, we first consider the performance of a high-inductance PMSM driven by CPA in Section 3.1 below. In Section 3.2, 
we show the current minimization made possible by the DMIC. The performance of CPA and DMIC are summarized in a single graph plotting normalized rms current versus normalized developed power for relative speeds above base speed.

\subsection{HIGH-INDUCTANCE PMSM DRIVEN BY CPA}

Assuming that the thyristors are removed from the inverter of Fig. 4, the fundamental-frequency model of Fig. 5 has $X_{\text {thy }}=0$ for all operating conditions. The model then represents a PMSM driven by CPA.

The discussion of the CPA driven PMSM in Section 2 focused on the relationship between the motor inductance and CPSR. In this section, it is assumed that the inductance is sufficiently large to meet a wide CPSR requirement and the focus is on the dependence, or lack thereof, of rms motor-current magnitude on speed, developed power, and available dc supply voltage.

From Section 2, when operating above base speed, the rms fundamental-frequency voltage applied by the inverter is

$$
V=V_{\max }=\frac{\sqrt{2} V_{d c}}{\pi}
$$

The inverter-lead angle depends on the dc supply voltage and the developed power and is found from Eq. (13) to be

$$
\delta=\sin ^{-1}\left(\frac{X_{b} P}{3 V_{\max } E_{b}}\right),
$$

and from Eq. (11) the resulting rms motor current at speed, $n$, is

$$
I=\frac{\sqrt{V_{\max }^{2}-2 n V_{\max } E_{b} \cos \delta+n^{2} E_{b}^{2}}}{n X_{b}} .
$$

Note that at any finite speed the rms current depends, at least to some degree, on dc supply voltage through the dependence on $V_{\max }$, on the developed power through the dependence on $\delta$, and on motor parameters, $E_{b}$ and $X_{b}$. However, for high speed the rms current approaches the "characteristic current" given by

$$
\lim _{n \rightarrow \infty} I=\frac{E_{b}}{X_{b}}=\frac{E_{b}}{\Omega_{b} L} .
$$

The characteristic current depends only on motor parameters. When the inductance is sufficiently large, the characteristic current is less than the rated motor current, and this is what 
enables the CPA driven PMSM to operate with an infinite CPSR. There are, however, two potential drawbacks for wide CPSR drives controlled by CPA.

The first drawback is that at sufficiently high speed, the rms motor current approaches the characteristic current which is independent of load, $P$. This means that the motor current is almost the same at no load as it is at full load. Consequently, the CPA drive cannot provide optimum "watts per amp" control at high speed and the efficiency may be poor when the load varies substantially at high speed.

One should expect that, if additional dc supply voltage were provided beyond the minimum necessary to produce rated torque at base speed, the result should be reduced-motor current; however, at high speed the motor current approaches the characteristic current which is independent of the dc supply voltage. Thus, the second drawback is that increases in dc supply voltage beyond the minimum required to support base-speed conditions are not effective in enhancing the efficiency of the wide CPSR drive at high speed.

If the motor inductance is the value given in Eq. (19) corresponding to an infinite CPSR, it follows from Eqs. (7), (9), (14), and (13) that

$$
\begin{aligned}
V_{\text {max }} & =E_{b} \sqrt{2} \\
P_{\text {max }} & =P_{R} \sqrt{2} \\
\sin \delta & =\frac{P}{P_{R} \sqrt{2}} \\
\cos \delta & =\sqrt{1-\sin ^{2} \delta}
\end{aligned} .
$$

Then the rms motor current from Eq. (27) is given by

$$
I=I_{R} \sqrt{\frac{n^{2}-2 n \sqrt{2-\left(\frac{P}{P_{R}}\right)^{2}}+2}{n^{2}}} .
$$

A plot of per unit rms current, $I / I_{R}$, versus per unit developed power, $P / P_{R}$, is shown in Fig. 6 for relative speeds of $2,4,6,8,10,20$, and $\infty$. The figure shows that when the motor inductance is sufficiently large, $L=L_{\infty}$ in this case, any developed power up to the rated power can be achieved without exceeding the rms current rating of the motor. Note that even though the inductance is large, the motor-current magnitude increases with speed. The "flatness" of the current versus power curves indicates that the copper losses in the motor are virtually independent of the developed power for the CPA strategy. Efficiency may be poor when highspeed operating conditions require a developed power less than the rated power. A method that can make the rms current proportional to output power can obviously reduce motor-copper losses as well as the losses in the VSI inverter. In the next section, it is shown that the DMIC enables motor-current-magnitude minimization or, equivalently, optimal watt per rms amp control. 


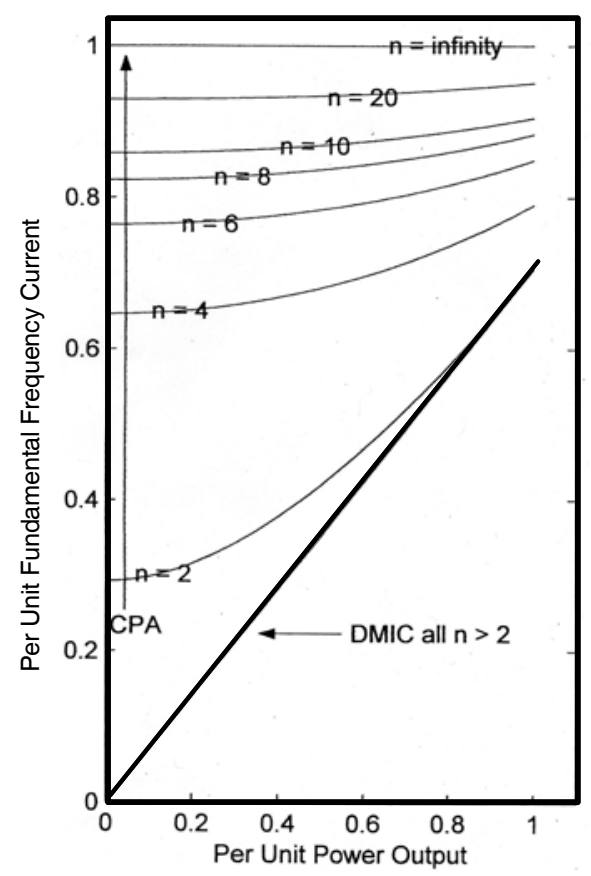

Fig. 6. Constant-power operation of a PMSM motor comparing CPA control with DMIC.

\subsection{PMSM CURRENT-MAGNITUDE MINIMIZATION WHEN DRIVEN BY DMIC}

Given that a PMSM with an inductance as large as that in Eq. (19) can achieve an infinite CPSR when driven by a VSI, is there any benefit to driving the same motor using the DMIC? To address this issue, we use the fundamental-frequency model of Fig. 5. Let the motor-current phasor be written in the rectangular form

$$
\begin{aligned}
& \bar{I}=I_{r}+j I_{x} \\
& I=|\bar{I}|=\sqrt{I_{r}^{2}+I_{x}^{2}},
\end{aligned}
$$

where $I_{r}$ is the component of motor current in phase with the back-emf and $I_{x}$ is the component in phase quadrature with the back-emf. The question is, can the equivalent reactance of the SCRs, $X_{\text {thy }}$, be chosen so that desired power, $P$, is developed while the magnitude of the motor current, $I$, is minimized? If so, the DMIC provides optimal "watts per rms amp" control. This is a distinctly different form of high-speed control than CPA where the high-speed rms current is the same at no load as at full load.

Observe that the value of the in-phase component of motor current results in the developed power 


$$
\begin{aligned}
& P=3 I_{r} n E_{B} \\
& I_{r}=\frac{P}{3 n E_{b}} .
\end{aligned}
$$

Since $I_{r}$ is fixed per Eq. (32), the minimization of current magnitude, $I$, is the same as minimizing the magnitude of the phase-quadrature component, $I_{x}$. Let

$$
X=X_{\text {thy }}+n X_{b},
$$

so that

$$
\begin{aligned}
\bar{I} & =\frac{\bar{V}_{i n v}-\bar{E}}{j X}=\frac{V_{\max }}{X} \sin \delta+j\left[\frac{n E_{b}}{X}-\frac{V_{\max }}{X} \cos \delta\right] . \\
& =I_{r}+j I_{x}
\end{aligned}
$$

Recognizing that

$$
\begin{aligned}
& 3 \frac{V_{\max } n E_{b}}{X} \sin \delta=P \\
& \cos \delta=\sqrt{1-\left(\frac{X P}{3 n E_{b} V_{\max }}\right)^{2}},
\end{aligned}
$$

we find that the phase-quadrature component of motor current becomes

$$
I_{x}=\frac{n E_{b}-V_{\max } \sqrt{1-\left(\frac{X P}{3 n E_{b} V_{\max }}\right)^{2}}}{X} .
$$

Differentiating $I_{x}$ with respect to $X$, setting the derivative equal to zero, and solving for the current minimizing reactance, $X^{*}$, yields

$$
X^{*}=\frac{3 V_{\max } \sqrt{n^{2} E_{b}^{2}-V_{\max }^{2}}}{P}=X_{\text {thy }}^{*}+n X_{b}
$$

or 


$$
\begin{aligned}
X_{\text {thy }}^{*} & =\frac{3 V_{\max } \sqrt{n^{2} E_{b}^{2}-V_{\max }^{2}}}{P}-n X_{b} \\
& =n\left(\frac{\left.3 V_{\max } \sqrt{E_{b}^{2}-\frac{V_{\text {max }}^{2}}{n^{2}}}-X_{b}\right)}{P}\right) \\
\mathrm{I}_{\mathrm{x}}^{*} & \left.=\frac{\mathrm{P}}{3 \mathrm{~V}_{\max }} \sqrt{1-\left(\frac{\mathrm{V}_{\max }}{\mathrm{nE}}\right)^{2}}\right)^{2} \\
I_{r}^{*} & =\frac{P}{3 V_{\text {max }}} \frac{V_{\text {max }}}{n E_{b}}
\end{aligned}
$$

Equation (38) for $\mathrm{X}^{*}$ thy clearly shows that no fixed inductance can provide the same effect as the thyristors in the DMIC inverter. Specifically, observe that the reactance doesn't vary exactly linearly with speed due to the $V_{\max }^{2} / n^{2}$ inside the brackets in the second expression of Eq. (38), and that the reactance is inversely proportional to developed power, $P$. Thus a fixed inductance can only achieve the same performance as DMIC at a single speed and power condition.

The antiparallel SCR pair cannot have a negative reactance, the minimum value of $X_{\text {thy }}$ is zero. A value of $X_{\text {thy }}$ equal to zero would mean that the thyristors were being fired such that they function as a short circuit. The value of $n$ in Eq. (38) must be sufficiently large that $X_{\text {thy }}$ has a non-negative value. For any given load power, $P$, the minimum value of $n$, which occurs when the bracketed term in Eq. (38) is zero, is

$$
n_{\min }=\frac{V_{\max }}{E_{b} \cos \delta}=\frac{V_{\max }}{E_{b} \cos \left(\sin ^{-1}\left(\frac{P}{P_{\max }}\right)\right)},
$$

where $P_{\max }$ is the maximum power-conversation capability of the motor as given by Eq. (14).

With the optimal value of thyristor reactance, the minimum rms motor current is

$$
I^{*}=\frac{P}{3 V_{\max }}=\frac{P}{3 \sqrt{E_{b}^{2}+\left(X_{b} I_{R}\right)^{2}}}
$$

Note that Eq. (40) is independent of speed and directly proportional to developed power. As the speed increases, the reactive-voltage phasor across the equivalent inductor remains perpendicular to the supply-voltage phasor. It also follows that the motor-current phasor is in phase with the inverter-voltage phasor, such that the inverter operates at unity power factor. Also note for any 
load level, $P$, an increase in dc supply voltage, which increases $V_{\max }$, will decrease the rms motor current since $I$ varies as $V_{\max }^{-1}$. Thus, high-speed operation with the DMIC can substantially benefit from extra supply voltage through a reduction in motor and inverter losses. This feature of DMIC is distinctly different from CPA where rms motor current at high speed is independent of dc supply voltage.

Equation (40) applies whether the inductance is large or small. In cases where the motor is to provide substantial regenerative braking for the vehicle, Eq. (14) shows that the inductance will necessarily need to be small such that $P_{\max }$ is substantially larger than the rated power, $P_{R}$. In such cases, the CPA method would not yield adequate CPSR and DMIC would be essential. In this discussion, we want to show that DMIC has substantial potential benefit even when the motor inductance is large.

Letting the motor inductance be $L_{\infty}$ from Eq. (19) and using the corresponding $V_{\max }$ from Eq. (29), the optimal rms fundamental-frequency motor-current magnitude is,

$$
I^{*}=\frac{P}{\sqrt{2} P_{R}} I_{R} .
$$

Note that Eq. (41) does not depend on speed. However, for the case under discussion, Eq. (39) requires that the relative speed be greater than or equal to two in order for Eq. (41) to be valid. A plot of per-unit motor current, $I^{*} / I_{R}$, versus per-unit developed power, $P / P_{R}$, is shown in Fig. 6 where the single curve shown is valid for any speed at and above $n=2$. For convenience, the same set of axes was used to display the current versus power data for the same inductance level when the motor is driven by CPA.

Although a motor with inductance, $L_{\infty}$, is considered well suited for high CPSR applications with CPA, the curves in Fig. 6 show that for relative speeds of two or greater the motor current is always less for the same motor driven by DMIC and for most operating conditions the current is substantially less with DMIC. Reductions in motor current will result in reduced motor-copper losses, which vary with the square of rms current and reduce the losses in the inverter components, which vary with the first power of the rms motor current. For example, at high speed and rated power, the rms motor current with the DMIC is 0.7071 that of the CPA driven motor. The motor losses are reduced by a factor of $50 \%$ while the inverter losses are decreased by $29.3 \%$. At high speed and $70 \%$ of full power, the rms current with the DMIC is $49.5 \%$ that of the VSI driven motor. The motor-copper losses are reduced by $75.5 \%$ while the inverter losses are reduced by $50.5 \%$. Depending on the application, particularly the speed/load profile, these loss reductions may more than compensate for the losses introduced by the addition of the SCRs and the value of the energy recovery over the life of the drive may more than offset the initial first cost of the SCRs.

The Deere 1 and Deere 2 designs are examined in the next section with respect to the currentmagnitude control properties with CPA and DMIC. 


\subsection{COMPARISON OF DEERE 1 MOTOR-CURRENT MAGNITUDE WITH CPA AND DMIC}

The analysis in Sections 2, 3.1, and 3.2 can be easily extended to include winding resistance and used to investigate the effects of using the minimum dc supply voltage or using a higher value. The minimum dc supply voltage required to supply a specified base speed, including the effects of winding resistance is given by

$$
V_{d c-\min }=\frac{\pi}{\sqrt{2}} \sqrt{\left(E_{b}+R I_{R}\right)^{2}+\left(X_{b} I_{R}\right)^{2}}
$$

For Deere 1 with specified base speed of $600 \mathrm{rpm}$, this voltage is $215.3 \mathrm{~V}$ as shown in Table 2, while for Deere 2 the minimum supply voltage is $252.7 \mathrm{~V}$. A higher voltage can be used but the "true base speed" is extended beyond $n=1$. For a given dc supply larger than that in Eq. (42), the true base speed can be found by solving

$$
\frac{\sqrt{2} V_{d c}}{\pi}=V_{\max }=\sqrt{\left(n_{b t} E_{b}+I_{R} R\right)^{2}+\left(n_{b t} X_{b} I_{R}\right)^{2}}
$$

for $n$ or equivalently solving

$$
\left(E_{b}^{2}+X_{b}^{2} I_{R}^{2}\right) n_{b t}^{2}+\left(2 E_{b} I_{R} R\right) n_{b t}+\left(I_{R}^{2} R^{2}-2 \frac{V_{d c}^{2}}{\pi^{2}}\right)=0
$$

If $V_{d c}$ is $350 \mathrm{~V}$, then the actual base speed for Deere 1 would be $989 \mathrm{rpm}$ rather than $600 \mathrm{rpm}$; while the true base speed for Deere 2 would be $843 \mathrm{rpm}$. The expression in Eq. (5), which neglects winding resistance, provides reasonable approximations to the solution to Eq. (44).

Figure 7 shows plots of rms fundamental-frequency motor current versus useful output power for the Deere 1 motor when driven by CPA and by DMIC. The plots were made for two dc supply voltages, $215.3 \mathrm{~V}$ and $350 \mathrm{~V}$. For the $215.3 \mathrm{~V}$ case a single curve represents all speeds of $\mathrm{n}=2.16$, which corresponds to any rpm greater than $1300 \mathrm{rpm}$. This speed was obtained by solving Eq. (39) when the load $P$ is $60 \mathrm{~kW}$ and $V_{\max }$ is 96.92 Vrms corresponding to a dc supply voltage of $215.3 \mathrm{~V}$. For the CPA, the curves are dependent on speed and separate plots are given for $1300,1800,3600$, and $6000 \mathrm{rpm}$ and infinite speed. The shape of the curves for the CPA cases is very similar to the "generic" curves shown in Fig. 6. For the $350 \mathrm{Vdc}$ supply, there is again a single plot of Irms versus Pout for DMIC which covers all speeds of $n=2.73$ or greater, or equivalently $1636 \mathrm{rpm}$, which is the solution to Eq. (39) when the load $P$ is the rated power of $60 \mathrm{~kW}$ and $V_{\max }$ is $157.6 \mathrm{Vrms}$ corresponding to a dc supply of $350 \mathrm{~V}$. For the CPA, separate Irms versus Pout curves are drawn for 1636, 1800, 3600, and $6000 \mathrm{rpm}$ and infinite speed. Note that the DMIC driven cases always have a lower rms motor current than the companion CPA case. Comparison of the $215.3 \mathrm{~V}$ and $350 \mathrm{~V}$ cases shows that the DMIC takes advantage of the higher dc supply voltage through lower motor current at all speeds (above $1651 \mathrm{rpm}$ ) and at all load levels. 

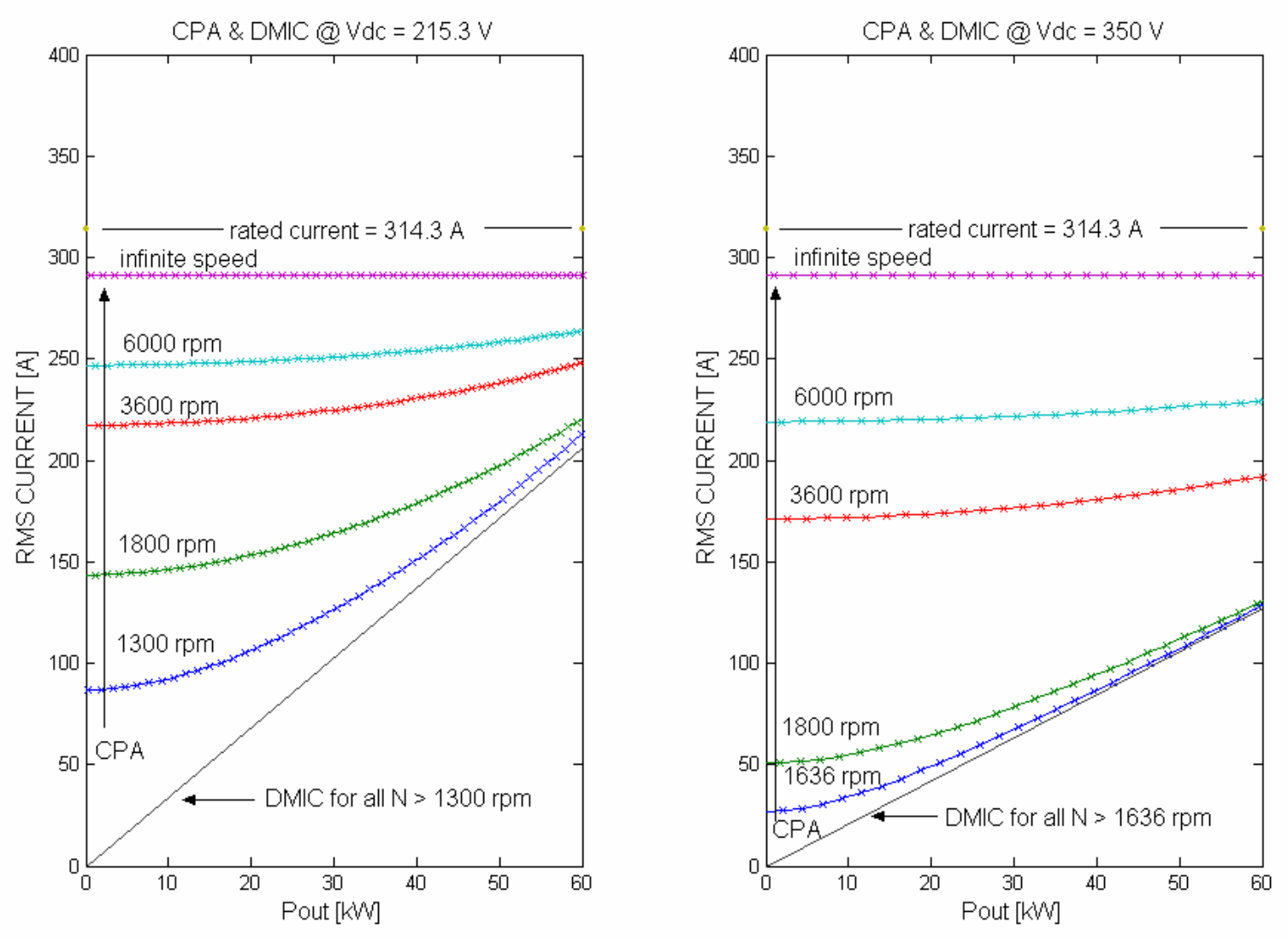

Fig. 7. RMS motor current vs. power output during high-speed operation of the Deere 1 motor with $215.3 \mathrm{~V}$ and $350 \mathrm{Vdc}$ supplies.

Figure 8 shows the high-speed current-magnitude control capability of CPA and DMIC for the Deere 2 design for dc supply voltages of $252.7 \mathrm{~V}$, which is the minimum required, and for $350 \mathrm{~V}$. As noted previously, the Deere 2 motor is low inductance because it falls below the value of $\mathrm{L}_{\min }$ required for a CPSR of 10; consequently it is and well suited for operation with CPA. Calculations in Table 2 show that the CPSR of Deere 2 is only 1.96 when driven by CPA from a 252.7 Vdc supply. The robustness of the DMIC can be seen by comparing Figs. 6 and 7, which shows that the DMIC is capable of providing excellent current-magnitude control despite substantial deviation in motor inductance.

Note that the performance of the Deere 1 and Deere 2 designs is almost the same with DMIC when the $350 \mathrm{Vdc}$ supply is used. The difference lies in the fact that the high-speed current asymptotic behavior in Fig. 7 is valid for speeds greater than $1636 \mathrm{rpm}$ for the high inductance Deere 1 while, for the low inductance Deere 2, the high-speed asymptote applies at and above $1047 \mathrm{rpm}$.

There would be an advantage to having the "high-speed" range begin at the lowest possible rpm. Once the true base speed is reached, the inverter switching becomes fundamental rate and the switching losses are decreased relative to the high frequency PWM used below base speed. 
Thus, the switching losses are reduced at lower rpm with the low inductance Deere 2 relative to the higher inductance Deere 1.
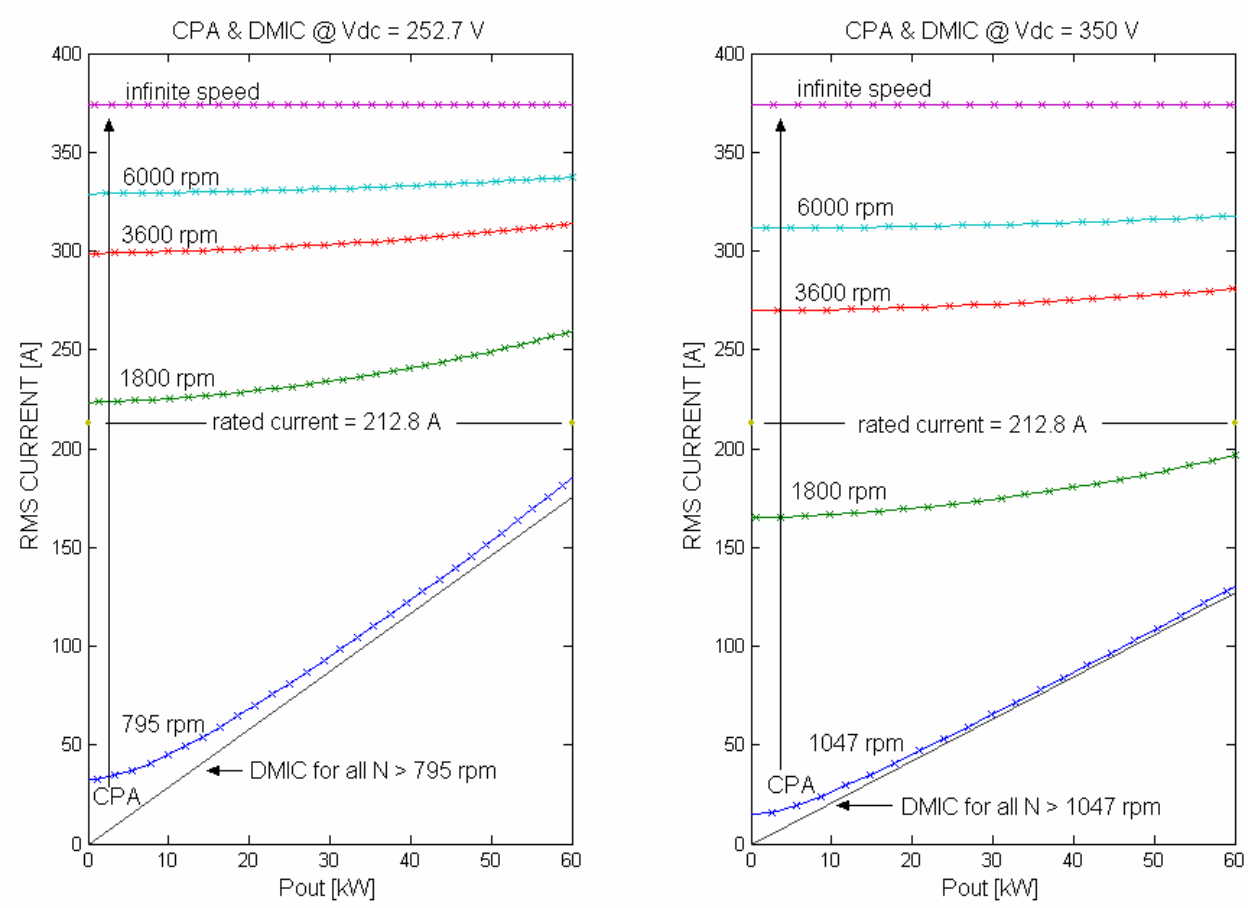

Fig. 8. RMS motor current vs. power output during high-speed operation of the Deere 2 motor with $252.7 \mathrm{~V}$ and $350 \mathrm{Vdc}$ supplies.

The results in this section highlight the key difference between CPA and DMIC with respect to motor-current-magnitude control during high-speed operation. At high speed, the rms motor current for the two different PMSM motor control methods approach

$$
\begin{gathered}
I_{C P A}=\frac{E_{b}}{X_{b}}=\frac{E_{b}}{\Omega_{b} L} \\
I_{D M I C}=\frac{P}{3 V_{\max }}=\frac{\pi P}{\sqrt{2} V_{d c}} .
\end{gathered}
$$

The motor current at high speed with CPA is the characteristic current which depends only on motor parameters. This has both positive and negative implications. On the positive side, if the motor inductance is sufficiently large, then the characteristic current is less than the rated current thereby enabling operation in a wide CPSR. On the negative side, two points can be made. First, the characteristic current is independent of load meaning that the efficiency can be poor under light load and variable load conditions at high speed. Second, since the characteristic current is independent of dc supply voltage, providing a dc supply voltage beyond that necessary to support rated torque at base speed cannot reduce the motor current at high speed. The motor current at high speed with DMIC is proportional to load power such that good efficiency can be maintained under light load and variable load conditions. Also, the high-speed current is independent of machine inductance. Whether the inductance is large or small, the high-speed 
current will be same. The difference in behavior between a large or small motor inductance will lie in the firing of the thyristors which will always adjust the total inductance to minimize the rms amps per developed watt. Finally with the DMIC, the high-speed current is inversely proportional to supply voltage. Therefore, significant reduction in motor-current magnitude and attendant reductions in motor and inverter losses can be achieved by providing supply voltage in excess of that required to support the specified base-speed conditions.

Inverter losses are an important factor in overall drive efficiency. The next section discusses the calculation of inverter losses. 


\section{INVERTER LOSSES}

Losses in inverter components include

- Blocking losses

- Conduction losses

- Switching losses (transistors)

- Reverse-recovery losses (diodes and thyristors)

Blocking losses are very small relative to the other inverter-loss mechanisms and are neglected in this work. The remaining loss mechanisms are important and must have a proper accounting. The method used to model and calculate the various inverter loss types are discussed individually below.

\subsection{CONDUCTION LOSSES}

Figure 9 shows "equivalents" of a transistor and bypass diode and thyristor that can be useful in determining the conduction losses.
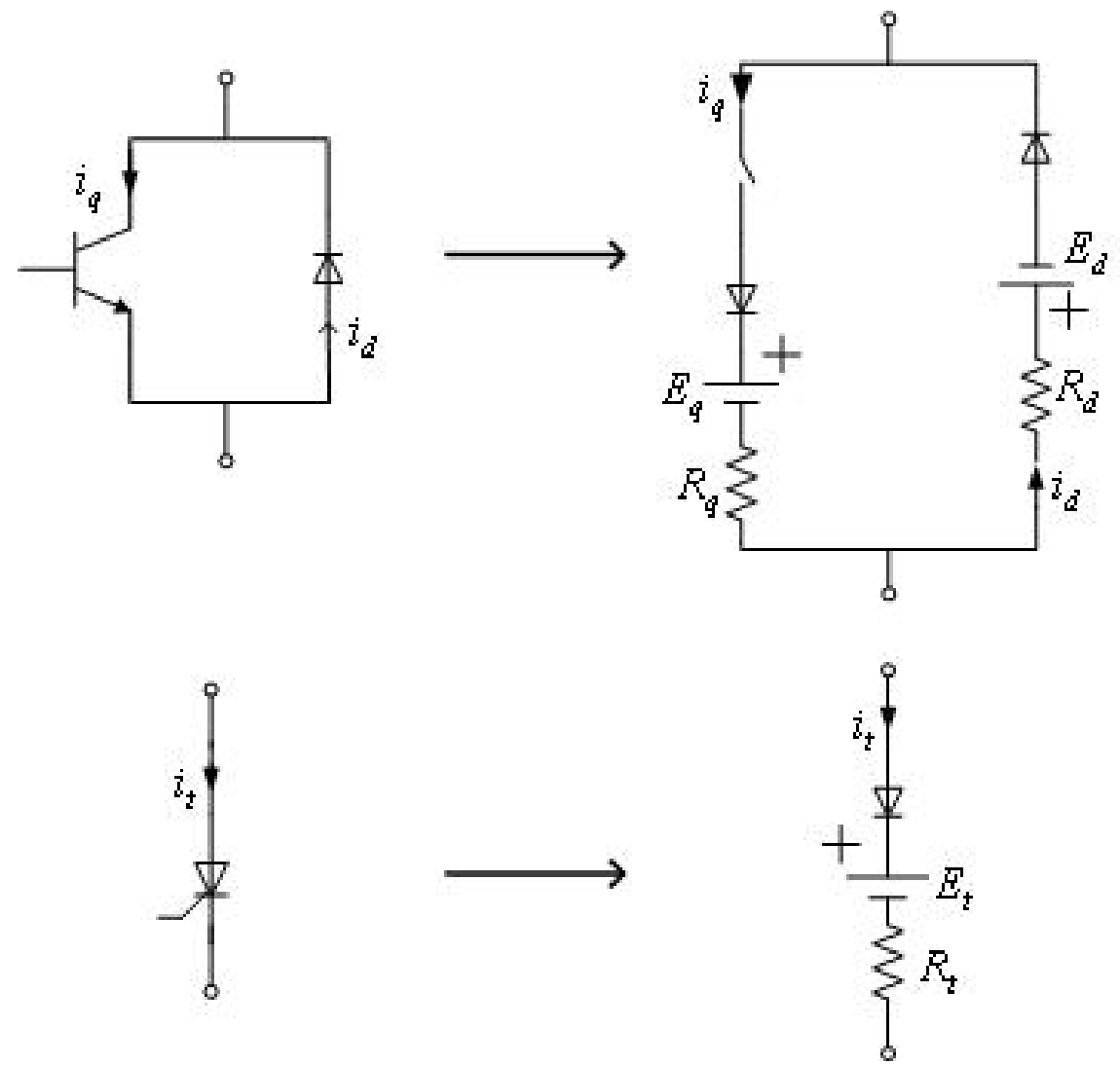

Fig. 9. Transistor with bypass diode and thyristor equivalents for determining conduction losses. 
The notation used in the figure is as follows:

$$
\begin{aligned}
& R_{q}=\text { transistor resistance } \\
& E_{q}=\text { transistor forward voltage drop } \\
& R_{d}=\text { diode resistance } \\
& E_{d}=\text { diode forward voltage drop } \\
& R_{t}=\text { thyristor resistance } \\
& E_{t}=\text { thyristor forward voltage drop }
\end{aligned}
$$

The conduction losses of the transistor, diode, and thyristor are computed as

$$
\begin{aligned}
P_{q-c} & =\text { transistor conduction losses } \\
& =I_{q-a v g} E_{q}+I_{q-r m s}^{2} R_{q} \\
P_{d-c} & =\text { diode conduction losses } \\
& =I_{d-a v g} E_{d}+I_{d-r m s}^{2} R_{d} \\
P_{t-c} & =\text { thyristor conduction losses } \\
& =I_{t-a v g} E_{t}+I_{t-r m s}^{2} R_{t}
\end{aligned}
$$

where

$$
\begin{aligned}
& I_{q-\text { avg }}=\text { average transistor current } \\
& I_{q-r m s}=\text { rms transistor current } \\
& I_{d-\text { avg }}=\text { average diode current } \\
& I_{d-r m s}=\text { rms diode current } \\
& I_{t-a v g}=\text { average thyristor current } \\
& I_{t-r m s}=\text { rms thyristor current }
\end{aligned} .
$$

The device parameters $\left(E_{q}, R_{q}, E_{d}, R_{d}, E_{t}, R_{t}\right)$ are generally contained on device-data sheets, or can be derived from device data. These parameters may be given in ranges of minimum, typical, and maximum and may be temperature/voltage sensitive. Thermal modeling is not incorporated in this work and all parameters will be determined at a single device temperature such as $125^{\circ} \mathrm{C}$. Voltage effects will be incorporated whenever possible and generally involve scaling parameters up or down based on dc supply voltage. The critical values needed to calculate the conduction losses are the average and rms currents through the transistors, diodes, and thyristors. Since PWM action is involved during low-speed motor operation, these currents are difficult to evaluate accurately without using time domain simulation of a detailed inverter model. While such a detailed simulation model is available, the engineering time to calculate inverter losses using such an approach would be prohibitive. An alternative approach uses the simplified fundamental-frequency models applied in Sections 2 and 3 to estimate the device currents 
needed to calculate conduction losses. These losses are then combined with switching and reverse-recovery loss calculations, which will be described subsequently.

Approximate values of the device average and rms currents can be obtained using the per-phase fundamental-frequency model shown in Fig. 10. The model applies for both CPA and DMIC, but $X_{\text {thy }}$ is zero for all operating conditions when using CPA.

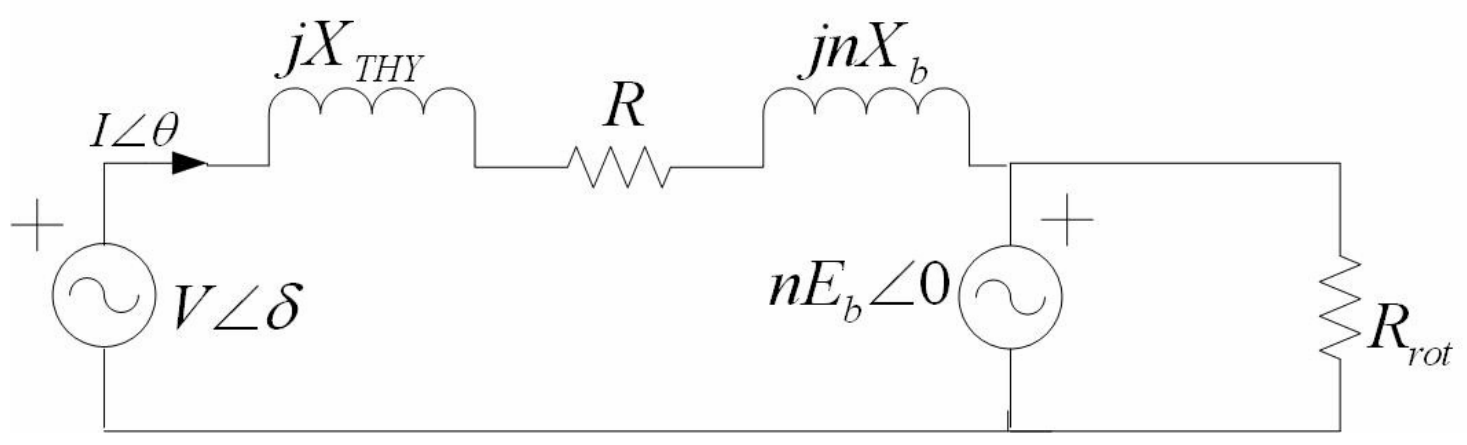

Fig. 10. Per-phase model used to calculate average and rms device currents.

The model of Fig. 10 explicitly represents motor copper and rotational losses since

$$
\begin{aligned}
& P_{c u}=3 I^{2} R \\
& P_{\text {rot }}=3 \frac{\left(n E_{b}\right)^{2}}{R_{r o t}} .
\end{aligned}
$$

In this study, the winding resistance is fixed for the Deere 1 and Deere 2 designs. No correction is attempted for temperature or skin effect. Similarly, the speed sensitive losses are fixed functions of speed, as shown in Table 1, and are not corrected for operating conditions such as current level or temperature. Inverter losses are not explicitly represented in the model of Fig. 10. The average and rms device currents required to compute conduction losses will be determined based on the rms motor current, $I$, and on the phase relationship between motorcurrent phasor, $\bar{I}$, and the inverter voltage and back-emf phasors, $\bar{V}$ and $\bar{E}$, respectively.

If the current and back-emf phasors are known, then combined with knowledge of the machine impedance at the given speed

$$
\bar{V}=\bar{E}+\bar{I}(R+j X)
$$

Let the motor back-emf be the phasor reference and let 


$$
\begin{aligned}
m_{a} & =\text { amplitude modulation index } \\
& =\frac{2 \sqrt{2} \mathrm{~V}}{V_{d c}} \\
\delta & =\text { inverter lead angle } \\
\theta & =\text { angle of motor current phasor }
\end{aligned}
$$

Due to the fact that the voltage-phasor magnitude, $V$, is limited by the dc supply voltage, the amplitude-modulation index lies in the range

$$
0 \leq m_{a} \leq \frac{4}{\pi}
$$

where $4 / \pi$ is the first term in the fundamental Fourier expansion of a square wave.

Approximate values of the average and rms device currents for a CPA drive can be calculated as

$$
\begin{aligned}
& I_{q-a v g}=\sqrt{2} I\left(\frac{1}{2 \pi}+\frac{m_{a} \cos (\delta-\theta)}{8}\right) \\
& I_{d-a v g}=\sqrt{2} I\left(\frac{1}{2 \pi}-\frac{m_{a} \cos (\delta-\theta)}{8}\right) \\
& I_{q-r m s}=\sqrt{2} I \sqrt{\frac{1}{8}+\frac{m_{a} \cos (\delta-\theta)}{3 \pi}}, \\
& I_{d-r m s}=\sqrt{2} I \sqrt{\frac{1}{8}-\frac{m_{a} \cos (\delta-\theta)}{3 \pi}}
\end{aligned}
$$

while the approximate values for a DMIC drive can be calculated from 


$$
\begin{aligned}
& \text { For } n<n_{\min }=\frac{V_{\text {max }}}{E_{b} \cos \delta}=\frac{V_{\text {max }}}{E_{b} \cos \left(\sin ^{-1}\left(\frac{P}{P_{\max }}\right)\right)} \\
& I_{q-\text { avg }}=\sqrt{2} I\left(\frac{1}{2 \pi}+\frac{m_{a} \cos (\delta-\theta)}{8}\right) \\
& I_{d-\text { avg }}=\sqrt{2} I\left(\frac{1}{2 \pi}-\frac{m_{a} \cos (\delta-\theta)}{8}\right) \\
& I_{t-\text { avg }}=\frac{\sqrt{2} I}{\pi} \\
& I_{q-\text { rms }}=\sqrt{2} I \sqrt{\frac{1}{8}+\frac{m_{a} \cos (\delta-\theta)}{3 \pi}} \\
& I_{d-\text { rms }}=\sqrt{2} I \sqrt{\frac{1}{8}-\frac{m_{a} \cos (\delta-\theta)}{3 \pi}} \\
& I_{t-\text { rms }}=\frac{I}{\sqrt{2}}
\end{aligned}
$$

For $n>n_{\min }$

$$
\begin{aligned}
& I_{q-a v g}=\frac{\sqrt{2} I}{\pi} \\
& I_{d-\text { avg }}=0 . \\
& I_{t-a v g}=\frac{\sqrt{2} I}{\pi} \\
& I_{q-\text { rms }}=\frac{I}{\sqrt{2}} \\
& I_{d-r m s}=0 \\
& I_{t-r m s}=\frac{I}{\sqrt{2}}
\end{aligned}
$$

These equations are adapted from the work described in Ref. [6]. The formulas apply for speed conditions above and below base speed. Above base speed the motor terminal voltage, $V$, is at the maximum value and the amplitude-modulation index is at its upper limit, $(4 / \pi)$. The expressions rely on the motor and inverter-component currents being dominated by their fundamental-frequency components which means that the effects of harmonic currents introduced by PWM and/or by six-step switching are neglected. 
To assess the accuracy of the above formulas two load conditions, one below and one above base speed are investigated using a detailed time domain switching model to calculate average and rms device currents, which are then compared with the approximate values given above. The Deere 1 design is used since it can be driven by either CPA or DMIC.

The first operating condition is one half of base speed, $(n=0.5)$ or $300 \mathrm{rpm}$, and $60 \%$ of rated torque $(578 \mathrm{Nm})$. The de supply voltage is assumed to be $340 \mathrm{~V}$. Rotational losses are neglected. In this case, the rms motor current is $60 \%$ of its rated value

$$
I=0.6 I_{R}=188.6 \mathrm{~A} .
$$

The motor current is in phase with the back-emf in order to maximize the torque per amp so that $\theta=0$. The applied fundamental-frequency phase voltage necessary to support this condition given by Eq. (49) is

$$
V\left\lfloor\underline{\delta}=n E_{b}+I\left\lfloor\underline{0}\left(R+j n X_{b}\right)=40.3172 \mid 30.7518^{\circ} .\right.\right.
$$

This result applies for both CPA and DMIC since the thyristors, which are fired so that $X_{\text {thy }}=0$, do not participate in the PWM control at low speed. Thus,

$$
\begin{aligned}
m_{a} & =\frac{2 \sqrt{2} \cdot 40.3172}{340}=0.3354 \\
\delta & =30.7518^{\circ} \\
\theta & =0^{\circ}
\end{aligned} .
$$

Applying the device current formulas, Eqs. (52) and (53)

$$
\begin{aligned}
I_{q-a v g} & =52.0 \mathrm{~A} \\
I_{d-a v g} & =32.8 \mathrm{~A} \\
I_{q-r m s} & =105.2 \mathrm{~A} \\
I_{d-r m s} & =81.9 \mathrm{~A} \\
I_{t-a v g} & =84.9 \mathrm{~A} \\
I_{t-r m s} & =133.4 \mathrm{~A}
\end{aligned}
$$

A detailed PSPICE time-domain simulator, which represents inverter components as ideal switches but includes PWM switching operations, was used to calculate the same values of current. Instantaneous and rms motor current and instantaneous, average, and rms values of transistor, bypass diode, and thyristor currents are shown in Fig. 11 for a PWM carrier frequency of $5940 \mathrm{~Hz}$ (frequency modulation index of 99). Figure 12 is the detailed simulation results for a carrier frequency of $900 \mathrm{~Hz}$ (frequency modulation index of 15). The simulated quantities and theoretical values are compared in Table 3. 


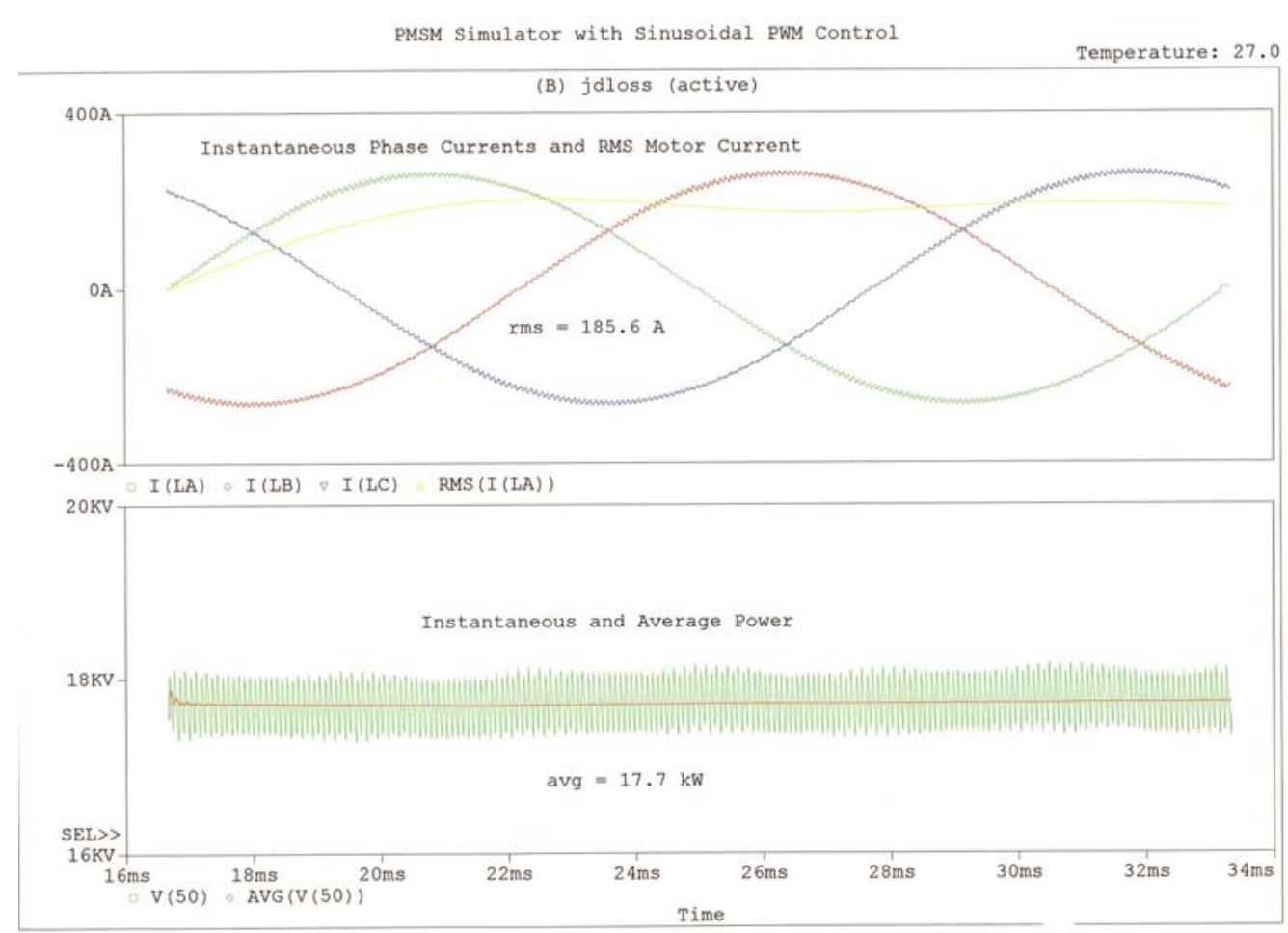

(a) Motor currents and power.

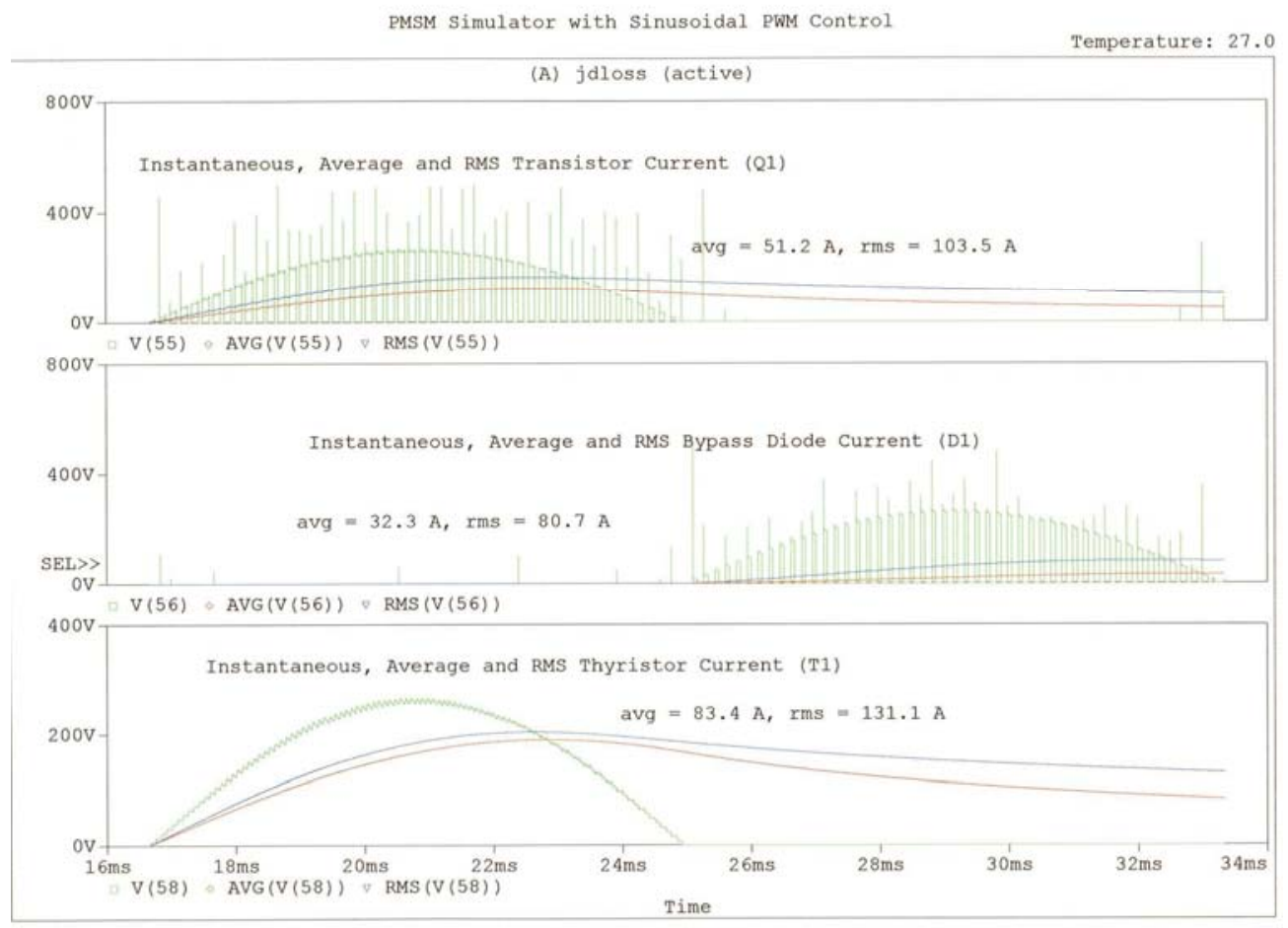

(b) Transistor, bypass diode, and thyristor currents.

Fig. 11. Time-domain simulation at $300 \mathrm{rpm}, 60 \%$ rated torque with $340 \mathrm{Vdc}$ supply, and a carrier frequency of $5940 \mathrm{~Hz}$. 


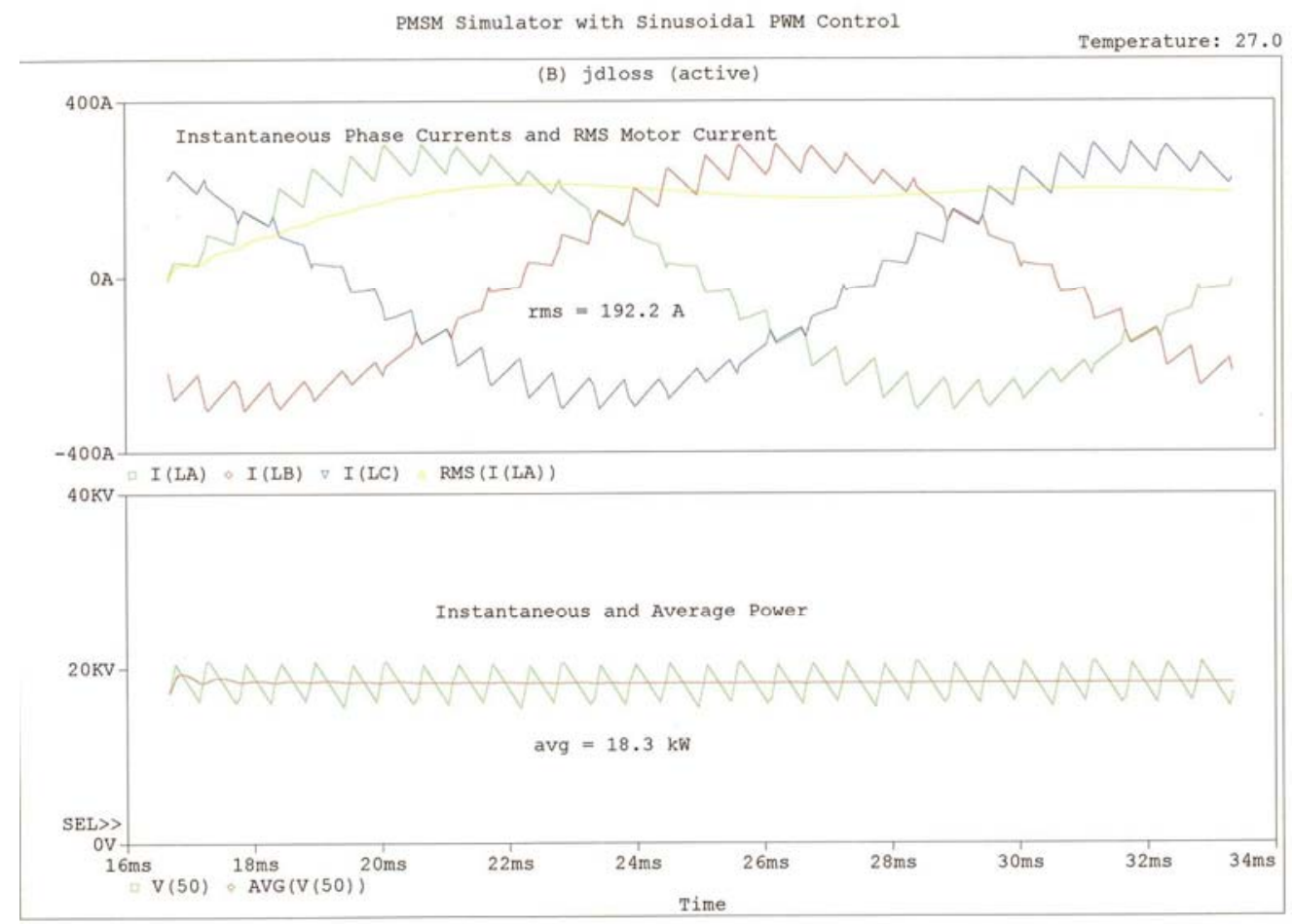

(a) Motor currents and power.

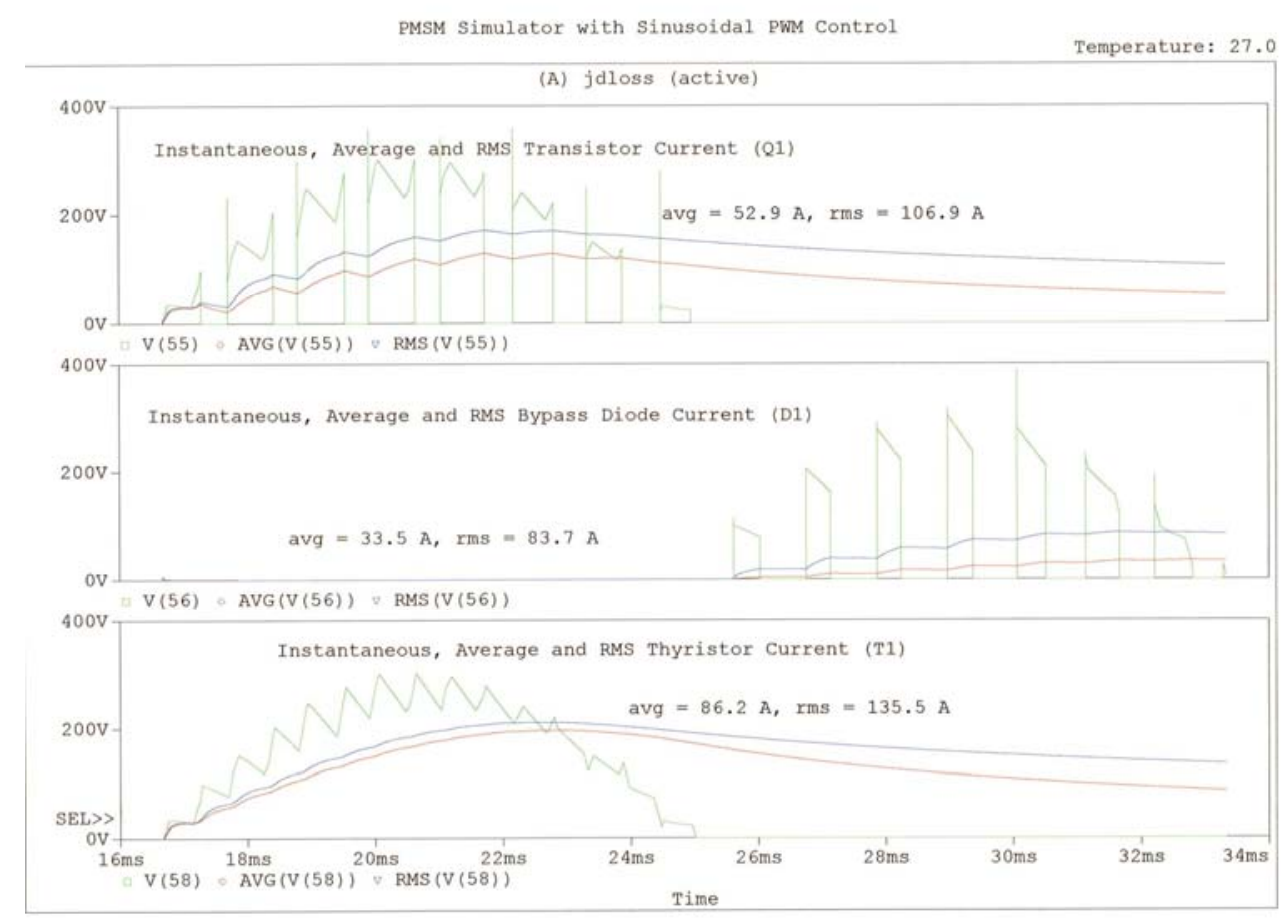

(b) Transistor, bypass diode, and thyristor currents.

Fig. 12. Time-domain simulation at $300 \mathrm{rpm}, 60 \%$ rated torque with $340 \mathrm{Vdc}$ supply, and a carrier frequency of $900 \mathrm{~Hz}$. 
Table 3. Comparison of theoretical and simulated motor and inverter-current magnitudes at $300 \mathrm{rpm}, 60 \%$ rated torque, and dc supply of $340 \mathrm{~V}$

\begin{tabular}{|c|c|c|c|}
\hline & Theoretical & $\mathbf{f c}=\mathbf{5 9 4 0 ~} \mathbf{~ z}$ & $\mathbf{f c}=\mathbf{9 0 0} \mathbf{~ H z}$ \\
\hline Parameter & & & \\
\hline$P_{\text {out }}$ & $18 \mathrm{~kW}$ & $17.7 \mathrm{~kW}$ & $18.3 \mathrm{~kW}$ \\
\hline $\begin{array}{c}I \\
\text { (rms motor current) }\end{array}$ & $188.6 \mathrm{~A}$ & $185.6 \mathrm{~A}$ & $192.2 \mathrm{~A}$ \\
\hline$I_{q-\text { avg }}$ & $52.0 \mathrm{~A}$ & $51.2 \mathrm{~A}$ & $52.9 \mathrm{~A}$ \\
\hline$I_{q-r m s}$ & $105.2 \mathrm{~A}$ & $103.5 \mathrm{~A}$ & 106.9 \\
\hline$I_{d-\text { avg }}$ & $32.8 \mathrm{~A}$ & $32.3 \mathrm{~A}$ & $33.5 \mathrm{~A}$ \\
\hline$I_{d-r m s}$ & $81.9 \mathrm{~A}$ & $80.7 \mathrm{~A}$ & $83.7 \mathrm{~A}$ \\
\hline$I_{t-\text { avg }}$ & $84.9 \mathrm{~A}$ & $83.4 \mathrm{~A}$ & $86.2 \mathrm{~A}$ \\
\hline$I_{t-r m s}$ & $133.4 \mathrm{~A}$ & $131.1 \mathrm{~A}$ & $135.5 \mathrm{~A}$ \\
\hline
\end{tabular}

The results in Table 3 show that the simplified fundamental-frequency model predicts average and rms inverter-component currents with accuracy within $2 \%$ of simulated values for this lowspeed operating point. The table also shows that switching frequency affects the device-current magnitudes computed with the detailed time-domain simulator. The time-domain simulator involves numerical simulation and small differences resulting from computational precision are to be expected. The results indicate that the fundamental-frequency model predicts average and rms inverter-component currents with sufficient accuracy to have confidence in the results obtained with this simplified model.

As a final test of the simplified model, the Deere 1 design was examined at a high-speed operating condition; $4200 \mathrm{rpm}(\mathrm{n}=7)$ and $70 \%$ of rated power $(42 \mathrm{~kW})$. Since the CPA and DMIC differ in their performance for this operating condition, both drive options were considered.

Figure 13 shows the simplified per-phase fundamental-frequency model solved for this operating condition for the CPA drive method including rotational losses. In constructing the phasor solutions, the analyses in Sections 2 and 3 were suitably modified to include the effects of copper and rotational losses.

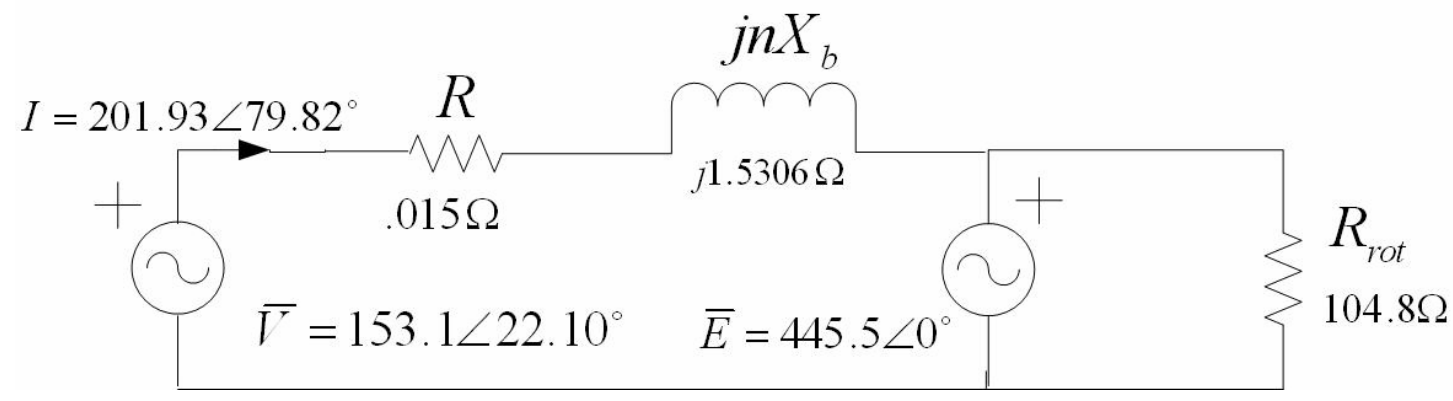

Fig. 13. Per-phase fundamental-frequency model of the Deere 1 design driven by driven by CPA at $4200 \mathrm{rpm}$ and $42 \mathrm{~kW}$ useful output power with rotational losses included. 
From Fig. 13 we find that

$$
\begin{aligned}
& m_{a}=\frac{4}{\pi} \\
& I=201.93 \mathrm{~A} . \\
& \delta=22.10^{\circ} \\
& \theta=79.82^{\circ}
\end{aligned}
$$

This load condition was simulated using the detailed time domain CPA simulator. Simulation results showing phase currents, developed power, and average and rms transistor and bypassdiode currents are given in Fig. 14. The device-current magnitudes computed with the fundamental-frequency model formulas are compared below with the values from the simulation

$$
\begin{aligned}
I & =201.93 \mathrm{~A} \text { (model), } 201.9 \mathrm{~A} \text { (simulation) } \\
I_{q-a v g} & =69.7 \mathrm{~A}(\text { model }), 69.6 \mathrm{~A}(\text { simulation }) \\
I_{q-r m s} & =126.8 \mathrm{~A}(\text { model }), 129.2 \mathrm{~A}(\text { simulation }) . \\
I_{d-a v g} & =21.2 \mathrm{~A}(\text { model }), 21.4 \mathrm{~A} \text { (simulation) } \\
I_{d-r m s} & =65.7 \mathrm{~A}(\text { model }), 60.2 \mathrm{~A} \text { (simulation) }
\end{aligned}
$$

The agreement between the simplified model and the detailed simulation is not quite as good at high speed as what was observed below speed. Perhaps the difference lies in the low-frequency harmonics introduced at high speed by six-step switching. However, transistor average and rms currents between the simplified model and the simulation are within $2 \%$. While the difference in rms diode current is more than $8 \%$, the average diode currents are within $2 \%$ of each other. Diode-conduction losses are generally a factor of two smaller than transistor-conduction losses, and except at very high diode currents the conduction losses of the diodes will be weighted more heavily towards the contribution of the forward voltage drop and average current than by the diode resistance and rms current. Based on this assessment, the simplified model is still considered sufficiently accurate to be used to predict the losses of the CPA driven Deere 1 and Deere 2 designs.

The same high-speed operating condition was examined using the DMIC. Figure 15 is a solved per-phase fundamental-frequency model of the condition using the DMIC. 


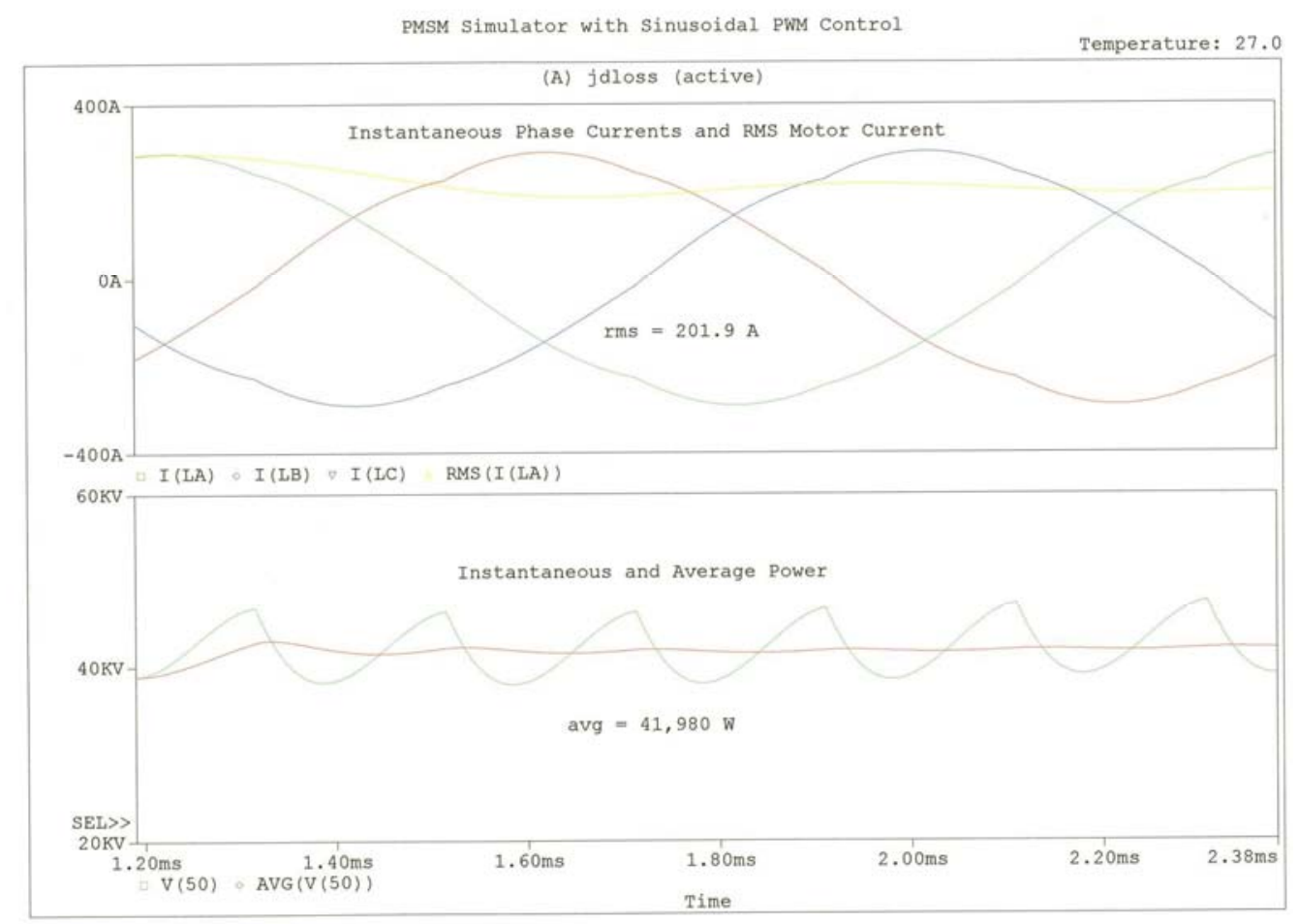

(a) Motor currents and power.

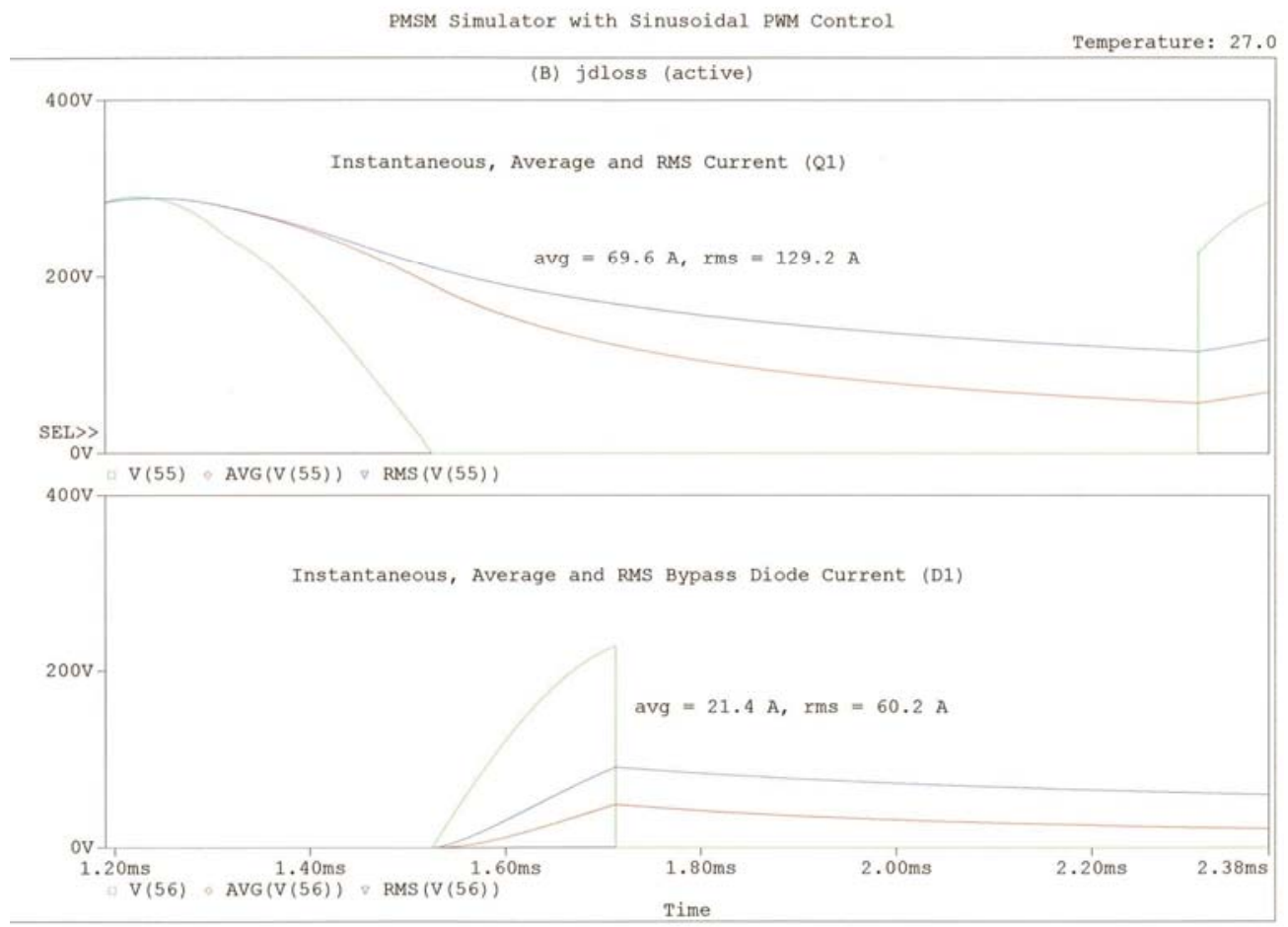

(b) Transistor, bypass diode, and thyristor currents.

Fig. 14. Time-domain simulation results of the CPA simulator driving the Deere 1 design at $4200 \mathrm{rpm}$ and $42 \mathrm{~kW}$ output with rotational losses included. 


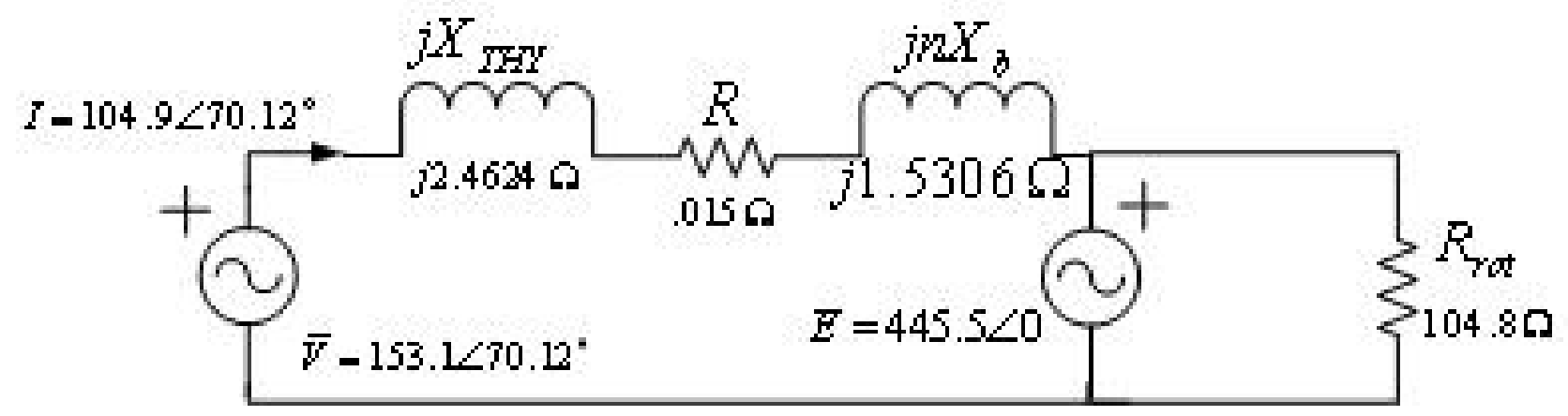

Fig. 15. Per-phase fundamental-frequency model of the Deere 1 design driven by DMIC at $4200 \mathrm{rpm}$ and $42 \mathrm{~kW}$ useful output power with rotational losses included.

From Fig. 15 we find that

$$
\begin{aligned}
& m_{a}=\frac{4}{\pi} \\
& I=104.9 \mathrm{~A} \\
& \delta=70.12^{\circ} \\
& \theta=70.12^{\circ} \\
& n_{\text {min }}=2.53(1520 \mathrm{rpm})
\end{aligned} .
$$

This load condition was simulated using the detailed time domain DMIC simulator. Simulation results showing phase currents, developed power, and average and rms transistor and bypassdiode currents are given in Fig. 16. The device-current magnitudes computed with the fundamental-frequency model formulas are compared below with the values from the simulation

$$
\begin{aligned}
& I=104.9 \text { A (model), } 112.9 \text { A (simulation) } \\
& I_{q-a v g}=47.2 \mathrm{~A} \text { (model), } 47.4 \mathrm{~A} \text { (simulation) } \\
& I_{q-r m s}=74.2 \mathrm{~A} \text { (model), 79.6 A (simulation) } \\
& I_{d-a v g}=0 . \text { A (model), 0. A (simulation) } \\
& I_{d-r m s}=0 . \text { A (model), 0. A (simulation) } \\
& I_{t-a v g}=47.2 \mathrm{~A} \text { (model), } 47.4 \mathrm{~A} \text { (simulation) } \\
& I_{t-r m s}=74.2 \mathrm{~A} \text { (model), 79.6 A (simulation) }
\end{aligned}
$$

The fundamental-frequency model predicts the average transistor, diode, and thyristor currents with less than $1 \%$ error; however, there is approximately $7 \%$ difference between the simplified model and the simulator with respect to the rms transistor and thyristor currents. This is due to the low frequency harmonics introduced by the six-step switching and by the action of the DMIC inverter at high speed. While this will result in some error in the estimation of the $i^{2} R$ losses in the transistors and thyristors, the loss of accuracy will be less than $10 \%$ of total semiconductor 
losses assuming that the forward-drop losses and body-resistance losses are about the same magnitude.

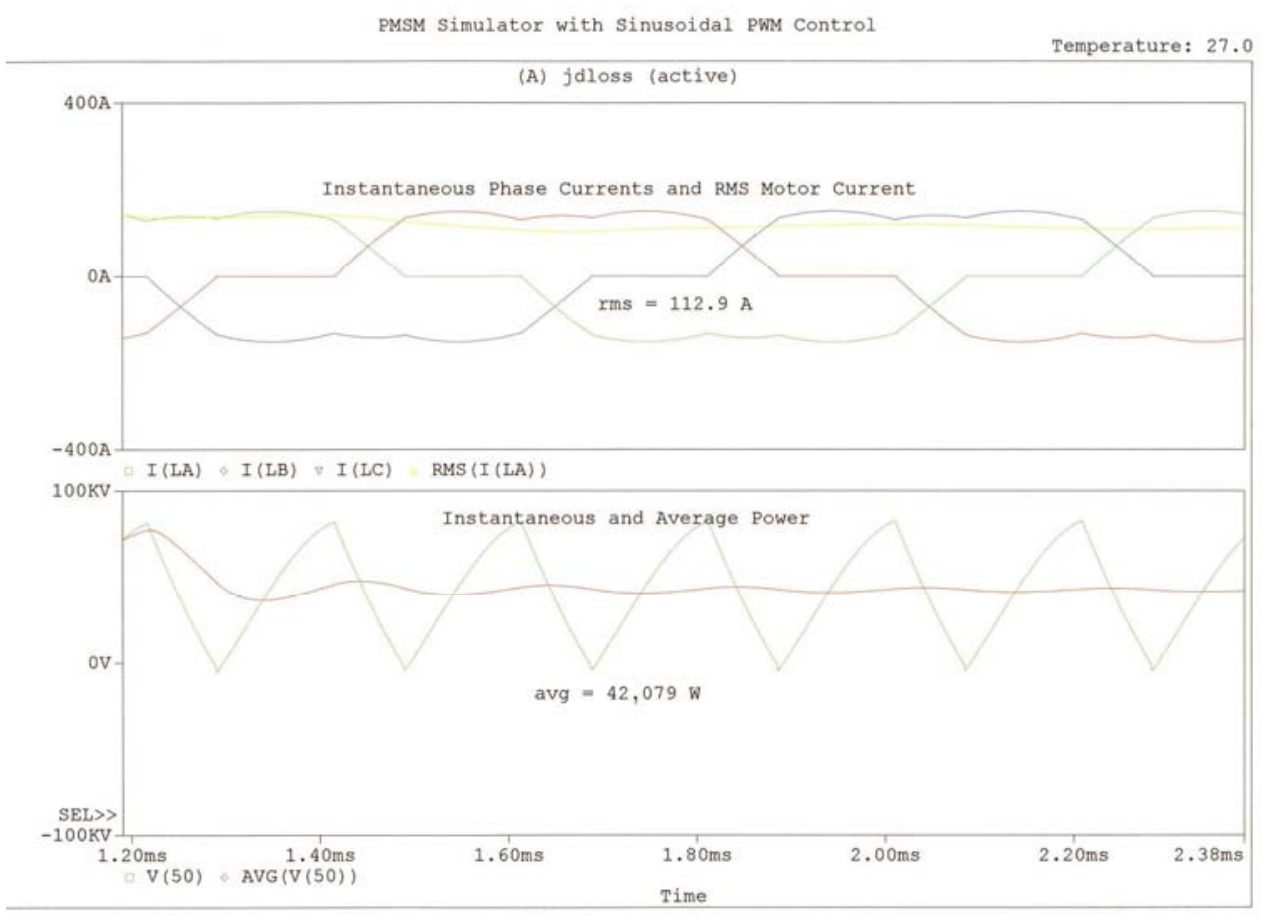

(a) Motor currents and power.

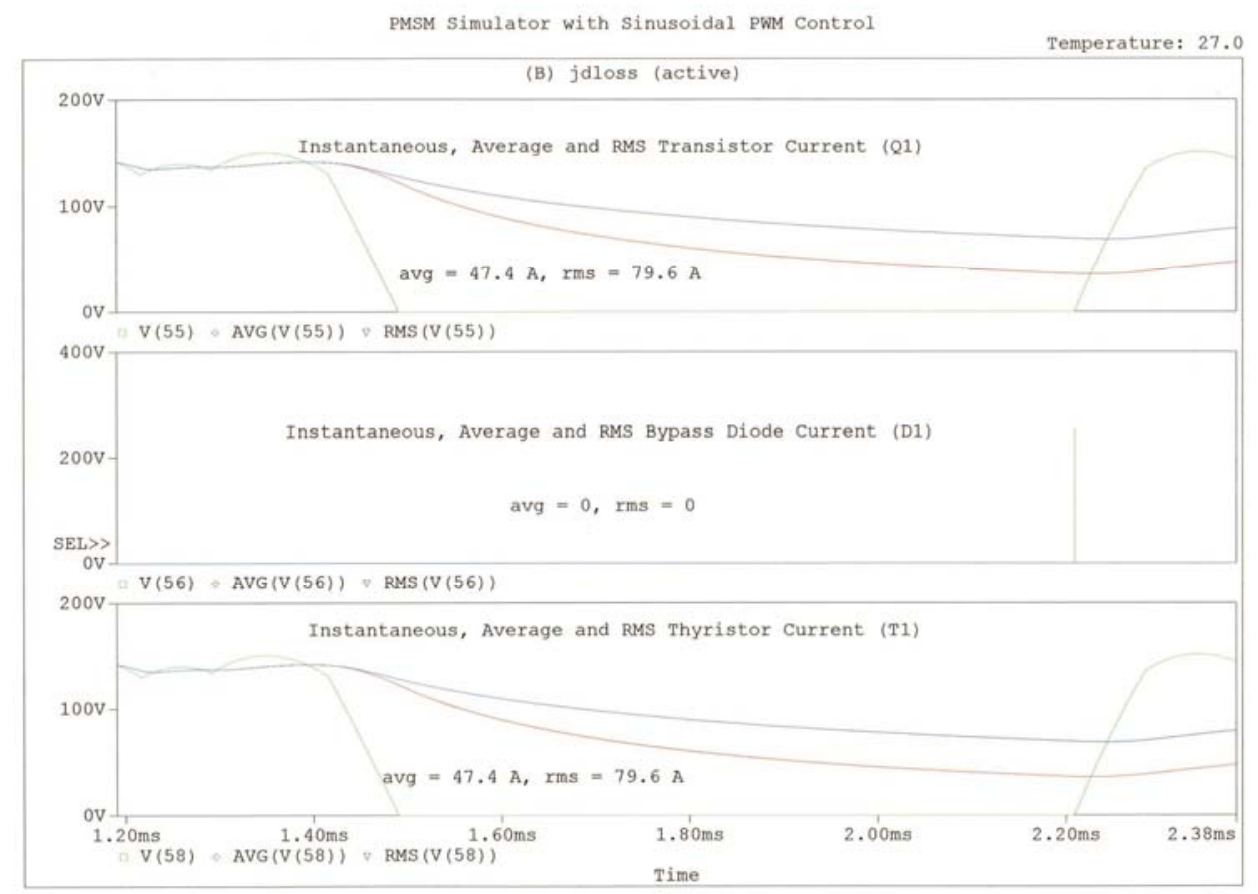

(b) Transistor, bypass diode, and thyristor currents.

Fig. 16. Time-domain simulation results of the DMIC simulator driving the Deere 1 design at $4200 \mathrm{rpm}$ and $42 \mathrm{~kW}$ output with rotational losses included. 
For the $4200 \mathrm{rpm} / 42 \mathrm{~kW}$ operating condition with Deere 1 driven by CPA, the total motor losses are $7514 \mathrm{~W}$. These losses are composed of $5680 \mathrm{~W}$ of rotational losses and $1834 \mathrm{~W}$ of copper losses. For comparison, the total losses are $6254 \mathrm{~W}$ when driven by DMIC; which is the $5680 \mathrm{~W}$ of rotational losses and $574 \mathrm{~W}$ of copper losses. The total motor losses with DMIC are reduced by $1260 \mathrm{~W}$ because the rms motor current is only 112.9 A with DMIC as opposed to 201.9 A for the CPA drive. Note also in comparing Figs. 14 and 15 that the torque ripple at high speed is far greater with DMIC than with CPA. The DMIC will operate with essentially the same torque ripple as CPA up to the relative speed, $n_{\min }$, and greater torque ripple at higher speeds. For the Deere 1 design with a $340 \mathrm{Vdc}$ supply, the value of $n_{\min }$ varies from 2.4 at no load to 2.7 at full load. Thus, the DMIC can operate at the low ripple of CPA up to at least $1440 \mathrm{rpm}$. At higher speeds, the inertia of the vehicle will attenuate the effects of the torque ripple. This point may be worthy of further study.

The next section considers the calculation of switching losses.

\subsection{SWITCHING LOSSES}

Figure 17 shows a simplified representation of the dynamics of switch turn-on and turn-off. In the figure, $V_{\text {off }}$ and $V_{\text {on }}$ are the off-state and on-state voltages respectively, while $I_{\text {off }}$ and $I_{\text {on }}$ are the off-state and on-state currents. The off-state voltage depends on the dc supply voltage and the on-state current will be dependent on the impedance of the load. The turn-on and turn-off times are denoted as $\tau_{\text {on }}$ and $\tau_{\text {off }}$. The off-state current and on-state voltages have minimal impact on the total energy absorbed by the switch during turn-on and turn-off. Neglecting $I_{\text {off }}$ and $V_{\text {on }}$, the energy absorbed during one turn-on and one turn-off operation, as depicted in the idealization of Fig. 17, is given by

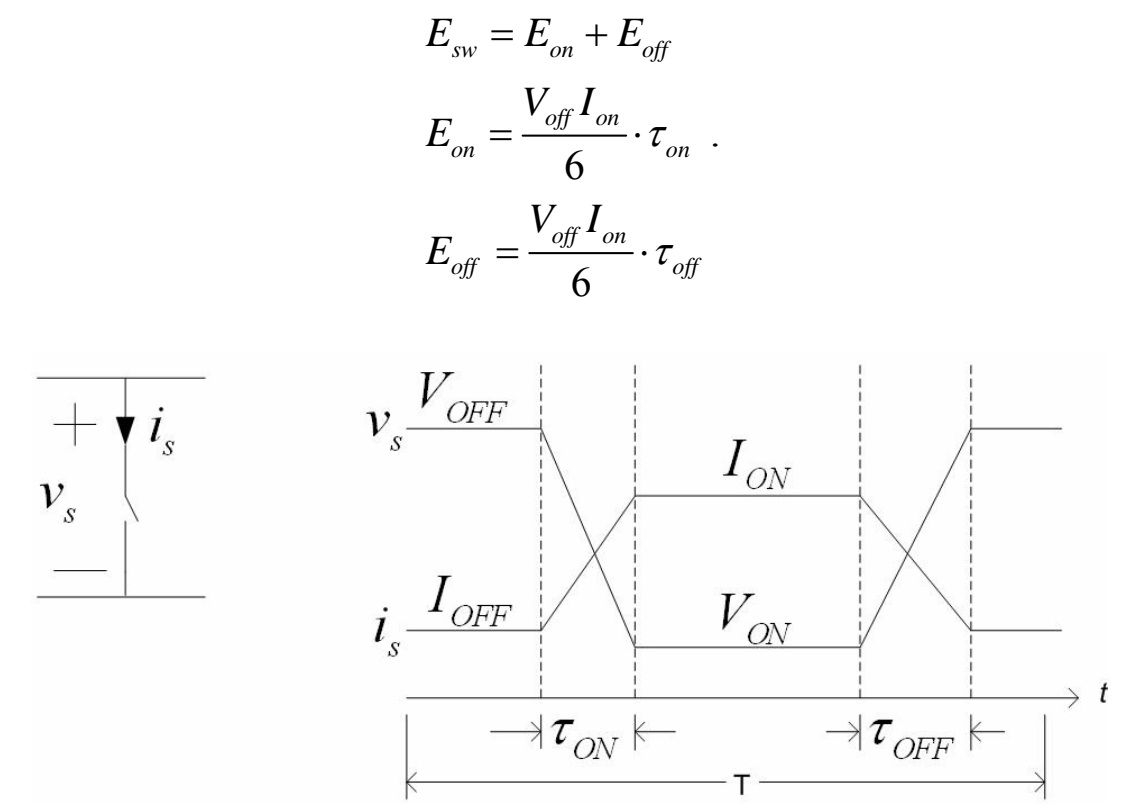

Fig. 17. Simplified description of switching dynamics during turn-on and turn-off. 
If there is one turn-on and one turn-off operation each time period, $T$, then the average switching losses over one period is given by

$$
\begin{aligned}
P_{\text {sw }} & =\frac{1}{T}\left(E_{\text {on }}+E_{\text {off }}\right) \\
& =f\left(E_{\text {on }}+E_{\text {off }}\right) . \\
& =f E_{\text {sw }}
\end{aligned}
$$

The voltage and current dynamics of semiconductors undergoing switching can be much more complicated than the idealization shown in Fig. 17. Generally, device-data sheets will display switching losses versus on-state current for a fixed voltage and one or more device temperatures, such as $25^{\circ} \mathrm{C}$ and $125^{\circ} \mathrm{C}$. Such characteristics can easily be corrected for actual voltage conditions since the switching energy is generally linear in voltage. In this study and evaluation, temperature effects will be incorporated by choosing the characteristics associated at maximum device temperature.

The switching losses described above apply to transistors. The main switching losses of diodes and thyristors are associated with reverse recovery which is described in the next section.

\subsection{REVERSE-RECOVERY LOSSES}

The reverse-recovery phenomenon is associated with a conducting diode or thyristor undergoing transition from the forward current-conducting state to the reverse-voltage blocking state. The process is dependent on forward current, reverse voltage, and temperature. Idealized voltage and current waveforms are shown in Fig. 18. In the figure, $I_{\text {on }}$ is the initial forward current, $I_{r r}$ is the peak reverse-recovery current, $V_{R}$ is the final reverse voltage, $t_{a}$ is the time between the current zero crossing and the instant that the peak-reverse current is reached, $t_{b}$ is the time for the reverse current to decay to $10 \%$ of the peak-reverse current, and $t_{r r}$ is the reverse-recovery time which is the sum of $t_{a}$ and $t_{b}$. For most devices the reverse-recovery time is dominated by the time, $t_{b}$. Since the device voltage is approximately zero during the interval denoted as $t_{a}$, the energy absorbed during reverse recovery is given by

$$
E_{r r}=V_{R} \frac{I_{r r}}{2} t_{b} \approx V_{R} \frac{I_{r r}}{2} t_{r r}=0.5 V_{R} Q_{r r}
$$

where $Q_{r r}$ is the peak-recovery charge. 


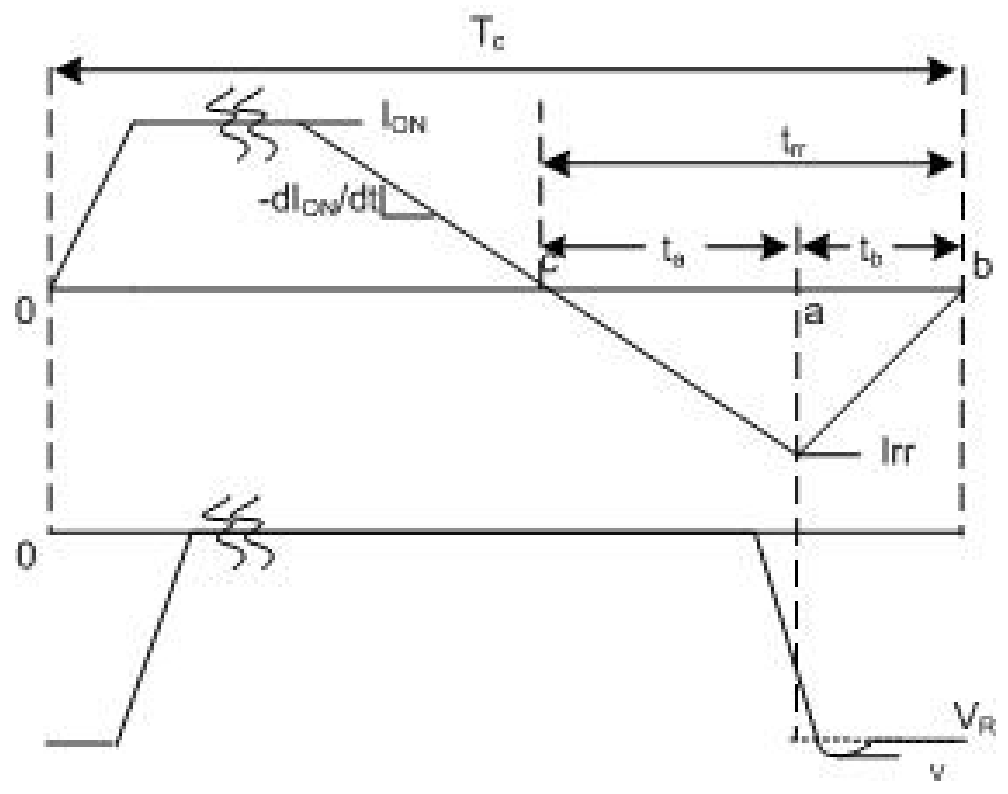

Fig. 18. Reverse-recovery current and voltage.

If there is one reverse recovery during each time period, $T$, then the average power loss during recovery is

$$
P_{r r}=\frac{1}{T} E_{r r}=f E_{r r} .
$$

A device-data sheet may specify the information needed to determine $E_{r r}$ in various ways. One common method for bypass diodes, is to provide plots of reverse-recovery time, $t_{r r}$, and reverserecovery current, $I_{r r}$, versus the forward current through the companion transistor. In the case of CPA and DMIC, the forward current through the companion transistor can be represented as the "average-transistor current" as determined in Section 4.1. For thyristors, the reverse-recovery charge, $Q_{r r}$, may be plotted versus the time rate of change of thyristor current at turn-off for various values of forward current. In the DMIC application, the commutation of thyristors is natural and occurs at the zero crossings of the thyristor current. Thus, it is appropriate to choose the $Q_{r r}$ curve corresponding to the smallest forward current for which data is given. The time rate of change of current can be approximated using the fundamental-current component. Let the instantaneous-fundamental current be written as

$$
i_{1}(t)=\sqrt{2} I \sin \left(n \omega_{b} t+\theta\right) .
$$

Then the rate of change of this current at its zero crossing is

$$
\frac{d i}{d t} \rightarrow n \omega_{b} \sqrt{2} I .
$$


In addition, the voltage blocked by a commutating thyristor at the commutation instant is not necessarily the dc supply voltage, as it is for the bypass diodes, but rather the instantaneous phase-to-neutral back-emf. Given the fundamental current as above which is zero at the commutation instant so that $n \omega_{b} t=-\theta$ and the instantaneous phase-to-neutral back-emf

$$
e(t)=n \sqrt{2} E_{b} \sin \left(n \omega_{b} t\right)
$$

the magnitude of the commutating voltage at the commutation instant is

$$
V_{R}=n \sqrt{2} E_{b} \sin (\theta)
$$

Thus, the rate of change of thyristor current during reverse recovery and reverse voltage both increase linearly with speed; therefore, the reverse-recovery losses of the thyristor will increase more than linearly with speed.

\subsection{INVERTER SEMICONDUCTOR SELECTIONS FOR THE DEERE 1 AND DEERE 2 DESIGNS AND LOSS-MODEL PARAMETERS}

The evaluation of the Deere 1 and Deere 2 designs will include driving Deere 1 by both CPA and DMIC. The low inductance Deere 2 will be evaluated only for DMIC. Suitable insulated gate bipolar transistor (IGBT) and thyristor (SCR) modules must therefore be selected for both Deere designs. Data sheets for all the selected components are given in Appendix A.

The two motor designs differ in the requirements that they place on the semiconductors required in their inverters; however, the dc supply for both motors is likely to be in the $350 \mathrm{~V}$ range and therefore the IGBTs in the VSI will be selected for a $600 \mathrm{~V}$ operation. The PWM frequency is likely to be $10 \mathrm{kHz}$.

The Deere 1 design has a rated current of 314.3 Arms, which corresponds to a 444 A peak. Therefore, a $600 \mathrm{~A}$ transistor/diode module is required. The POWEREX ${ }^{\mathrm{TM}}$ PM600DVA060 is chosen for Deere 1. Since the Deere 1 design will be investigated with both CPA and DMIC, a suitable thyristor module must also be chosen. The thyristor must be capable of blocking the peak line-to-neutral back-emf at $6000 \mathrm{rpm}$. For Deere 1, the required blocking-voltage level is $900 \mathrm{~V}$. The thyristor must have an rms current rating consistent with the rms motor-current rating divided by $\sqrt{2}$. For Deere 1 , this value is 222.2 Arms. The EUPEC ${ }^{\mathrm{TM}}$ TT162N has a $1400 \mathrm{~V}$ and 260 Arms rating and was selected for the DMIC inverter to drive Deere 1.

The Deere 2 design has rated a current of 212.8 Arms or 301 A peak. A 300 A IGBT module is chosen for Deere 2 which has a peak collector capability of $600 \mathrm{~A}$. The selected module is a POWEREX PM300DSA060. The peak blocking-voltage requirement on the thyristors for the Deere 2 DMIC inverter is $1329 \mathrm{~V}$ and the rms current-rating requirement is $150.5 \mathrm{~A}$. A EUPEC TT121N module is chosen which has $1400 \mathrm{~V}$ blocking capability and a 160 Arms current rating.

Based on the device-data sheets given in Appendix A, the loss-model parameters are given in Table 4 for the Deere 1 inverter and in Table 5 for the Deere 2 inverter. Since the VSI 
components in the CPA and DMIC drives for Deere 1 are the same, the parameters in Table 4 cover both inverter types. The parameters in the tables are for "typical parameters" at maximum junction temperatures.

Table 4. Typical semiconductor parameters for the Deere 1 drive

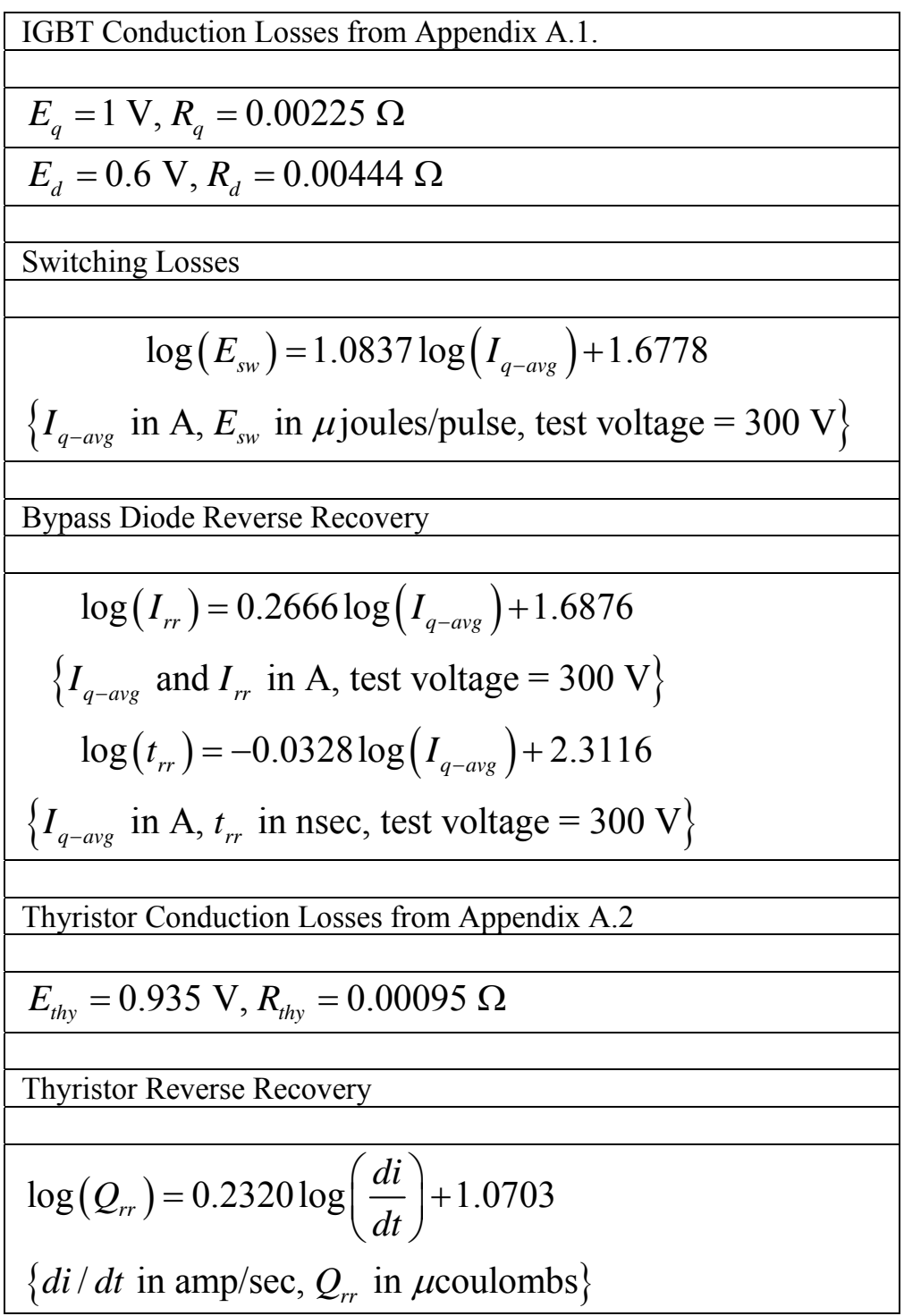


Table 5. Typical semiconductor parameters for the Deere 2 drive

\begin{tabular}{|c|c|}
\hline IGBT Conduction Losses from Appendix A.3 & \\
\hline$E_{q}=1 \mathrm{~V}, R_{q}=0.004 \Omega$ & \\
\hline$E_{d}=0.6 \mathrm{~V}, R_{d}=0.0072 \Omega$ & \\
\hline Switching Losses & \\
\hline $\begin{array}{r}\log \left(E_{s w}\right)=1.0281 \log \left(I_{q-a v g}\right)+ \\
\left\{I_{q-a v g} \text { in } \mathrm{A}, E_{s w} \text { in } \mu \text { joules/pulse, test }\right.\end{array}$ & $\begin{array}{l}+1.9438 \\
\text { voltage }=300 \mathrm{~V}\}\end{array}$ \\
\hline Bypass Diode Reverse Recovery & \\
\hline $\begin{array}{r}\log \left(I_{r r}\right)=0.3604 \log \left(I_{q-a v g}\right)+1.31 \\
\left\{I_{q-a v g} \text { and } I_{r r} \text { in A, test voltage }=30\right. \\
\log \left(t_{r r}\right)=-0.1047 \log \left(I_{q-a v g}\right)+2.3 \\
\left\{I_{q-a v g} \text { in } \mathrm{A}, t_{r r} \text { in nsec, test voltage }=\right.\end{array}$ & $\begin{array}{l}27 \\
\begin{array}{l}27 \\
008 \\
300 \mathrm{~V}\}\end{array}\end{array}$ \\
\hline Thyristor Conduction Losses from Appendix & A.4. \\
\hline$E_{\text {thy }}=0.95 \mathrm{~V}, R_{\text {thy }}=0.002 \Omega$ & \\
\hline Thyristor Reverse Recovery & \\
\hline $\begin{array}{l}\log \left(Q_{r r}\right)=.2320 \log \left(\frac{d i}{d t}\right)+1.0703 \\
\left\{d i / d t \text { in amp/sec, } Q_{r r} \text { in } \mu \text { coulombs }\right\}\end{array}$ & \\
\hline
\end{tabular}

Laboratory test data was available on the Deere 1 design driven by CPA. Data from the testing is given in Appendix B. In the next section, the test data is compared to model outputs in order to test the validity of the model and make adjustments in the model parameters if necessary. Note that the inverter-loss models contained in Tables 4 and 5 involve 15 parameters. Without extensive instrumentation and appropriate test measurements, it may not be practical to "tune" the model to exactly match the test data over an extended range of operating conditions. The model developed here does, however, provide the means to compare the performance of CPA and DMIC using the same motor and inverter-component models. 


\subsection{MODEL VALIDATION USING EXPERIMENTAL DATA FOR THE CPA DRIVEN DEERE 1 DESIGN}

The loss-model performance for the Deere 1 design driven by CPA was compared with experimental data taken at the base speed of $600 \mathrm{rpm}$ and at 5 load conditions, $20-100 \%$ torque in $20 \%$ steps. It was found that a dc supply voltage of $340 \mathrm{~V}$ and the "typical" semiconductor loss parameters of Table 4 consistently under-represented the losses observed experimentally. The loss parameters were doubled to bring the model more in line with experimental data. This makes the semiconductor model more consistent with "maximum" characteristics rather than "typical" characteristics. The revised semiconductor parameters are given in Table 6. A dc supply voltage of $360 \mathrm{~V}$ was found to give reasonable agreement between experimentally observed rms motor current and the motor current from the model

Table 6. Maximum semiconductor parameters for the Deere 1 drive

\begin{tabular}{|c|c|}
\hline IGBT Conduction Losses & \\
\hline$E_{q}=2 \mathrm{~V}, R_{q}=0.0045 \Omega$ & \\
\hline$E_{d}=1.2 \mathrm{~V}, R_{d}=0.00888 \Omega$ & \\
\hline Switching Losses & \\
\hline $\begin{array}{r}\log \left(E_{s w}\right)=1.0837 \log \left(I_{q-a v g}\right)+ \\
\left\{I_{q-a v g} \text { in } \mathrm{A}, E_{s w} \text { in } \mu \text { joules/pulse, test }\right.\end{array}$ & $\begin{array}{l}1.9788 \\
\text { voltage }=300 \mathrm{~V}\}\end{array}$ \\
\hline Bypass Diode Reverse Recovery & \\
\hline $\begin{array}{r}\log \left(I_{r r}\right)=0.2666 \log \left(I_{q-a v g}\right)+1.98 \\
\left\{I_{q-a v g} \text { and } I_{r r} \text { in A, test voltage }=30\right. \\
\log \left(t_{r r}\right)=-0.0328 \log \left(I_{q-a v g}\right)+2.6 \\
\left\{I_{q-a v g} \text { in } \mathrm{A}, t_{r r} \text { in nsec, test voltage }=\right.\end{array}$ & $\begin{array}{l}86 \\
\begin{array}{l}0 \\
126 \\
00 \mathrm{~V}\}\end{array}\end{array}$ \\
\hline Thyristor Conduction Losses & \\
\hline$E_{\text {thy }}=0.935 \mathrm{~V}, R_{\text {thy }}=0.00095 \Omega$ & \\
\hline Thyristor Reverse Recovery & \\
\hline $\begin{array}{l}\log \left(Q_{r r}\right)=0.2320 \log \left(\frac{d i}{d t}\right)+1.0703 \\
\left\{d i / d t \text { in amp/sec, } Q_{r r} \text { in } \mu \text { coulombs }\right\}\end{array}$ & \\
\hline
\end{tabular}


The performance of the adjusted model in predicting inverter and total drive losses is compared with experimental data at $600 \mathrm{rpm}$ in Fig. 19. The agreement between the model and experimental data, although not perfect, does suggest that the model provides a reasonable common platform on which to compare the performance of CPA and DMIC. It is preferable that inaccuracy in the model result in overstating the losses. Observe that the model is conservative in the sense that the losses predicted by the model are larger than what was measure.
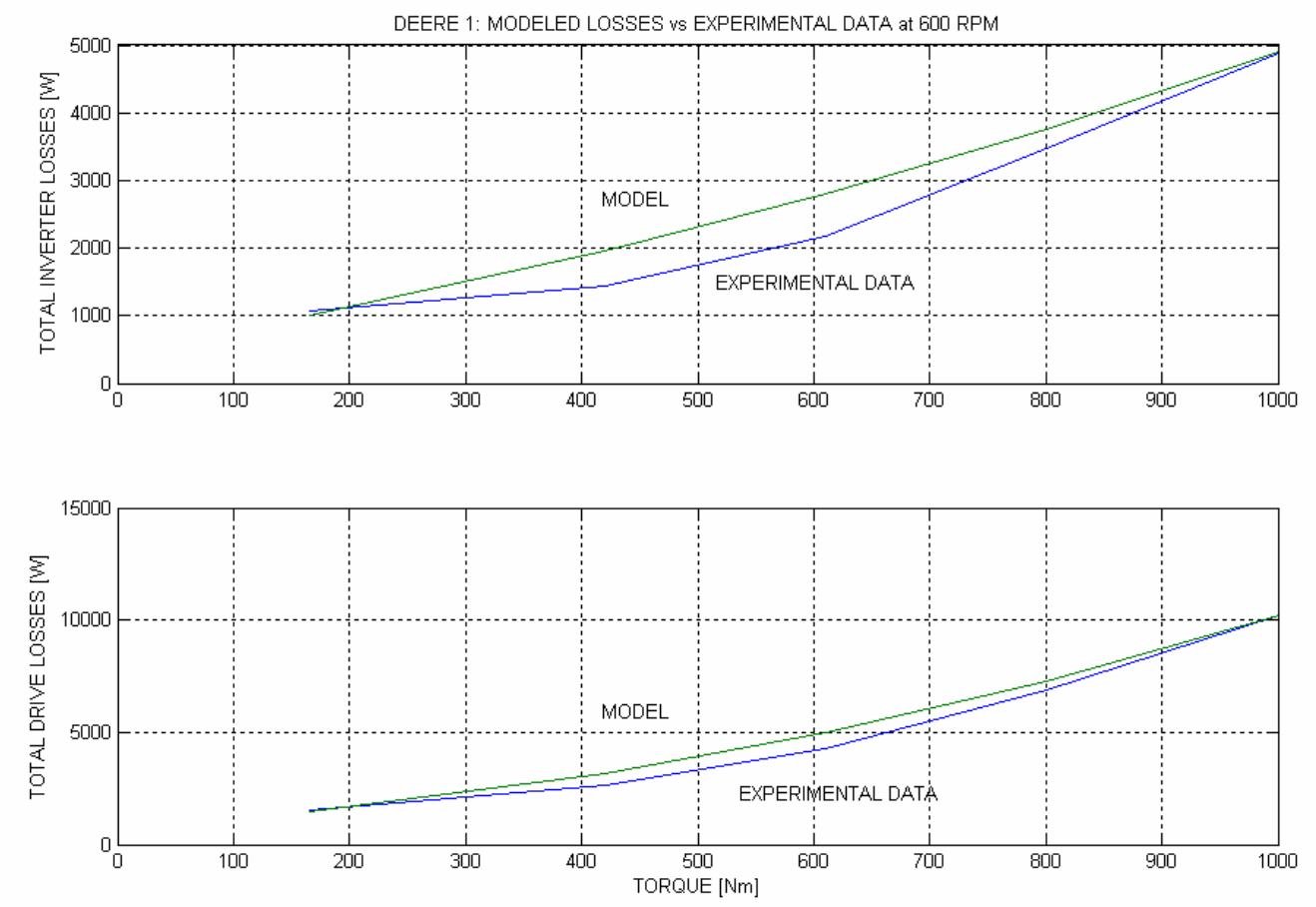

Fig. 19. Comparison of modeled and measured losses for Deere 1 when driven by CPA at $600 \mathrm{rpm}$.

The performance of CPA and DMIC in driving the Deere 1 and Deere 2 designs are investigated in the next section using the model. 


\section{MODELED PERFORMANCE OF CPA AND DMIC DRIVING THE DEERE 1 AND DEERE 2 DESIGNS}

The high-inductance Deere 1 can be driven by either CPA or DMIC. In Section 5.1, the model developed in Section 4 is used to predict the torque-speed and loss/efficiency performance of Deere 1 driven by CPA. Deere 1 driven by DMIC is considered in Section 5.2. The modeled loss/efficiency performance of the CPA and DMIC drives for Deere 1 are compared in Section 5.3. The low inductance Deere 2 driven by DMIC is discussed in Section 5.4. The DMIC drives for Deere 1 and Deere 2 are compared in Section 5.5. The modeled loss efficiency performance of Deere 1 driven by CPA and Deere 2 driven by DMIC are compared in Section 5.6. Finally, in Section 5.7 the modeled loss/efficiency performance of a CPA driven Deere 1 motor is compared with the enhanced performance of Deere 1 driven by a DMIC modified to eliminate SCR losses below base speed and transistor losses above base speed.

\subsection{DEERE 1 DRIVEN BY CPA}

The predicted performance of the high-inductance Deere 1 design driven by CPA is considered in this section. In the first subsection, the results of the model are given including the effects of the rotational losses as in Table 1. In the second subsection, the model results are presented with the rotational losses neglected. The semiconductor parameters used are the "maximum" values shown in Table 6.

\subsubsection{Deere 1 Driven by CPA with Rotational Losses}

The performance of the Deere 1 design driven by CPA at maximum required torque over the full speed range including the rotational loss effects is shown in Fig. 20.

Inspection of Fig. 20(a) shows that the CPA driven Deere 1 meets the torque-speed, power-speed envelope required by the Deere application. When producing rated power at high speed, the motor current is well below the rated current of 314.3 Arms that is required to produce rated torque at and below the base speed. For a CPA drive, the high-speed current approaches the characteristic current which for a high-inductance motor such as Deere 1 is less than the rated current.

Figure 20(b) shows that the switching frequency remains $10 \mathrm{kHz}$ out to $1000 \mathrm{rpm}$ where the amplitude-modulation index reaches a value of unity. Between $1000 \mathrm{rpm}$ and $1300 \mathrm{rpm}$, the switching becomes a mixture of PWM and six-step and the switching frequency decreases from the $10 \mathrm{kHz}$ rate to the fundamental rate determined by motor-pole count and speed. Note that the IGBT losses are a combination of conduction, switching, and bypass diode reverse-recovery losses. The dominant mechanism is the conduction loss. The switching and reverse-recovery losses become insignificant once the switching degenerates to six-step operation at and above $1300 \mathrm{rpm}$.

Figure 20(c) shows that the rotational losses at high speed dominate the motor and total losses of the drive. The overall drive efficiency at rated power and $6000 \mathrm{rpm}$ is $80 \%$. The total losses at this condition are about $15 \mathrm{~kW}$ and over two-thirds of these losses are rotational losses. 

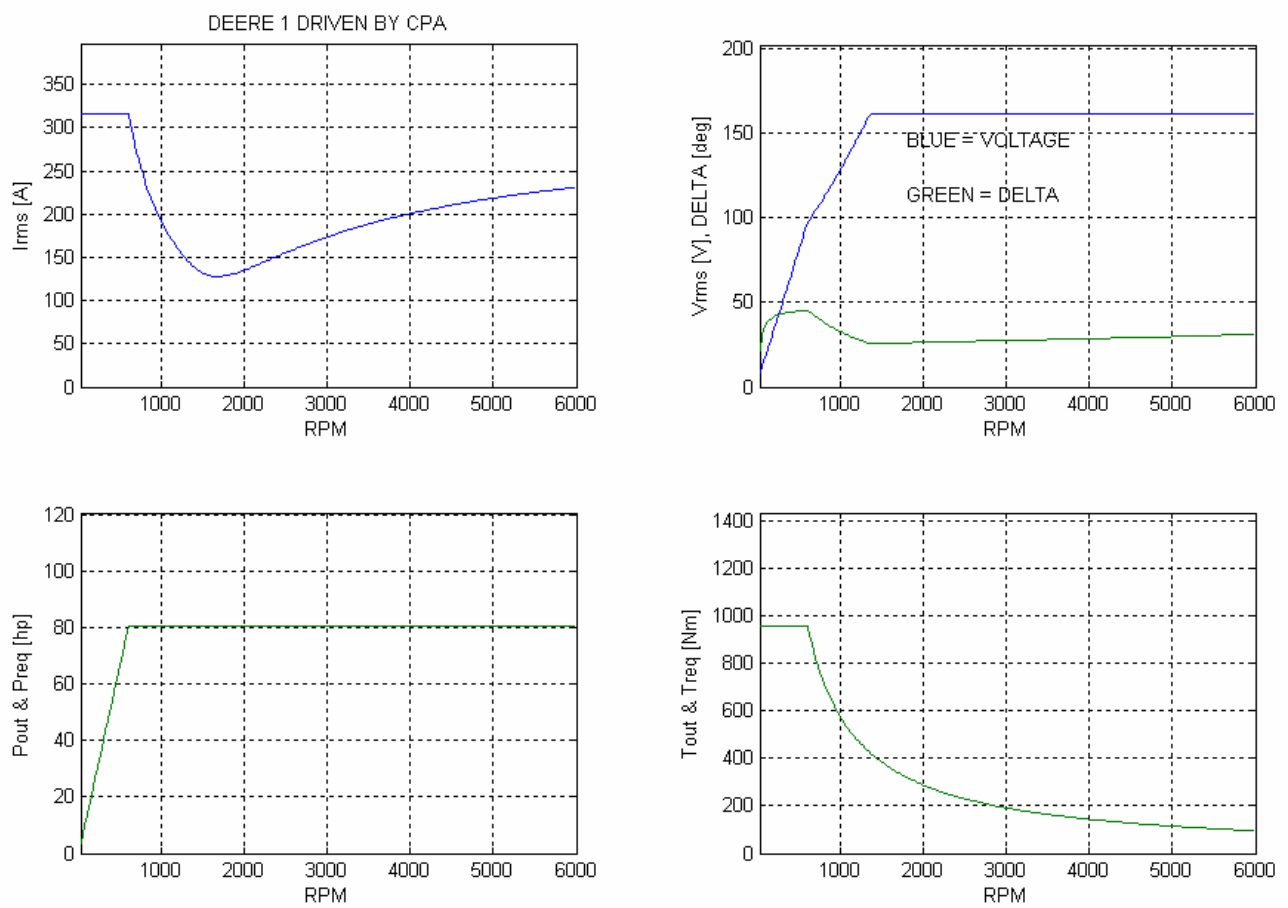

(a) Current, voltage, lead angle, power, and torque.
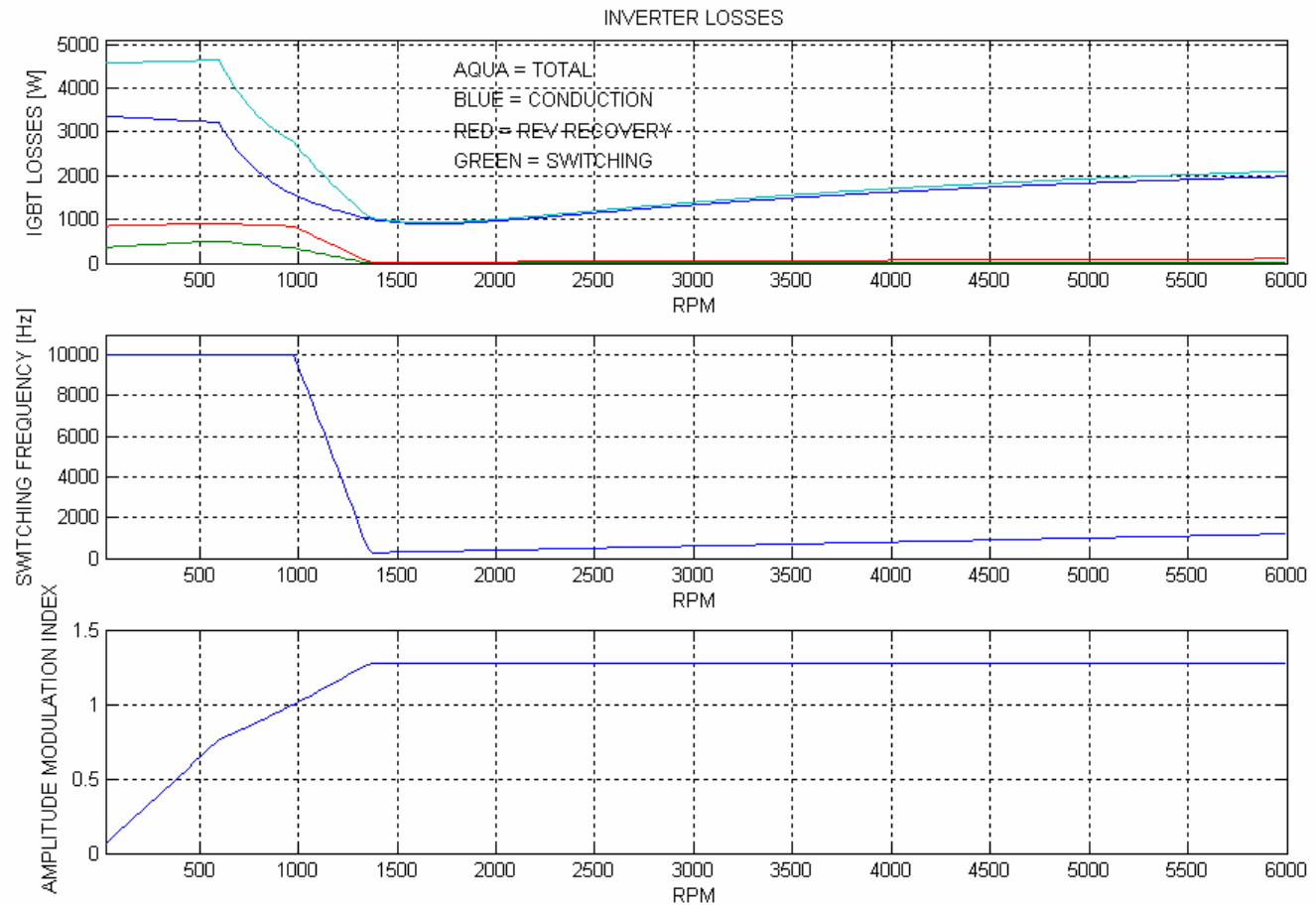

(b) IGBT losses, modulation index, and switching frequency.

Fig. 20. Performance of Deere 1 driven at maximum torque driven by CPA from 0-6000 rpm with rotational losses. 

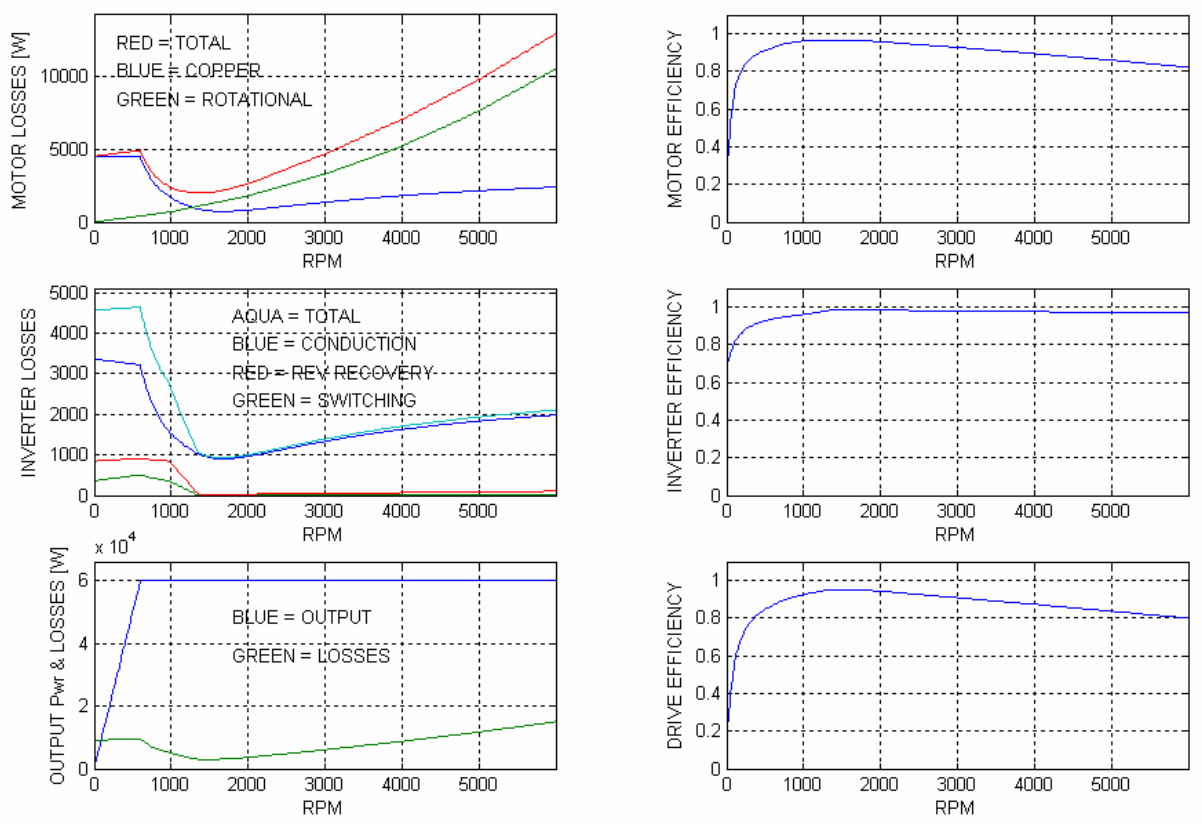

(c) Motor losses and efficiency, inverter losses and efficiency and output power, total losses and drive efficiency.

Fig. 20. Performance of Deere 1 driven at maximum torque driven by CPA from 0-6000 rpm with rotational losses (cont'd).

The model was also used to explore the impact of partial load conditions on loss performance. Specifically, the model was used to calculate total motor, inverter, and drive losses for speeds from 25-6000 rpm in steps of $25 \mathrm{rpm}$, and loads from zero to full load in 100 steps at each speed. The results are graphically displayed in the 3D plots of Fig. 21.

A red color in Fig. 21 represents "hot" or regions of high losses. Blue denotes "cold" or a region of low losses. The transition red-yellow-green-blue is a transition from very high to very low losses. Motor losses at low speed are dominated by the copper losses while rotational losses dominate at high speed. Inverter losses are large at low speed and high torque due to the large motor-current requirement and significantly lower during high-speed operation consistent with lower motor current at high speed. At base speed and full torque, the inverter losses are approximately $5 \mathrm{~kW}$. Note that the total losses at low speed and full load are about equally divided between motor and inverter losses. At high speed, the total drive losses are clearly dominated by the rotational losses of the motor. This study is repeated in Section 5.1.2 below with rotational losses neglected. 

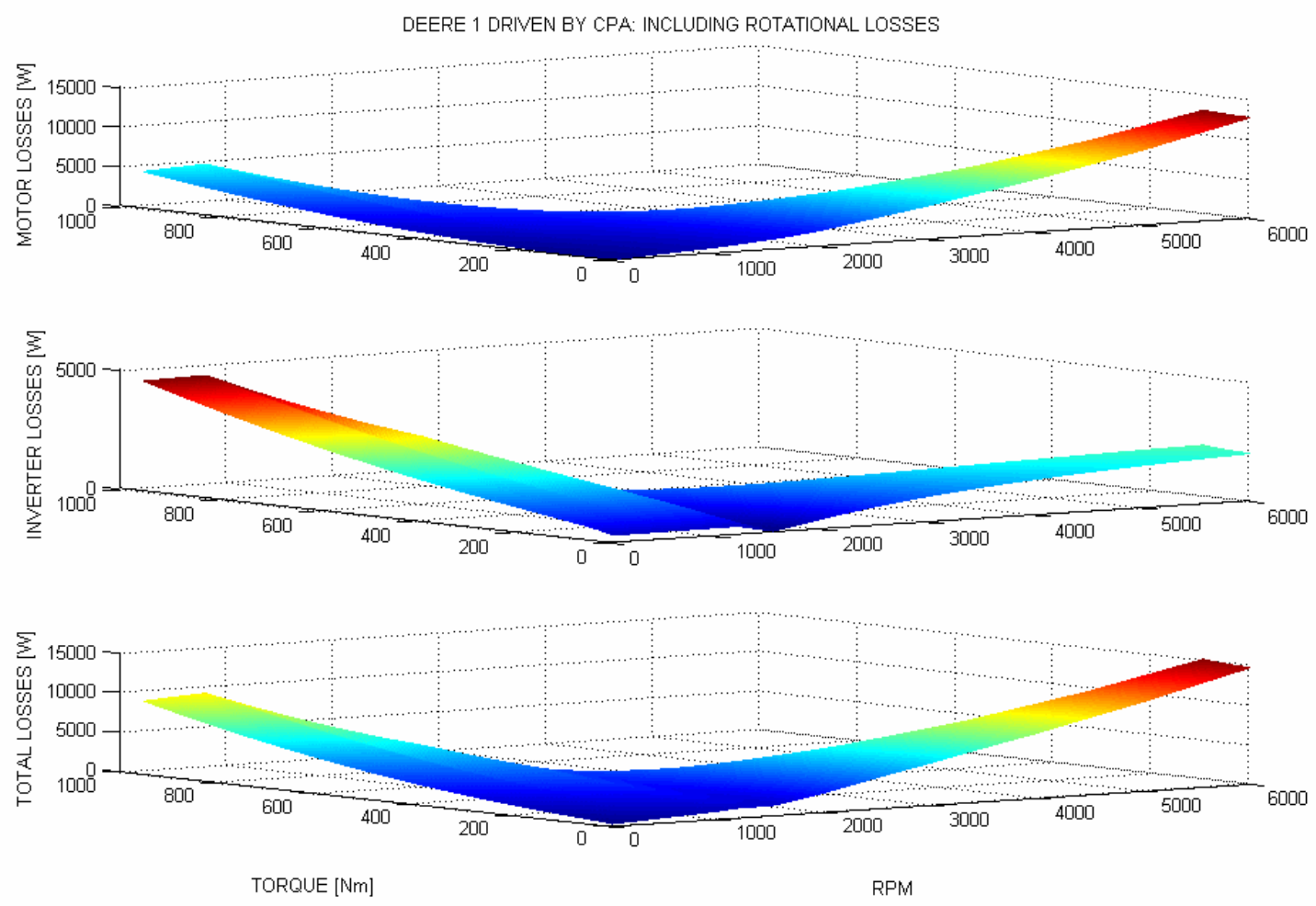

Fig. 21. Motor, inverter, and total losses of Deere 1 driven by CPA vs. torque and speed with rotational losses included.

The information in Fig. 21 is displayed in a different format in Fig. 22. In Fig. 22, efficiency contours are displayed on the torque-speed envelope required in the Deere application. Each colored area in the figure represents operating points that are within an efficiency band of $1 \%$. For example, considering the motor-efficiency contours in Fig. 22, the blue colored region noted by the arrow is the operating region where the highest motor efficiency occurs. The value of that efficiency identified with a label. Only seven colors are displayed in the figure: blue, green, red, aqua, magenta, yellow, and black. Each color area is separated by a $1 \%$ efficiency range; e.g., the green area surrounding the $96-97 \%$ blue region has an efficiency range of $95-96 \%$. A total of 21 areas are displayed, with the 7 basic colors being used 3 times each, but each successive area has a reduction in efficiency of $1 \%$. 

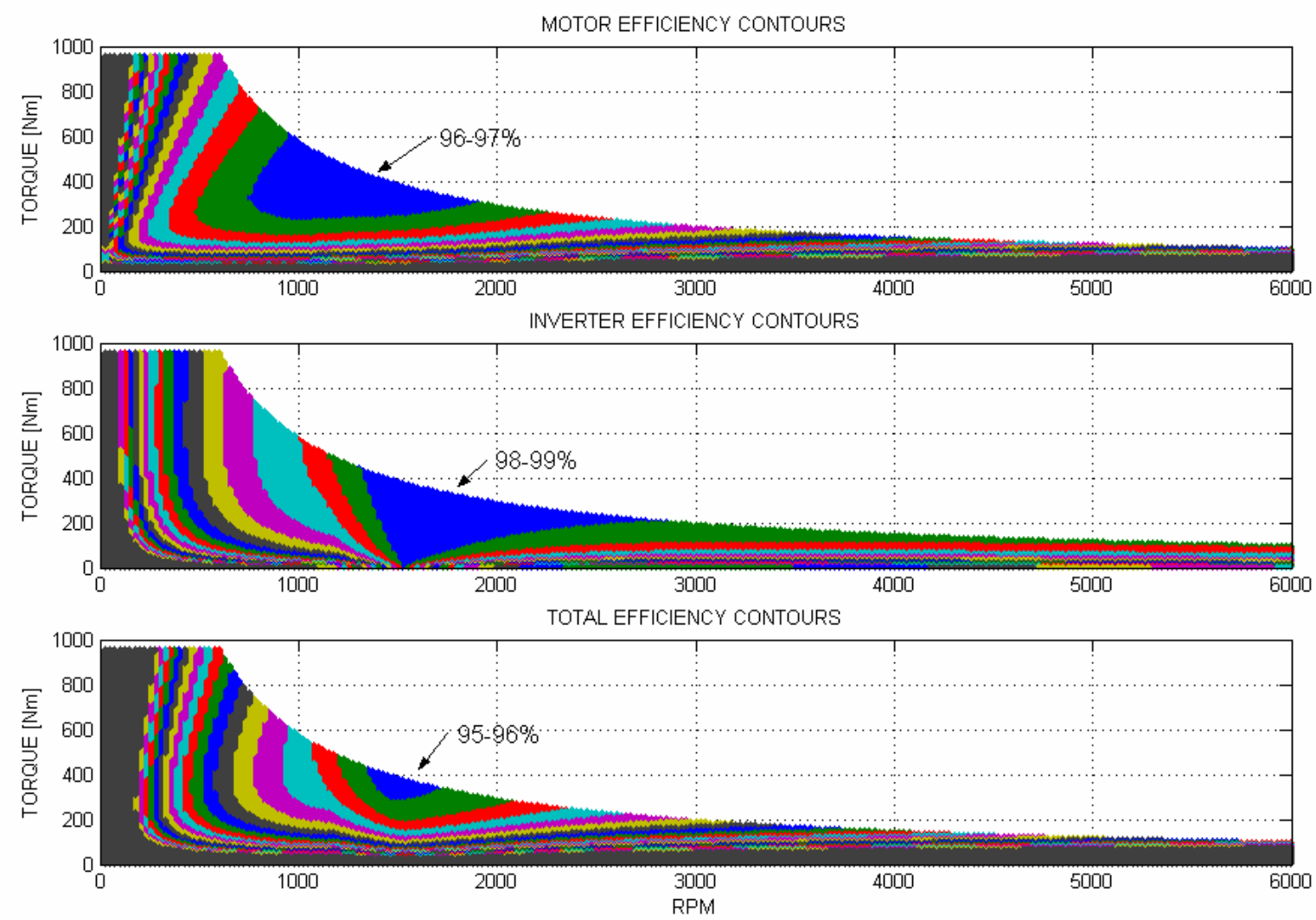

Fig. 22. Motor, inverter, and total drive-efficiency contours overlayed on the torque-speed envelope of the Deere application for Deere 1 driven by CPA with the effects of rotational losses.

The next subsection considers Deere 1 driven by CPA but with rotational losses neglected.

\subsubsection{Comparison of Deere 1 Driven by CPA With and Without Rotational Losses}

The simulations in the previous section were repeated with rotational losses neglected. Figure 23 compares the motor, inverter, and total losses of the CPA driven Deere 1 with and without the rotational losses. Figure 24 shows the motor, inverter, and total efficiency contours of Deere 1 driven by CPA with and without rotational losses.

Figure 23 clearly shows the impact of reducing, in this case eliminating, the rotational losses on loss performance. The high-speed motor and overall drive losses decrease by $10.5 \mathrm{~kW}$ at $6000 \mathrm{rpm}$. The inverter losses are virtually unchanged.

Figure 24 shows that the elimination of the rotational losses has little impact on the CPA inverter efficiency. However, the maximum motor and drive efficiency increase $2.3 \%$ and the regions of the torque-speed plane where the motor and drive efficiency are large are expanded. Despite the elimination of the high-speed rotational losses, the CPA drive still doesn't display high efficiency at high speed, especially for less than full load conditions.

The predicted performance of the DMIC driven Deere 1 drive is considered in the next section. 

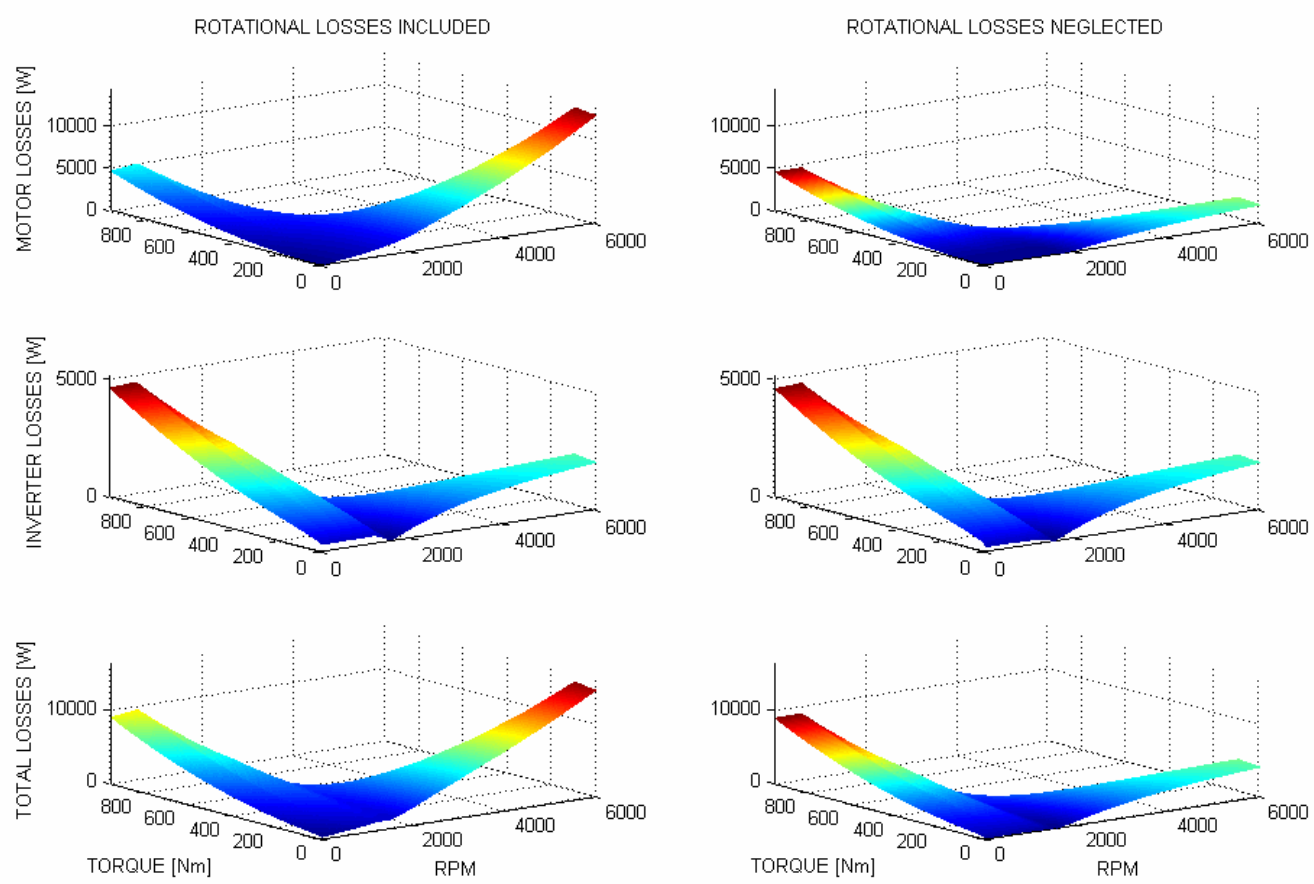

Fig. 23. Comparison of the motor, inverter, and total losses of Deere 1 driven by CPA with and without rotational losses.
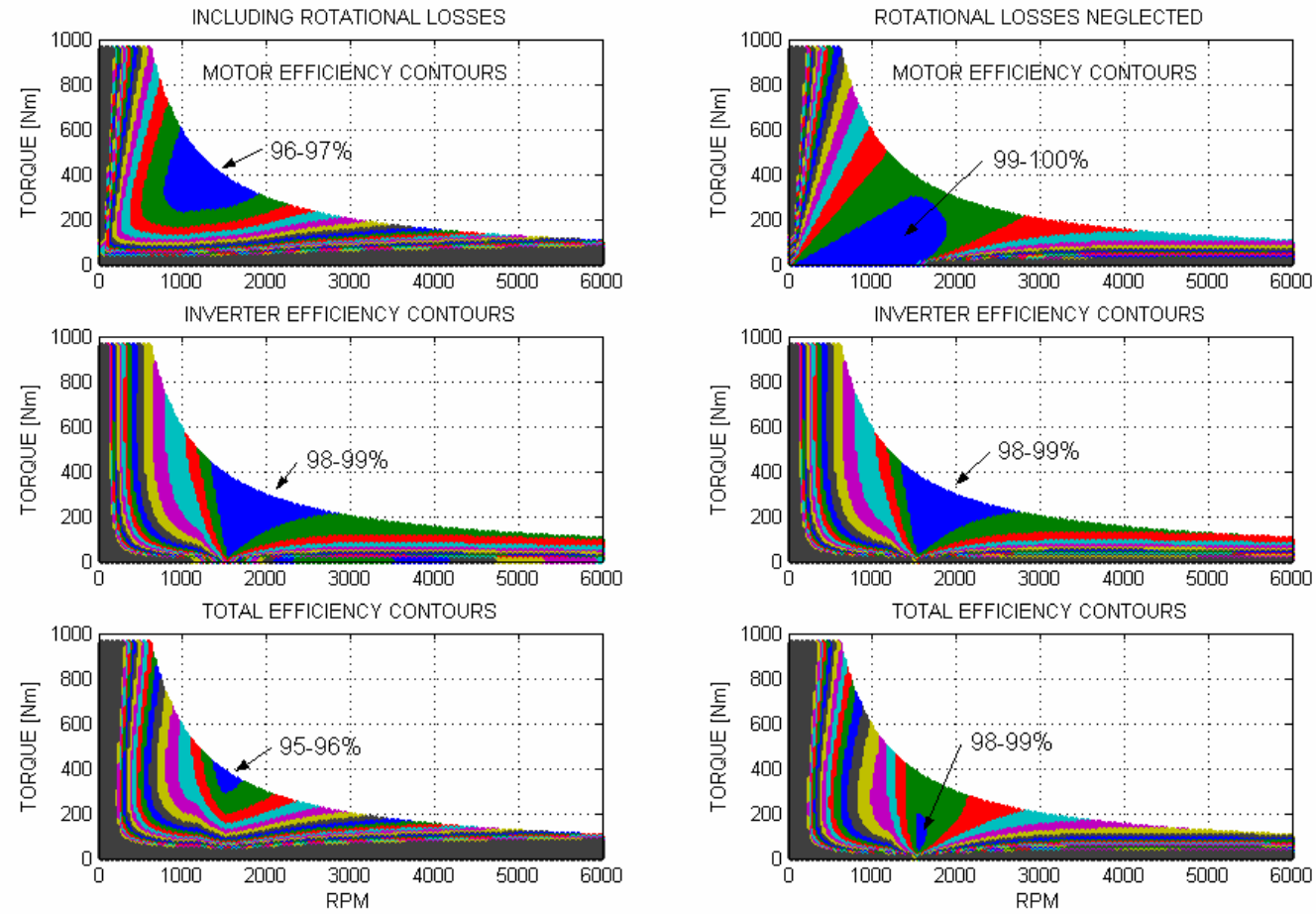

Fig. 24. Comparison of motor, inverter, and total drive-efficiency contours of Deere 1 driven by CPA with and without rotational losses. 


\subsection{DEERE 1 DRIVEN BY DMIC}

The predicted performance of the high-inductance Deere 1 design driven by DMIC is considered in this section. In the first subsection, the results of the model are given including the effects of the rotational losses as in Table 1. In the second subsection, the model results are presented with the rotational losses neglected.

\subsubsection{Deere 1 Driven by DMIC with Rotational Losses}

The performance of the Deere 1 design driven by DMIC at maximum required torque over the full speed range, including the rotational loss effects, is shown in Fig. 25.
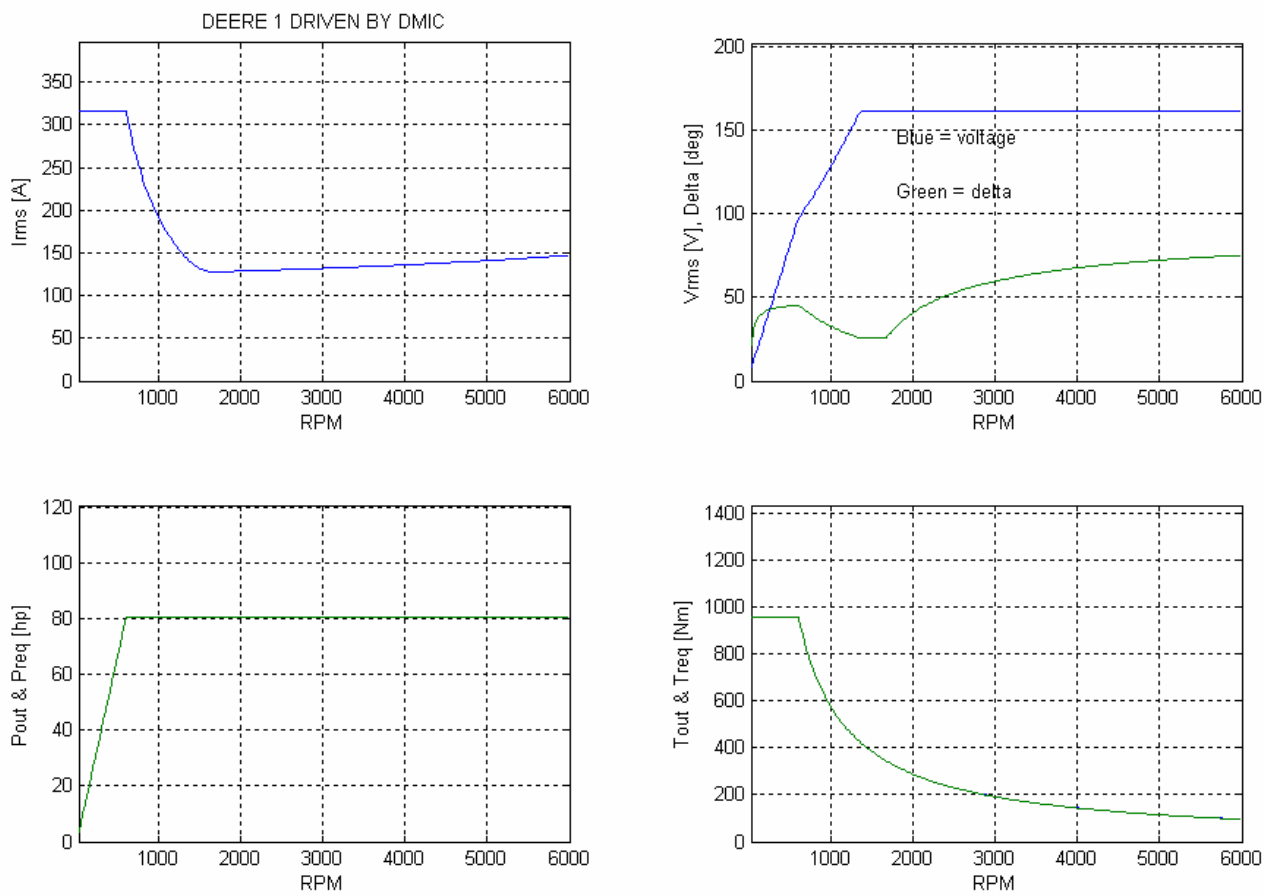

(a) Current, voltage, lead angle, power, and torque vs. rpm.

Fig. 25. Performance of Deere 1 driven at maximum torque by DMIC from 0-6000 rpm, with rotational losses. 

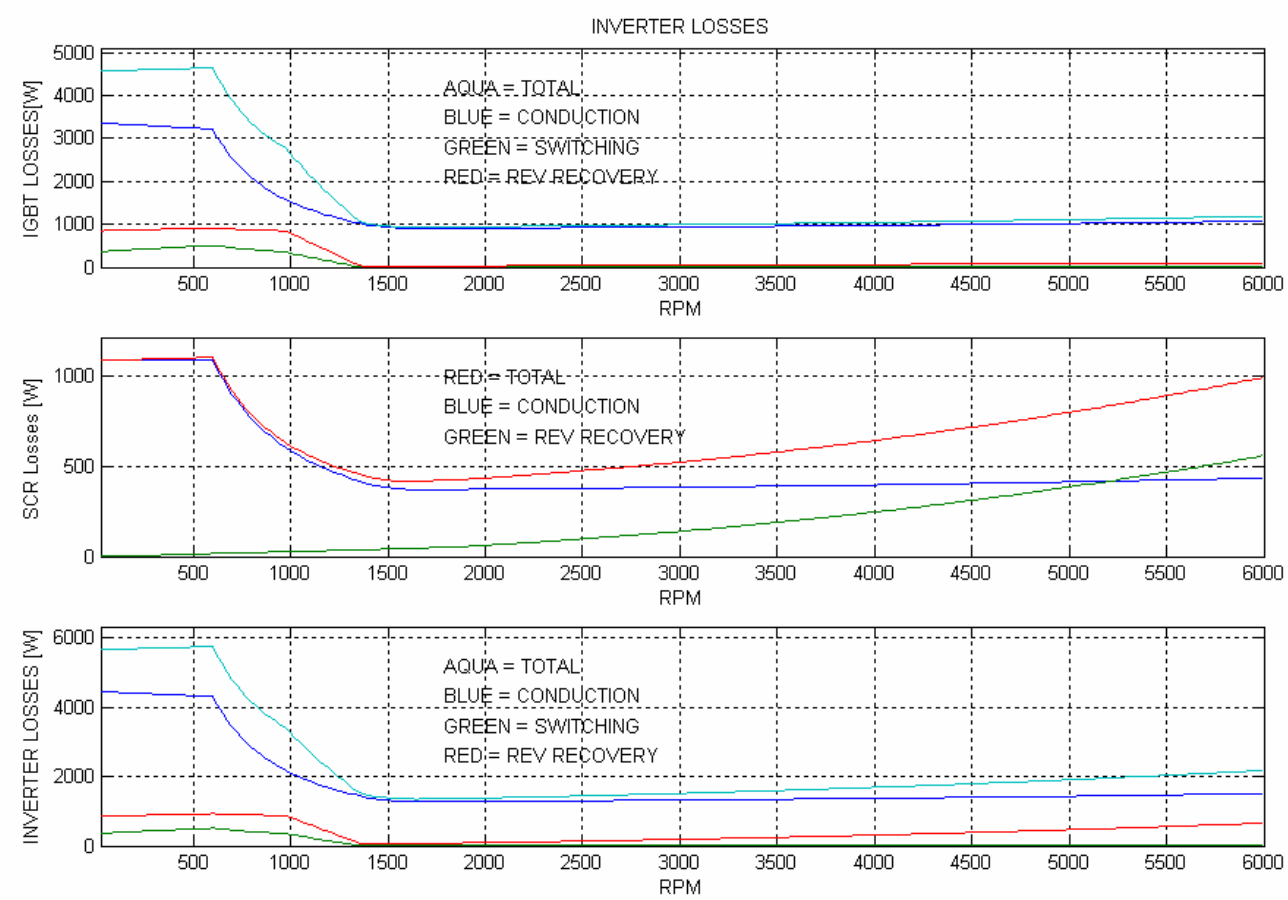

(b) IGBT losses, SCR losses, and total inverter losses.
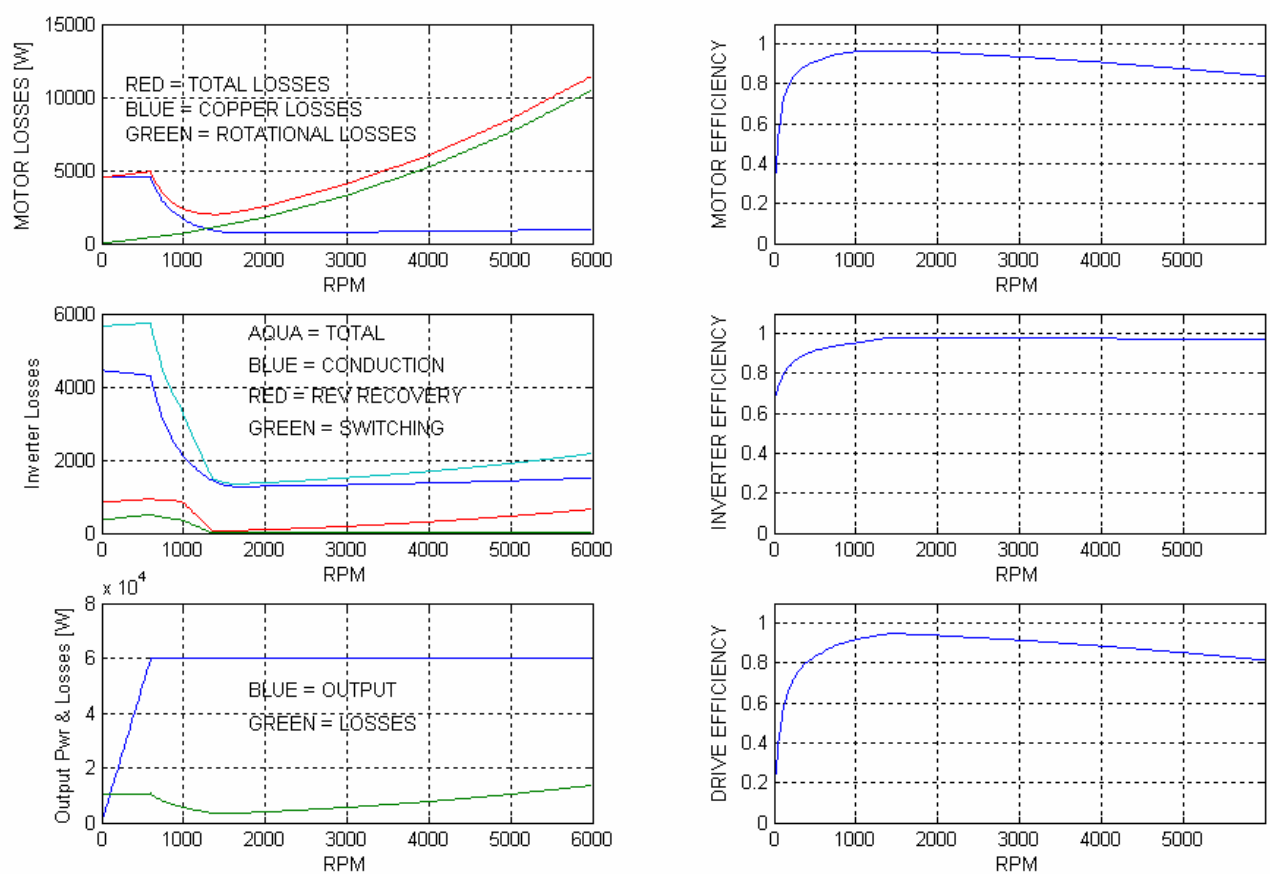

(c) Motor losses and efficiency, inverter losses and efficiency, and output power total losses and drive efficiency.

Fig. 25. Performance of Deere 1 driven at maximum torque by DMIC from 0-6000 rpm, with rotational losses (cont'd). 
The plots in Fig. 25(a) show that the DMIC driven Deere 1 meets the torque-speed, power-speed envelope required by the Deere application. The rms current drops from the rated value of 314.3 Arms required to produce rated torque at and below base speed to approximately $140 \mathrm{~A}$ at $1600 \mathrm{rpm}$. Beyond $1600 \mathrm{rpm}$, this value rises slightly in order to compensate for rotational losses.

The IGBT losses in Fig. 25(b) are virtually identical to those observed with CPA in Fig. 20(b). The SCR losses clearly show that the thyristor reverse-recovery losses increase with speed due to increased back-emf voltage to be blocked and increased $d i / d t$. The reverse-recovery losses grow at a rate that is more than linear with speed.

Figure 25(c) is about the same as for the CPA case shown in Fig. 20(c). Both cases show the dominance of the rotational losses of the Deere 1 design on the motor and total drive losses and efficiency.

The model was also used to explore the impact of partial-to-full load conditions on loss performance. The model was used to calculate total motor, inverter, and drive losses for speeds from $25-6000 \mathrm{rpm}$ in steps of $25 \mathrm{rpm}$ and 600 load steps from zero to full load. The results are graphically displayed in the 3D plots of Fig. 26.
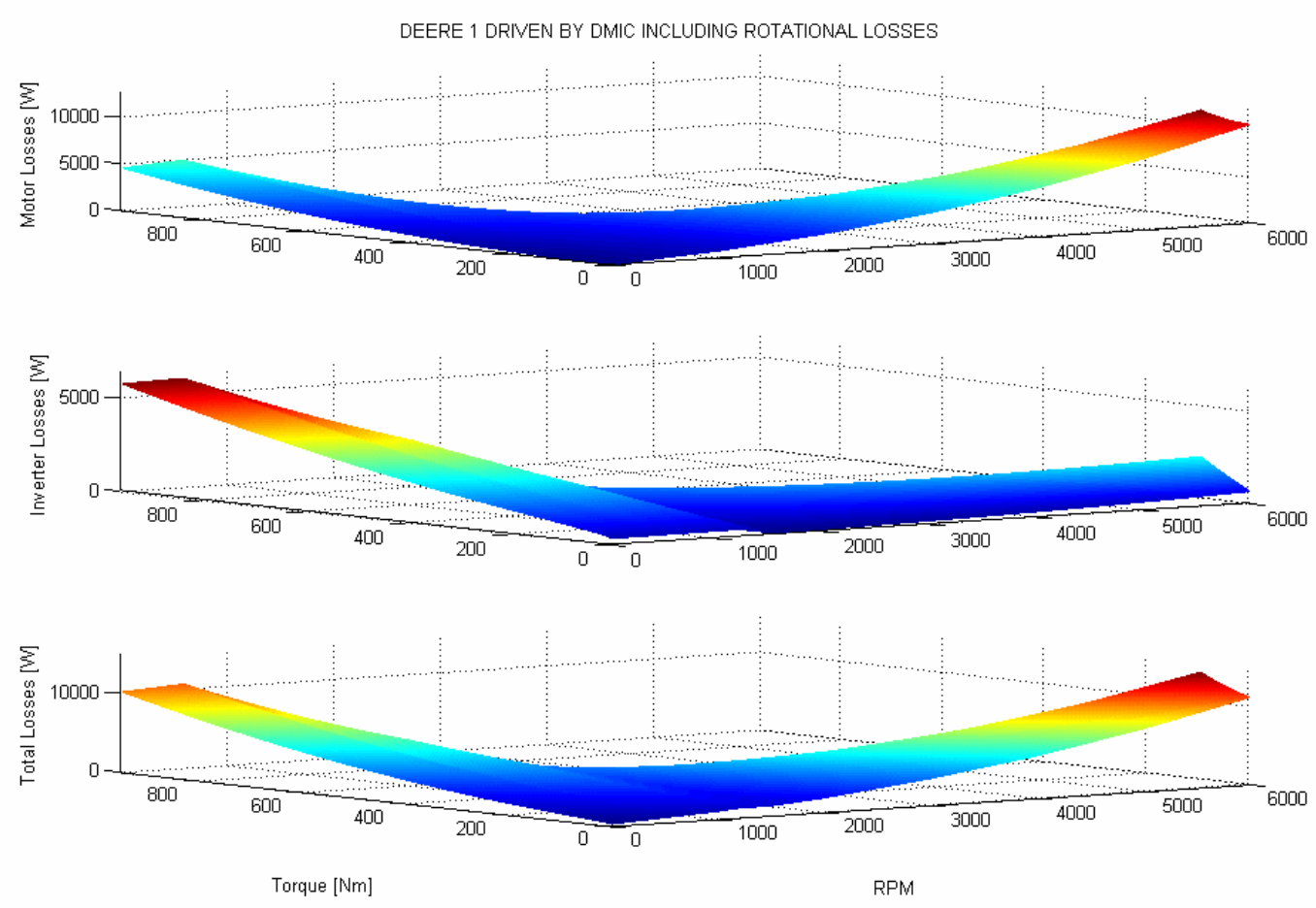

Fig. 26. Motor, inverter, and total losses of Deere 1 driven by DMIC vs. torque and speed with rotational losses.

The low-speed motor losses with DMIC depicted in Fig. 26 are about the same as those shown for CPA in Fig. 21. However, the high-speed motor losses are lower with DMIC due to the reduced current and lower copper losses. The low speed/full load inverter losses with DMIC in 
Fig. 26 are about $1 \mathrm{~kW}$ higher than with CPA in Fig. 21. This is due to the additional conduction losses associated with the SCRs. At high speed, the DMIC has significantly lower inverter losses at full load and especially at reduced load. Note that the total drive losses with DMIC at $6000 \mathrm{rpm}$ are $1-4 \mathrm{~kW}$ lower with DMIC than with CPA.

Efficiency contour plots corresponding to the data in Fig. 26 are displayed in Fig. 27.
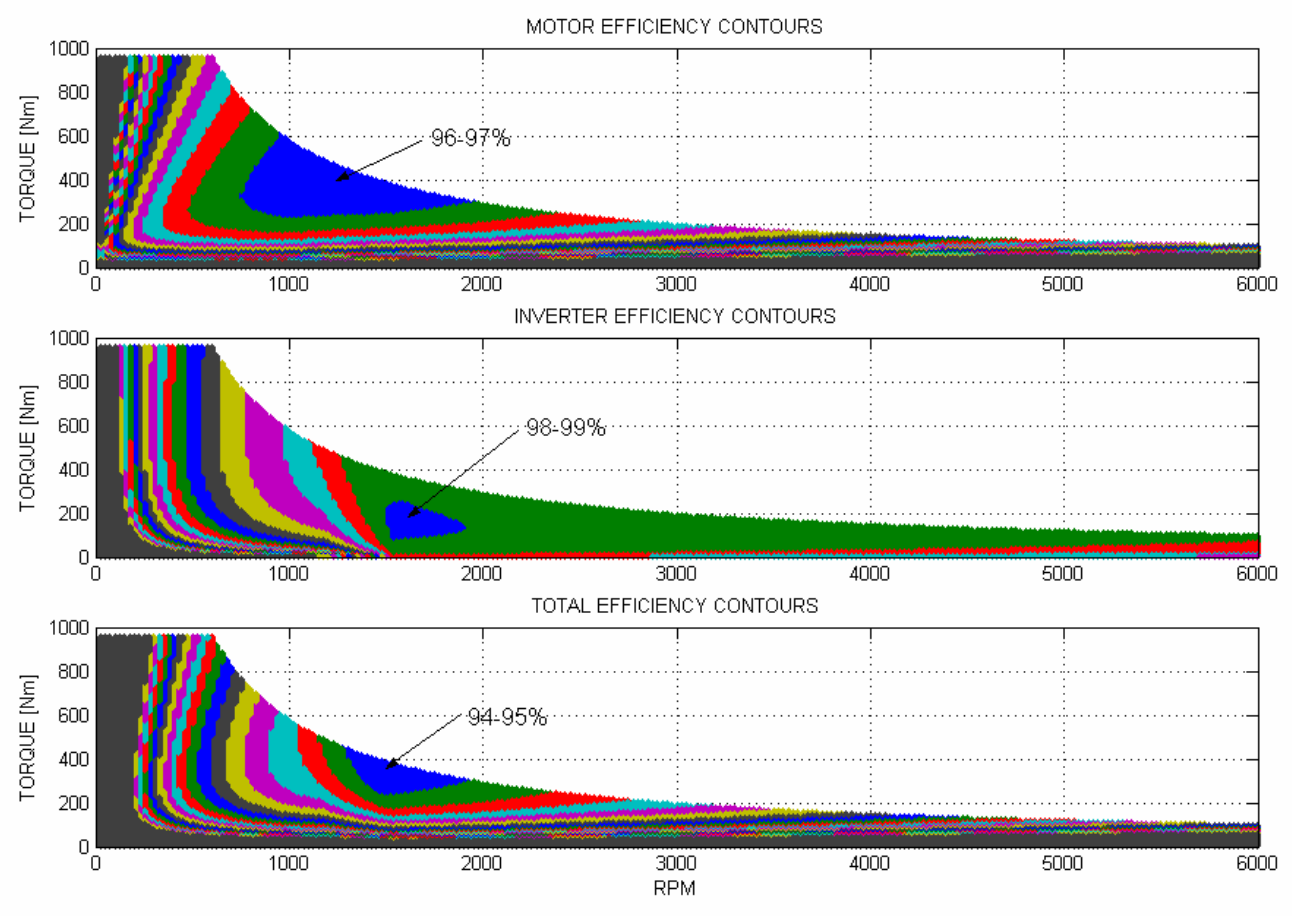

Fig. 27. Motor, inverter, and total drive-efficiency contours overlayed on the torque-speed envelope of the Deere application for Deere 1 driven by DMIC with the effects of rotational losses.

The rotational losses of the Deere 1 design are so large that they make performance differences between DMIC and CPA difficult to see in the comparison of Fig. 27 for DMIC and the corresponding Fig. 22 for the CPA drive. The differences between the CPA and DMIC drives for Deere 1 are made clearer in Section 5.3 where rotational losses are neglected and the loss/efficiency curves of the CPA and DMIC drives for Deere 1 are placed side-by-side.

\subsubsection{Deere 1 Driven by DMIC Neglecting Rotational Losses}

The simulations in the previous section were repeated with rotational losses neglected. Figure 28 compares the motor, inverter, and total losses of the DMIC driven Deere 1 with and without the rotational losses. Figure 29 shows the motor, inverter, and total efficiency contours of Deere 1 driven by DMIC with and without rotational losses. 

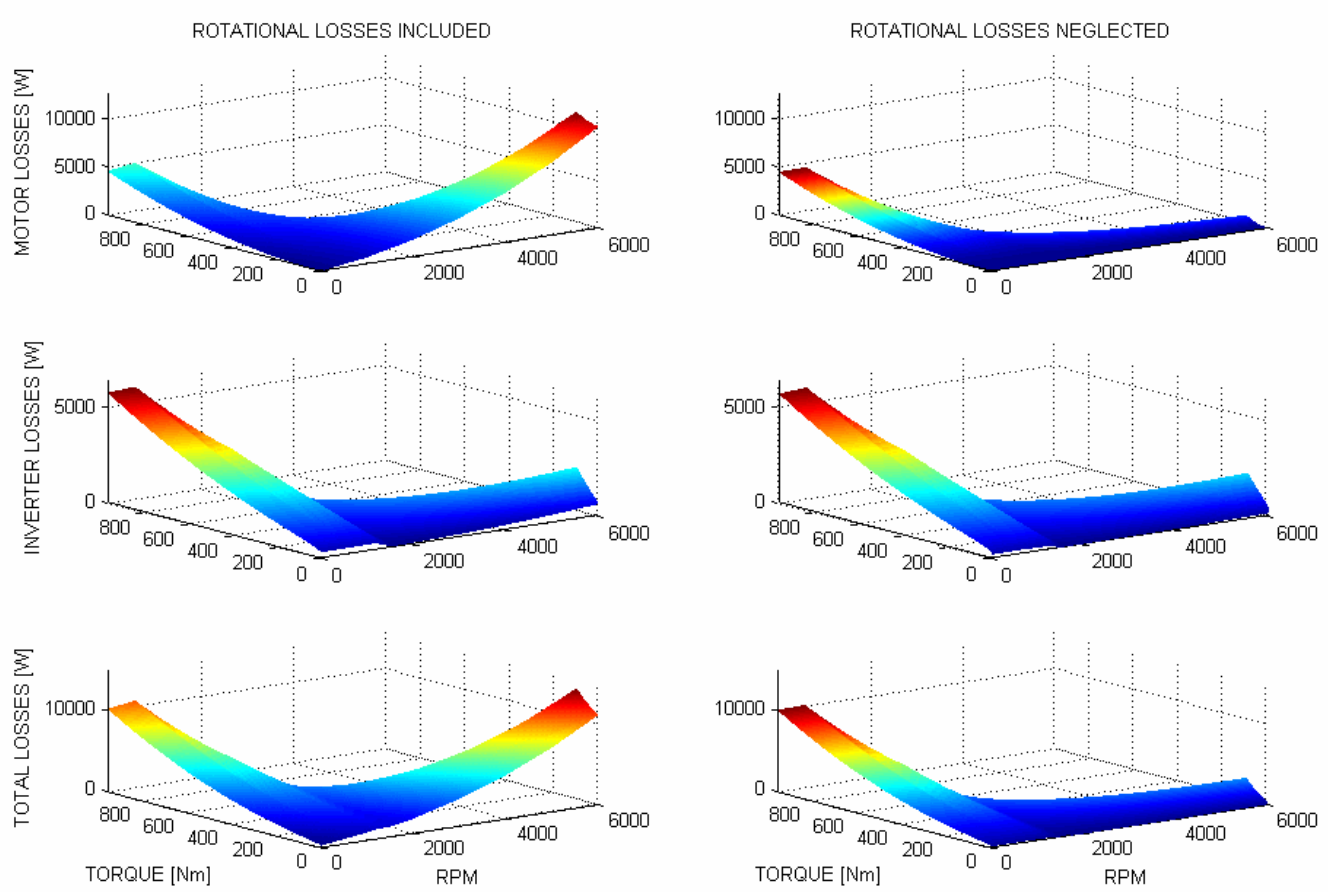

Fig. 28 Comparison of the motor, inverter, and total losses of Deere 1 driven by DMIC with and without rotational losses.
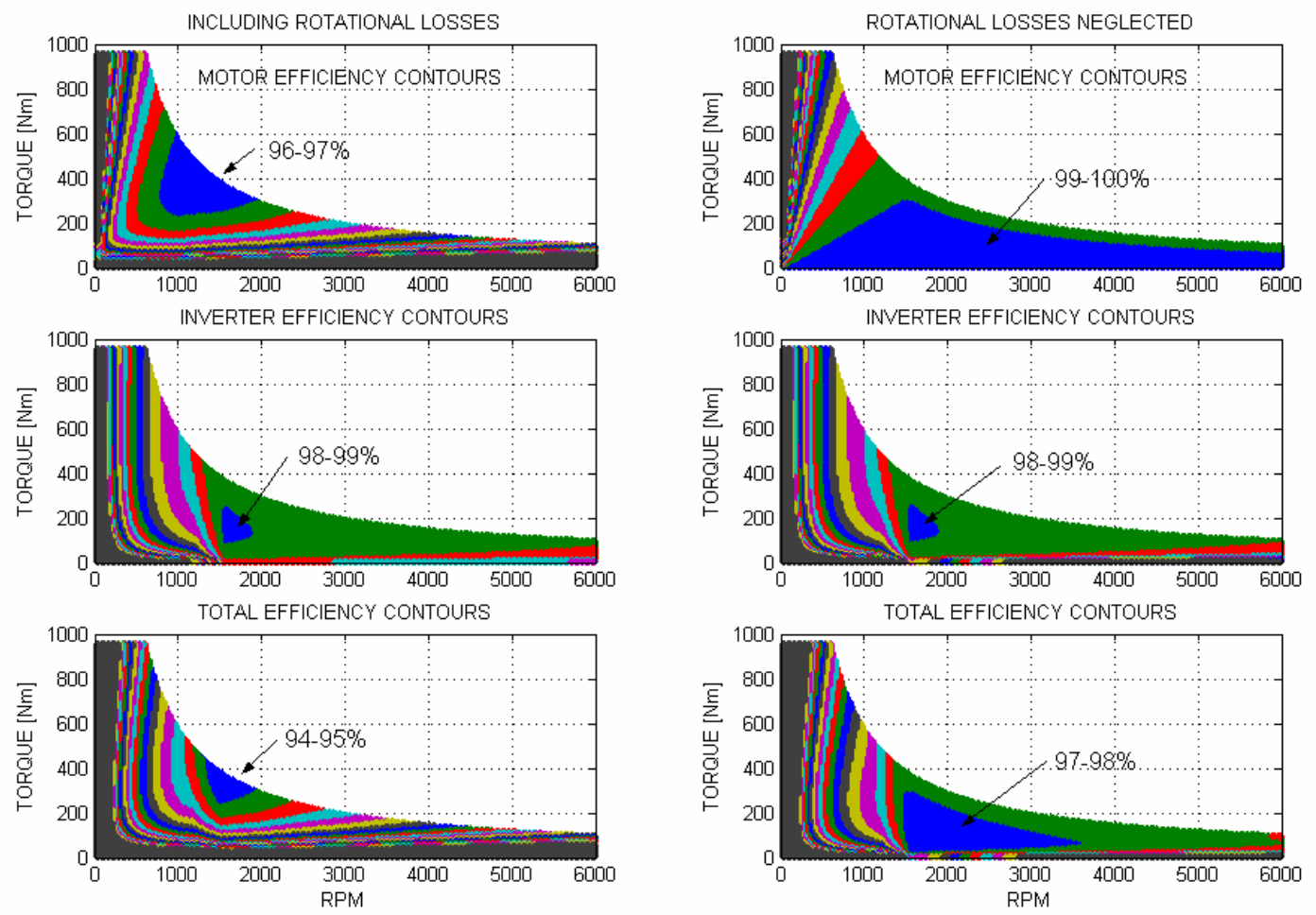

Fig. 29. Comparison of motor, inverter, and total drive-efficiency contours of Deere 1 driven by DMIC with and without rotational losses. 
Figure 28 shows the substantial improvement in high-speed motor and overall drive losses with the elimination of the rotational losses. There is a slight, but discernible, decrease in the highspeed inverter losses when rotational losses are eliminated.

Figure 29 shows the improvement in motor and overall efficiency when rotational losses are eliminated. Overall efficiency is $96 \%$ or better for virtually all operating conditions beyond $1300 \mathrm{rpm}$. For the CPA drive depicted in Fig. 24, the rpm range for $96 \%$ or better after the elimination of rotational losses is approximately 1300-2700 rpm and doesn't include light-load conditions at the upper end of the speed range.

The modeled performance of the Deere 1 design driven by CPA and DMIC are compared in the next section.

\subsection{COMPARISON OF THE MODELED PERFORMANCE OF DEERE 1 DRIVEN BY CPA AND DMIC}

The modeled performances of the Deere 1 design driven by CPA and DMIC have been considered separately above. In this section, the loss and efficiency performance of the two control methods are compared side-by-side. Rotational losses are neglected in order to sharpen the distinction between the two methods. Figure 30 compares the total motor, inverter, and drive losses while the motor, inverter, and overall drive efficiency are compared in Fig. 31.
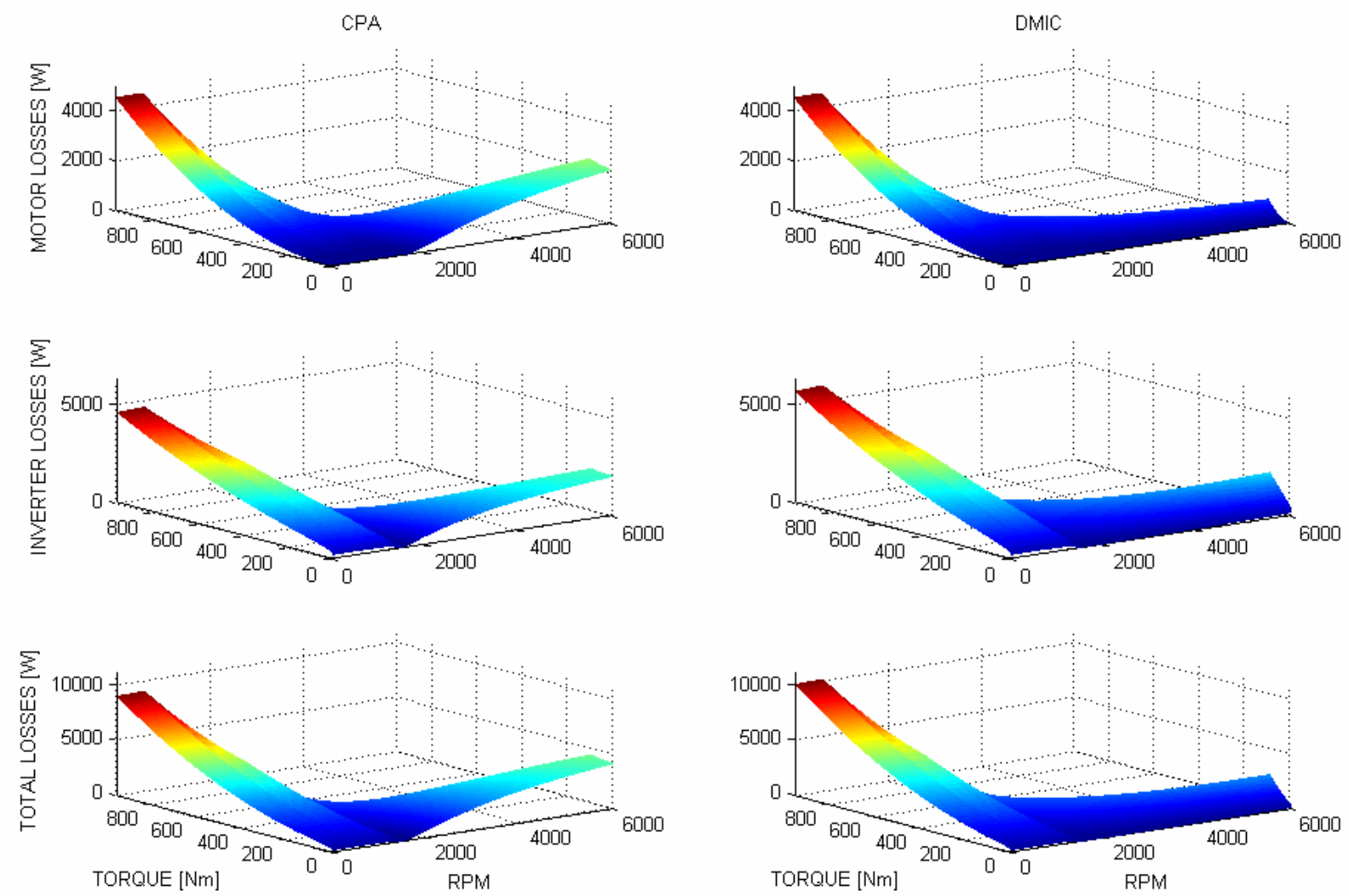

Fig. 30. Comparison of the motor, inverter, and total losses of Deere 1 driven by CPA and DMIC with rotational losses neglected. 

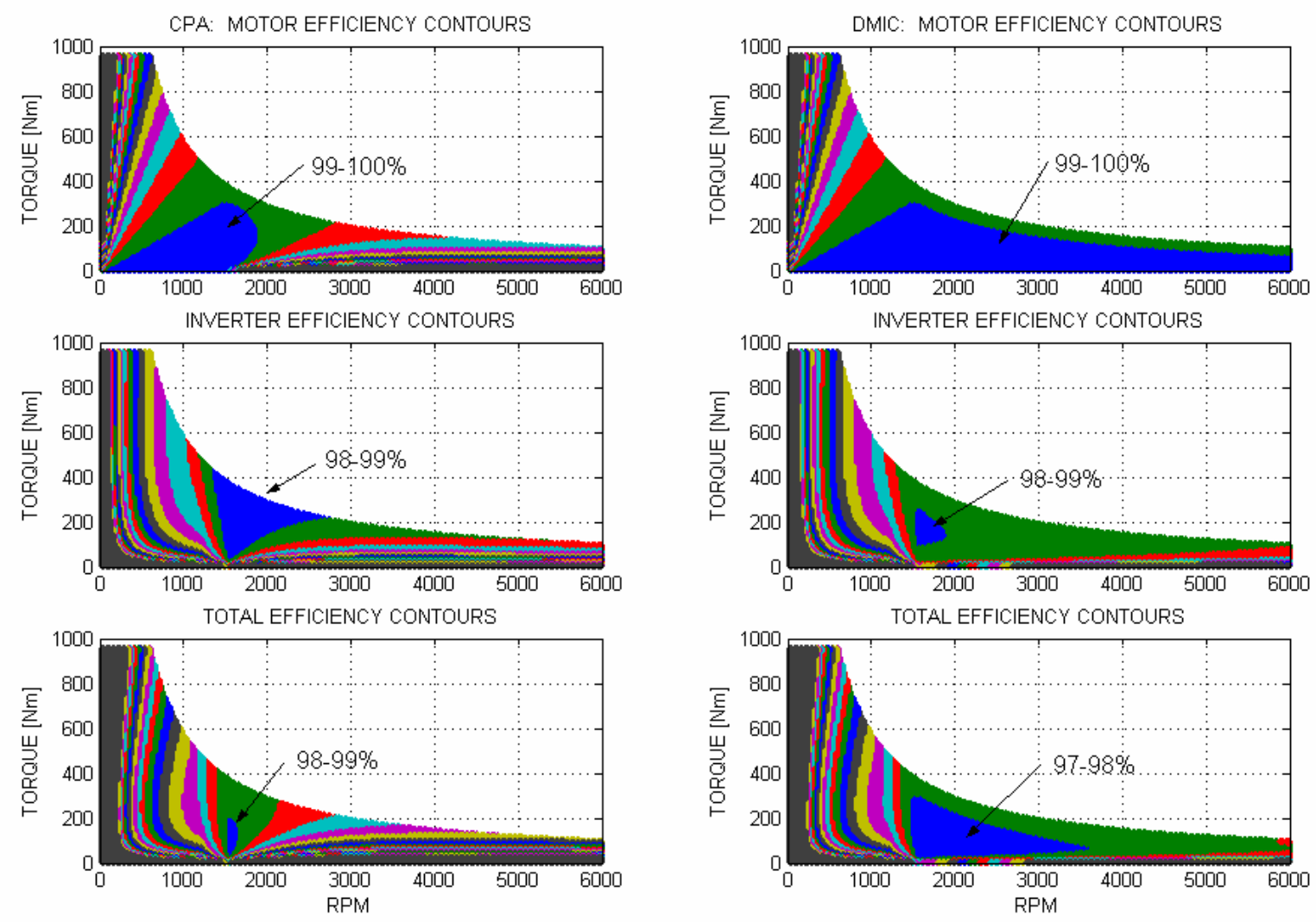

Fig. 31. Comparison of motor, inverter, and total drive-efficiency contours of Deere 1 driven by CPA and DMIC with rotational losses neglected.

Note in Fig. 30 that the motor losses at low speed are essentially the same but beyond $2000 \mathrm{rpm}$ the motor losses are significantly lower with DMIC. The inverter losses at low speed and full load are about $1 \mathrm{~kW}$ higher with DMIC due to the addition of the SCRs. At high speed, the inverter losses are lower with DMIC particularly at less than full load. Total losses of the CPA drive are lower than DMIC at and below base speed, again due to the SCRs in the DMIC inverter. At speeds above $2000 \mathrm{rpm}$, the total losses are lower with DMIC.

Figure 31 shows that the rpm range of highest motor efficiency is much larger with the DMIC and extends from low speed/medium load to any load condition at high speed. For the CPA, the highest efficiency range extends from low speed/medium load to high-load conditions up to $3000 \mathrm{rpm}$. The two methods have similar overall efficiency characteristics up to about $2000 \mathrm{rpm}$. Beyond this range, the DMIC efficiency is higher.

The predicted performance of the DMIC driven Deere 2 drive is considered in the next section.

\subsection{DEERE 2 DRIVEN BY DMIC}

The Deere 2 design is compared based on the "typical" semiconductor parameters of Table 5 and "maximum" parameters that are displayed in Table 7. The maximum parameters were determined by doubling all loss effects in the VSI components. Since the focus here is on 
inverter effects, the rotational losses for both inverter cases are the design values given in Table 1.

Table 7. Maximum semiconductor parameters for the Deere 2 drive

\begin{tabular}{|c|c|}
\hline IGBT Conduction Losses & \\
\hline$E_{q}=2 \mathrm{~V}, R_{q}=0.008 \Omega$ & \\
\hline$E_{d}=1.2 \mathrm{~V}, R_{d}=0.0144 \Omega$ & \\
\hline Switching Losses & \\
\hline $\begin{array}{r}\log \left(E_{s w}\right)=1.0281 \log \left(I_{q-a v g}\right)+ \\
\left\{I_{q-a v g} \text { in A, } E_{s w} \text { in } \mu \text { joules/pulse, test }\right.\end{array}$ & $\begin{array}{l}2.2448 \\
\text { voltage }=300 \mathrm{~V}\}\end{array}$ \\
\hline Bypass Diode Reverse Recovery & \\
\hline $\begin{array}{r}\left.\log \left(I_{r r}\right)=0.3604 \log \left(I_{q-a v g}\right)+1.61\right\} \\
\left\{I_{q-a v g} \text { and } I_{r r} \text { in A, test voltage }=30\right. \\
\log \left(t_{r r}\right)=-0.1047 \log \left(I_{q-a v g}\right)+2.6 \\
\left\{I_{q-a v g} \text { in A, } t_{r r} \text { in nsec, test voltage }=3\right.\end{array}$ & $\begin{array}{l}37 \\
018\} \\
00 \mathrm{~V}\}\end{array}$ \\
\hline Thyristor Conduction Losses & \\
\hline$E_{\text {thy }}=0.95 \mathrm{~V}, R_{\text {thy }}=0.002 \Omega$ & \\
\hline Thyristor Reverse Recovery & \\
\hline $\begin{array}{l}\log \left(Q_{r r}\right)=0.2320 \log \left(\frac{d i}{d t}\right)+1.0703 \\
\left\{d i / d t \text { in amp/sec, } Q_{r r} \text { in } \mu \text { coulombs }\right\}\end{array}$ & \\
\hline
\end{tabular}

Figure 32 compares the total motor, inverter, and drive losses over the speed/load range required in the Deere application for the two sets of inverter parameters. Similarly, Fig. 33 compares the motor, inverter, and overall drive-efficiency contours. 

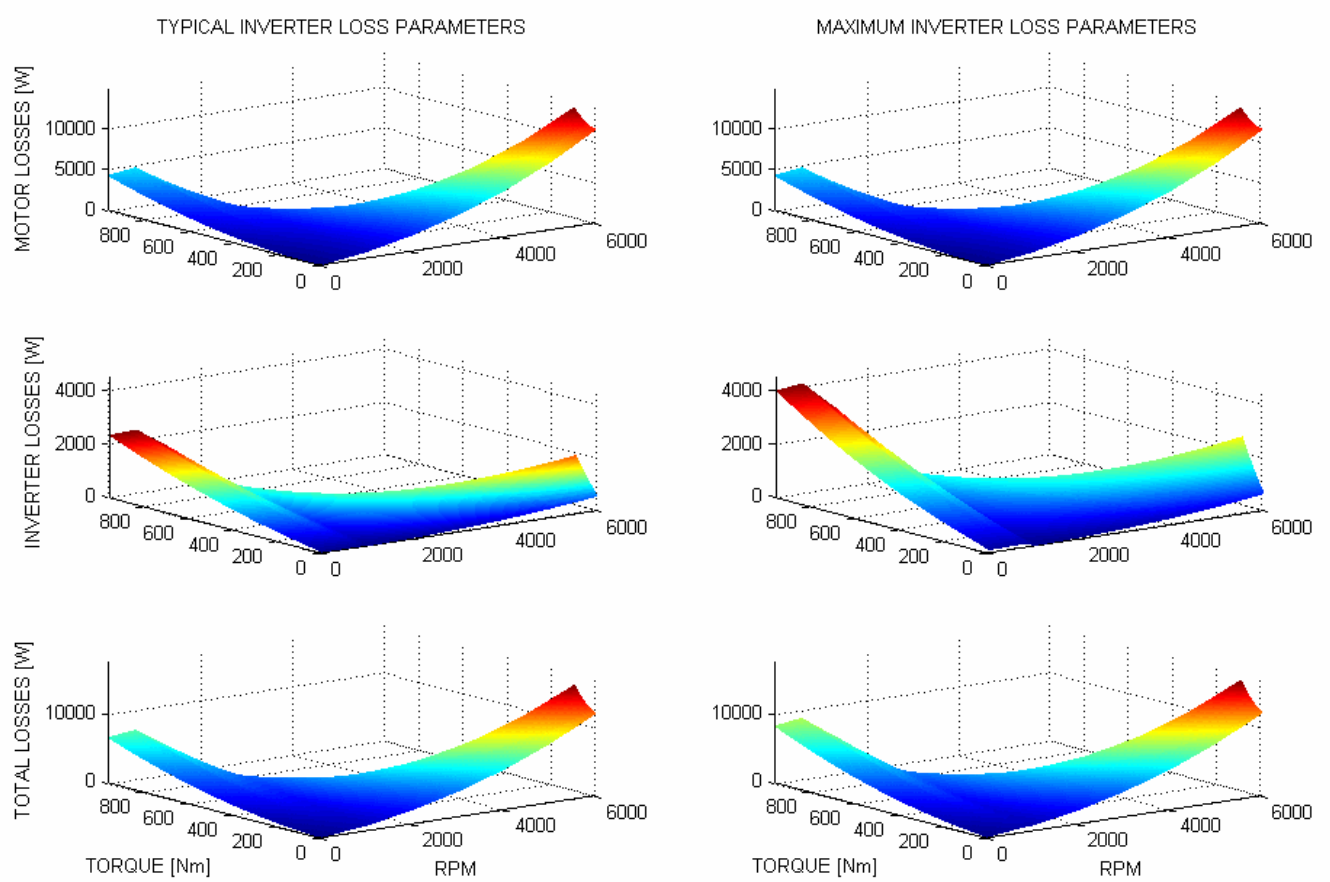

Fig. 32. Comparison of the motor, inverter, and total losses of Deere 2 driven by DMIC with "typical" and "maximum" VSI loss parameters.
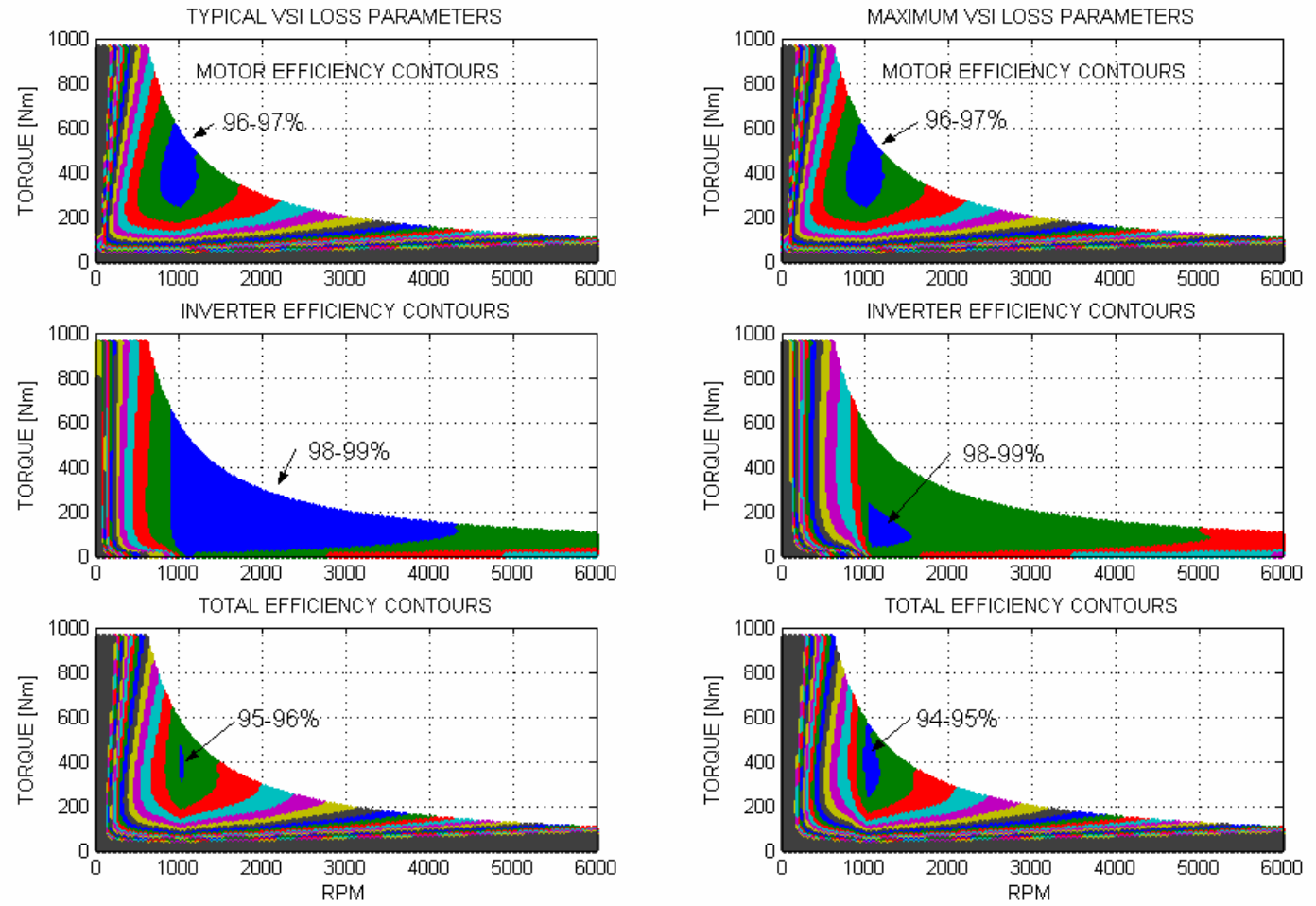

Fig. 33. Comparison of motor, inverter, and total drive-efficiency contours of Deere 2 driven by DMIC with "typical" and "maximum" VSI loss parameters. 
The motor losses in Fig. 33 are essentially identical for the typical and maximum inverter-lossparameter cases. The doubling of the inverter losses is obvious at low speed, but at high speed the losses are higher for the maximum case but the increase is far less than a factor of 2 . Overall losses are higher at both low speed and high speed when the inverter losses assume the maximum values. Obviously, any drive can benefit from semiconductors lying in the typical rather than the maximum range. But the example does bring out the need for appropriate specifications.

The motor-efficiency contours in Fig. 33 are virtually the same between the typical and maximum VSI loss-parameter cases. Increasing the losses degrades the inverter and overall efficiency by about $1 \%$ at most operating conditions.

\subsection{COMPARISON OF THE DMIC DRIVEN DEERE 1 AND DEERE 2}

The loss/efficiency performance of the DMIC drives for Deere 1 and Deere 2 are compared in this section. Semiconductor parameters are the "maximum" values of Tables 6 and 7 and for each motor the rotational losses are the values given in Table 1. The motor, inverter, and total losses are compared in Fig. 34 while the corresponding comparison of efficiency contours is given in Fig. 35.
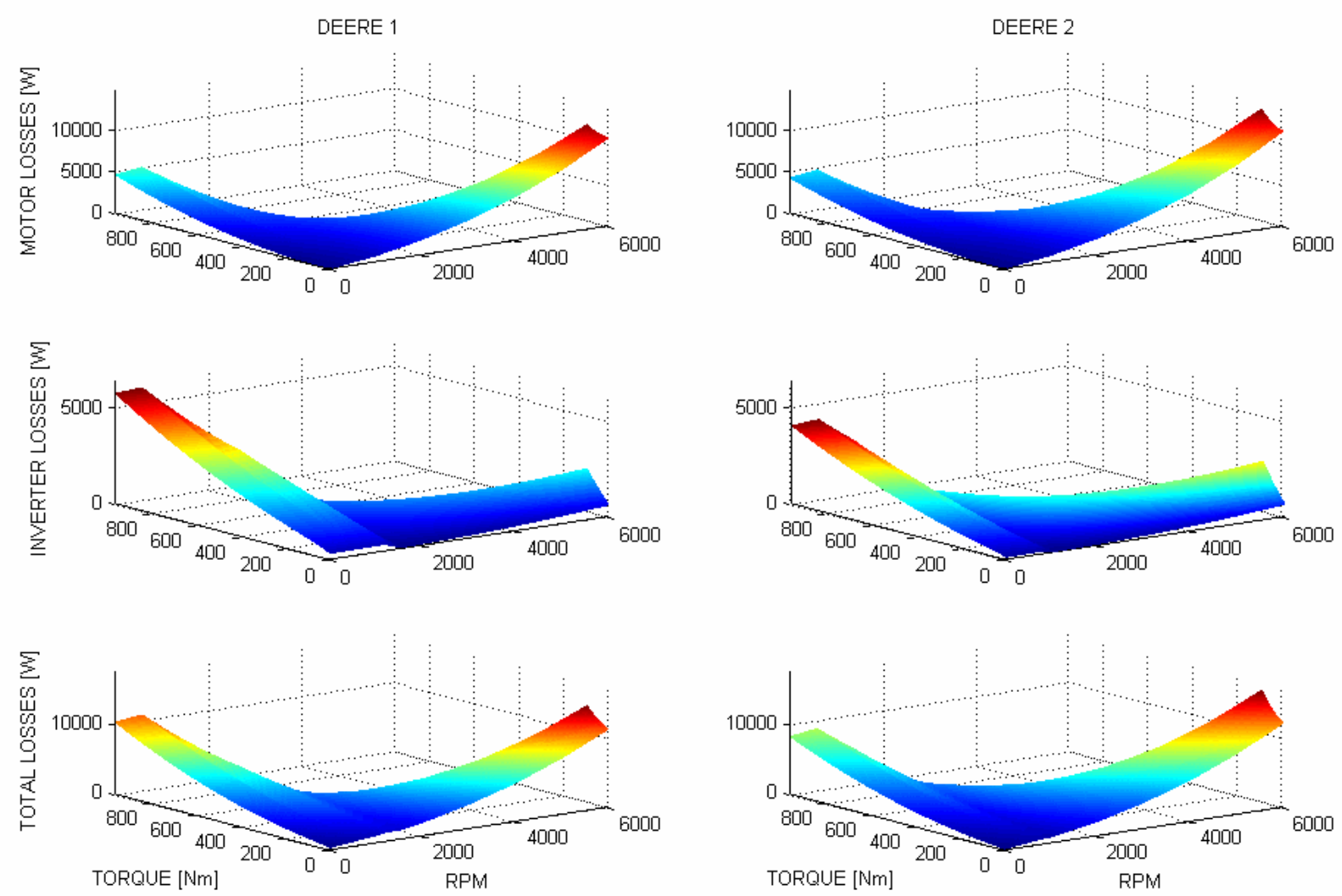

Fig. 34. Comparison of the motor, inverter, and total losses of Deere 1 and Deere 2 driven by DMIC with "maximum" VSI loss parameters and with rotational losses. 

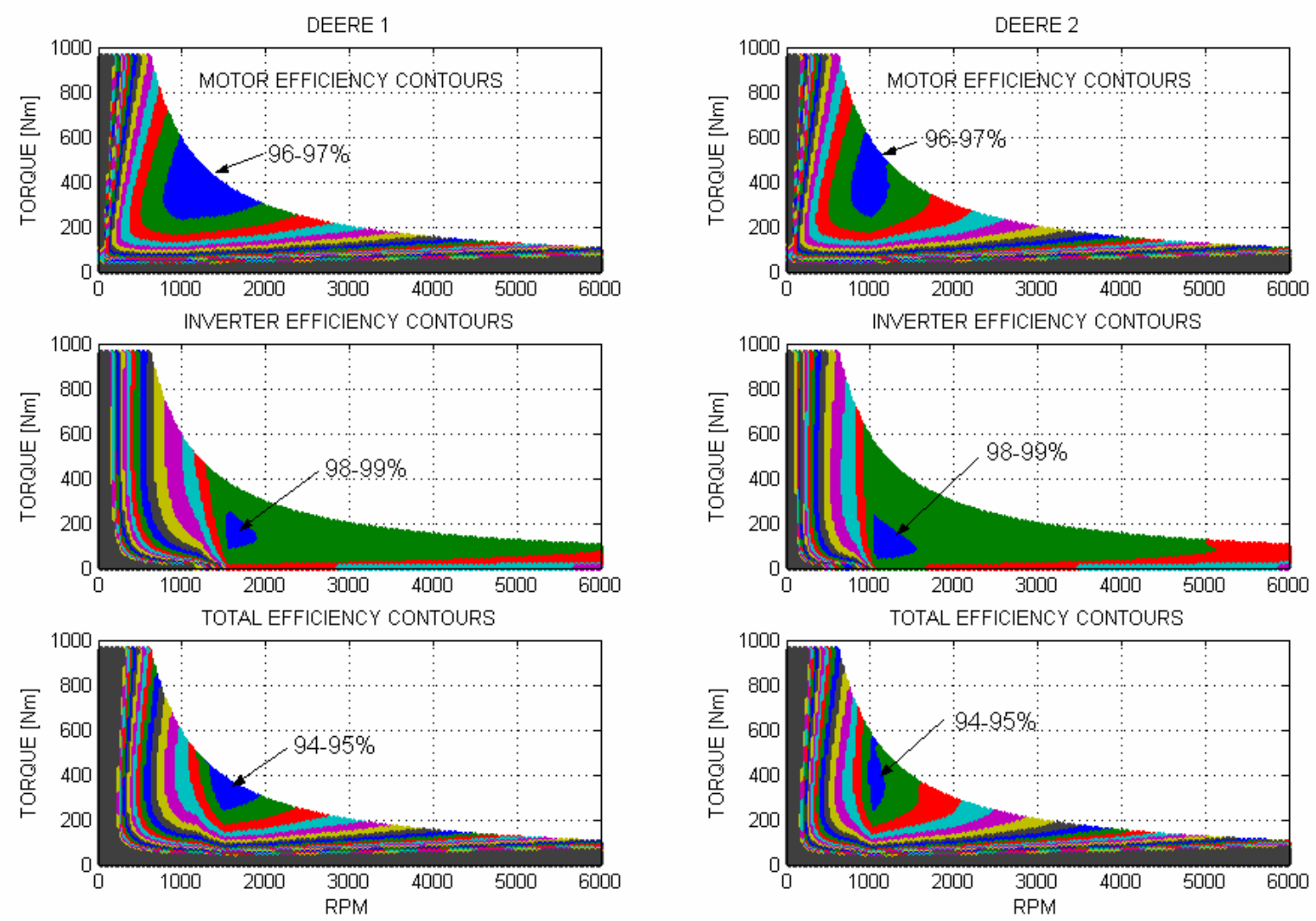

Fig. 35. Comparison of motor, inverter, and total drive-efficiency contours of Deere 1 and Deere 2 driven by DMIC with "maximum" VSI loss parameters and with rotational losses.

The motor losses of the two designs are very similar at low speed despite the lower rated current for Deere 2. The lower current rating of Deere 2 is offset by the fact that its resistance is twice as large as for Deere 1. At high speed, the motor losses of Deere 2 are higher which is at least partially due to an additional $800 \mathrm{~W}$ of rotational losses at $6000 \mathrm{rpm}$. Inverter losses are higher at low speed for Deere 1 which has the higher rated current; but Deere 1 has lower inverter losses at high speed. Overall losses are lower at low speed with Deere 2, but Deere 1 has the lower overall losses at high speed. There isn't a great deal of difference in the loss performance of the two designs and they would likely be even more nearly the same if they had the same rotational losses. The IGBTs for Deere 1 are 600 A devices while those for Deere 2 are 300 A devices. In principle, the Deere 2 design should have the lower cost inverter.

Figure 35 shows that the rpm regions of highest motor and overall efficiency are slightly larger for Deere 1 than Deere 2. Other than this observation, the efficiency of both drives is about the same.

Losses and efficiency are compared in the next section for Deere 1 driven by CPA and Deere 2 driven by DMIC. 


\subsection{COMPARISON OF THE CPA DRIVEN DEERE 1 AND DMIC DRIVEN DEERE 2}

The loss/efficiency performance of the CPA driven Deere 1 and the DMIC driven Deere 2 are compared in this section. Semiconductor parameters are the "typical" values of Tables 4 and 5 . The dc supply voltage is $360 \mathrm{~V}$ for both drives and to focus on the differences between CPA and DMIC the rotational losses are neglected. The motor, inverter, and total losses are compared in Fig. 36 while the corresponding comparison of efficiency contours is given in Fig. 37.
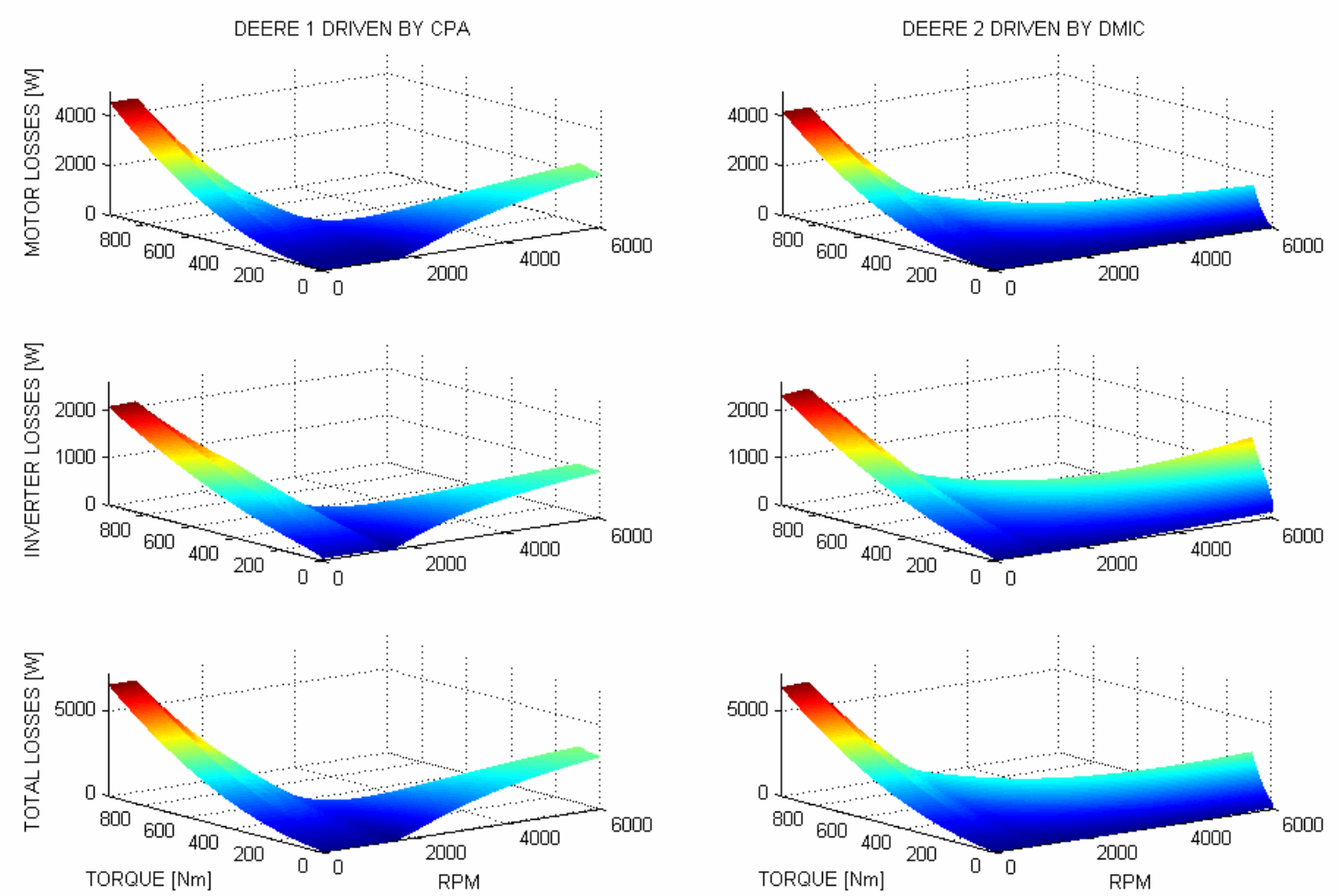

Fig. 36. Comparison of the motor, inverter, and total losses of Deere 1 driven by CPA and Deere 2 driven by DMIC with "typical" VSI loss parameters and rotational losses neglected.

The motor losses at low speed are slightly lower for Deere 2 despite the addition of the SCRs as well as the fact that the winding resistance in Deere 2 is twice the value for Deere 1 . This is due to the reduced current in Deere 2 resulting from the larger magnitude back emf. For most load conditions at speeds above $2000 \mathrm{rpm}$ the motor losses and total losses of Deere 2 are lower than for Deere 1. This is the result of the DMIC's ability to perform current-magnitude minimization at high speed. The inverter losses of Deere 2 are larger than for Deere 1 at high speed and full load due to the reverse-recovery losses of the SCRs. If Deere 2 were re-designed for fewer than 20 poles, the fundamental frequency would be reduced and the reverse-recovery losses of the SCRs would be correspondingly reduced. As noted in the previous section, the IGBTs in the Deere 1 VSI will be 600 A devices while 300 A devices can be used with Deere 2. 

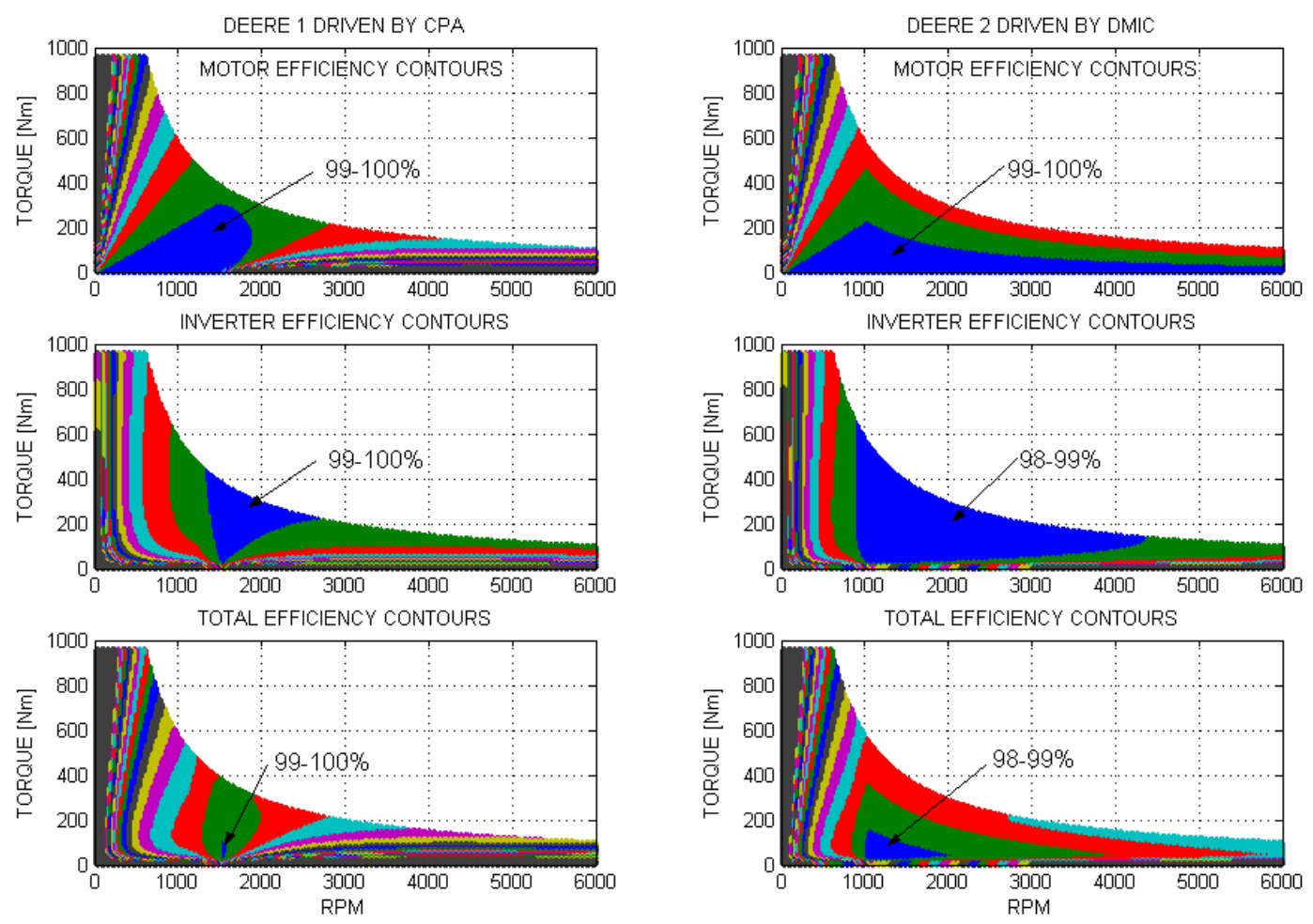

Fig. 37. Comparison of the motor, inverter, and total efficiency contours of Deere 1 driven by CPA and Deere 2 driven by DMIC with "typical” VSI loss parameters with rotational losses neglected.

The efficiency contours of Fig. 37 show that the performance of the two drives is very similar at low speed, while motor, inverter and total efficiency is better with Deere 2 for most load conditions beyond $2000 \mathrm{rpm}$. The figure confirms a basic conclusion that a drive that spends the bulk of its operating time in the vicinity of base speed and below will not benefit significantly from DMIC. However a drive that operates mainly well above base speed will have significant improvement in efficiency with DMIC.

Losses and efficiencies of Deere 1 driven by CPA are compared with those of Deere 1 driven by a modified DMIC in the next section.

\subsection{DEERE 1 DRIVEN BY THE MODIFIED DMIC}

The DMIC inverter of Fig. 4 involves the VSI and the ac voltage controller. Consequently, at any operating condition and speed, the motor current flows through the transistors/bypass diodes of the VSI and through the SCRs of the ac voltage controller. At low speed, the SCRs serve no control function and yet each SCR conducts for one half cycle. Similarly, at high speed the transistors serve no control function, and yet each transistor conducts motor current during a substantial portion of each half cycle. The efficiency of the DMIC can be improved by removing the SCRs during low-speed operation, thereby running solely on the VSI as in CPA; and removing the VSI during high-speed operation, thereby running solely on the ac voltage controller. An appropriately modified DMIC inverter is shown in Fig. 38. This configuration will be referred to as the "Modified DMIC." The addition of an in-line switch between the dc 
supply and positive rail of the VSI means that the Modified DMIC will have a cost even higher than that of the DMIC. However, this configuration maximizes motor, inverter, and overall drive efficiency across the entire range of speed and load. In applications where energy efficiency is a driving concern, this configuration may be highly desirable and will be superior in this respect to any equivalent CPA or DMIC drive.

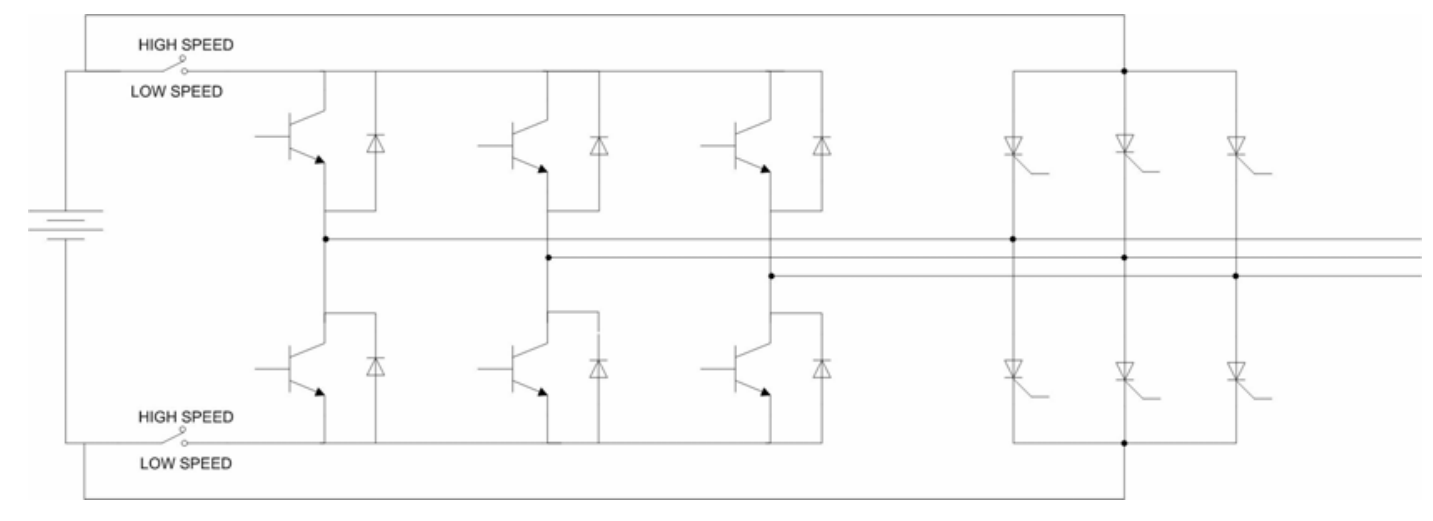

Fig. 38. Modified DMIC inverter.

The in-line switch in the Modified DMIC inverter has two positions denoted in Fig. 38 as "high speed" and "low speed." During low-speed operation, the SCRs are not fired and all motor current is supplied through the VSI components. This will improve low-speed efficiency by eliminating the extra losses associated with the SCRs. During high-speed operation, the transistors of the VSI are not fired and all motor current is supplied through the SCRs of the ac voltage controller. This improves high-speed efficiency by eliminating the extra losses associated with the VSI. The in-line switch could be a static switch, or preferably, a speedactivated mechanical switch. The switch can always be operated at low current by coordinating its operation with the firing of the transistors in the VSI and the SCRs. For transition from low speed to high speed, the firing of the SCRs would commence prior to opening the switch. Since the SCRs have inherently lower voltage drop than the IGBTs of the VSI, the motor current will be mainly carried by the SCRs. After one fundamental cycle of operating on both the VSI and SCRs, the switch can be changed to the high-speed position while there is low current flow through it. Conversely during the transition from high speed to low speed, the switch is operated with zero current flow through it and once closed, the firing of SCR Tx is replaced by the firing of IGBT Qx. After one fundamental cycle, the motor current is transferred completely from the SCRs to the VSI and there is no further firing of the SCRs. The scheme can use a hysteresis band to avoid continual switching back and forth between the high speed and low-speed modes during sustained operation of the vehicle at the boundary between high and low speed. In the envisioned control, the low-speed to high-speed transition would take place at a relative speed, say $n_{1}$, and the transition from high-speed to low-speed mode would take place at a lower relative speed, $n_{2}<n_{1}$. In this way, "chattering" of the switch would be avoided.

Figure 39(a), (b) and (c) show the performance of the Modified DMIC driving Deere 1 across the full speed range at maximum required torque. Figure 39(a) is identical to Fig. 25(a) which is for Deere 1 driven by DMIC. Comparing Fig. 25(b) with Fig. 39(b) shows the distinct difference between the regular DMIC and the Modified DMIC. In Fig. 25(b), it is clear that the motor 
current flows through both the VSI and the ac voltage controller components at all speeds. However, Fig. 39(b) shows that for the Modified DMIC that the motor operates solely on the VSI at "low speed," which is approximately $1625 \mathrm{rpm}$, and solely on the SCRs at high speed. Figures 25(c) and 39(c) are similar due to the fact that the rotational losses dominates all other loss mechanisms at high speed, i.e. it is difficult to see the improvement in over all efficiency due to the Modified DMIC configuration.
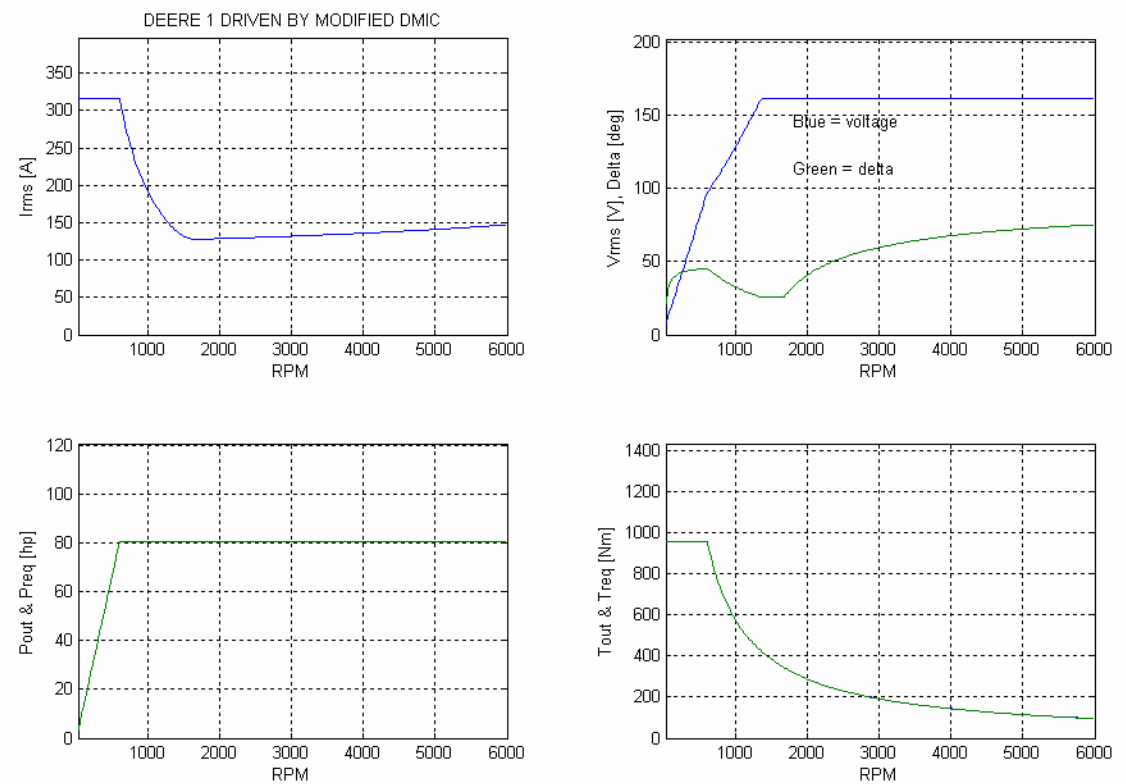

(a) Current, voltage, lead angle, power and torque vs. rpm
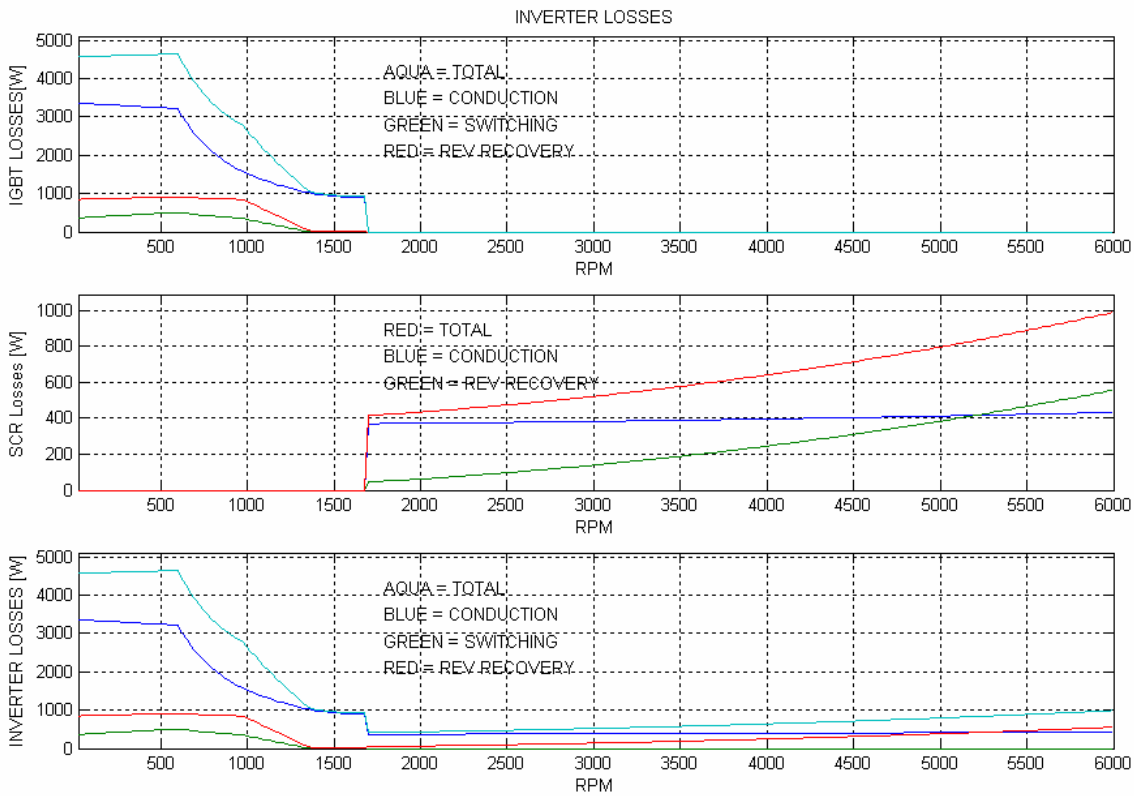

(b) IGBT losses, SCR losses, and total inverter losses.

Fig. 39. Performance of Deere 1 driven at maximum torque by Modified DMIC from 0-6000 rpm with rotational losses. 

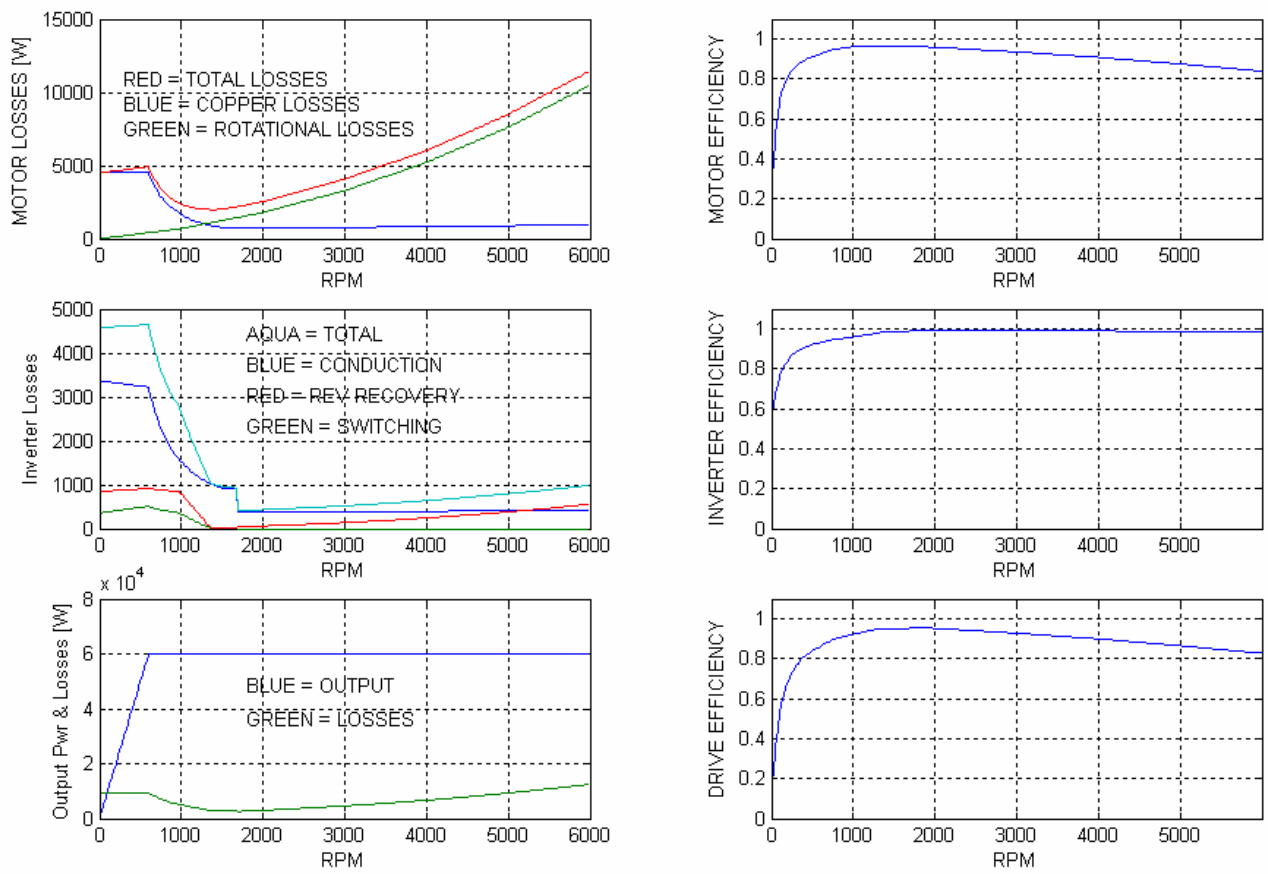

(c) Motor losses and efficiency, inverter losses and efficiency, output power, total losses, and drive efficiency.

Fig. 39. Performance of Deere 1 driven at maximum torque by Modified DMIC from 0-6000 rpm with rotational losses (cont'd).

To focus more clearly on the benefit of the Modified DMIC inverter, the rotational losses are neglected and the motor, inverter, and total losses of Deere 1 driven by CPA are compared with the losses of Deere 1 driven by the Modified DMIC in Fig. 40. The semiconductor loss parameters are the "maximum" loss parameters given in Table 6. The corresponding motor, inverter, and total efficiency contours are shown in Fig. 41. 

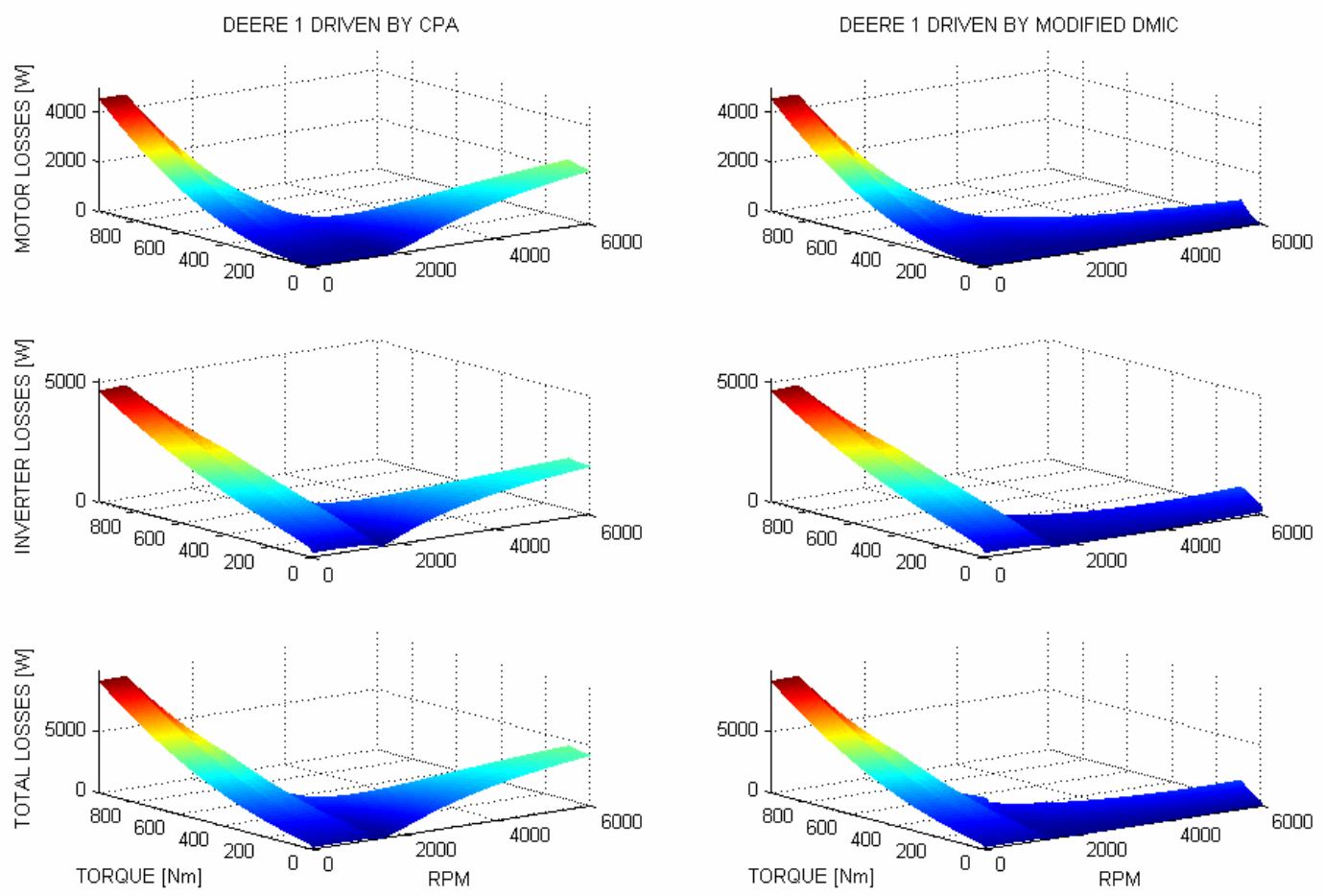

Fig. 40. Comparison of the motor, inverter, and total losses of Deere 1 driven by Deere 1 with CPA and Deere 1 with Modified DMIC without rotational losses.
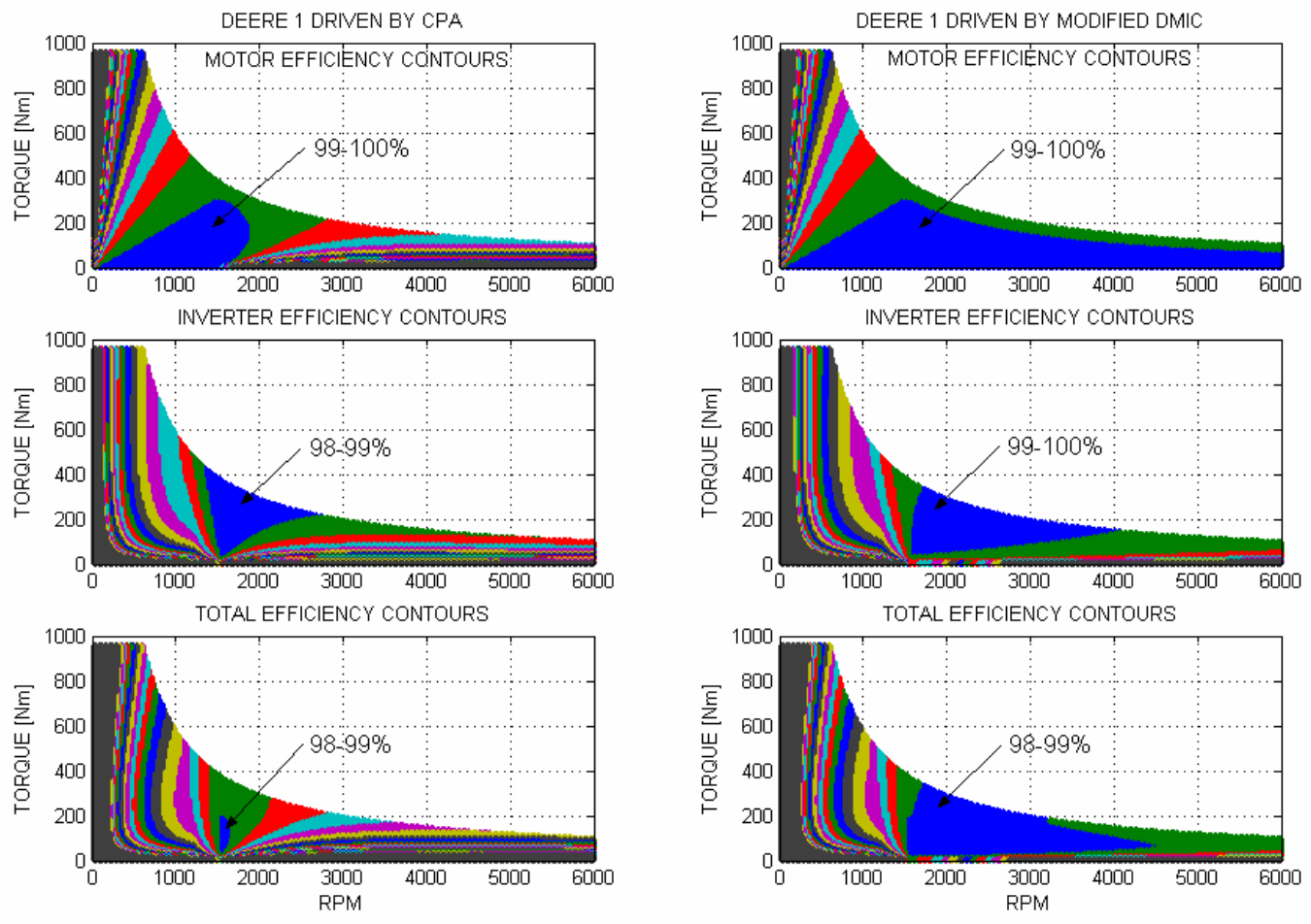

Fig. 41. Comparison of motor, inverter, and total drive-efficiency contours of Deere 1 driven by CPA and by Modified DMIC without rotational losses. 
Figure 40 shows that the loss profiles of the CPA and Modified DMIC Deere 1 drives are identical below base speed. Above base speed the motor, inverter, and total losses are lower for the Modified DMIC for all operating conditions from full load to no load. Note that at the $6000 \mathrm{rpm}$ top speed, the losses with the Modified DMIC are 3000-4500 W lower with the Modified DMIC as with CPA.

Figure 41 shows that for operating conditions below $1625 \mathrm{rpm}$ that the motor, inverter, and total efficiency of the Modified DMIC is the same as that of the CPA drive. However, for almost all load conditions beyond $1625 \mathrm{rpm}$, the overall drive efficiency with the Modified DMIC is at least $97 \%$ while for the CPA drive the efficiency can be $92 \%$ or less.

The Modified DMIC represents a configuration that provides the maximum possible motor, inverter, and overall efficiency. This configuration may be attractive in applications requiring a wide CPSR with emphasis on energy efficiency. 


\section{COST STUDY}

\subsection{MOTOR DESIGN AND SELECTION}

The baseline $60 \mathrm{~kW}$ motor, whose parameters are in Table 1, is named Deere 1 for this study and represents existing commercial technology. Both UQM and ORNL used their design capabilities attempting to design a lower cost motor with minimum possible inductance and a line-to-neutral rms back-emf of $94 \mathrm{~V}$ at a base speed of $600 \mathrm{rpm}$. This is the voltage that will not exceed the peak line-to-line $2300-\mathrm{V}$ insulation capabilities of the motor windings at $6000 \mathrm{rpm}(\mathrm{CPSR}=10)$. The equation for calculating the rms line-to-neutral back-emf is

$$
E_{\text {line-to-neutral }}^{\text {rms }}=\frac{E_{\text {line-to-line }}^{\text {peek }}}{\sqrt{3} \sqrt{2}} * \frac{600}{6000} .
$$

The UQM design, whose parameters are also in Table 1, is named Deere 2. It was selected for comparison with Deere 1 instead of the ORNL design, named Deere 3, because it achieved the desired power with less magnet material and was therefore cheapest (Table 8).

Table 8. Weight and cost comparison of three permanent magnet (PM) motor designs

\begin{tabular}{|l|c|c|c|c|}
\hline Motor Description & Lams(kg) & CU(kg) & Mag(kg) & $\begin{array}{c}\text { Pur(\$) - } \\
\text { \%Change }\end{array}$ \\
\hline Deere 1 & 56 & 14 & 3.2 & \\
\hline Deere 2 (UQM) & 49 & 13 & 3.5 & $-2.6 \%$ \\
\hline $\begin{array}{l}\text { Deere 3 (ORNL) not } \\
\text { selected }\end{array}$ & 51.5 & 13.1 & 4.8 & $5.0 \%$ \\
\hline
\end{tabular}

A discrepancy between ORNL's Deere 3 design and UQM's Deere 2 design is that Deere 3's $685 \mathrm{uH}$ inductance is much higher than Deere 2's $400 \mathrm{uH}$ inductance. The discrepancy, which still needs resolution, is between the standard inductance formulas used by ORNL and the finiteelement techniques used by UQM. It is possible that the standard formulas do not work as well for a larger number of poles, although ORNL has obtained good agreement between theoretical inductances and measured inductances for 18 pole axial-gap PM motors.

\subsection{MOTOR COST}

After development of the comparative motor designs, a purchase cost estimate was developed on the base motor from detailed quoted component material costs. These costs where extended to the redesigned motors by using a simplified commercial model. The investigation had hoped to find that the newly designed motors with reduced inductance and a stronger torque constant would yield some commercial benefit from reduction of materials. For the example under study, no benefit in motor cost reduction was found. From Table 8, one redesign did lead to a slight reduction while the other actually lead to a cost increase. For design 1 and 2, the cost estimate did not account for a higher-voltage insulation class to offset the impact of the motor seeing actual higher back-emf's. As a result, no motor cost reduction was found. The redesign did lead to some package size reduction, but was not significant. 


\subsection{INVERTER SEMICONDUCTOR COST}

To evaluate the inverter cost impact, a production quotation on the inverter used to drive the base motor was obtained. This inverter quotation was updated with a reduced peak-continuous current requirement to estimate base savings from silicon savings reduction due to increased motor torque constant. The savings had some impact on cost, but was limited. Next, the cost increase due to additional SCRs was investigated.

To estimate the cost impact due to the addition of SCRs, a semi-conductor manufacturer was engaged. Initially, due to the device frequency requirements, an inverter grade SCR was recommended. Previous testing and experience at ORNL indicated that, due to the soft nature of the current turn-off cycle, non-inverter grade devices have potential application. After sharing this experience and subsequent modeled current wave-forms, the semi-conductor manufacturer believed non-inverter grade would be possible. Non-inverter grade SCRs cost less than inverter grade SCRs. Actual testing of the devices was not done to confirm this application. Based on SCR cost information from the semi-conductor manufacturer, the addition of separate SCR components would lead to a significant inverter cost increase. One option to reduce this cost increase might be to combine the IGBT and SCR semi-conductors on the same direct bonded copper (DBC) substrate with wire bonding. This would be an opportunity for further investigation of DMIC technology system cost impacts. 


\section{CONCLUSIONS}

- Both Deere 1 and Deere 2 can meet a 10:1 CPSR requirement.

- The efficiency of the CPA driven Deere 1 is higher than that of the DMIC driven Deere 1 at speeds up to and slightly beyond base speed. The reason for this lies in the added losses resulting from the additional inverter components (thyristors) in the DMIC inverter. An application whose load involves a high percentage of operation in the vicinity of base speed will not likely benefit from DMIC.

- The use of the thyristors in the DMIC design allows the motor to be designed for high motor back-emf and lower motor current. The lower current handling requirement may allow the DMIC inverter to be lower in cost than the CPA inverter especially if the difference in current is at a "technology" breakpoint; e.g. if the use of DMIC were to allow 300A transistors to be used when 600A transistors would otherwise be required.

- The rotational losses of both motor designs are large at high speed and reach approximately $10 \mathrm{~kW}$ at the top speed of $6000 \mathrm{rpm}$. The cause of the rotational losses and means for substantially reducing them warrants further study. Reducing these losses would greatly enhance the overall efficiency of both the CPA and DMIC driven machines.

- The rotational losses at high speed dominate other loss mechanisms such as motor-copper losses and inverter losses. To sharpen the distinction between the DMIC and CPA driven cases relative to motor and inverter losses, the efficiency studies were performed twice. In the first analysis the rotational losses of Deere 1 and Deere 2, which are recorded in Table 1, were included while, in the second analysis, the rotational losses were neglected. Efficiency maps, with and without rotational losses, were constructed showing regions of similar efficiency plotted on the torque speed envelope of the drives.

- Above base speed, the efficiency of the DMIC driven Deere 2 configuration is superior to that of the CPA driven Deere 1. This is due to the current minimizing, optimal watt per amp control enabled by DMIC in the constant power mode. The efficiency enhancement of DMIC is most pronounced for load conditions less than full power when operating at high speed. The value of DMIC for Deere applications will depend strongly on the load-duty cycle. Applications with varying duty cycle that involve considerable operating time above base speed will have the greatest gain in energy efficiency from the application of DMIC.

- The Deere 2 redesign did lead to a slight cost reduction while the Deere 3 design actually led to a small cost increase; but, for the examples under study, no significant benefit in motor cost reduction was found.

- The redesign did lead to some slight but insignificant package size reduction.

- Drive efficiency can be improved, at high speed, using the DMIC even when the motor inductance is high. Providing additional dc supply voltage can further improve the advantage of DMIC relative to CPA.

- The main consideration in whether or not the DMIC has value in a given application depends greatly on how much time is spent at high speed and on load-duty cycle at high speed. A highly variable, high-speed load would benefit substantially from DMIC. A drive that spends the greatest portion of its time in the vicinity of base speed operating at near full load would most likely perform well with CPA 
- In this study there is little difference in performance between the Deere 1 and Deere 2 drives with respect to losses and efficiency so that selection decisions would necessarily be based on motor cost, which was not sufficient to pay for the DMIC's thyristors.

- For the examples under study, no significant benefit in motor cost reduction was found.

- Use of DMIC is a mismatch for the cases examined because motor redesign doesn't lead to motor cost reduction and the Deere application spends most of its duty cycle at or below base speed where the efficiency gains do not pay for the additional SCRs required by DMIC. 


\section{FUTURE COLLABORATION}

There are four types of research activities related to traction-motor drives that ORNL and Deere could collaborate on:

- Determination of the maximum commutation switching speed of thyristors (SCRs) and transistors (IGBTs).

- Search for Deere applications that have a large percentage of their duty cycle at high speeds and large load variations.

- Explore with Deere expansion of their product line to include traction drives for hybrid electric heavy on-road vehicles, such as 18-wheelers.

- Explore the use of switched reluctance motors (SRMs) operated in the continuousconduction mode for Deere applications.

- Explore the use of ORNL's High (magnetic) Strength Undiffused Brushless (HSUB) dc motors for use in Deere applications.

Economically beneficial collaborative research among Deere, UQM, and ORNL could identify and quantify the measured losses in the UQM motor and find ways to reduce these losses.

Another potentially useful collaborative research project among Deere, Semikron, and ORNL could identify methods of packaging VSI/SCR components to reduce DMIC inverter costs.

\subsection{MAXIMUM COMMUTATION SPEED OF THYRISTORS AND TRANSISTORS}

This collaborative research has shown that the primary justification for using DMIC is operational savings, which occur because of current minimization when a motor operates near the top of its CPSR and has a wide torque/power variation as shown in Fig. 36. The DMIC speed is limited by the maximum electrical frequency at which the semiconductor switches may operate. Electrical frequency, $f_{e l}$, is related to the mechanical rotational frequency, $\Omega_{\mathrm{rpm}}$, by

$$
f_{\text {electrical }}=\frac{\Omega_{r p m}}{60} \frac{p}{2},
$$

where $p$ is the number of magnetic poles. The circuit-commutated control time listed for the thyristors in this study range from 180-200 us. At $6000 \mathrm{rpm}$, this is about $1 / 4$ of the electrical period of operation. Future collaboration would be directed to show just how high thyristoroperating frequency may be pushed and indicate if it will be necessary to use IGBTs, which have circuit commutate switching time of 3-4 us but are more expensive.

\subsection{SEARCH FOR DEERE DMIC-USEFUL LIFETIME DUTY CYCLE MATCHES}

Deere provided a lifetime duty cycle for the application studied in the first collaboration which, although it demonstrated operational savings, did not spend a sufficient portion of its life demanding wide-power variations at high speeds to justify the cost of the additional DMIC thyristors. If a DMIC-useful lifetime duty cycle match may be found among Deere applications, 
future collaboration would be to estimate the actual benefit using the techniques for estimating motor losses developed during the initial collaboration.

\subsection{TRACTION DRIVES FOR HEAVY ON-ROAD VEHICLES}

An on-road heavy vehicle, such as an 18-wheeler which spends most of its life at highway speeds with very large power demands as it pulls and coasts on hills, has a DMIC-useful duty cycle match. If there are Deere applications like these, they could experience significant operational cost benefits. This might also fit into future Deere market applications if the company plans to provide traction drives for on-road hybrid electric vehicles like 18-wheelers.

\subsection{HIGH CPSR SRMs OPERATING IN THE CONTINUOUS-CONDUCTION MODE}

SRMs have many desirable features, such as ruggedness and simplicity, which make it attractive to Deere. But when operated in conventional mode where the current returns to zero after each work cycle, they have low-power densities that do not meet Deere's specifications.

There is a new application of SRMs operating in the continuous-conduction mode that Deere may want to consider for use in a traction drive for its off-road applications and possible future on-road applications [7]. Using a linear-magnetic model that neglects saturation, which proved to be highly accurate in predicting high-speed performance when the SRM operates in continuous conduction, this analysis shows that in the absence of speed sensitive losses, the CPSR of the SRM is infinite when continuous conduction is allowed. Therefore, the SRM is a candidate motor for all traction applications including those involving heavy vehicles which may require a CPSR of 10:1 or greater.

Analysis of an example SRM with 8 stator poles and 6 rotor poles, a base speed of $240 \mathrm{rpm}$, and a supply voltage of $700 \mathrm{Vdc}$ shows the benefit from continuous conduction. Figure 42 shows the phase A current, voltage, co-energy, and useful power at base speed with discontinuous conduction.

Figure 43 compares the phase A current, voltage, co-energy, and useful power for discontinuous conduction and continuous conduction at $6500 \mathrm{rpm}(\mathrm{n}=26)$. 

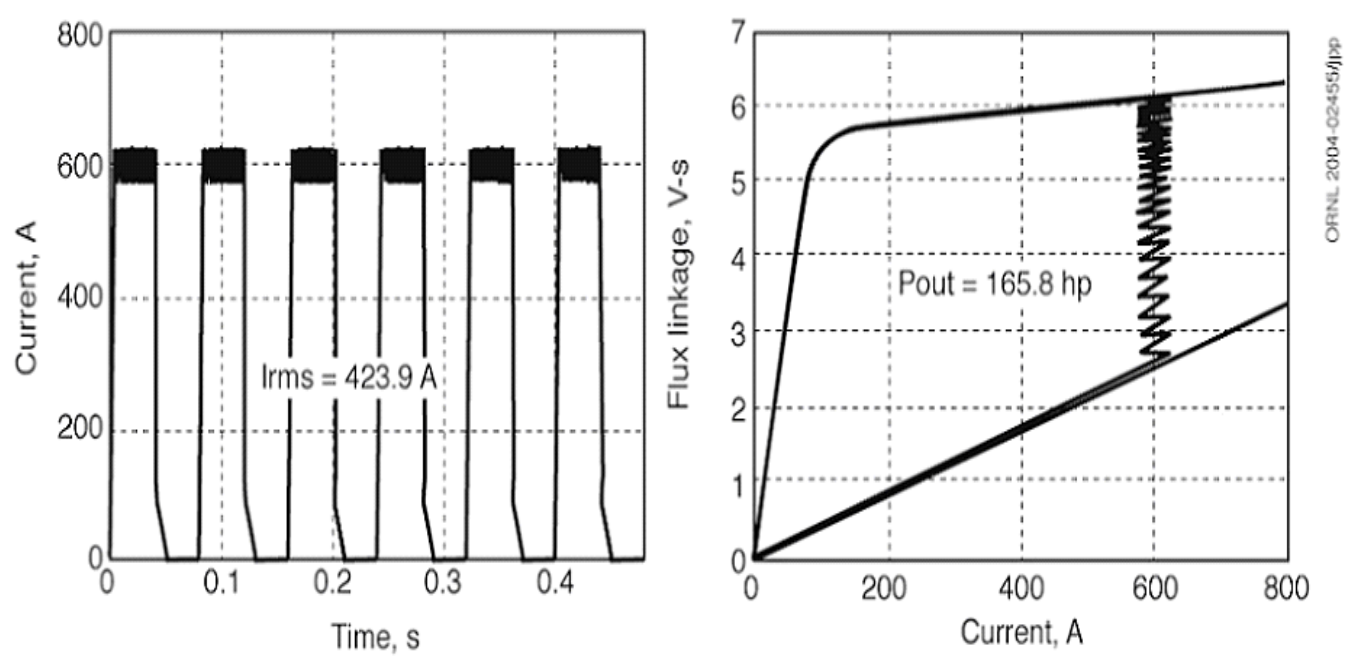

(a) $125 \mathrm{rpm}(\mathrm{n}=.05), \theta_{\mathrm{a}}=9.5^{\circ}, \theta_{d}=31.5^{\circ}$.
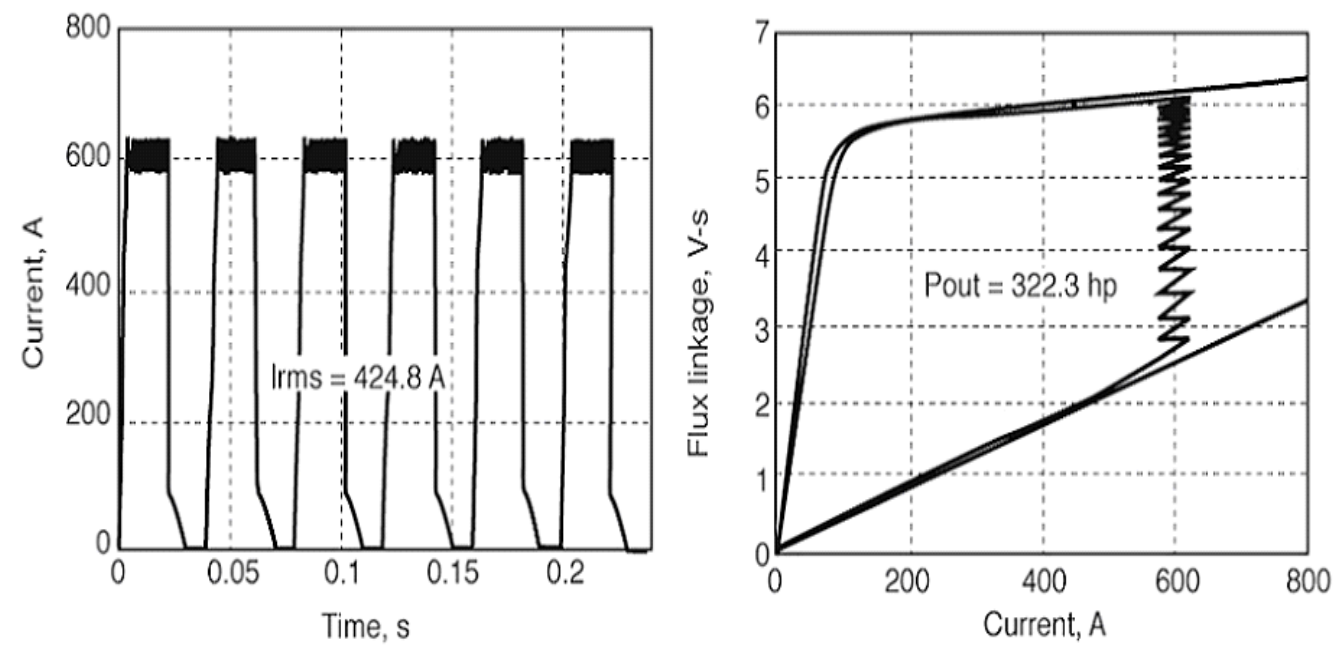

(b) $250 \operatorname{rpm}(\mathrm{n}=1.0), \theta_{\mathrm{a}}=11.25^{\circ}, \theta_{d}=32.75^{\circ}$.

Fig. 42. Phase A current, co-energy, and useful power for a hypothetical $320 \mathrm{hp} 8 / 6 \mathrm{SRM}$ at half-base speed and base speed with supply voltage, $V_{\mathrm{dc}}=700 \mathrm{~V}$, and current limit, $I_{\text {set }}=600 \mathrm{~A}$. 

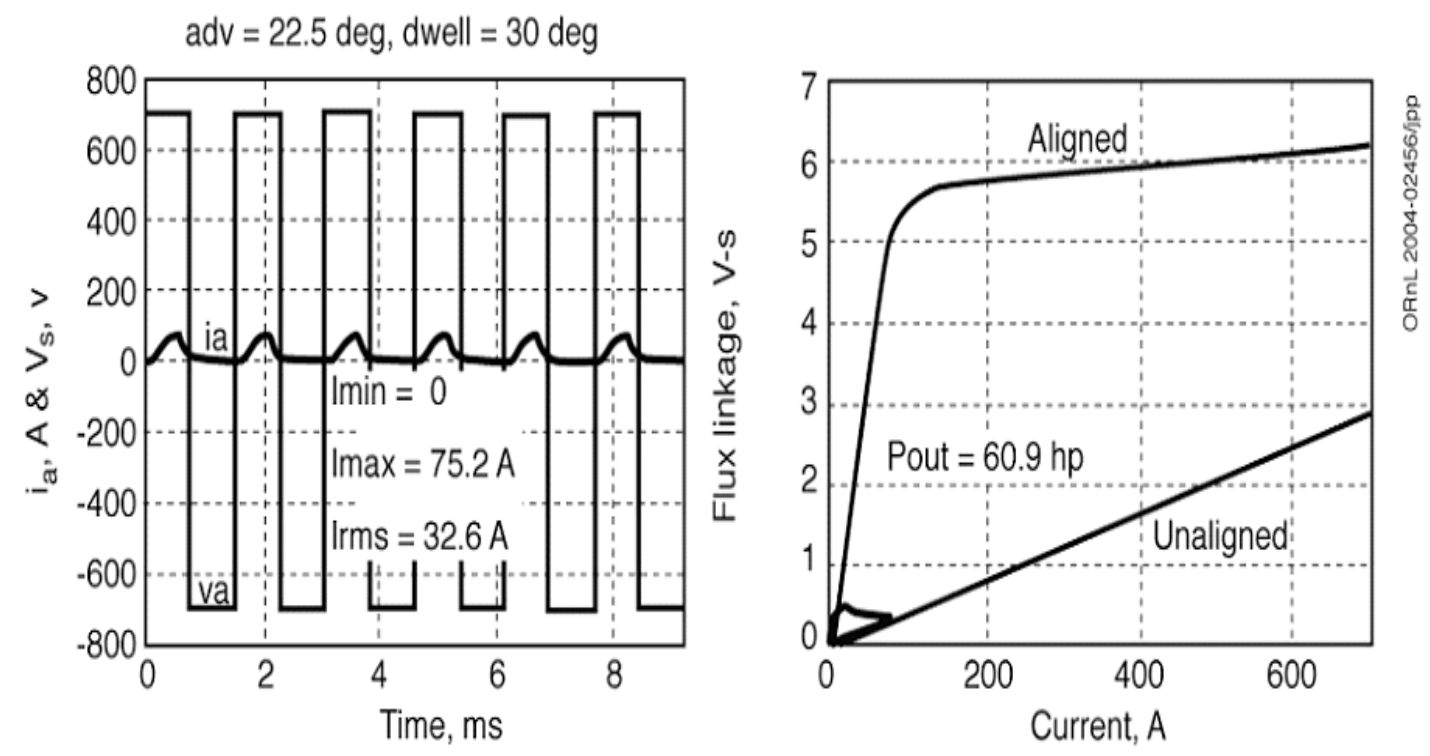

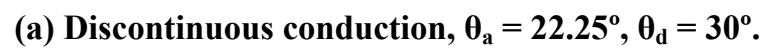
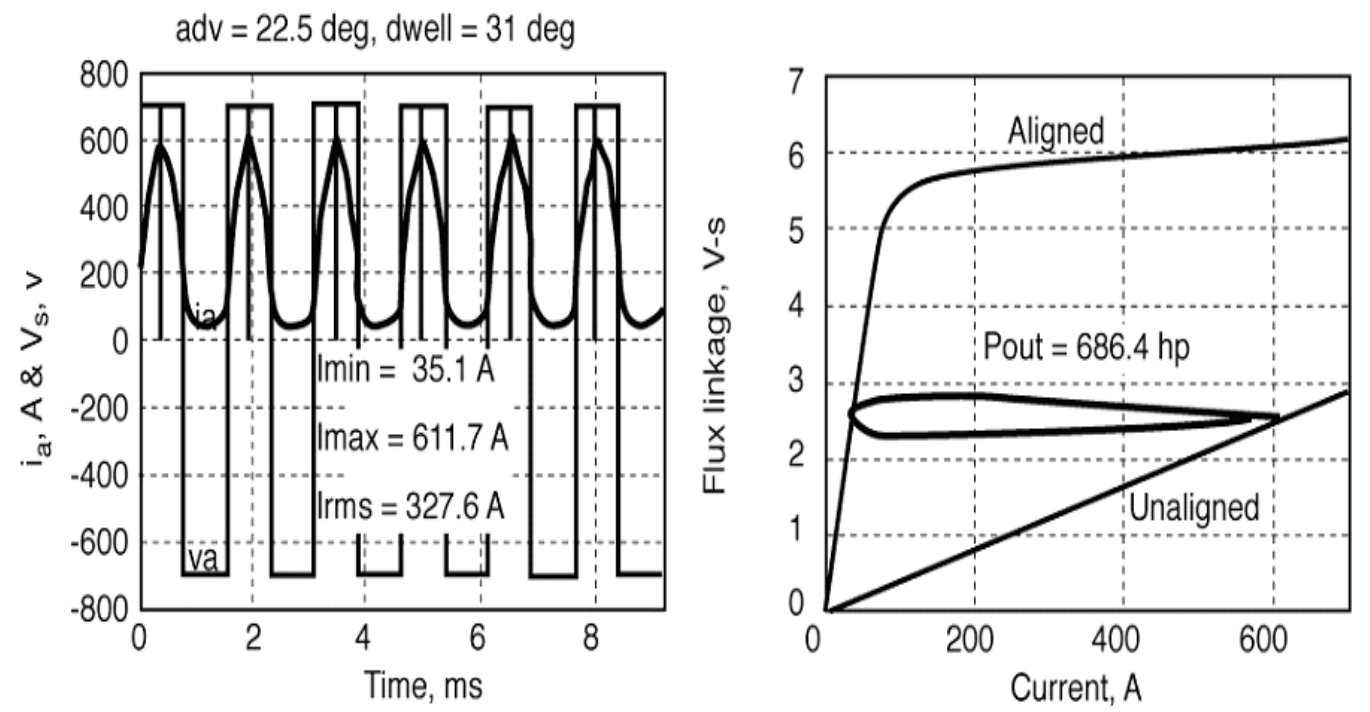

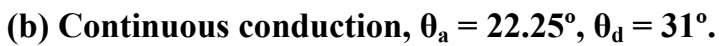

Fig. 43. Phase A current, voltage, co-energy, and useful power for a hypothetical $320 \mathrm{hp} \mathrm{8/6} \mathrm{SRM} \mathrm{at}$ $6500 \mathrm{rpm}(\mathrm{n}=26)$ with supply voltage, $V_{\mathrm{dc}}=700 \mathrm{~V}$, and current limit $I_{\text {set }}=600 \mathrm{~A}$.

Figure 42 shows that the $700 \mathrm{~V}$ dc supply is adequate to produce $320 \mathrm{hp}$ required at base speed without exceeding the $600 \mathrm{~A}_{\text {peak }}$ and $425 \mathrm{~A}_{\mathrm{rms}}$ rating of the example motor. Figure 43(a) shows that at $6500 \mathrm{rpm}$ very little current is driven into the motor when it must return to zero every cycle as it must in the discontinuous-conduction mode. What is remarkable is that, when current is not required to return to zero, a rms current of only $327 \mathrm{~A}_{\text {rms }}$ will deliver $686 \mathrm{hp}$ at $6500 \mathrm{rpm}$...far above rated power and far below rated current. 
Collaboration between Deere and ORNL would involve determining the maximum reasonable CPSR by determining the mechanical limits of the rotating components and the electrical frequency limits of the switches used in the controller. Control of the SRM in continuous conduction is extremely sensitive to the dwell angle and control sensitivities and development of algorithms; to accomplish this control would be part of the collaboration. SRM motors have more ripple than PM motors, but control techniques can be used to reduce ripple at low speeds while at high speeds ripple is filtered out by the inertia of the vehicle it is driving. The rotor of an SRM is a cylinder of steel with steel tabs for poles, so there are no magnets to pay for and worry about demagnetizing and radial growth diminishes the gap which increases the torque. It is a robust motor whose traction-drive potential is gradually being exposed by theoretical analyses [7].

\subsection{THE HSUB DC MOTOR AS A TRACTION DRIVE FOR DEERE APPLICATIONS}

The HSUB motor was proposed in the original CRADA with Deere as a possible candidate for some of their off-road applications. ORNL studies have shown that "doubly fed" machines, such as the separately excited dc motor and the conventional synchronous motor where both the armature and field are excited, have a large CPSR capability. Unfortunately, the commutator in the dc motor and the slip rings in the synchronous motor pose reliability problems for Deere tractor applications. The HSUB motor circumvents this difficulty because it is a doubly-fed synchronous motor without the slip rings.

ORNL has combined recent research on controlling magnetic flux (flux focusing) and on brushless magnetic field weakening to invent and demonstrate the HSUB (flux lines) electric motor for which Patent No. 6,573,634 was awarded with the issue date of June 3, 2003. Its magnetic field is determined by a stationary coil embedded in part of the housing which produces flux. The flux crosses a small gap into a rotor, which acts as a rotating-flux guide directing the flux through the gap of a conventional stator. Eddy currents are negligible in the rotor. The coil and stator are stationary structures where they may be readily cooled. The rotating-flux guide is ferromagnetic material.

The motor is easy to manufacture using a technique developed at ORNL to insert the magnets. The technique, which eliminates most of the flux fringing, injects a slurry of un-magnetized powder and epoxy between the rotor teeth where it is cured and magnetized after assembly. This makes it much easier to handle than motors requiring assembly with strong PMs.

Strong magnets may also be added to increase the magnetic field. The CPSR is controlled by changing the current in the static coil just like a dc motor with a separately excited field, thereby giving the motor an "infinite" CPSR. The motor's simplicity, brushless-field weakening, infinite CPSR, manufacturability, and configuration for easy heat removal make it attractive as a drive motor for Deere's farm implements and possibly for some future on-road application. The motor may be controlled with a standard voltage-fed PWM inverter.

Collaboration would involve selection of an application to which this motor is well suited, design of the motor and inverter controller, simulation of its operating performance, fabrication of the motor and controller, and laboratory characterization. This is a new concept in motors which has 
potential high-torque production using flux enhancement and high-speed operation using flux weakening.

\subsection{IDENTIFICATION, QUANTIFICATION, AND REDUCTION OF DEERE 1 MOTOR LOSSES}

The objective would be to reduce the open circuit losses from $10 \mathrm{~kW}$ to less than $2 \mathrm{~kW}$. The approach would be to model potential loss mechanisms to compare them with what has been measured on the UQM dynamometer. Once identified, means would be sought to reduce or eliminate them without impacting the motor performance. It has already been mentioned in this report that one possible significant reduction could probably be achieved by using soft magnetic material. Its increased resistivity will reduce eddy currents induced in the magnets by the stator slots as the magnets pass them. The losses that will be explored are induced by magnet eddy currents, stator core eddy currents, windage, and friction.

\subsection{PACKAGING VSI/SCR COMPONENTS TO REDUCE COSTS}

Semikron has already shown that inverter costs may be significantly reduced by the way the components are packaged. The objective would be to explore the limits that packaging and assembly techniques may be used to reduce costs. That limit would be expected to provide cost, which when added to the silicon cost would represent the inverter cost. With this information, the cost impact of additional silicon, such as the SCRs, could be more readily determined. 


\section{APPENDIX A. SEMICONDUCTOR DATA SHEETS}

\section{A.1. IGBTS FOR DEERE 1}

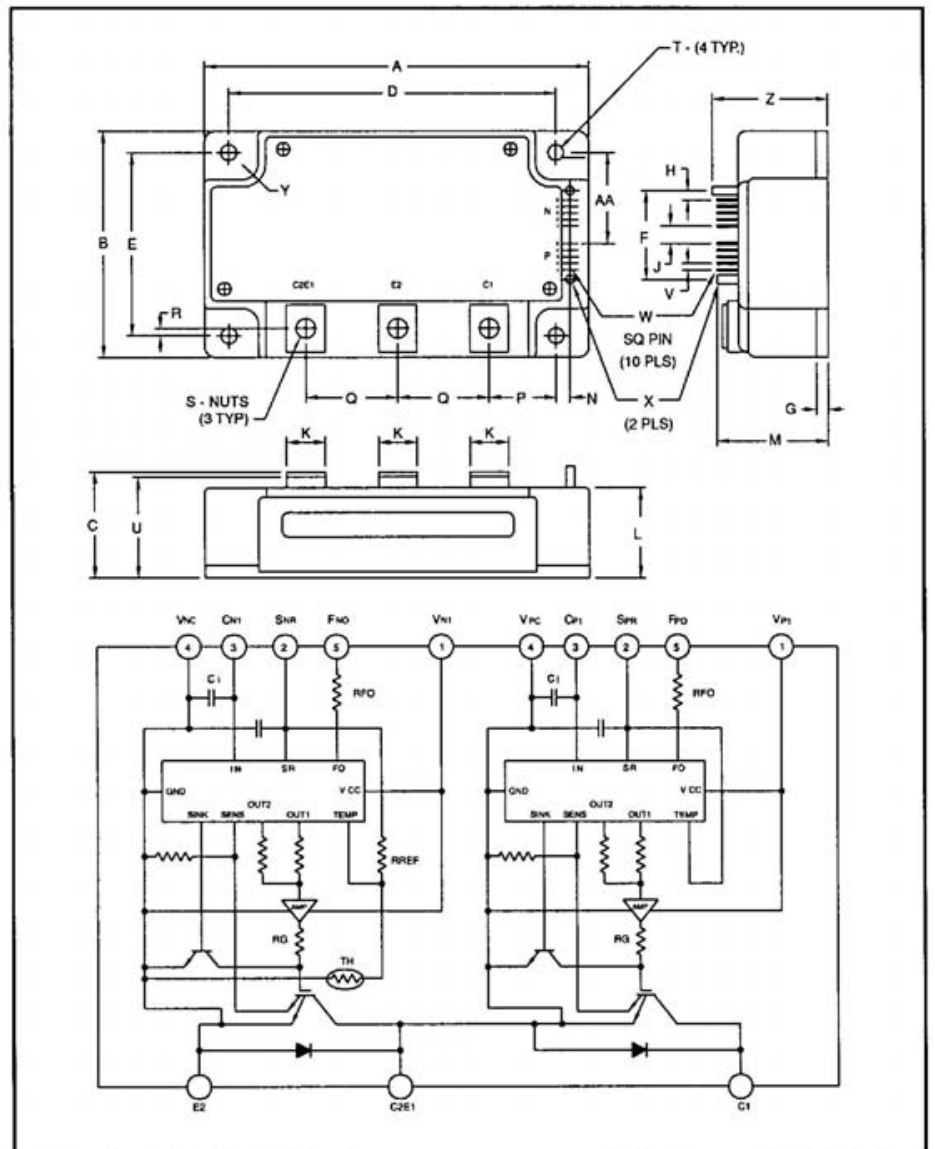

\begin{tabular}{|c|c|c|c|c|c|}
\hline \multicolumn{3}{|c|}{ Outline Drawing and Circuit Diagram } & \multirow[b]{2}{*}{ Dimensions } & \multirow[b]{2}{*}{ Inches } & \multirow[b]{2}{*}{ Millimeters } \\
\hline Dimensions & Inches & Millimeters & & & \\
\hline A & 4.72 & 120.0 & $P$ & 1.22 & 31.0 \\
\hline B & 3.54 & 90.0 & Q & 1.10 & 28.0 \\
\hline C & $1.34+0.04 /-0.02$ & $34+1.0 /-0.5$ & R & 0.12 & 3.0 \\
\hline $\mathrm{D}$ & $4.17 \pm 0.010$ & $106.0 \pm 0.25$ & S & M8 Metric & M8 \\
\hline $\mathrm{E}$ & $2.99 \pm 0.010$ & $76.0 \pm 0.25$ & $\mathrm{~T}$ & 0.26 Dia. & Dia. 6.5 \\
\hline $\mathrm{F}$ & 1.52 & 38.5 & $U$ & 1.29 & 32.8 \\
\hline G & 0.16 & 4.0 & V & 0.10 & 2.54 \\
\hline $\mathrm{H}$ & 0.16 & 4.01 & W & $0.025 \mathrm{SQ}$ & $0.64 \mathrm{SQ}$ \\
\hline$J$ & 0.40 & 10.16 & $x$ & 0.14 Dia. & 3.5 Dia. \\
\hline $\mathrm{K}$ & 0.71 & 18.0 & $Y$ & 0.26 Dia. & Dia. 6.5 \\
\hline L & 1.22 & 31.0 & $z$ & 1.79 & 45.5 \\
\hline$M$ & 1.73 & 44.0 & $A A$ & 1.5 & 38.0 \\
\hline
\end{tabular}

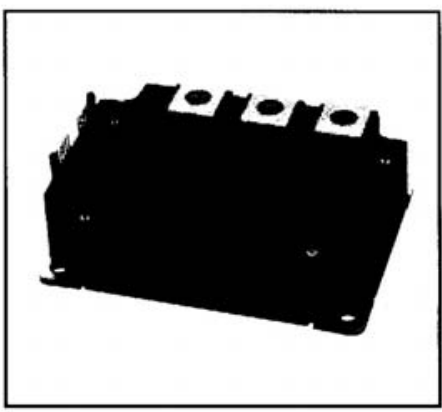

Description:

Powerex Intellimod ${ }^{\mathrm{TM}}$ Intelligent Power Modules are isolated base modules designed for power switching applications operating at frequencies to $20 \mathrm{kHz}$. Built-in control circuits provide optimum gate drive and protection for the IGBT and free-wheel diode power devices.

Features:

$\square$ Complete Output Power Circuit

$\square$ Gate Drive Circuit

$\square$ Protection Logic

- Short Circuit

- Over Temperature

- Under Voltage

\section{Applications:}

$\square$ Inverters

$\square$ UPS

$\square$ Motion/Servo Control

$\square$ Power Supplies

Ordering Information:

Example: Select the complete part number from the table below -i.e. PM600DVA060 is a 600V, 600 Ampere Intellimod $^{\mathrm{TM}}$ Intelligent Power Module.

\begin{tabular}{ccc}
\hline Type & $\begin{array}{c}\text { Current Rating } \\
\text { Amperes }\end{array}$ & $\begin{array}{c}V_{\text {CES }} \\
\text { Volls }(\times 10)\end{array}$ \\
\hline PM & 600 & 60 \\
\hline
\end{tabular}


Powerex, Inc., 200 Hillis Street, Youngwood, Pennsylvania 15697-1800 (724) 925-7272

\section{PM600DVA060}

Intellimodrm Module

Single Phase IGBT Inverter Output

600 Amperes $/ 600$ Volts

Absolute Maximum Ratings, $\mathrm{T}_{\mathbf{j}}=25^{\circ} \mathrm{C}$ unless otherwise specified

\begin{tabular}{|c|c|c|c|}
\hline Characteristics & Symbol & PM600DVA060 & Units \\
\hline Power Device Junction Temperature & $T_{j}$ & -20 to 150 & ${ }^{\circ} \mathrm{C}$ \\
\hline Storage Temperature & $T_{\text {stg }}$ & -40 to 125 & ${ }^{\circ} \mathrm{C}$ \\
\hline Case Operating Temperature & $T_{C}$ & -20 to 100 & ${ }^{\circ} \mathrm{C}$ \\
\hline Mounting Torque, M6 Mounting Screws (Typical) & 一 & 26 & in-lb \\
\hline Mounting Torque, M8 Main Terminal Screws (Typical) & - & 95 & in-lb \\
\hline Module Weight (Typical) & 一 & 720 & Grams \\
\hline Supply Voltage (Applied between C1-E2) & $\mathrm{V}_{\mathrm{CC}}$ (surge) & 500 & Volts \\
\hline Supply Voltage Protected by SC $\left(V_{D}=13.5 \sim 16.5 \mathrm{~V}\right.$, Inverter Part, $T_{j}=125^{\circ} \mathrm{C}$ Start $)$ & $\mathrm{V}_{\mathrm{CC}}$ (prot.) & 400 & Volts \\
\hline Isolation Voltage, AC 1 minute, $60 \mathrm{~Hz}$ Sinusoidal & V RMS & 2500 & Volts \\
\hline \multicolumn{4}{|l|}{ Control Sector } \\
\hline Supply Voltage Applied between $\left(\mathrm{V}_{\mathrm{P} 1}-\mathrm{V}_{\mathrm{PC}}, \mathrm{V}_{\mathrm{N} 1}-\mathrm{V}_{\mathrm{NC}}\right)$ & $V_{D}$ & 20 & Volts \\
\hline Input Voltage Applied between $\left(\mathrm{C}_{\mathrm{P}_{1}}-\mathrm{V}_{\mathrm{PC}}, \mathrm{V}_{\mathrm{N1}}-\mathrm{V}_{\mathrm{NC}}\right)$ & $\mathrm{V}_{\mathrm{CIN}}$ & 10 & Volts \\
\hline Fault Output Supply Voltage (Applied between $\mathrm{F}_{\mathrm{PO}}-\mathrm{V}_{\mathrm{PC}}, \mathrm{F}_{\mathrm{NO}}-\mathrm{V}_{\mathrm{NC}}$ ) & $\mathrm{V}_{\mathrm{FO}}$ & 20 & Volts \\
\hline Fault Output Current (Sink Current at Fo Terminals) & IFO & 20 & $\mathrm{~mA}$ \\
\hline \multicolumn{4}{|l|}{ IGBT Inverter Sector } \\
\hline Collector-Emitter Voltage $\left(V_{D}=15 \mathrm{~V}, V_{\mathrm{CIN}}=5 \mathrm{~V}\right)$ & $V_{\text {CES }}$ & 600 & Volts \\
\hline Collector Current, $\pm\left(T_{C}=25^{\circ} \mathrm{C}\right)$ & $\mathrm{I}_{\mathrm{C}}$ & 600 & Amperes \\
\hline Peak Collector Current, $\pm\left(T_{C}=25^{\circ} \mathrm{C}\right)$ & $\mathrm{I} C P$ & 1200 & Amperes \\
\hline Collector Dissipation $\left(T_{C}=25^{\circ} \mathrm{C}\right)$ & $\mathrm{PC}_{\mathrm{C}}$ & 1260 & Watts \\
\hline
\end{tabular}

Electrical and Mechanical Characteristics, $T_{j}=25^{\circ} \mathrm{C}$ unless otherwise specified

\begin{tabular}{|c|c|c|c|c|c|c|}
\hline Characteristics & Symbol & Test Conditions & Min. & Typ. & Max. & Units \\
\hline \multicolumn{7}{|l|}{ Control Sector } \\
\hline Short Circuit Trip Level & SC & $-20^{\circ} \mathrm{C} \leq \mathrm{T}_{\mathrm{j}} \leq 125^{\circ} \mathrm{C}, \mathrm{V}_{\mathrm{D}}=15 \mathrm{~V}$ & 740 & - & - & Amperes \\
\hline Short Circuit Current Delay Time & $t_{\text {off(SC) }}$ & $V_{D}=15 \mathrm{~V}$ & - & 10 & - & $\mu S$ \\
\hline Over Temperature Protection & OT & Trip Level & 111 & 118 & 125 & ${ }^{\circ} \mathrm{C}$ \\
\hline$\left(V_{D}=15 \mathrm{~V}\right.$, Lower Arm $)$ & $\mathrm{OT}_{\mathrm{r}}$ & Reset Level & - & 100 & - & ${ }^{\circ} \mathrm{C}$ \\
\hline Supply Circuit Under Voltage Protection & UV & Trip Level & 11.5 & 12.0 & 12.5 & Volts \\
\hline$\left(-20^{\circ} \mathrm{C} \leq \mathrm{T}_{j} \leq 125^{\circ} \mathrm{C}\right)$ & $U V_{r}$ & Reset Level & - & 12.5 & - & Volts \\
\hline \multirow[t]{2}{*}{ Circuit Current } & id & $V_{D}=15 V, V_{C I N}=5 V, V_{N 1}-V_{N C}$ & - & 27 & 38 & $\mathrm{~mA}$ \\
\hline & & $V_{D}=15 V, V_{C I N}=5 V, V_{P_{1}}-V_{P C}$ & - & 27 & 38 & $\mathrm{~mA}$ \\
\hline Input ON Threshold Voltage & $\mathrm{V}_{\mathrm{CIN} \text { (on) }}$ & Applied between & 1.2 & 1.5 & 1.8 & Volts \\
\hline Input OFF Threshold Voltage & $\mathrm{V}_{\mathrm{CIN}(\mathrm{off})}$ & $\mathrm{C}_{\mathrm{P}_{1}}-\mathrm{V}_{\mathrm{PC}}, \mathrm{C}_{\mathrm{N} 1}-\mathrm{V}_{\mathrm{NC}}$ & 1.7 & 2.0 & 2.3 & Volts \\
\hline \multirow[t]{2}{*}{ Fault Output Current } & $\mathrm{IFO}(\mathrm{H})$ & $V_{D}=15 V, V_{F O}=15 V$ & - & - & 0.01 & $\mathrm{~mA}$ \\
\hline & $\mathrm{I}_{\mathrm{FO}(\mathrm{L})}$ & $V_{D}=15 V, V_{F O}=15 V$ & - & 10 & 15 & $\mathrm{~mA}$ \\
\hline Minimum Fault Output Pulse Width & tFo & $V_{D}=15 \mathrm{~V}$ & 1.0 & 1.8 & - & $\mathrm{mS}$ \\
\hline SXR Terminal Output Voltage & $V_{S X R}$ & $T_{j} \leq 125^{\circ} \mathrm{C}, R_{i n}=6.8 \mathrm{k} \Omega\left(S_{P R}, S_{N R}\right)$ & 4.5 & 5.1 & 5.6 & Volts \\
\hline
\end{tabular}




\section{Hew}

Powerex, Inc., 200 Hillis Street, Youngwood, Pennsylvanla 15697-1800 (724) 925-7272

PM600DVA060

Intellimodrm Module

Single Phase IGBT Inverter Output

600 Amperes 600 Volts

SATURATION VOLTAGE CHARACTERISTICS

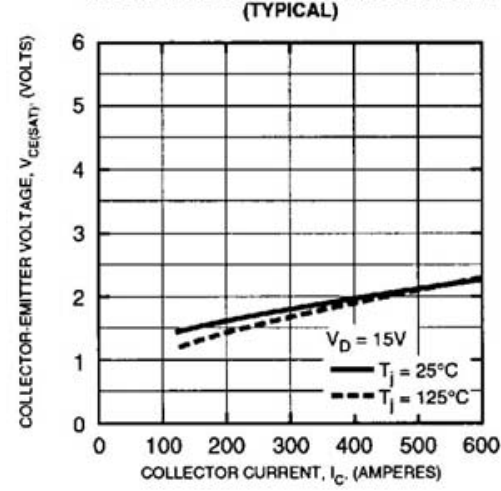

SWITCHING TIME VS. COLLECTOR CURRENT (TYPICAL)

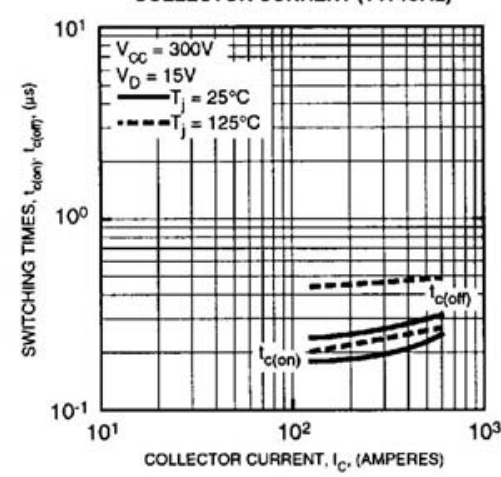

DIODE FORWARD CHARACTERISTICS

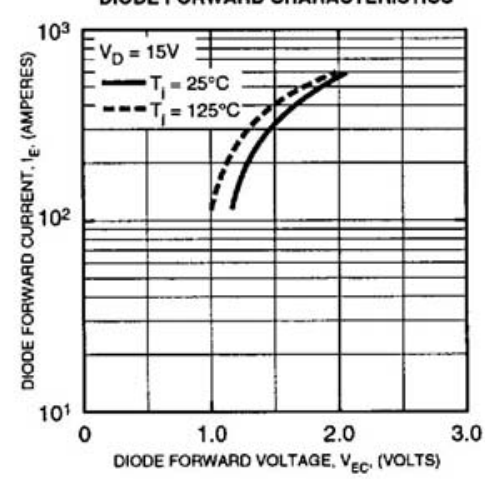

COLLECTOR-EMITTER SATURATON YOLTAGE CHARACTERISTICS (TYPICAL)

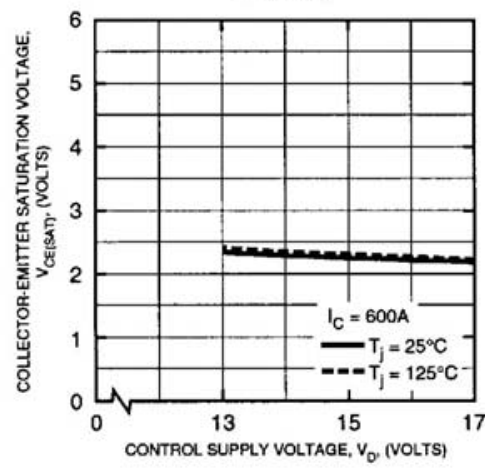

SWITCHING LOSS CHARACTERISTICS (TYPICAL)

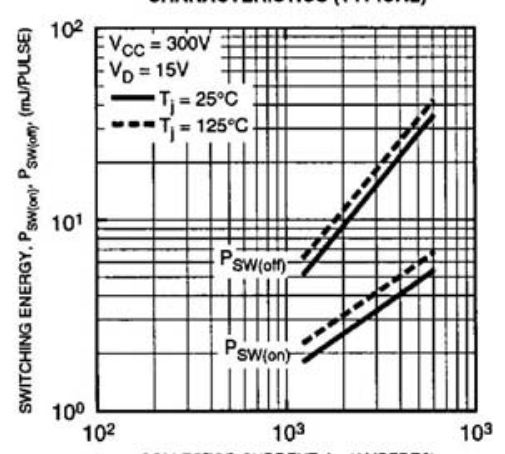

COLLECTOR CURAENT, IC. (AMPEAES)
SWITCHING TIME VS. COLLECTOR CURRENT (TYPICAL)

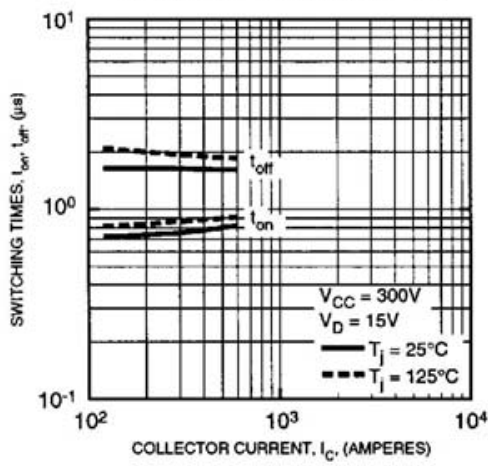

FWDI REVERSE RECOVERY CURRENT VS. COLLECTOR CURRENT (TYPICAL)

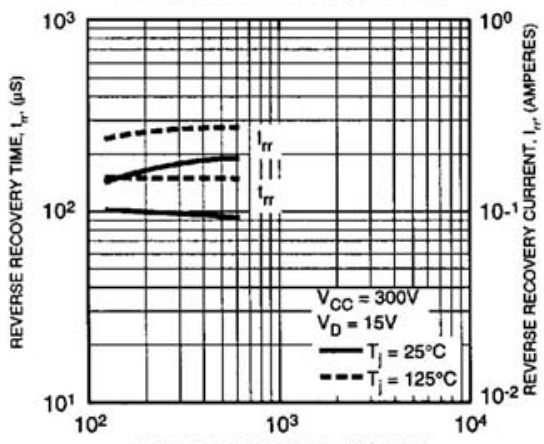

COLLECTOR CURAENT, le, (AMPERES)

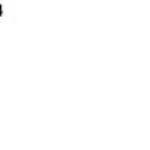




\section{A.2. SCRS FOR DEERE 1}

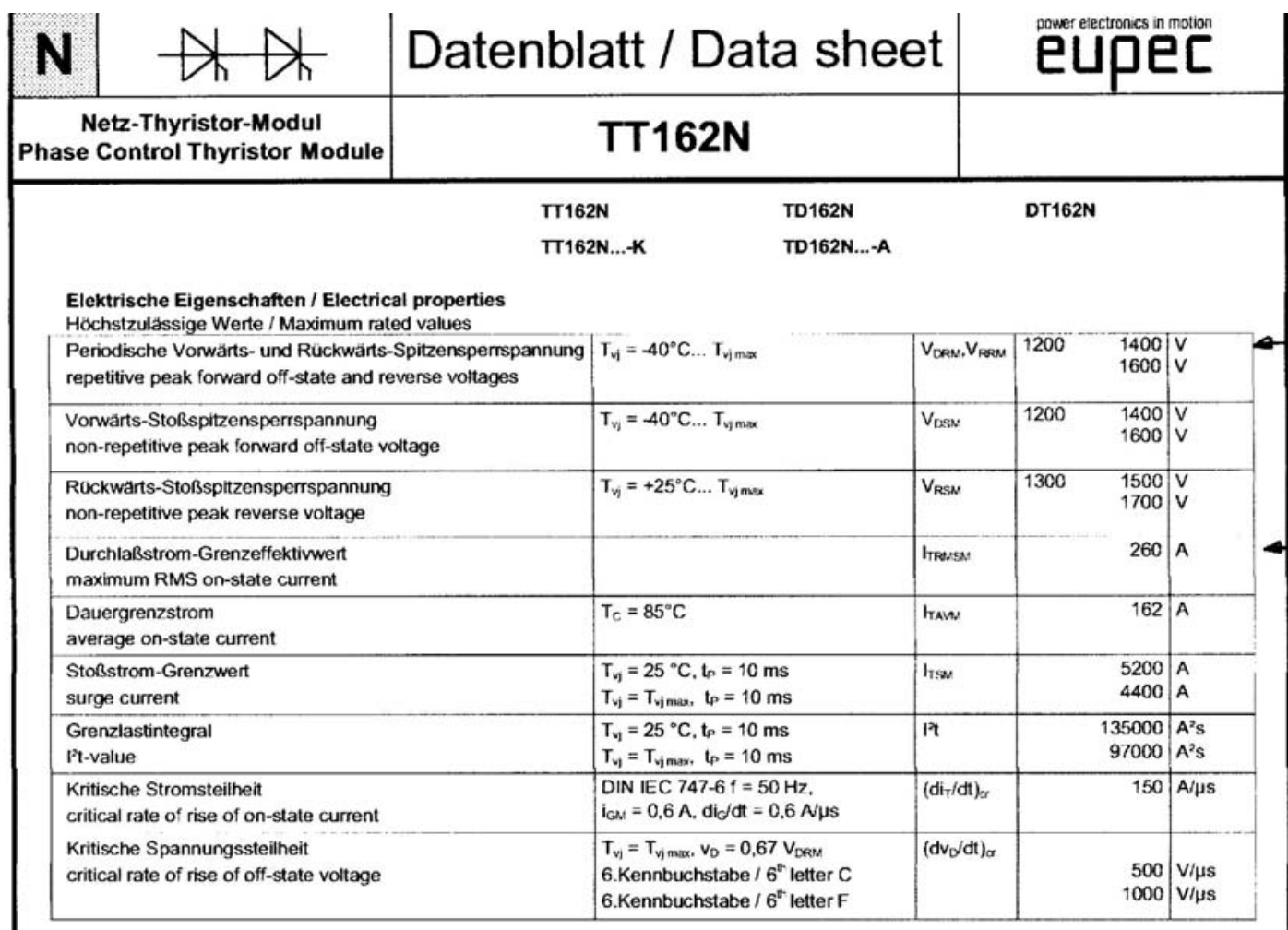

\begin{tabular}{|c|c|c|c|c|c|c|}
\hline $\begin{array}{l}\text { Durchlaßspannung } \\
\text { on-state voltage }\end{array}$ & \multicolumn{2}{|l|}{$T_{\mathrm{vi}}=\mathrm{T}_{\mathrm{i} \max }, \mathrm{h}_{\mathrm{T}}=500 \mathrm{~A}$} & $v_{T}$ & $\max$. & 1,41 & v \\
\hline $\begin{array}{l}\text { Schleusenspannung } \\
\text { threshold voltage }\end{array}$ & \multicolumn{2}{|l|}{$T_{v j}=T_{v i \max }$} & $\mathrm{V}_{(\pi 0)}$ & & 0.85 & $\mathrm{v}$ \\
\hline $\begin{array}{l}\text { Ersatzwiderstand } \\
\text { slope resistance }\end{array}$ & \multicolumn{2}{|l|}{$T_{v y}=T_{v i \max }$} & $\mathrm{rT}_{\mathrm{T}}$ & & 0,95 & $\mathrm{~m} \Omega$ \\
\hline $\begin{array}{l}\text { Zundstrom } \\
\text { gate trigger current }\end{array}$ & \multicolumn{2}{|l|}{$\mathrm{T}_{\mathrm{vi}}=25^{\circ} \mathrm{C}, \mathrm{v}_{\mathrm{D}}=6 \mathrm{~V}$} & IGT & $\max$ & 150 & $\mathrm{~mA}$ \\
\hline $\begin{array}{l}\text { Zündspannung } \\
\text { gate trigger voltage }\end{array}$ & \multicolumn{2}{|l|}{$T_{v i}=25^{\circ} \mathrm{C}, v_{D}=6 \mathrm{~V}$} & $V_{G r}$ & $\max$. & 2 & v \\
\hline $\begin{array}{l}\text { Nicht zundender Steuerstrom } \\
\text { gate non-trigger current }\end{array}$ & \multicolumn{2}{|l|}{ 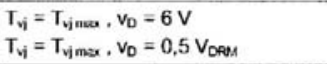 } & $l_{\infty}$ & $\begin{array}{l}\max . \\
\max .\end{array}$ & $\begin{array}{r}10 \\
5\end{array}$ & $\begin{array}{l}\mathrm{mA} \\
\mathrm{mA}\end{array}$ \\
\hline $\begin{array}{l}\text { Nicht zündende Steuerspannung } \\
\text { gate non-trigger voltage }\end{array}$ & \multicolumn{2}{|l|}{$T_{v \mid}=T_{v i \text { max }}, v_{D}=0,5 V_{\text {ofed }}$} & $V_{G O}$ & $\max$. & 0,25 & v \\
\hline $\begin{array}{l}\text { Haltestrom } \\
\text { holding current }\end{array}$ & \multicolumn{2}{|c|}{$T_{V_{l}}=25^{\circ} \mathrm{C}, v_{D}=6 \mathrm{~V}, R_{A}=5 \Omega$} & $I_{H}$ & $\max$ & 200 & $\mathrm{~mA}$ \\
\hline $\begin{array}{l}\text { Einraststrom } \\
\text { latching current }\end{array}$ & \multicolumn{2}{|c|}{$\begin{array}{l}\mathrm{T}_{\mathrm{v}_{\mathrm{i}}}=25^{\circ} \mathrm{C}, \mathrm{v}_{\mathrm{D}}=6 \mathrm{~V}, \mathrm{R}_{\mathrm{GK}} \geq 10 \Omega \\
\mathrm{icN}_{\mathrm{cN}}=0,6 \mathrm{~A}, \mathrm{di}_{\mathrm{C}} / \mathrm{dt}=0,6 \mathrm{~A} / \mathrm{s}, \\
\mathrm{t}_{\mathrm{g}}=20 \mu \mathrm{s}\end{array}$} & h & $\max$ & 800 & $\mathrm{~mA}$ \\
\hline $\begin{array}{l}\text { Vorwarts- und Ruckwarts-Sperrstrom } \\
\text { forward off-state and reverse current }\end{array}$ & \multicolumn{2}{|c|}{$\begin{array}{l}T_{V j}=T_{\text {Vimax }} \\
V_{D}=V_{\text {DRM }} \cdot V_{R}=V_{\text {RReM }}\end{array}$} & b. $i_{R}$ & $\max$ & 30 & $\mathrm{~mA}$ \\
\hline $\begin{array}{l}\text { Zundverzug } \\
\text { gate controlled delay time }\end{array}$ & \multicolumn{2}{|c|}{$\begin{array}{l}\text { DIN IEC } 747-6 T_{v j}=25^{\circ} \mathrm{C}, \\
i_{\mathrm{C} N}=0,6 \mathrm{~A}, \mathrm{di} / \mathrm{dt}=0,6 \mathrm{~A} / \mu \mathrm{s}\end{array}$} & $t_{x}$ & $\max$ & 3 & $\mu \mathrm{s}$ \\
\hline prepared by: C.Drilling & date of publication: & 04.07 .02 & & & & \\
\hline approved by: J.Novotny & revision: & 1 & & & & \\
\hline
\end{tabular}

BIP AC / Warstein,den 18.01.88 Spec

$$
R_{\text {THY }}=.00095 \Omega V_{\text {THY }}=1.41-500 \times .00095=.935 \mathrm{VO} .
$$




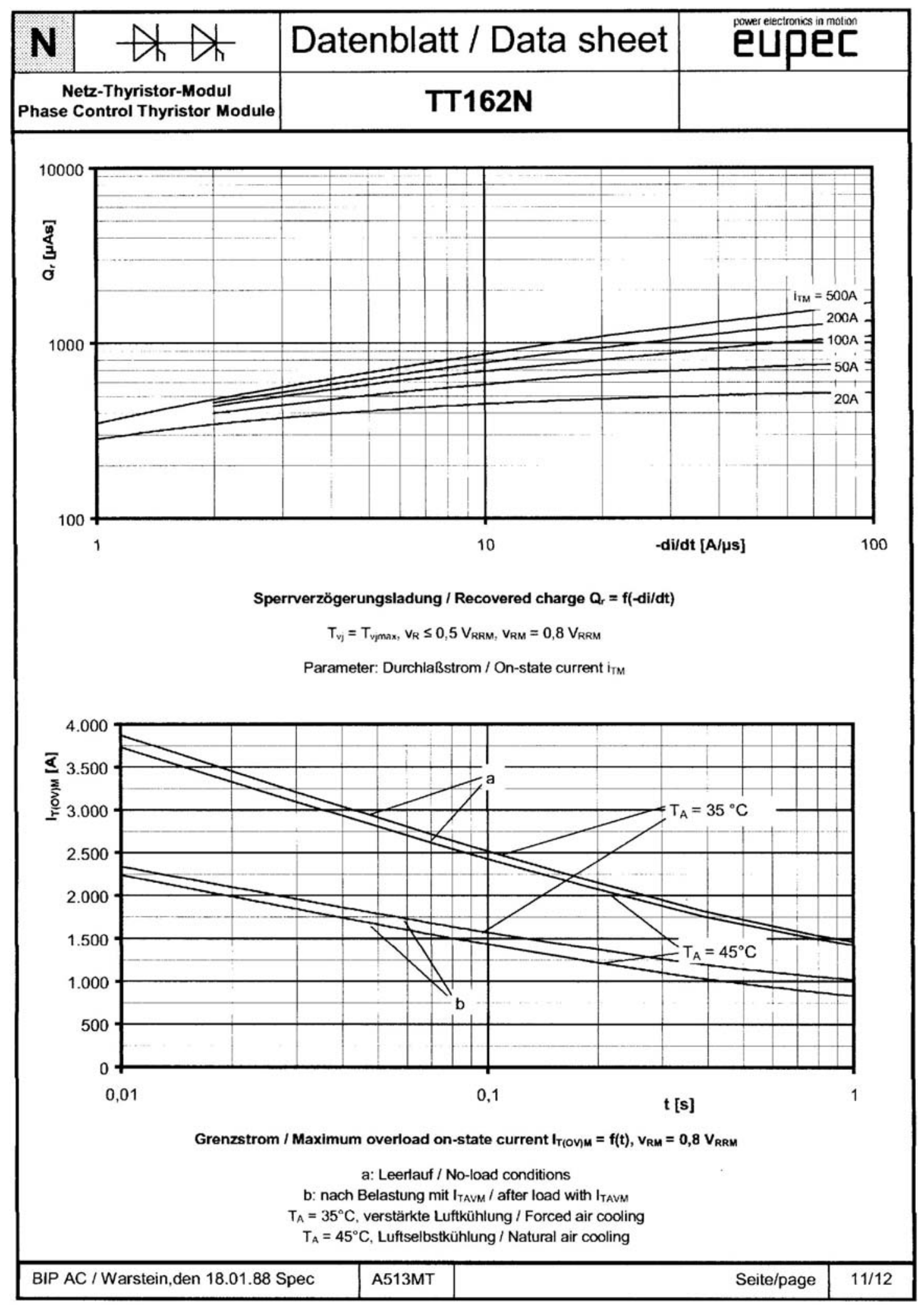




\section{A.3. IGBTS FOR DEERE 2}

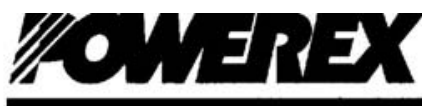

PM300DSA060

Powerex, Inc., 200 Hillis Street, Youngwood, Pennsylvania 15697-1800 (724) 925-7272

Intellimod ${ }^{\mathrm{TM}}$ Module

Single Phase

IGBT Inverter Output

300 Amperes/600 Volts

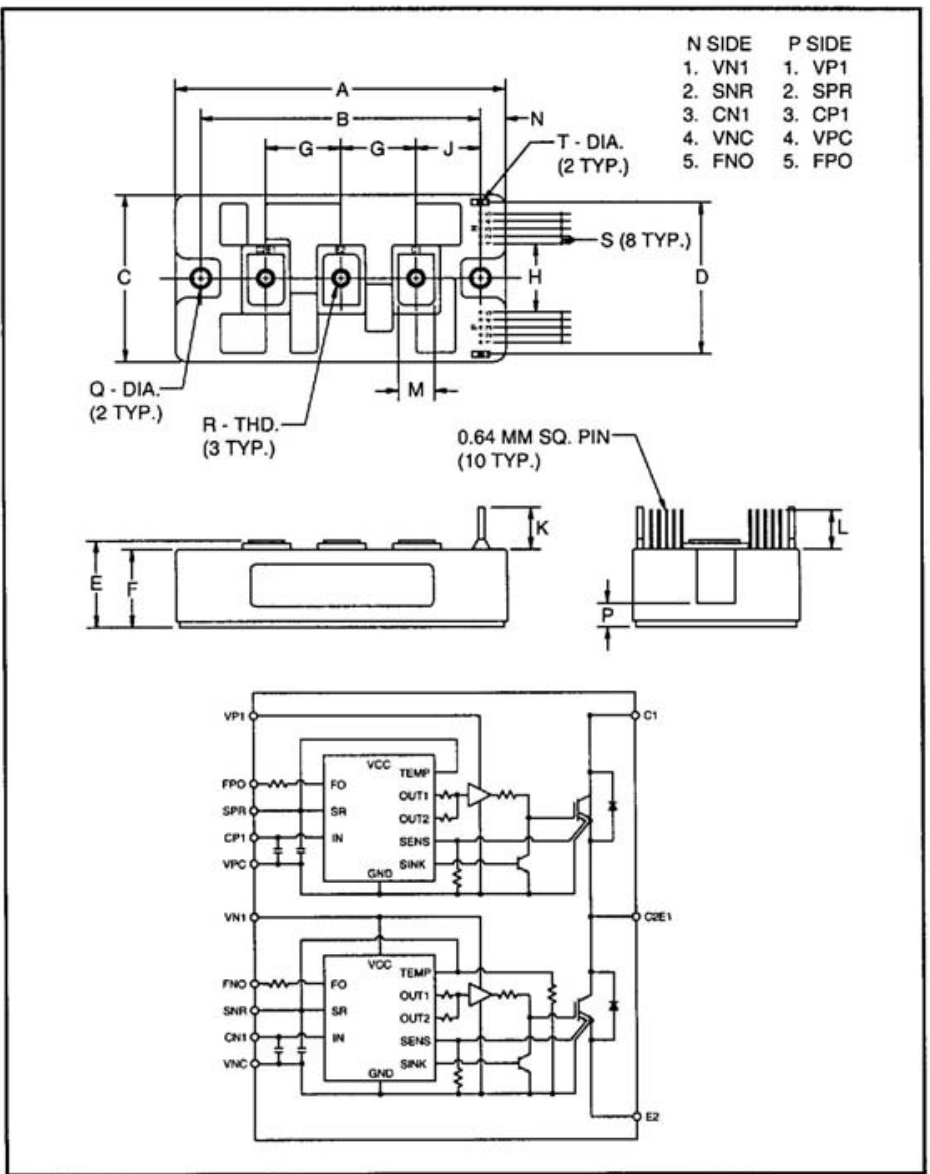

Outline Drawing and Circuit Diagram

\begin{tabular}{ccc}
\hline Dimensions & Inches & Millimeters \\
\hline $\mathrm{A}$ & 4.33 & 110.0 \\
\hline $\mathrm{B}$ & $3.66 \pm 0.010$ & $93.0 \pm 0.25$ \\
\hline $\mathrm{C}$ & 2.20 & 56.0 \\
\hline $\mathrm{D}$ & 2.01 & 51.0 \\
\hline $\mathrm{E}$ & $1.14+0.04 /-0.02$ & $29.0+1 /-0.5$ \\
\hline $\mathrm{F}$ & 1.02 & 26.0 \\
\hline $\mathrm{G}$ & 0.98 & 25.0 \\
\hline $\mathrm{H}$ & 0.90 & 23.0 \\
\hline $\mathrm{J}$ & 0.85 & 21.5 \\
\hline
\end{tabular}

\begin{tabular}{ccc}
\hline Dimensions & Inches & Millimeters \\
\hline $\mathrm{K}$ & 0.55 & 14.0 \\
\hline $\mathrm{L}$ & 0.51 & 13.0 \\
\hline $\mathrm{M}$ & 0.47 & 12.0 \\
\hline $\mathrm{N}$ & 0.33 & 8.5 \\
\hline $\mathrm{P}$ & 0.28 & 7.0 \\
\hline $\mathrm{Q}$ & 0.22 Dia. & Dia. 5.5 \\
\hline $\mathrm{R}$ & M5 Metric & M5 \\
\hline $\mathrm{S}$ & 0.100 & 2.54 \\
\hline $\mathrm{T}$ & 0.08 Dia. & Dia. 2.0 \\
\hline & &
\end{tabular}

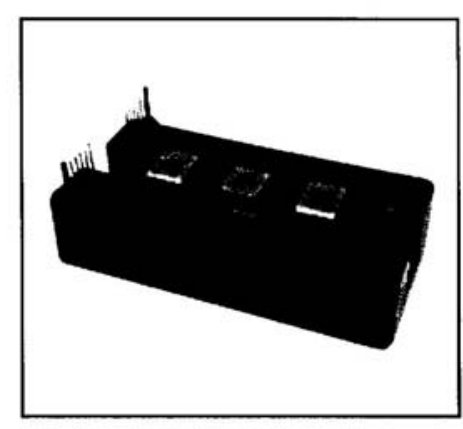

Description:

Powerex Intellimod ${ }^{\mathrm{TM}}$ Intelligent Power Modules are isolated base modules designed for power switching applications operating at frequencies to $20 \mathrm{kHz}$. Built-in control circuits provide optimum gate drive and protection for the IGBT and free wheel-diode power devices.

Features:

$\square$ Complete Output Power

Circuit

Gate Drive Circuit

Protection Logic

- Short Circuit

- Over Current

- Over Temperature

- Under Voltage

Applications:
$\square$ Inverters
$\square$ UPS
Motion/Servo Control
Power Supplies

\section{Ordering Information:}

Example: Select the complete part number from the table below -i.e. PM300DSA060 is a $600 \mathrm{~V}$, 300 Ampere Intellimod ${ }^{\mathrm{TM}}$ Intelligent Power Module.

\begin{tabular}{ccc}
\hline Type & $\begin{array}{c}\text { Current Rating } \\
\text { Amperes }\end{array}$ & $\begin{array}{c}\mathbf{V}_{\text {CES }} \\
\text { Volts }(\times 10)\end{array}$ \\
\hline PM & 300 & 60 \\
\hline
\end{tabular}


Powerex, Inc., 200 Hillis Street, Youngwood, Pennsylvanla 15697-1800 (724) 925-7272

PM300DSA060

Intellimod ${ }^{\mathrm{MM}}$ Module

Single Phase IGBT Inverter Output

300 Amperes/ 600 Volts

Electrical and Mechanical Characteristics, $\mathrm{T}_{\mathrm{j}}=25^{\circ} \mathrm{C}$ unless otherwise specified

\begin{tabular}{|c|c|c|c|c|c|c|}
\hline Characteristics & Symbol & Test Conditions & Min. & Typ. & Max. & Units \\
\hline \multicolumn{7}{|l|}{ Control Sector } \\
\hline Over Current Trip Level Inverter Part & $O C$ & $-20^{\circ} \mathrm{C} \leq \mathrm{T} \leq 125^{\circ} \mathrm{C}$ & 390 & 540 & - & Amperes \\
\hline Short Circuit Trip Level Inverter Part & SC & $-20^{\circ} \mathrm{C} \leq \mathrm{T} \leq 125^{\circ} \mathrm{C}$ & 540 & 760 & - & Amperes \\
\hline Over Current Delay Time & toff(OC) & $V_{D}=15 \mathrm{~V}$ & - & 5 & - & $\mu \mathrm{S}$ \\
\hline \multirow[t]{2}{*}{ Over Temperature Protection } & OT & Trip Level & 100 & 110 & 120 & ${ }^{\circ} \mathrm{C}$ \\
\hline & $O_{\mathrm{A}}$ & Reset Level & 85 & 95 & 105 & ${ }^{\circ} \mathrm{C}$ \\
\hline \multirow[t]{2}{*}{ Supply Circuit Under Voltage Protection } & UV & Trip Level & 11.5 & 12.0 & 12.5 & Volts \\
\hline & $U V_{R}$ & Reset Level & - & 12.5 & - & Volts \\
\hline Supply Voltage & $v_{D}$ & Applied between $V_{\mathrm{P} 1}-V_{\mathrm{PC}}, \mathrm{V}_{\mathrm{N} 1}-\mathrm{V}_{\mathrm{NC}}$ & 13.5 & 15 & 16.5 & Volts \\
\hline \multirow[t]{2}{*}{ Circuit Current } & ID & $\mathrm{V}_{\mathrm{D}}=15 \mathrm{~V}, \mathrm{~V}_{\mathrm{CIN}}=5 \mathrm{~V}, \mathrm{~V}_{\mathrm{N} 1}-\mathrm{V}_{\mathrm{NC}}$ & - & 19 & 26 & $\mathrm{~mA}$ \\
\hline & & $V_{D}=15 \mathrm{~V}, V_{C I N}=5 \mathrm{~V}, V_{X P 1} \cdot V_{X P C}$ & - & 19 & 26 & $\mathrm{~mA}$ \\
\hline Input ON Threshold Voltage & $\mathrm{V}_{\mathrm{CIN}(\mathrm{on})}$ & Applied between & 1.2 & 1.5 & 1.8 & Volts \\
\hline Input OFF Threshold Voltage & $\mathrm{V}_{\mathrm{CIN}(\mathrm{off})}$ & 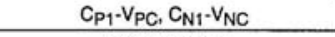 & 1.7 & 2.0 & 2.3 & Volts \\
\hline PWM Input Frequency & fPWM & $3-\varnothing$ Sinusoidal & - & 15 & 20 & $\mathrm{kHz}$ \\
\hline \multirow[t]{2}{*}{ Fault Output Current } & $I_{F O}(H)$ & $V_{D}=15 \mathrm{~V}, V_{F O}=15 \mathrm{~V}$ & - & - & 0.01 & $\mathrm{~mA}$ \\
\hline & $\mathrm{I}_{\mathrm{FO}}(\mathrm{L})$ & $V_{D}=15 \mathrm{~V}, V_{F O}=15 \mathrm{~V}$ & - & 10 & 15 & $\mathrm{~mA}$ \\
\hline Minimum Fault Output Pulse Width & tFo & $V_{D}=15 \mathrm{~V}$ & 1.0 & 1.8 & - & $\mathrm{mS}$ \\
\hline SXR Terminal Output Voltage & $V_{S X R}$ & $\mathrm{~T}_{\mathrm{j}} \leq 125^{\circ} \mathrm{C}, \mathrm{Rin}=6.8 \mathrm{k} \Omega\left(\mathrm{S}_{\mathrm{PR}}, \mathrm{S}_{\mathrm{NR}}\right)$ & 4.5 & 5.1 & 5.6 & Volts \\
\hline
\end{tabular}

\section{TOWEPJX}

Powerex, Inc., 200 Hillis Street, Youngwood, Pennsylvanla 15697-1800 (724) 925-7272

PM30ODSA060

Intellimod ${ }^{\mathrm{MM}}$ Module

Single Phase IGBT Inverter Output

300 Amperes/600 Volts

Absolute Maximum Ratings, $\mathrm{T}_{\mathrm{j}}=25^{\circ} \mathrm{C}$ unless otherwise specified

\begin{tabular}{lccc}
\hline Characteristics & Symbol & PM300DSA060 & Units \\
\hline Power Device Junction Temperature & $\mathrm{T}_{\mathrm{j}}$ & -20 to 150 & ${ }^{\circ} \mathrm{C}$ \\
\hline Storage Temperature & $\mathrm{T}_{\text {stg }}$ & -40 to 125 & ${ }^{\circ} \mathrm{C}$ \\
\hline Case Operating Temperature & $\mathrm{T}_{\mathrm{C}}$ & -20 to 100 & ${ }^{\circ} \mathrm{C}$ \\
\hline Mounting Torque, M5 Mounting Screws & - & 17 & in-lb \\
\hline Mounting Torque, M5 Main Terminal Screws & - & 17 & in-lb \\
\hline Module Weight (Typical) & - & 430 & Grams \\
\hline Supply Voltage Protected by OC and SC $\left(\mathrm{V}_{\mathrm{D}}=13.5-16.5 \mathrm{~V}\right.$, Inverter Part) & $\mathrm{V}_{\mathrm{CC}(\text { prot.) }}$ & 400 & Volts \\
\hline Isolation Voltage, AC 1 minute, $60 \mathrm{~Hz}$ Sinusoidal & $\mathrm{V}_{\mathrm{PMS}}$ & 2500 & Volts \\
\hline
\end{tabular}

\section{Control Sector}

\begin{tabular}{lccc}
\hline Supply Voltage Applied between $\left(\mathrm{V}_{\mathrm{P} 1}-\mathrm{V}_{\mathrm{PC}}, \mathrm{V}_{\mathrm{N} 1}-\mathrm{V}_{\mathrm{NC}}\right)$ & $\mathrm{V}_{\mathrm{D}}$ & 20 & Volts \\
\hline Input Voltage Applied between $\left(\mathrm{C}_{\mathrm{P} 1}-\mathrm{V}_{\mathrm{PC}}, \mathrm{C}_{\mathrm{N} 1}-\mathrm{V}_{\mathrm{NC}}\right)$ & $\mathrm{V}_{\mathrm{CIN}}$ & 10 & Volts \\
\hline Fault Output Supply Voltage (Applied between $\mathrm{F}_{\mathrm{po}}-\mathrm{V}_{\mathrm{pC}}$ and $\left.\mathrm{F}_{\mathrm{no}}-\mathrm{V}_{\mathrm{nC}}\right)$ & $\mathrm{V}_{\mathrm{FO}}$ & 20 & Volts \\
\hline Fault Output Current & $\mathrm{I}_{\mathrm{FO}}$ & 20 & $\mathrm{~mA}$ \\
\hline IGBT Inverter Sector & & & \\
\hline Collector-Emitter Voltage $\left(\mathrm{V}_{\mathrm{D}}=15 \mathrm{~V}, \mathrm{~V}_{\mathrm{CIN}}=5 \mathrm{~V}\right)$ & $\mathrm{V}_{\mathrm{CES}}$ & 600 & Volts \\
\hline Collector Current, \pm & $\mathrm{I}_{\mathrm{C}}$ & 300 & Amperes \\
\hline Peak Collector Current, \pm & $\mathrm{I}_{\mathrm{CP}}$ & 600 & Amperes \\
\hline Supply Voltage (Applied between C1 $-\mathrm{E2})$ & $\mathrm{V}_{\mathrm{CC}}$ & 450 & Volts \\
\hline Supply Voltage, Surge (Applied between C1 - E2) & $\mathrm{V}_{\mathrm{CC}(\mathrm{surge})}$ & 500 & Volts \\
\hline Collector Dissipation & $\mathrm{P}_{\mathrm{C}}$ & 960 & Watts \\
\hline
\end{tabular}


Powerex, Inc., 200 Hillis Street, Youngwood, Pennsylvania 15697-1800 (724) 925-7272

PM300DSA060

Intellimod ${ }^{\mathrm{TM}}$ Module

Single Phase IGBT Inverter Output

300 Amperes $/ 600$ Volts

Electrical and Mechanical Characteristics, $\mathrm{T}_{\mathrm{j}}=25^{\circ} \mathrm{C}$ unless otherwise specified

\begin{tabular}{|c|c|c|c|c|c|c|}
\hline Characteristics & Symbol & Test Conditions & Min. & Typ. & Max. & Units \\
\hline \multicolumn{7}{|l|}{ IGBT Inverter Sector } \\
\hline \multirow[t]{2}{*}{ Collector Cutoff Current } & ICEX & $V_{C E}=V_{C E X}, T_{j}=25^{\circ} \mathrm{C}$ & - & - & 1 & $\mathrm{~mA}$ \\
\hline & & $V_{C E}=V_{C E X}, T_{j}=125^{\circ} \mathrm{C}$ & 一 & - & 10 & $\mathrm{~mA}$ \\
\hline Diode Forward Voltage & $\mathrm{V}_{\mathrm{FM}}$ & ${ }^{-} \mathrm{C} C=300 \mathrm{~A}, \mathrm{~V}_{\mathrm{D}}=15 \mathrm{~V}, \mathrm{~V}_{\mathrm{CIN}}=5 \mathrm{~V}$ & - & 1.9 & 2.8 & Volts \\
\hline \multirow[t]{2}{*}{ Collector-Emitter Saturation Voltage } & $\mathrm{V}_{\mathrm{CE} \text { (sat) }}$ & $V_{D}=15 V, V_{C I N}=0 V, I_{C}=300 A$ & - & 1.8 & 2.6 & Volts \\
\hline & & $\begin{array}{c}V_{D}=15 V, V_{C I N}=0 V, I_{C}=300 A, \\
T_{j}=125^{\circ} \mathrm{C}\end{array}$ & - & 1.9 & 2.7 & Volts \\
\hline \multirow[t]{5}{*}{ Inductive Load Switching Times } & $t_{\text {on }}$ & & 0.5 & 1.4 & 2.5 & $\mu \mathrm{S}$ \\
\hline & $t_{r r}$ & $V_{D}=15 V, V_{C I N}=0 \sim 5 V$ & - & 0.15 & 0.3 & $\mu \mathrm{S}$ \\
\hline & ${ }^{t} \mathrm{C}$ (on) & $V_{C C}=300 \mathrm{~V}, I_{C}=300 A$ & - & 0.4 & 1.0 & $\mu \mathrm{S}$ \\
\hline & toff & $T_{j}=125^{\circ} \mathrm{C}$ & - & 2.0 & 3.0 & $\mu \mathrm{S}$ \\
\hline & ${ }^{t} \mathrm{C}$ (off) & & - & 0.5 & 1.0 & $\mu \mathrm{S}$ \\
\hline
\end{tabular}

Thermal Characteristics

\begin{tabular}{|c|c|c|c|c|c|c|}
\hline Characteristic & Symbol & Condition & Min. & Typ. & Max. & Units \\
\hline \multirow[t]{2}{*}{ Junction to Case Thermal Resistance } & $R_{\text {th(j-c)Q }}$ & Each IGBT & - & - & 0.13 & ${ }^{\circ} \mathrm{C} /$ Watt \\
\hline & $R_{\text {th }(j-c) D}$ & Each FWDi & - & - & 0.25 & ${ }^{\circ} \mathrm{C} /$ Watt \\
\hline & & Thermal Grease Applied & & & & \\
\hline
\end{tabular}

Recommended Conditions for Use

\begin{tabular}{|c|c|c|c|c|}
\hline Characteristic & Symbol & Condition & Value & Units \\
\hline \multirow[t]{2}{*}{ Supply Voltage } & $\mathrm{v}_{\mathrm{CC}}$ & Applied across C1-E2 Terminals & $0 \sim 400$ & Volts \\
\hline & $V_{D}$ & Applied between $V_{P_{1}}-V_{P C}, V_{N 1}-V_{N C}$ & $15 \pm 1.5$ & Volts \\
\hline Input OFF Voltage & $\mathrm{V}_{\mathrm{CIN} \text { (off) }}$ & $\mathrm{C}_{\mathrm{P} 1}-\mathrm{V}_{\mathrm{PC}}, \mathrm{C}_{\mathrm{N} 1}-\mathrm{V}_{\mathrm{NC}}$ & $4.0 \sim V_{S \times R}$ & Volts \\
\hline PWM nput Frequency & fPWM & Using Application Circuit & $5 \sim 20$ & $\mathrm{kHz}$ \\
\hline
\end{tabular}




\section{XOWEPJX}

Powerex, Inc., 200 Hillis Street, Youngwood, Pennsylvania 15697-1800 (724) 925-7272

PM300DSA060

Intellimod ${ }^{\mathrm{TM}}$ Module

Single Phase IGBT Inverter Output

300 Amperes $/ 600$ Volts

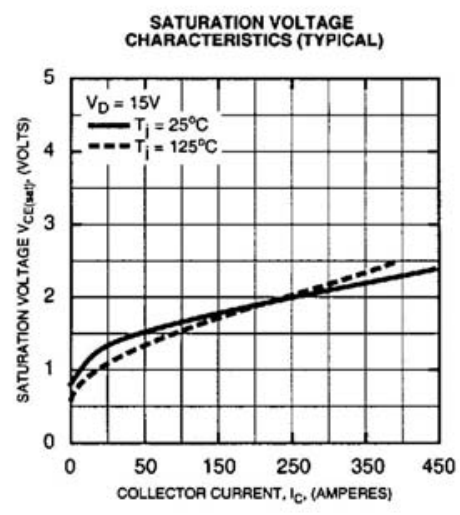

SWITCHING TIME VS.

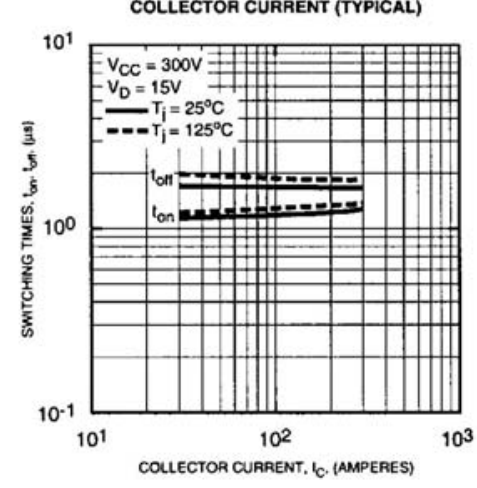

DIODE FORWARD CHARACTERISTICS

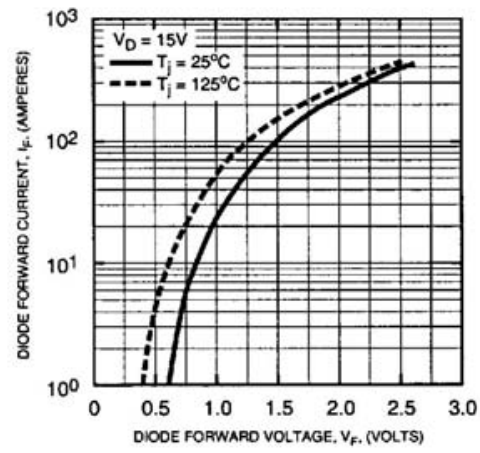

COLLECTOR-EMITTER SATURATION

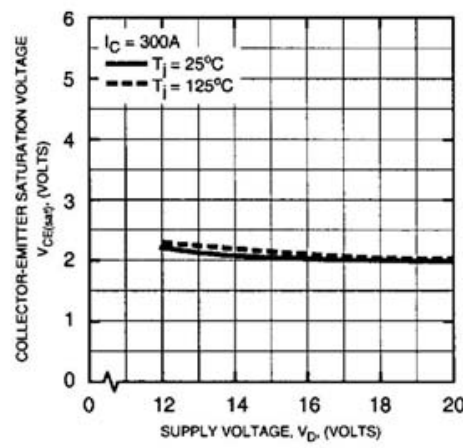

SWITCHING TIME VS
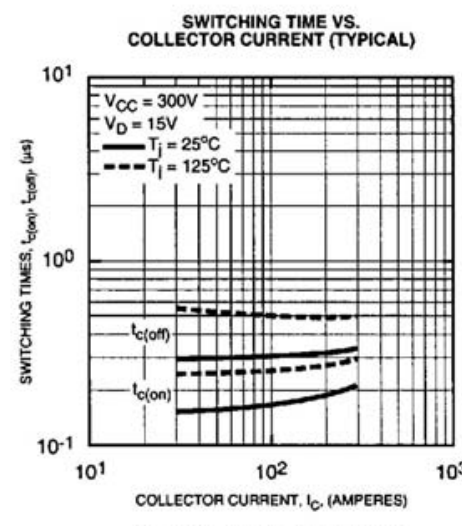

OVER CURRENT TRIP LEVEL VS.

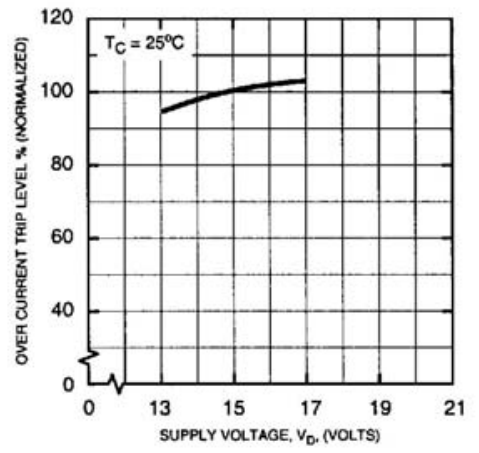

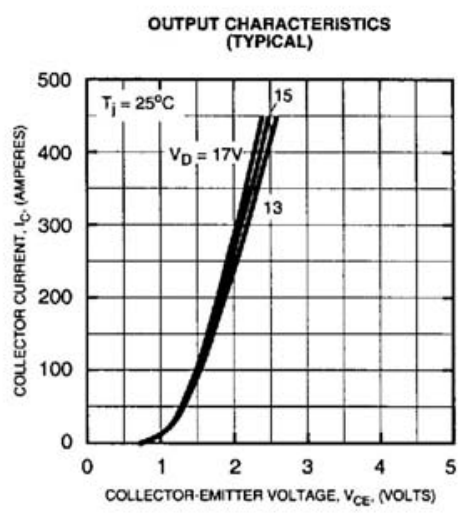

REVERSE RECOVERY CURRENT YS.
COLLECTOR CURRENT (TYPICAL)

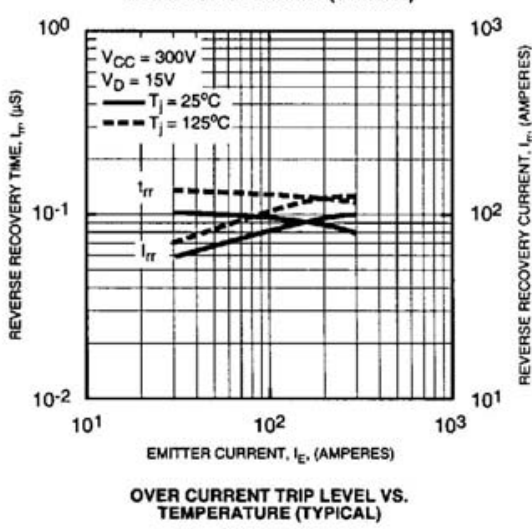

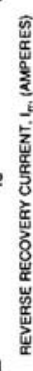

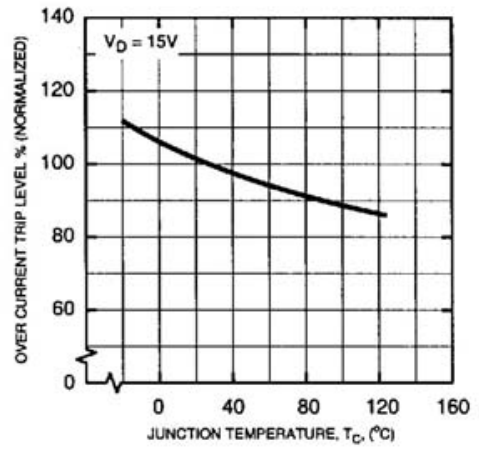




\section{ROMEPJX}

Powerex, Inc., 200 Hillis Street, Youngwood, Pennsylvania 15697-1800 (724) 925-7272

PM300DSA060

Intellimodrm Module

Single Phase IGBT Inverter Output

300 Amperes/ 600 Volts

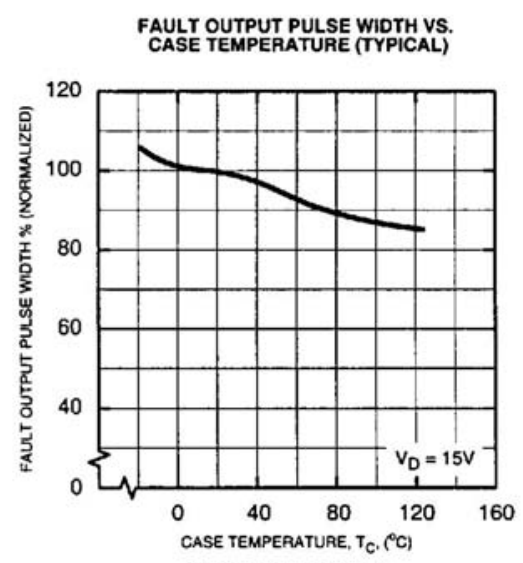

TRANSIENT THERMAL

IMPEDANCE CHARACTERISTICS

(FWDI)

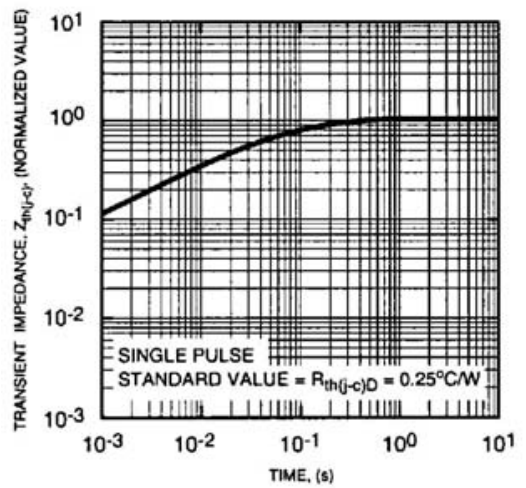

CONTROL SUPPLY YOLTAGE TRIP-RESET LEVEL TEMPERATURE DEPENDENCY (TYPICAL)
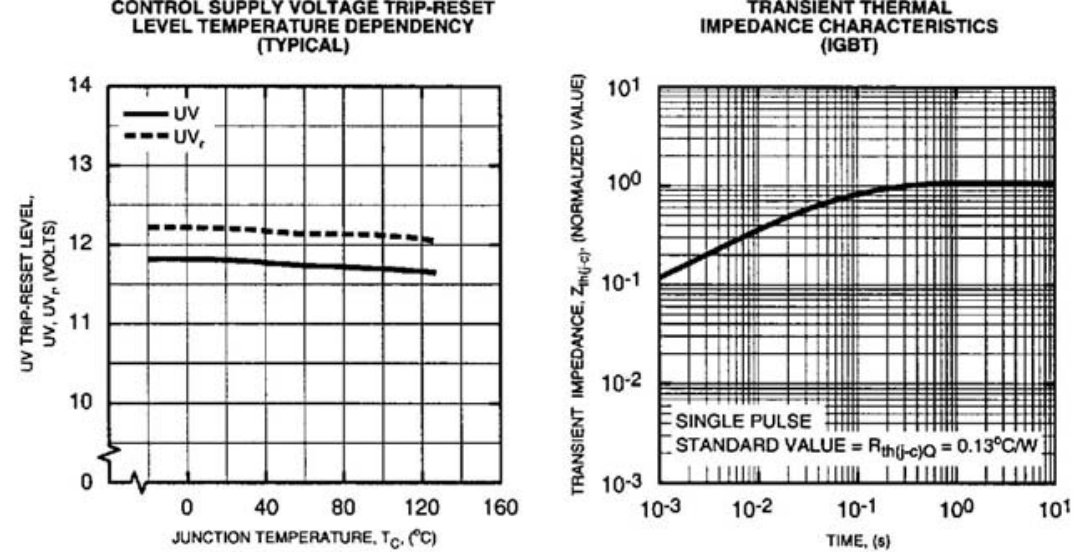


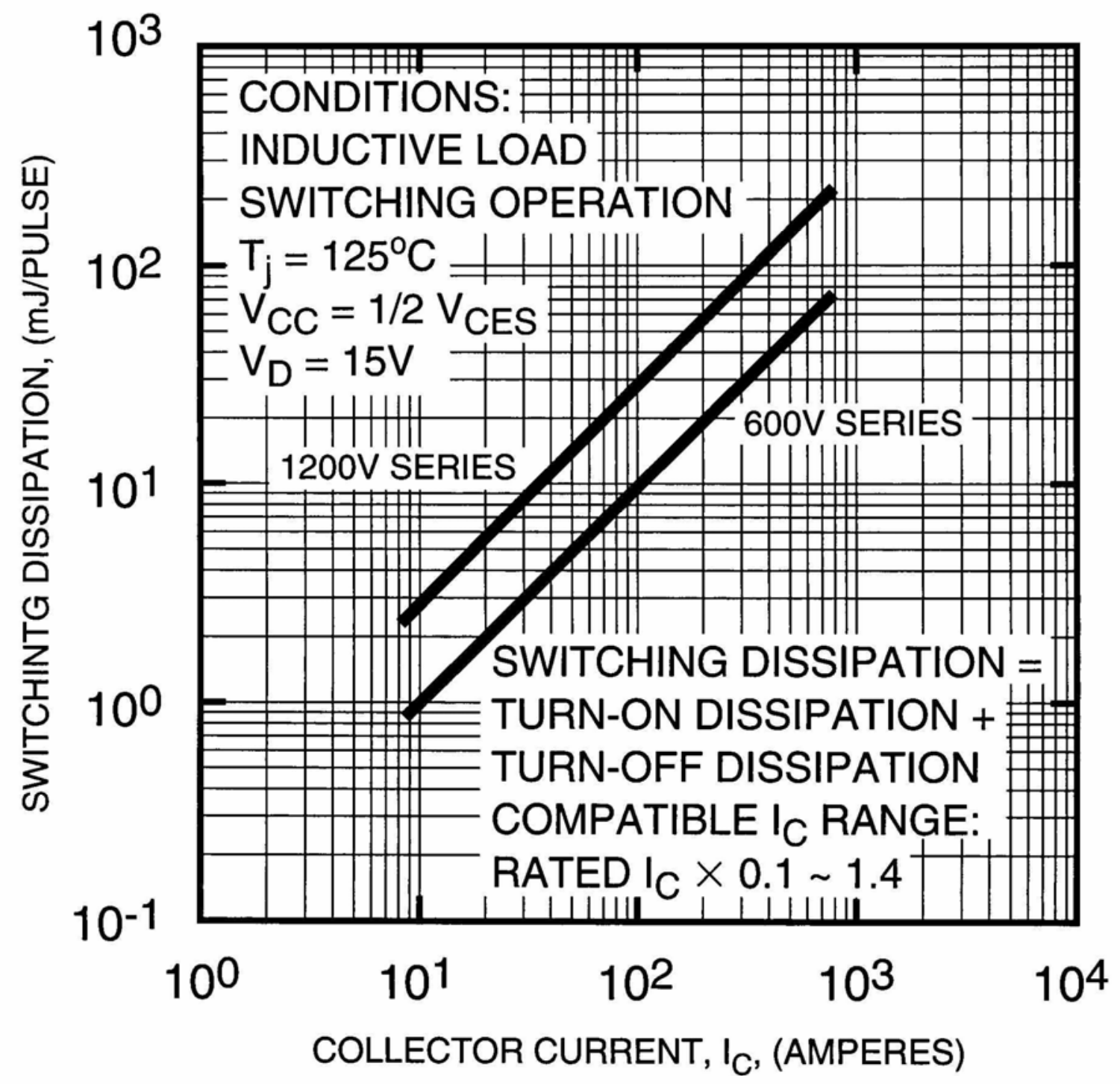

THIRD-GENERATION IPM 
A.4. SCRS FOR DEERE 2

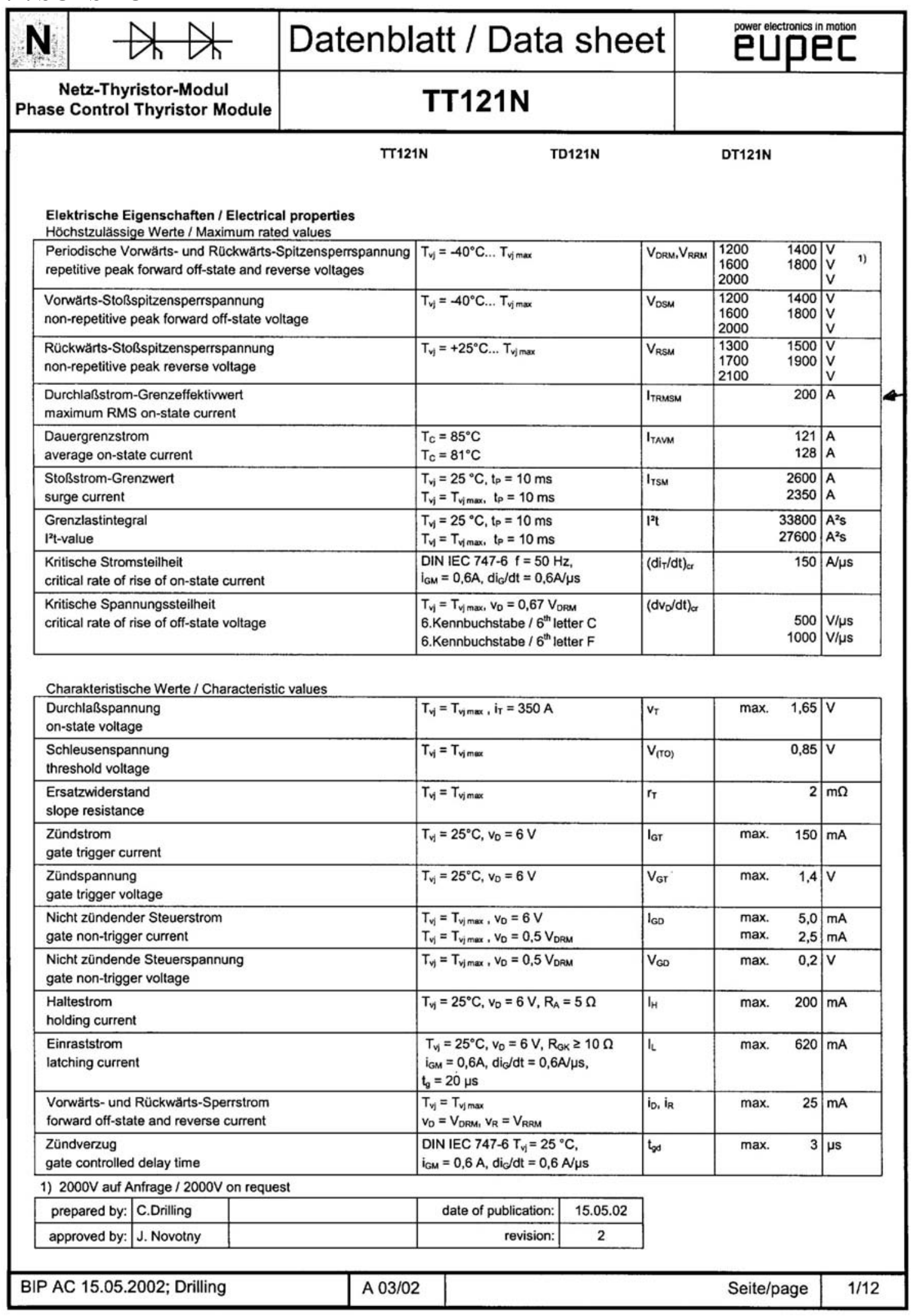




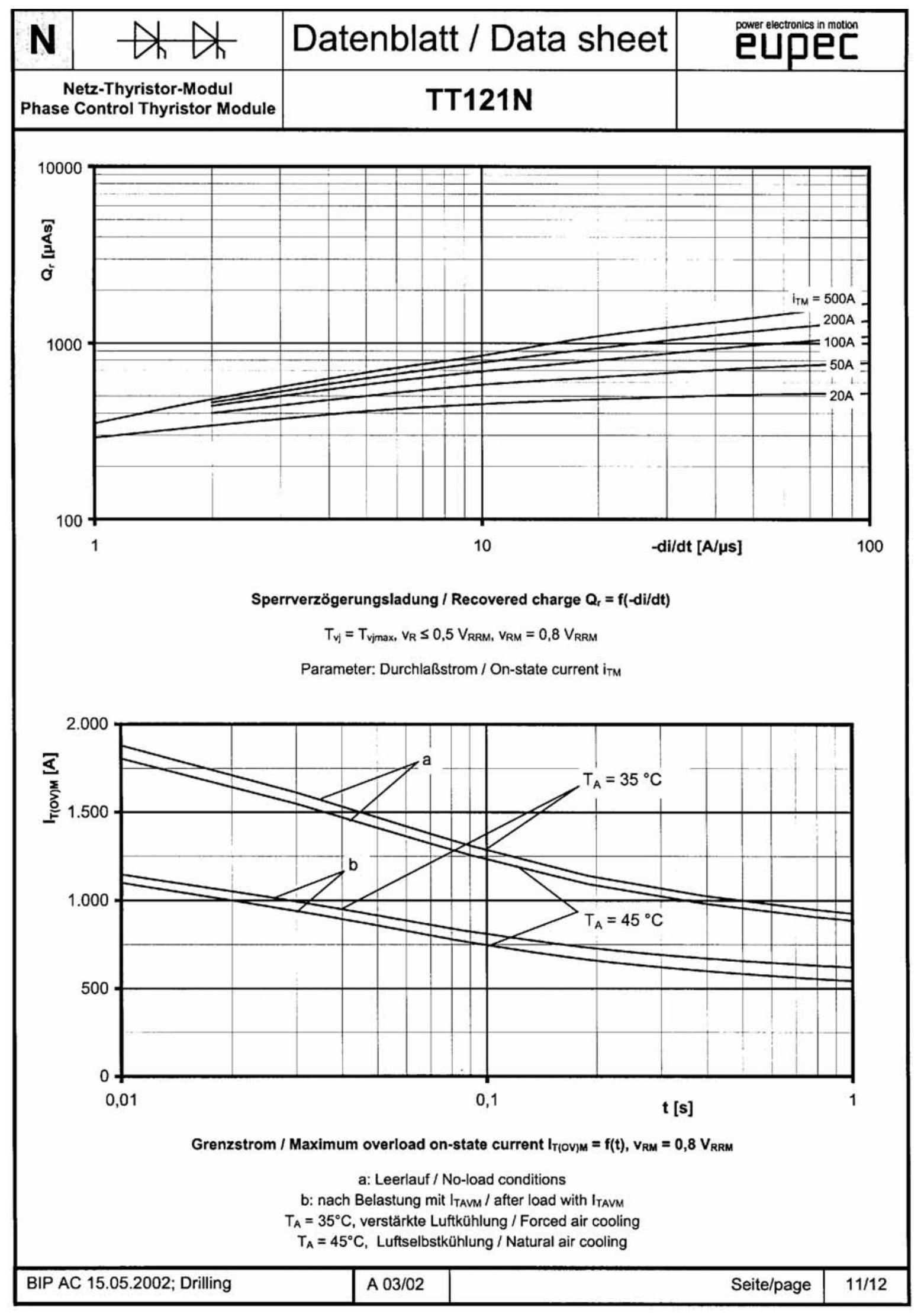




\section{APPENDIX B: DEERE 1 TEST DATA}

\section{Performance Test Results on Deere 1 PM Motor for DMIC Evaluation Program}

October 26, 2004

600 RPM; 165 N-m ( 20\% Output)

Efficiency $=87 \%$

RMS Current $=54 \mathrm{~A}(3.05 \mathrm{~N}-\mathrm{m} / \mathrm{A})$

Calculated Losses: $340 \mathrm{~W}$ Fe; $130 \mathrm{~W} \mathrm{Cu}(95.6 \%$ motor efficiency)
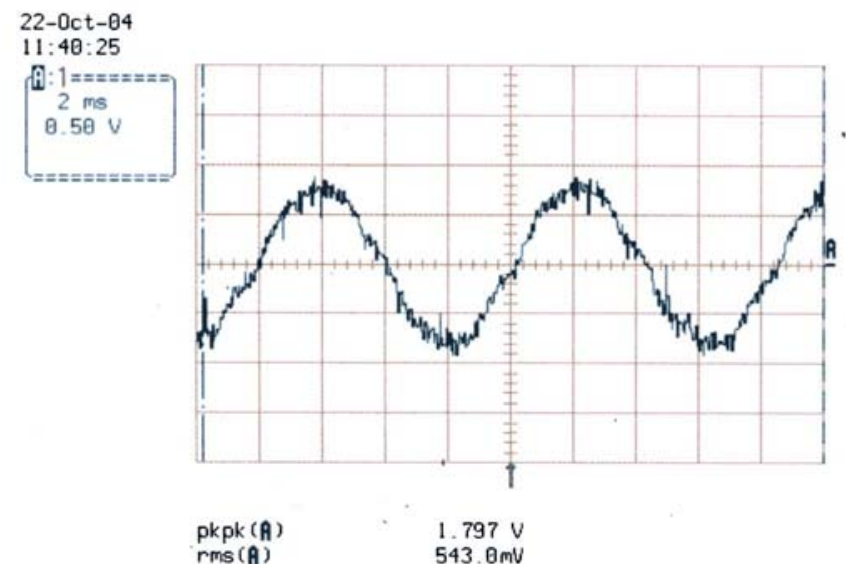

$2 \mathrm{~ms}$ BWL
$11.5 \vee$ DC
2.5 trig only
$3.2 v$ oC
4 trig only

- 1 HFREJ $0.00 \mathrm{~V}$

$25 \mathrm{kS} / \mathrm{s}$

D STOPPED

600 RPM; 420 N-m ( 40\% Output)

Efficiency $=91 \%$

RMS Current $=136 \mathrm{~A}(3.09 \mathrm{~N}-\mathrm{m} / \mathrm{A})$

Calculated Losses: 340 W Fe; 830 W Cu (95.8\% motor efficiency)
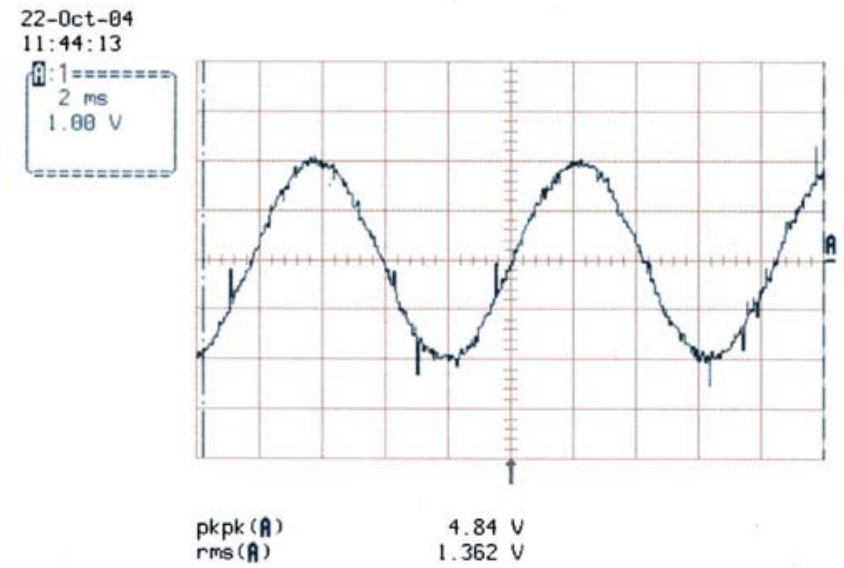
600 RPM; 610 N-m ( 60\% Output)

Efficiency $=90 \%$

RMS Current $=197 \mathrm{~A}(3.10 \mathrm{~N}-\mathrm{m} / \mathrm{A})$

Calculated Losses: 340 W Fe; 1746 W Cu (94.8\% motor efficiency)
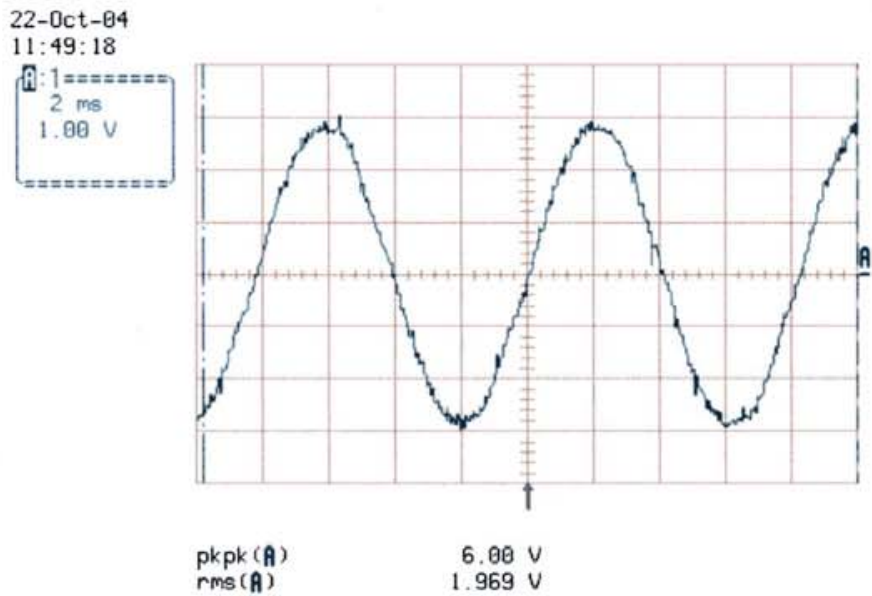

1 $1 \vee \mathrm{DC}$

2 trig only

3 trig only

4 trig only

1 HFREJ $0.00 \mathrm{~V}$

$25 \mathrm{kS} / \mathrm{s}$

STOPPED

600 RPM; 800 N-m ( 80\% Output)

Efficiency $=88 \%$

RMS Current $=260$ A $(3.08 \mathrm{~N}-\mathrm{m} / \mathrm{A})$

Calculated Losses: 340 W Fe; 3042 W Cu (93.7\% motor efficiency)
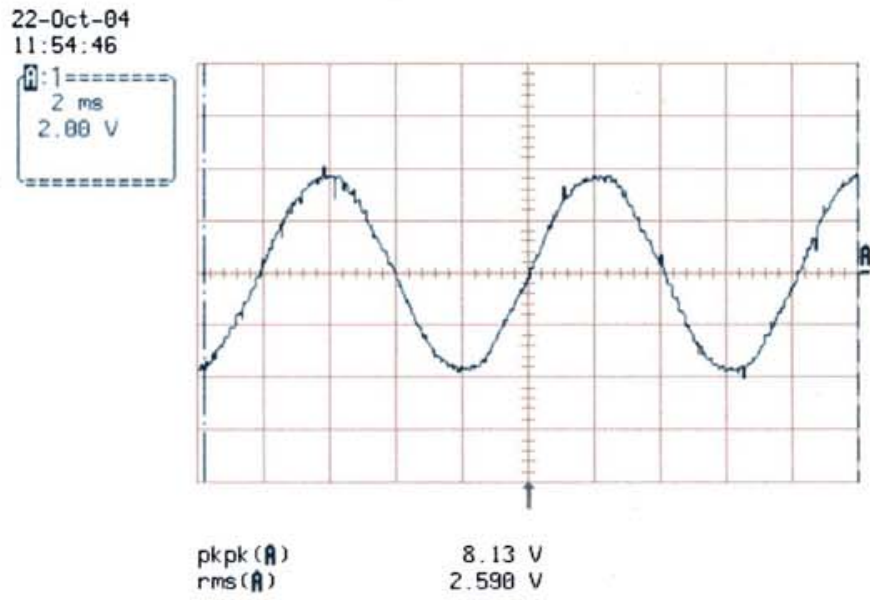

2 ms BWL
$\frac{1}{2}$ trig only $^{2} \mathrm{DC}$
$3.2 \mathrm{DC}$
4 trig only

$25 \mathrm{kS} / \mathrm{s}$

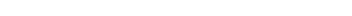

[ STOPPED 
600 RPM; 1000 N-m ( 100\% Output)

Efficiency $=86 \%$

RMS Current $=332 \mathrm{~A}(3.01 \mathrm{~N}-\mathrm{m} / \mathrm{A})$

Calculated Losses: 340 W Fe; 5000 W Cu (92.1\% motor efficiency)

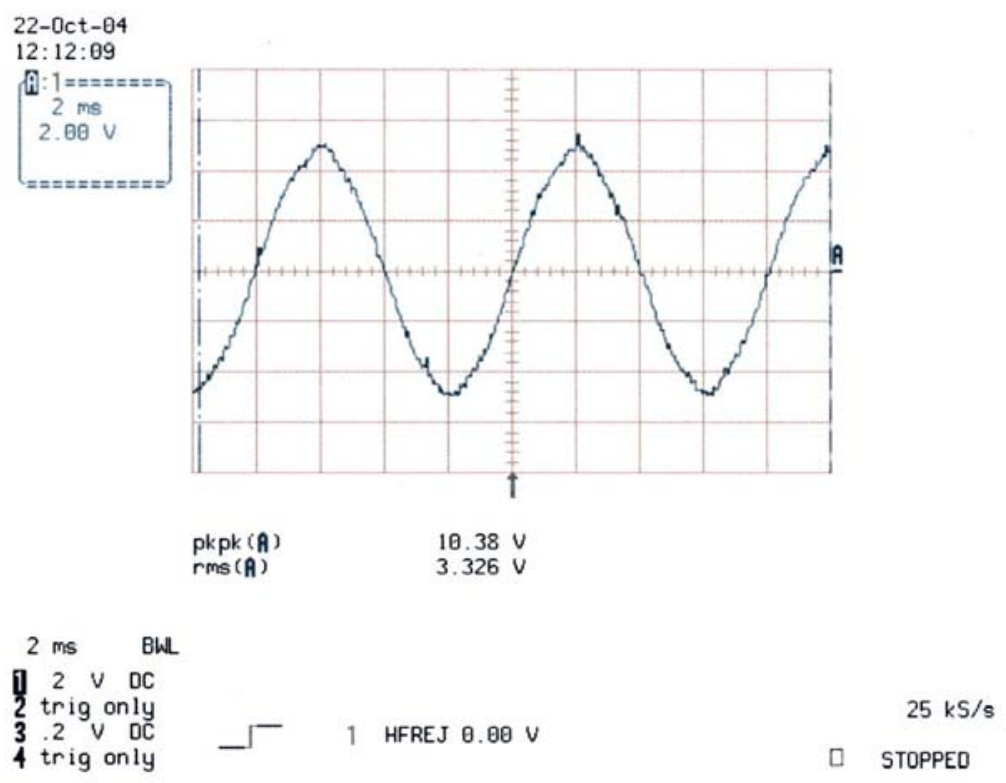

1200 RPM; 75 N-m ( 20\% Output)

Efficiency $=82 \%$

RMS Current $=24$ A $(3.12 \mathrm{~N}-\mathrm{m} / \mathrm{A})$

Calculated Losses: 900 W Fe; 26 W Cu (91\% motor efficiency)

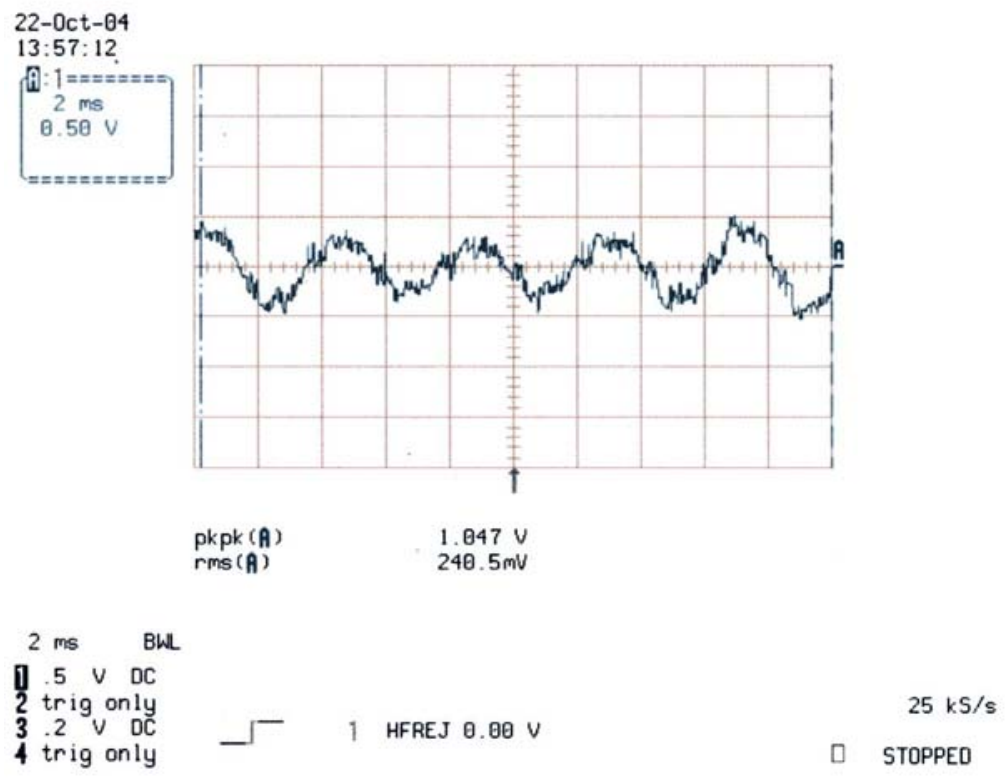


1200 RPM; $240 \mathrm{~N}-\mathrm{m}$ ( $40 \%$ Output)

Efficiency $=96 \%$ - suspect measurement

RMS Current $=78 \mathrm{~A}(3.08 \mathrm{~N}-\mathrm{m} / \mathrm{A})$

Calculated Losses: 900 W Fe; 275 W Cu (96.3\% motor efficiency)
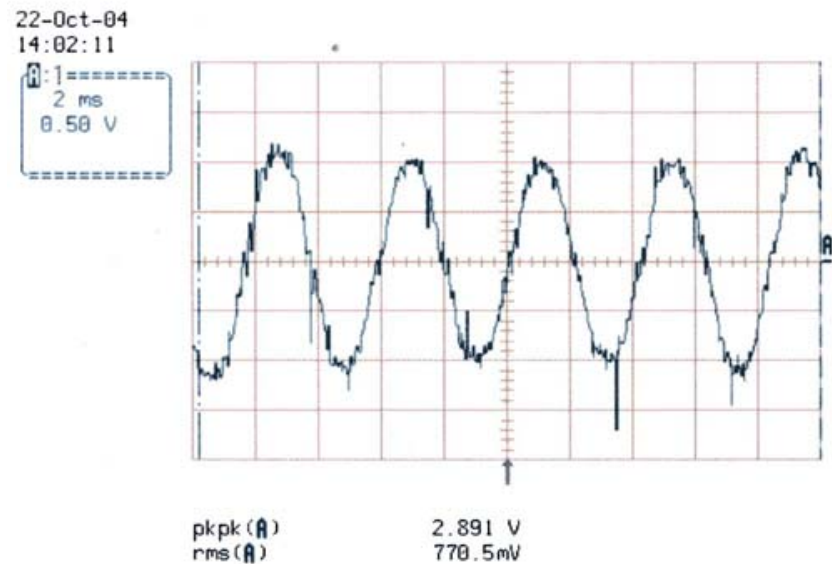

$2 \mathrm{~ms}$ BWL

$1.5 \vee \mathrm{DC}$

2 trig only

$3.2 \mathrm{~V}$ OC

4 trig only

—- 1 HFREJ $0 . \theta 0 \mathrm{~V}$

$25 \mathrm{kS} / \mathrm{s}$

[ STOPPED

1200 RPM; 320 N-m ( $60 \%$ Output)

Efficiency $=97 \%$ - suspect measurement

RMS Current $=119 \mathrm{~A}(2.69 \mathrm{~N}-\mathrm{m} / \mathrm{A})$

Calculated Losses: 900 W Fe; 212 W Cu (97.3\% motor efficiency)
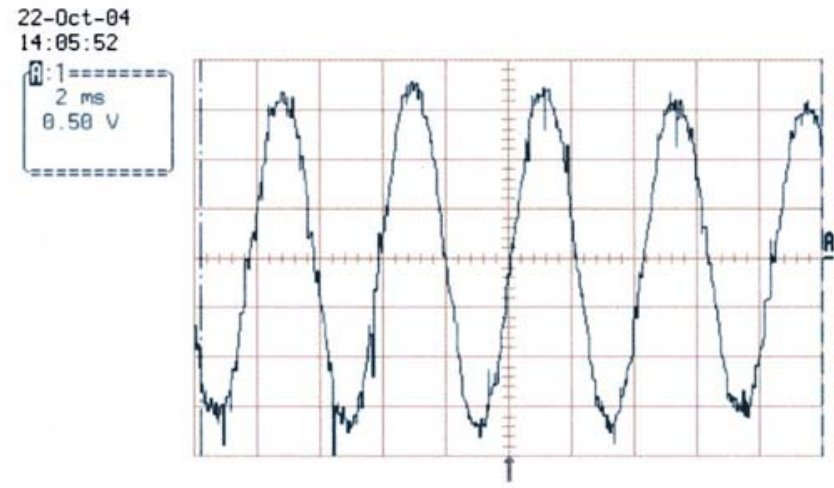

$\begin{array}{lll}\operatorname{pkpk}(\text { A }) & \Downarrow & 3.781 \mathrm{~V} \\ \operatorname{rms}(\text { A }) & \Downarrow & 1.1859 \mathrm{~V}\end{array}$

$2 \mathrm{~ms} \quad$ BWL

11. $5 \vee \mathrm{DC}$

2 trig only $3.2 \mathrm{~V}$ DC -1 HFREJ $0.00 \mathrm{~V}$

$25 \mathrm{kS} / \mathrm{s}$

4 trig only

—- 1 HFREJ 0.00 V

D STOPPED 
1200 RPM; $420 \mathrm{~N}-\mathrm{m}$ ( $80 \%$ Output)

Efficiency $=97 \%$ - suspect measurement

RMS Current $=149 \mathrm{~A}(2.82 \mathrm{~N}-\mathrm{m} / \mathrm{A})$

Calculated Losses: 900 W Fe; 1000 W Cu (96.5\% motor efficiency)

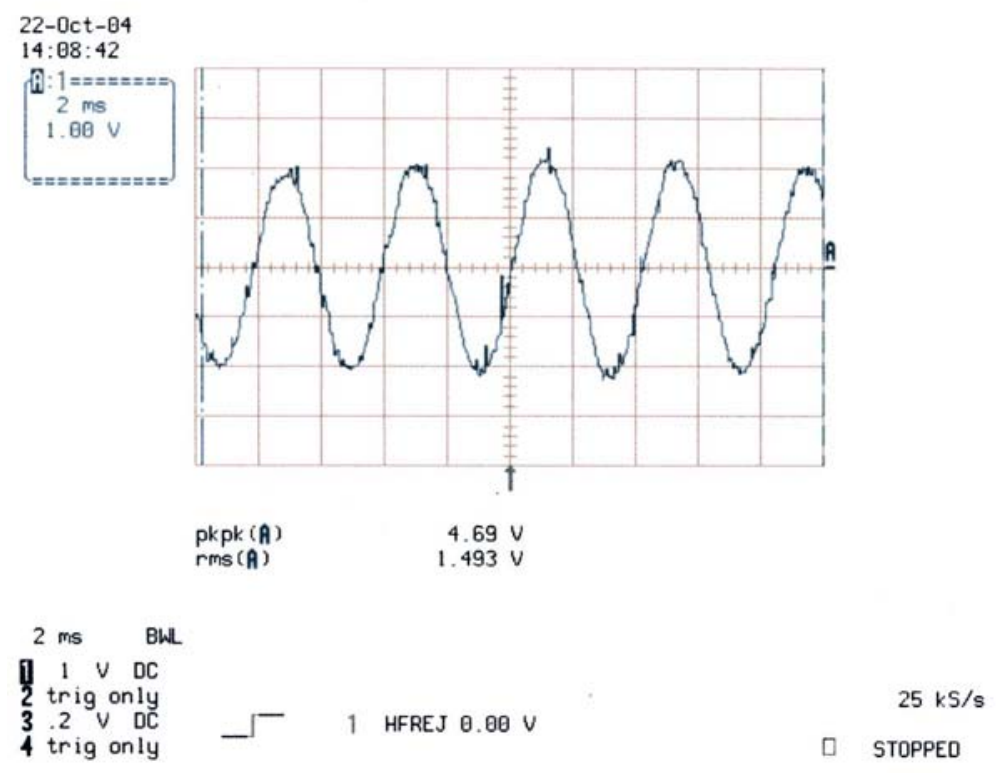

1200 RPM; $520 \mathrm{~N}-\mathrm{m}(\sim 100 \%$ Output $)$

Efficiency $=98 \%$ - suspect measurement

RMS Current $=179 \mathrm{~A}(2.90 \mathrm{~N}-\mathrm{m} / \mathrm{A})$

Calculated Losses: 900 W Fe; 1440 W Cu (96.5\% motor efficiency)

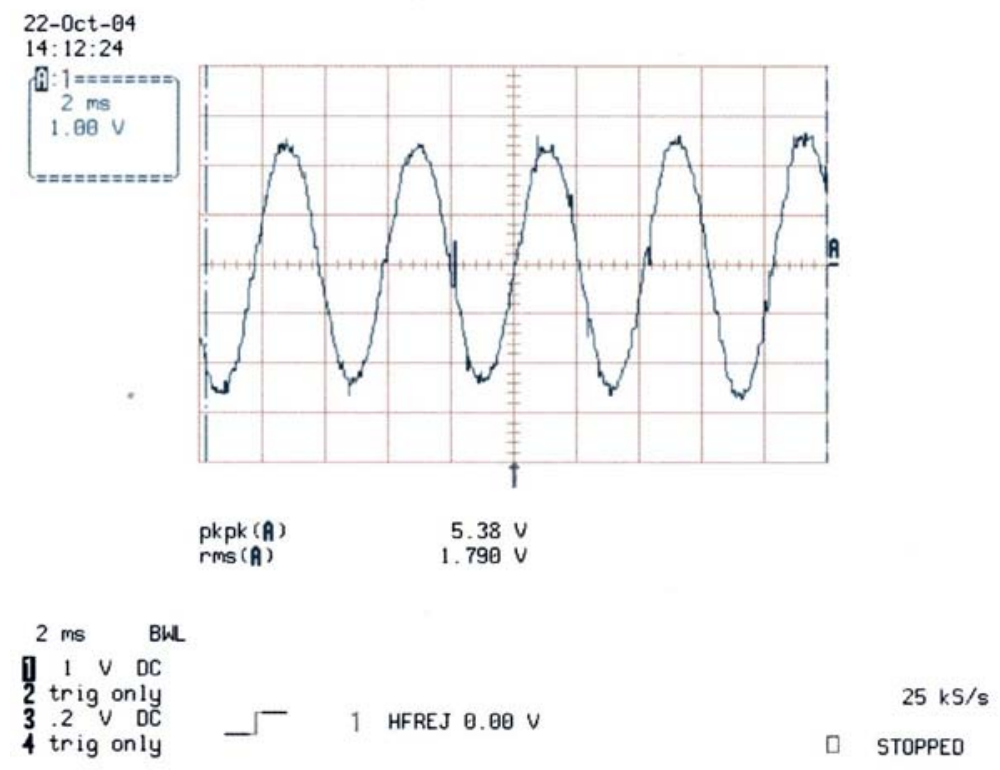


1800 RPM; $68 \mathrm{~N}-\mathrm{m}$ ( $20 \%$ Output)

Efficiency $=89 \%$

RMS Current $=50 \mathrm{~A}(1.36 \mathrm{~N}-\mathrm{m} / \mathrm{A})$

Calculated Losses: 1450 W Fe; $110 \mathrm{~W} \mathrm{Cu}$ ( $90 \%$ motor efficiency)

1800 RPM; $130 \mathrm{~N}-\mathrm{m}$ ( $40 \%$ Output)

Efficiency $=93 \%$

RMS Current $=65 \mathrm{~A}(2.00 \mathrm{~N}-\mathrm{m} / \mathrm{A})$

Calculated Losses: 1450 W Fe; 190 W Cu (94\% motor efficiency)

1800 RPM; $195 \mathrm{~N}-\mathrm{m}$ ( $60 \%$ Output)

Efficiency $=95 \%$

RMS Current $=86 \mathrm{~A}(2.26 \mathrm{~N}-\mathrm{m} / \mathrm{A})$

Calculated Losses: $1450 \mathrm{~W} \mathrm{Fe} ; 330 \mathrm{~W}$ Cu (95.5\% motor efficiency)

1800 RPM; $260 \mathrm{~N}-\mathrm{m}$ ( $80 \%$ Output)

Efficiency $=95 \%$

RMS Current $=107 \mathrm{~A}(2.43 \mathrm{~N}-\mathrm{m} / \mathrm{A})$

Calculated Losses: $1450 \mathrm{~W}$ Fe; $520 \mathrm{~W}$ Cu ( $96 \%$ motor efficiency)

1800 RPM; $320 \mathrm{~N}-\mathrm{m}$ ( 100\% Output)

Efficiency $=95.5 \%$

RMS Current $=121 \mathrm{~A}(2.64 \mathrm{~N}-\mathrm{m} / \mathrm{A})$

Calculated Losses: $1450 \mathrm{~W}$ Fe; $660 \mathrm{~W}$ Cu (96.5\% motor efficiency) 


\section{REFERENCES}

1. A. M. El-Refaie et al., "Analysis of Surface Permanent Magnet Machines with FractionalSlot Concentrated Windings," scheduled for publication in IEEE Trans. on Ind. Appl., May/June 2005.

2. J. S. Lawler et al., "Minimum Current-Magnitude Control of Surface PM Synchronous Machines During Constant Power Operation," Power Electronics Letters, June 2005.

3. T. Sebastian and G. R. Slemon, "Operating Limits of Inverter-Driven PM Motor Drives," IEE Trans. Ind. Appl. Syst., 23, March/April 1987.

4. J. S. Lawler et al., "Limitations of the Conventional Phase Advance Method for Constant Power Operation of the Brushless DC Motor," IEEE Southeast Conference 2002, SEC-118, April 5-7, 2002.

5. J. S. Lawler et al., "Extending the Constant Power Speed Range of the Brushless DC Motor Through Dual-Mode Inverter Control," IEEE Trans. on Power Electronics, 19(3), May 2004.

6. Burak Ozpineci, "System Impact of Silicon Carbide Power Electronics on Hybrid Electric Vehicle Applications," Ph.D. Dissertation, the University of Tennessee, Knoxville, Tennessee, August 2002.

7. J. S. Lawler et al., "Impact of Continuous Conduction on the Constant Power Speed Range of the Switched Reluctance Motor," Conference Proceedings of the International Electric Machines and Drives Conference, San Antonio, Texas, May 15-18, 2005. 


\section{DISTRIBUTION}

\section{Internal}

1. D. J. Adams

2. R. G. Boeman

3. M. A. Brown

4. J. C. Conklin

5. M. E. Downing

6. R. L. Graves

7. J. B. Green, Jr.
8. W. K. Kahl

9. J. W. McKeever

10. M. Olszewski

11. P. J. Otaduy

12. A. K. Wolfe

13. Laboratory Records

\section{External}

14. R. Bremmer, John Deere and Company, Moline Tech Center, One John Deere Place, Moline, Illinois 61265.

15. P. A. Carpenter, ORNL Site Office, Bethel Valley Road, Bldg. 4500N, Rm. 242, Oak Ridge, Tennessee 37831-6269.

16. T. Q. Duong, U.S. Department of Energy, EE-2G/Forrestal Building, 1000 Independence Avenue, S.W., Washington, D.C. 20585.

17. P. Finamore, John Deere and Company, SEEC, P.O. Box 7047, Charlotte, North Carolina 28241.

18. J. S. Lawler, The University of Tennessee-Knoxville, Computer Engineering Department, 402 Ferris Hall, Knoxville, Tennessee 37996-2100.

19. J. Lutz, UQM Technologies, Inc., 7501 Miller Drive, Frederick, Colorado 80530.

20. B. Poore, John Deere and Company, Moline Tech Center, One John Deere Place, Moline, Illinois 61265.

21. A. K. Seksarian, John Deere and Company, Moline Tech Center, One John Deere Place, Moline, Illinois 61265.

22. J. M. Shoemaker, John Deere and Company, Moline Tech Center, One John Deere Place, Moline, Illinois 61265.

23. G. Singh, Office of FreedomCAR and Vehicle Technologies, Advanced Combustion and Emissions Control, EE-2G/Forrestal Building, 1000 Independence Avenue, S.W., Washington, D.C. 20585

24. R. D. Stahlhut, John Deere and Company, Moline Tech Center, One John Deere Place, Moline, Illinois 61265.

25. K. M. Wilson, ORNL Office of Technical Information and Classification, Bethel Valley Road, Bldg. 4500N, Rm. 135, Oak Ridge, Tennessee 37831-6196. 